\title{
Work and individual determinants of intrinsic work motivation, emotional exhaustion and turnover intention : a study among bank employees and teachers
}

Citation for published version (APA):

Houkes, I. (2002). Work and individual determinants of intrinsic work motivation, emotional exhaustion and turnover intention : a study among bank employees and teachers. [Doctoral Thesis, Maastricht University]. Universiteit Maastricht. https://doi.org/10.26481/dis.20020118ih

Document status and date:

Published: 01/01/2002

DOI:

10.26481/dis.20020118ih

Document Version:

Publisher's PDF, also known as Version of record

Please check the document version of this publication:

- A submitted manuscript is the version of the article upon submission and before peer-review. There can be important differences between the submitted version and the official published version of record. People interested in the research are advised to contact the author for the final version of the publication, or visit the DOI to the publisher's website.

- The final author version and the galley proof are versions of the publication after peer review.

- The final published version features the final layout of the paper including the volume, issue and page numbers.

Link to publication

\footnotetext{
General rights rights.

- You may freely distribute the URL identifying the publication in the public portal. please follow below link for the End User Agreement:

www.umlib.nl/taverne-license

Take down policy

If you believe that this document breaches copyright please contact us at:

repository@maastrichtuniversity.nl

providing details and we will investigate your claim.
}

Copyright and moral rights for the publications made accessible in the public portal are retained by the authors and/or other copyright owners and it is a condition of accessing publications that users recognise and abide by the legal requirements associated with these

- Users may download and print one copy of any publication from the public portal for the purpose of private study or research.

- You may not further distribute the material or use it for any profit-making activity or commercial gain

If the publication is distributed under the terms of Article 25fa of the Dutch Copyright Act, indicated by the "Taverne" license above, 


\section{Work and individual determinants of intrinsic work motivation, emotional exhaustion and turnover intention}

A study among bank employees and teachers

Inge Houkes 
Work and individual determinants of intrinsic work motivation, emotional exhaustion and turnover intention. A study among bank employees and teachers.

Inge Houkes.

Thesis Maastricht University, Maastricht.

With summary in Dutch.

Printing: Datawyse B.V.| Universitaire Pers Maastricht, Maastricht, The Netherlands.

Cover design: Olaf Janssen.

(c) 2002 by Inge Houkes

All rights reserved. No part of this publication may be reproduced, stored in a retrieval system, or transmitted, in any form or by any means, electronic, mechanical, photocopying, recording, or otherwise, without the prior written permission from the publisher.

ISBN 90-9015283-0

Subject headings: work characteristics, intrinsic work motivation, emotional exhaustion, turnover intention, longitudinal study, bank employees, teachers. 


\section{Work and individual determinants of intrinsic work motivation, emotional exhaustion and turnover intention}

A study among bank employees and teachers

\section{PROEFSCHRIFT}

ter verkrijging van de graad van doctor aan de Universiteit Maastricht,

op gezag van de Rector Magnificus, Prof. dr. A.C. Nieuwenhuijzen Kruseman volgens het besluit van het College van Decanen, in het openbaar te verdedigen op vrijdag 18 januari 2002 om 14.00 uur

door

Inge Houkes

geboren op 27 april 1973 te Heerlen 


\section{Promotor:}

Prof. dr. F.J.N. Nijhuis

\section{Co-promotores:}

Dr. P.P.M. Janssen

Dr. J. de Jonge (Universiteit Utrecht)

\section{Beoordelingscommissie:}

Prof. dr. M.P.F. Berger (voorzitter)

Dr. J.A. Landeweerd

Dr. M.J.D. Schalk (Katholieke Universiteit Brabant)

Prof. dr. W.B. Schaufeli (Universiteit Utrecht)

Prof. dr. H. de Vries 


\section{Contents}

Chapter 1 General introduction $\quad 9$

1.1 The world of work 10

1.2 Research problem and aim of the study 13

1.3 Outline of the thesis 14

$\begin{array}{lr}\text { Chapter } 2 \text { Theoretical outline } & 15\end{array}$

2.1 Introduction 16

2.2 Three prominent stress models in the field of Work and Organizational Psychology: a critical review 16

2.2.1 Several meta-theoretical issues regarding model development 16

2.2.2 The Michigan Model 21

2.2.3 The Demand-Control(-Support) Model 24

2.2.4 The Model of Work, Stress and Health 27

2.2.5 Conclusion and implications for further model development 29

2.3 The selection of outcome variables, the categorization of work characteristics, and a theoretical elaboration on the specific relationships between these variables $\quad 30$

2.3.1 Introduction 30

2.3.2 Selection of outcome variables 31

2.3.3 A categorization of possible predictors of the three outcome variables: work characteristics

2.3.4 Work-related determinants of the selected psychological outcome variables

2.3.4.1 Work motivation: intrinsic work motivation 35

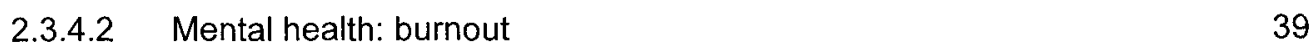

2.3.4.3 Turnover: turnover intention 45

$\begin{array}{lll}\text { 2.3.5 Study hypotheses and research model } & 50\end{array}$

2.4 The specific influence of personal characteristics on the three selected outcome variables and on the relationships between work characteristics and these outcome variables 51

2.4.1 Introduction 51

2.4.2 Selection of relevant personal characteristics for each psychological outcome variable 53

2.5 Summary 58

$\begin{array}{ll}\text { Chapter } 3 \text { Method } & 61\end{array}$

3.1 Introduction $\quad 62$

3.2 Design of the study 62

3.3 Study populations and design of the samples 66

$\begin{array}{lll}3.3 .1 & \text { Introduction } & 66\end{array}$

3.3.2 Sample 1: banking sector $\quad 67$

$\begin{array}{lll}\text { 3.3.3 Sample 2: education } & 69\end{array}$ 
$\begin{array}{lll}3.4 & \text { Procedure, fieldwork and respondents } & 71\end{array}$

$\begin{array}{lll}3.5 & \text { Measures } & 74\end{array}$

$\begin{array}{lll}3.5 .1 & 74\end{array}$

$\begin{array}{lll}\text { 3.5.2 Work characteristics . : } & 75\end{array}$

$\begin{array}{ll}\text { 3.5.3 Personal characteristics } & 78\end{array}$

$\begin{array}{lll}3.5 .4 & \text { Outcome variables } & 79\end{array}$

$\begin{array}{lll}3.6 & \text { Data analyses } & 80\end{array}$

3.6.1 Introduction 80

3.6.2 Structural Equation Modeling (SEM) $\quad 81$

3.6.3 Multi-Sample Analysis (MSA) using SEM $\quad 85$

3.6.4 Cross-lagged panel designs using SEM $\quad 85$

3.6.5 Testing interaction effects using SEM 88

$\begin{array}{lll}3.7 & \text { Summary } & 89\end{array}$

Chapter 4 Cross-sectional analyses $\quad 91$

4.1 Introduction 93

4.2 Specific relationships between work characteristics and intrinsic work motivation, emotional exhaustion and turnover intention: a multi-sample analysis 93

4.2.1 Hypotheses, background and data analyses 93

4.2.2 Results 94

$\begin{array}{lll}4.2 .2 .1 & \text { Preliminary analyses } & 94\end{array}$

4.2.2.2 Multi-sample analysis $\quad 96$

4.3 Work and individual determinants of intrinsic work motivation, emotional exhaustion and turnover intention: a multi-sample analysis 102

4.3.1 Hypotheses, background and data analyses 102

4.3.2 Results 104

4.3.2.1 Preliminary Analyses 104

4.3.2.2 Testing hypotheses $4 a$ to 10a in both samples separately 109

4.3.2.3 Testing hypothesis 12: multi-sample analysis of the personal characteristics 112

$\begin{array}{lll}4.4 & \text { Summary } & 118\end{array}$

$\begin{array}{ll}\text { Chapter } 5 \text { Panel study } & 121\end{array}$

5.1 Introduction 122

5.2 Specific determinants of intrinsic work motivation, emotional exhaustion and turnover intention: A multi-sample longitudinal study 124

$\begin{array}{lll}\text { 5.2.1 Hypotheses, background and data analyses } & 124\end{array}$

$\begin{array}{lll}5.2 .2 & \text { Results } & 126\end{array}$

$\begin{array}{ll}\text { 5.2.2.1 Non-response analysis } & 126\end{array}$

$\begin{array}{lll}\text { 5.2.2.2 Preliminary analyses } & 128\end{array}$

5.2.2.3 Testing hypothesis I: the stability of the proposed pattern of
relationships

5.2.2.4 Panel analyses: testing hypotheses II and 1b to 3b 132 
5.3 A longitudinal analysis of the additive and moderating influence of personality on the relationships between work characteristics and psychological well-being

$\begin{array}{lll}\text { 5.3.1 Hypotheses, background and data analyses } & 140\end{array}$

$\begin{array}{lll}\text { 5.3.2 Results } & 143\end{array}$

5.3.2.1 Non-response analysis and preliminary analyses 143

5.3.2.2 Testing hypothesis III: the direct longitudinal effects of personal characteristics on the outcome variables

5.3.2.3 Testing hypothesis $6 \mathrm{~b}$ : the longitudinal additive effect of negative affectivity

5.3.2.4 Testing hypotheses $5 b, 7 b, 8 b$, and $9 b$ : the moderating effects of personal characteristics

5.4 Summary

Chapter 6 General conclusion and discussion

6.1 Introduction

6.2 Summary and conclusions of the main findings

6.2.1 Study hypotheses

6.2.2 Main findings of the cross-sectional study

6.2.3 Main findings of the panel study

6.3 Methodological reflections

6.4 Theoretical discussion and practical implications

6.4.1 Theoretical discussion of the results

6.4.2 Practical implications of the study results

6.5 Recommendations for future research

Samenvatting (Summary in Dutch)

References

Appendix Measurement instruments 
Chapter 1

General introduction 


\section{$1.1 \quad$ The world of work}

Important changes are affecting the world of work. Examples of these changes are increased global competition, the impact of information technology, the re-engineering of business processes, and the development of the services sector (cf. Cascio, 1995; Cooper, 1998; Frese, 2000; Howard, 1995; Kompier, 1996). This transformation of the work setting has shifted the work balance "from hand to head", and is likely to increase in particular the mental demands that people are exposed to in their work (Howard, 1995; Kompier \& Vink, 1994). Physical demands did not disappear, however, but rather changed (e.g., a transformation from dynamic to static physical demands has taken place; Dul \& Vink, 1995; Kompier \& Vink, 1994). The increase in mental demands is illustrated by three studies of Paoli (Merllié \& Paoli, 2001; Paoli, 1992, 1997) among 12.500 (in 1991) to 21.500 (in 2001) workers in the member states of the European Union, which indicate that the percentage of the European working population that has to work under high time pressure has increased from approximately $47 \%$ in 1991 , to $54 \%$ in 1996 , to $56 \%$ in the year 2001 . The percentage of workers that has to work under tight deadlines has increased from $49 \%$ in 1991 , to $56 \%$ in 1996 , to $60 \%$ in 2001 .

In order to prevent and reduce work-related health risks, government and organizations in Europe have developed and applied several laws, rules and programs (e.g., the European Union Framework Directive 89/391/EEC, cf. Levi, 1998; European Commission, 1997). In this regard, the Dutch government developed the ARBO-law (i.e., the Occupational Health and Safety Act; a law that regulates health, safety and well-being at the workplace; Lenderink, 1998), and introduced occupational health services in order to assist and control organizations pertaining to their work and health policy. Notwithstanding the latter, several studies (Houtman, Smulders, Bloemhoff \& Kompier, 1994; Merllié \& Paoli, 2001; Paoli, 1997) have shown that the work pace and the amount of uninteresting work (such as monotonous work and repetitive tasks) in Europe and in The Netherlands are still high. Research has further indicated that these work stressors can result in several mental, physical and behavioral stress reactions, such as burnout, depression, psychosomatic diseases, and a decrease in work motivation (cf. Cooper, 1998; Cooper \& Payne, 1988; De Jonge \& Kompier, 1997; Parker \& Wall, 1998; Schaufeli, Maslach \& Marek, 1993; Thierry, 1998). Eventually, these stress reactions may result in sickness absence, work disablement and turnover (cf. Cooper, 1998; Cooper \& Payne, 1988; Parker \& Wall, 1998; Schaufeli \& Enzmann, 1998). Illustrative in this respect are figures that reveal that among people who were assessed as disabled for work, mental disorders are the second major diagnostic group, after musculoskeletal diseases in three European countries (i.e., The Netherlands, Germany, and Belgium) (cf. Schaufeli \& Enzmann, 1998). In the United Kingdom, 30 to $40 \%$ of all sickness absence is attributable to some form of mental illness (O'Leary, 1993). In The Netherlands, one in every three disability benefit recipients is assessed as disabled on mental grounds (LISV, 2000). On average, $55 \%$ of the disability benefit recipients consider their former working situation as the main cause of their disability for work (Van Dierendonck, 1997). In 
Europe, approximately $30 \%$ of the workers report that their health and safety are at risk because of their work (Merllié \& Paoli, 2001).

The costs that are associated with occupational stress are huge (cf. Janssen \& Houkes, 2000b; Schaufeli \& Enzmann, 1998). In the United States, approximately 200 billion dollars per year are spent on occupational stress (e.g., absenteeism, reduced productivity, medical expenses, compensation claims) (International Labour Office, 1993). In the United Kingdom, the costs of sickness absence for stress and mental disorders are about 5 billion pounds sterling a year (Cooper, Liukkonen \& Cartwright, 1996). It appears that in The Netherlands, in 1994, about half the expenditures for absenteeism and workers' compensation claims (i.e., about 22.7 billion Euro per year) were spent on stress-related disorders. Similar trends have been observed in other industrialized countries such as Australia, Canada, and Japan (Schaufeli \& Enzmann, 1998). In addition to these direct costs of occupational stress, there are costs that are more difficult to quantify, but that are also related to diminished well-being at the workplace (see, for instance, Janssen \& Houkes, 2000b). Examples of these costs that are related to reduced productivity, loss of quality of goods and services as a result of decreasing work motivation, and costs that are related to turnover.

In sum, it appears that the level of occupational stress has increased steadily during the past decades, and has become an important concern in Western countries. In combination with the dynamic and complex environment of current organizations, this situation can be detrimental to an organization's effectiveness. Therefore, it is recommended that organizations take systematic action to prevent these stress related problems and pay serious attention to the psychological well-being of their employees (cf. Cooper, 1998). Considerable effort should be put into preventing and reducing work-related health risks by means of assessing and monitoring the workplace, identifying problems, and formulating interventions (Cooper, 1998; Levi, 1998; European Commission, 1997). Although there is ample evidence for the (long term) positive effects of such interventions, there exist many studies that are negative, or at least inconclusive in this regard. At best, evidence is mixed (cf. Cummings \& Worley, 1997; Schaufeli, 1990). According to, for instance, Cooper (1998) and Schaefer and Moos (1993), these preventive efforts can benefit substantially from conceptually integrated measures that cover the area of work-related stressors and stress reactions. Comprehensive frameworks, categorization schemes, or models that will allow organizational psychologists to make sense of the theory and knowledge that already exist, are needed in organizational development (see also Woodman, 1989).

In order to describe and explain the relationships between work stressors and the well-being of people at work, several heuristic stress models have been developed over time. In meta-theoretical terms, most of these models can be considered conceptual models (Walker \& Avant, 1995). Illustrative in this regard is the Michigan Model (Kahn \& Byosiere, 1992). These conceptual models and the empirical studies 
that have been performed to validate these models, have yielded valuable insights regarding work stress experiences and outcome variables, but have also been the subject of criticism (cf. Cooper, 1998). This criticism generally concerns the lack of specificity of these models. Most of these models are heuristic and based upon global theoretical frameworks that hardly lead to any specific hypothesis. They encompass many different categories of variables and only globally defined relationships between these categories of variables (cf. Buunk, De Jonge, Ybema \& De Wolff, 1998; Cooper, 1998).

In many cases, these models not only describe relationships between (categories of) work stressors and well-being, but also include the influence of personal characteristics. More specifically, these models, as well as the studies that are based on these models, suggest that outcome variables and/or the relationships between work characteristics and outcome variables, may be influenced by personal characteristics (e.g., Buunk, 1993; Furda, 1995; Kasl \& Rapp, 1991; Parkes, 1991). Not all employees respond similarly to the working situation. These insights, however, are still quite "general" (just like the models they are based on): the precise influence of personal characteristics on work-related outcome variables or on the relationships between work characteristics and specific outcome variables remains unclear (Furnham, 1992; Kasl, 1996; Kasl \& Rapp, 1991; Parkes, 1994; Warr, 1987). Knowledge about the specific influence of relevant personal characteristics, though, can contribute to the prediction of outcome variables and the development of efficient interventions aimed at the individual employee, as well as to techniques to match the right person to the right job (cf. Cummings \& Worley, 1997; Dunnette, 1998).

Considering the limitations of existing conceptual stress models as well as the rather global insights regarding the role of personal characteristics resulting from these models, we might argue that there is a need for further refinement and extension of existing stress models. In line with Cooper (1998), Parkes (1994), and Kasl (1996), we conclude that the formulation of a pattern of specific relationships between work characteristics and work-related outcome variables, as well as a theoretical investigation regarding personal characteristics that may influence these relationships, will be a step forward in the disentanglement of the precise influence of the working situation on the worker. In meta-theoretical terms, such a pattern of specific relationships would be called a theoretical model (Walker \& Avant, 1995). In this regard, we are in particular interested in personal characteristics that are relatively stable, and that have a theoretically sound relationship with the variables under study (see also Warr, 1987).

Moreover, the development of a pattern of relationships that describes specific effects of work characteristics and personal characteristics on a set of relevant outcome variables may form a basis for the development of more effective and efficient interventions aimed at improving the workplace. 


\subsection{Research problem and aim of the study}

The present study aims to provide a better insight in the specific relationships between work characteristics and personal characteristics on the one hand, and work-related outcome variables on the other. As we concluded above, a suchlike insight can contribute to the refinement of existing conceptual models of work-related stress, and might be helpful in developing interventions aimed at improving the workplace (cf. Cummings \& Worley, 1997).

As a basis for this thesis, we formulated the following general research questions:

1. What are the specific relationships between work characteristics and workrelated outcome variables?

2. What is the specific influence of personal characteristics on the workrelated outcome variables, as well as on the specific relationships between work characteristics and these outcome variables?

Thus, the general aim of the study is twofold. First, we aim to gain more insight in the specific relationships between work characteristics and outcome variables, and second, we aim to examine the specific influence of personal characteristics on this pattern of relationships. We will try to answer these research questions by means of an empirical field study.

Hitherto, the larger part of studies in the area of Work and Organizational Psychology have been cross-sectional, and included one sample (e.g., Schaufeli \& Enzmann, 1998; Zapf, Dormann \& Frese, 1996). Although cross-sectional research can provide knowledge about associations between variables, it is not possible to demonstrate causal relationships. Furthermore, testing data in only one sample may be problematic because of variance restrictions and the limited level of external validity of the study results (Dormann \& Zapf, 1999). Therefore, in the present study the hypothesized pattern of relationships will be tested in multiple samples, cross-sectionally as well as and longitudinally. 


\subsection{Outline of the thesis}

In order to answer the research questions of this study, several steps will be taken. First, a literature study will be carried out in order to formulate a theoretical model that describes a specific pattern of relationships between theoretically and socially relevant work characteristics and outcome variables. As a prerequisite to this model formulation, several meta-theoretical issues will be addressed. Furthermore, several personal characteristics that contribute to the prediction of these outcome variables will be selected. This theoretical outline will be described in chapter 2. Second, the proposed pattern of relationships and the influence of personal characteristics will be empirically validated. Chapter 3 describes the research design and method. That is, the samples and procedures we used, the design of the study, the fieldwork and respondents, the measurement instruments, and the general methods of data analysis.

The design of the empirical study will be twofold. The first part of the empirical study involves a cross-sectional design, that is, data are collected at one time point. The results of the cross-sectional analyses will be described in chapter 4 . The second part of the empirical study involves a longitudinal design, or more specifically, a panel design with two waves. Chapter 5 addresses the results of the panel study. In chapter 6 , the general findings of this study are presented and discussed. In addition, this chapter presents some methodological reflections of this study, as well as several theoretical and practical implications of the study results. Finally, several clues for future research are provided. 


\section{Chapter 2}

\section{Theoretical outline}

Parts of this chapter have been published under the titles:

Houkes, I., Janssen, P.P.M., Jonge, J., de \& Nijhuis, F.J.N. (1997). Verbanden tussen werkkenmerken en reacties: Een literatuurstudie naar specifieke determinanten van motivatie, gezondheid en verloop [Relationships between work characteristics and outcome variables: A literature study regarding specific determinants of motivation, health and turnover]. Studies bedrijfsgezondheidszorg nummer 12 . Maastricht, The Netherlands: Maastricht University.

Houkes, I., Janssen, P.P.M., Jonge, J. de, \& Nijhuis, F.J.N. (2001). Specific relationships between work characteristics and intrinsic work motivation, burnout and turnover intention: A multi-sample analysis. European Journal of Work and Organizational Psychology, 10, 1-23.

Janssen, P.P.M., \& Houkes, I. (2000a). Determinanten en gevolgen van werkstress [Determinants and outcomes of work stress]. In M. Schabracq, H. Maassen van den Brink, W. Groot, P.P.M. Janssen, \& I. Houkes, De prijs van stress (pp. 55-62). 's Gravenhage, The Netherlands: Elsevier Bedrijfsinformatie.

Janssen, P.P.M., \& Houkes, 1. (2000b). Drie belangrijke stressgevolgen en de relatie met kosten: motivatie, gezondheid en verloop [Three important stress outcomes and their relationships with costs: motivation, health and turnover]. In M. Schabracq, H. Maassen van den Brink, W. Groot, P.P.M. Janssen, \& I. Houkes, De prijs van stress (pp. 75-84). 's Gravenhage, The Netherlands: Elsevier Bedrijfsinformatie.

Janssen, P.P.M., \& Houkes, I. (2000c). Specifieke verbanden tussen werkkenmerken en stressgevolgen: theorie en empirie [Specific relationships between work characteristics and stress outcomes: theory and empirical studies]. In M. Schabracq, H. Maassen van den Brink, W. Groot, P.P.M. Janssen, \& 1. Houkes, De prijs van stress (pp. 63-74). 's Gravenhage, The Netherlands: Elsevier Bedrijfsinformatie. 


\section{$2.1 \quad$ Introduction}

This chapter presents the theoretical outline of the current study. Over time, many stress models that describe relationships between work characteristics, personal characteristics and outcome variables have been developed. Three important and well-known models in this regard are the Michigan Model (e.g., Kahn, 1981), the Demand-Control(-Support) Model (e.g., Johnson \& Hall, 1988; Karasek \& Theorell, 1990), and the Model of Work, Stress and Health (e.g., Kompier \& Marcelissen, 1990). These models have stimulated many empirical studies, which have yielded a considerable amount of knowledge regarding relationships between characteristics of the work setting and work-related outcome variables. However, they do not provide insight into more specific relationships between work characteristics, personal characteristics and outcome variables, which is the aim of the present study.

This chapter is divided into three parts. In the first part (section 2.2), we will present several meta-theoretical issues and criteria that are being proposed for the development and improvement of models (section 2.2.1), as well as an overview of the main insights that can be deduced from the above-mentioned stress models (section 2.2.2). The purpose of section 2.2.1 is twofold. First, we will use this metatheoretical knowledge to gain insight into the nature and goals of the three stress models, as well as their limitations in the light of the purpose of this study. Second, these meta-theoretical insights will be applied to provide clues for the development of a pattern of specific relationships. More specifically, in part two of this chapter (section 2.3), we will formulate a theoretical model that describes a suchlike pattern of specific relationships, taking into account the meta-theoretical insights and criteria described in section 2.2.1. For this purpose, we will first turn to the selection of the outcome variables and work characteristics. Additionally, we will display an up to date picture of the literature regarding specific determinants of the selected outcome variables. The third and final part of this chapter, section 2.4, addresses the issue of the influence of personal characteristics on the selected outcome variables, as well as on the proposed pattern of relationships between work characteristics and outcome variables. This chapter will be completed with a summary (section 2.5).

\subsection{Three prominent stress models in the field of Work and Organizational Psychology: a critical review}

\subsubsection{Several meta-theoretical issues regarding model development}

In this first subsection, we will introduce several meta-theoretical issues regarding model development. We will start with a short description of the concept of models in general: What are models? What purpose do they serve? Next, we will describe four levels of model development. Models can have several levels of abstraction. Each level has its own characteristics and goals. In the subsections 2.2.2 to 2.2.4 we will describe and discuss three well-known stress models in the light of these meta- 
theoretical issues (see also section 2.1). At the end of the present subsection, we will formulate several criteria for the systematic development and refinement of a pattern of specific relationships between work characteristics, personal characteristics and outcome variables (i.e., a theoretical model).

\section{What are models?}

In the social and behavioral sciences, social systems (e.g., a human being in his environment) are the subject of research. Knowledge about a system can be postulated in models. A model can be defined as a simplified reproduction of (a part of) reality, and is often constructed to improve the understanding and knowledge about this reality (Lave \& March, 1980). According to Cornelisse (1985), theories or models may serve three purposes: First, they may explain certain phenomena in reality, second, they may systematize this reality, and third, they may generate hypotheses and new expectations regarding reality.

Generally, models consist of concepts or variables, relationships or propositions, and measurement units (Lave \& March, 1980). In most studies in the field of Work and Organizational Psychology, individuals are the measurement units. The concepts or variables in a model can be defined as the properties of these measurement units (e.g., a type A personality, a high workload, or a certain level of work motivation). A model postulates the expected relationships between these concepts or variables.

\section{Four levels of model development}

Walker and Avant (1995) distinguish four levels of model development. The first level is that of the meta-theories. Meta-theories focus on philosophical and methodological questions related to the development of a theory base in a research area. They focus on broad issues related to theory in general. Analyzing the purpose and kind of theory needed in a research area, proposing and critiquing the sources and methods of theory development, and proposing the criteria most suitable for evaluating theories, are important issues at this level. The themes that are discussed in this subsection can be considered meta-theoretical. The second level of theory development is that of grand theories or conceptual models. Grand theories are highly abstract, include multidimensional concepts, and are generally proposed to give some broad perspective on a research area. As such, they are very difficult to validate. The third level of theory development consists of the middle-range theories or theoretical mode/s, which generally contain a smaller number of narrowly bounded specific variables, and hence they are more limited in scope than grand theories or conceptual models. These theoretical models are testable, yet sufficiently general to be scientifically interesting. Theoretical models share some of the conceptual economy of grand theories, but also provide the specificity to be useful in research and practice. They are explanatory or predictive in nature, and are constructed from available theories and empirical findings, by means of induction and deduction.

The fourth level of theory development consists of (practice) theories (Walker \& Avant, 1995). Generally, theoretical models refer to a group of interrelated (practice) theories. The theories in this fourth and most detailed level of model development encompass 
fewer phenomena than the three preceding levels, and can be defined as a set of interrelated constructs, definitions and propositions that present a systematic view of phenomena by specifying relationships among variables. As such, (practice) theories are aimed at a very small part of reality and do not include general propositions. The four levels of theory development are considered to be linked to each other. For instance, grand theories or conceptual models may serve as guides and heuristics for the phenomena of concern at the third level (middle-range theories or theoretical models). Empirical tests of theoretical models can provide material to refine existing grand theories or conceptual models.

The researchers Earp and Ennett (1991) distinguish two levels of model development that are similar to the second and third level of Walker and Avant (1995), respectively: general theoretical frameworks and conceptual models. A general theoretical framework provides an overview of an existing field of research, and is concerned with global classes of behavior. A conceptual model aims to predict one or more specific variables in a specific context, and is often based on several theories and empirical findings. Conceptual models are useful for summarizing and integrating existing knowledge, defining concepts, providing explanations for causal linkages and generating hypotheses (Earp \& Ennett, 1991). As opposed to theoretical frameworks (which aim to describe a whole research area), conceptual models are often limited to a certain part of the causal chain (Earp \& Ennett, 1991). Contrary to Walker and Avant (1995), Earp and Ennett use the term "conceptual models" for the third level of theory development.

Figure 2.1 shows a schematic overview and comparison of the two perspectives on theory development discussed above. 


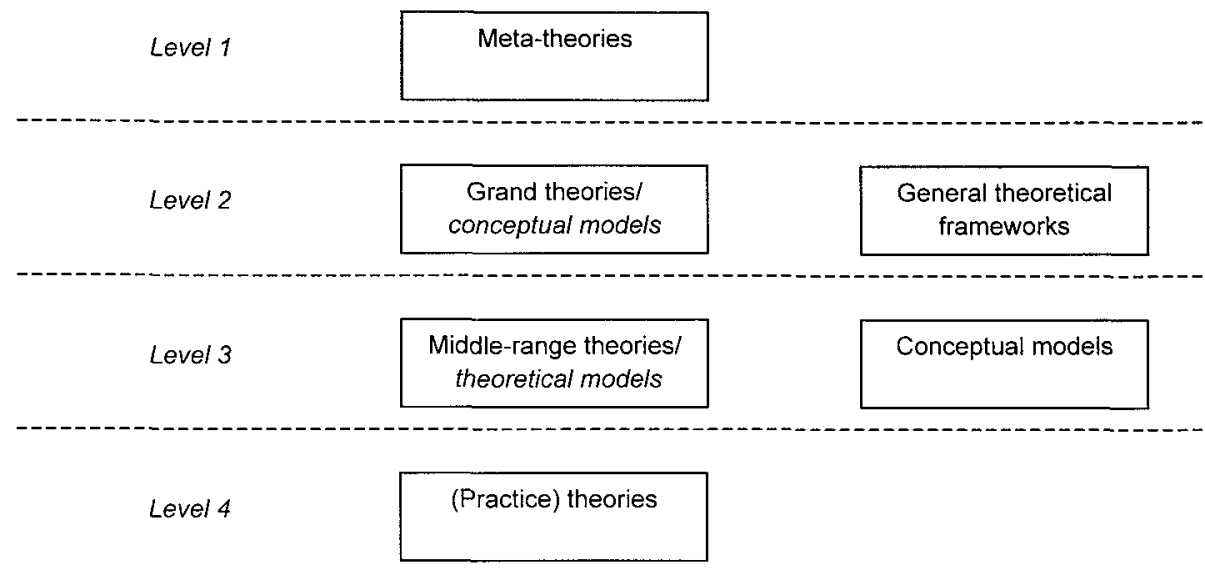

Figure 2.1 Comparison between different levels of model development according to Walker \& Avant (1995) (@ 1995 by Appleton \& Lange) and Earp \& Ennett (1991)

Throughout the remaining part of this thesis, we will use the term conceptual mode/s to indicate models at the second level of model development (level 2), and the term theoretical models to indicate the third level of model development (level 3 ).

\section{Developing models}

When developing a model, the goal of the model should be taken into account (Earp \& Ennett, 1991). The goal of the present thesis is to develop a pattern of specific relationships between work characteristics, personal characteristics, and outcome variables (see also chapter 1 ). It can be concluded from the propositions regarding the levels of model development described above and from the issues described in chapter 1, that we need a theoretical model in order to achieve this goal. The existing heuristic stress models mentioned above (i.e., the Michigan Model, the DC(S) Model, and the Model of Work, Stress and Health) can generally be classified as conceptual models (these models will be discussed more extensively in sections 2.2 .2 to 2.2.4). In addition, there exist many examples of theories in the domain of Work and Organizational Psychology (e.g., the Job Characteristics Theory of Hackman \& Oldham, 1980; many theories regarding burnout, see Schaufeli \& Enzmann, 1998). Several of these theories will be discussed in section 2.3. Examples of theoretical models that cover a relevant range of the area of Work and Organizational Psychology, and that are at the same time specific enough to be empirically tested, appear to be lacking, however (cf. Cooper, 1998). Therefore, the remaining part of this chapter will be applied to the formulation of such a theoretical model. 
This theoretical model should have predictive power with regard to the outcome variables. This model should be empirically testable, and at the same time be sufficiently global to be scientifically interesting (i.e., covering a relevant range of the working situation). In order to predict what work characteristics are of influence on certain outcomes, a range of different conceptual models (second level of model development) and theories (fourth level of model development) can be relevant. These conceptual models and theories may serve as a guidance in selecting and narrowing the concepts to be included in the theoretical model to be developed, and in understanding and formulating relationships.

\section{Developing a theoretical model: criteria}

In order to develop a theoretical model, it is most appropriate to start with the selection of the relevant outcome variables (Earp \& Ennett, 1991). Having chosen the endpoints of interest, a next step is to select potential and relevant determinants and indicating relationships between the variables. Causal explanations are made explicit by the directionality of the arrows between the variables. Causal relationships indicate that a change in the value of the independent variable leads to a change in the value of the dependent variable (Saris \& Stronkhorst, 1984).

There are several criteria to take into account when evaluating and developing a theoretical model (Cornelisse, 1985; Lave \& March, 1980; Walker \& Avant, 1995):

- A theoretical model should lead to useful and meaningful implications. That is, a theory should be helpful in understanding and/or predicting outcome variables.

- A theoretical model should have a certain level of generalizability or transferability. The more widely a theory can be applied, the more generalizable it is.

- A theoretical model should be as parsimonious as possible. That is, a model should be as simple and brief as possible, but still complete in its explanation of the phenomena under study. A parsimonious theory can be simple, but still broad in its content.

- A theoretical model should be empirically testable, otherwise it can never be validated. This implies that the model should contain a limited number of variables, should not be too complex (i.e., containing different kinds of relationships and feedback loops), should not contain similar variables, and finally, the variables included in the model should be defined precisely.

Generally, process models are preferred over state models (cf. Lave \& March, 1980). However, in order to develop a process model, knowledge about the relevant determinants and their relationships with outcome variables, is a prerequisite (cf. Van Breukelen, 1989; Earp \& Ennett, 1991). In other words, state models precede process models. More specifically, state models provide knowledge about the factors that initiate and influence the dynamics described in the process models. A second reason to start with state models in the development of theories, is that process models are more difficult to test than state models (cf. Earp \& Ennett, 1991). 
In the forthcoming subsections we will describe three well-known heuristic stress models from the field of Work and Organizational Psychology: the Michigan Model, the Demand-Control(-Support) Model, and the Model of Work, Stress and Health.

For each model, we will describe and discuss the following aspects: its content, a summary of the empirical evidence, the insights that can be deduced from the model with regard to the formulation of a specific pattern of relationships between work characteristics, personal characteristics and outcome variables, and finally, its limitations with regard to the formulation of a suchlike pattern of relationships. With regard to the latter aspect, we will discuss each model in the light of the criteria regarding the development of theoretical models formulated above.

\subsubsection{The Michigan Model}

During the early sixties, a research program with regard to "Social Environment and Health" was initiated at the University of Michigan. Researchers such as Katz, Kahn, French and Caplan participated in this program and formed the so-called Michigangroup. This research group focused on the effects organizations may have on individuals. The research activities of this group eventually resulted in an integrated research model known as the Michigan Model (Kahn, 1981; Kahn, Wolfe, Quinn, Snoek \& Rosenthal, 1964). The Michigan Model is a rather broad stress model that reflects several work-related variables, which may be of influence on the origination of strains. The Michigan Model has initiated several large studies in which this model was tested and elaborated (cf. Kleber, 1982). The version of the Michigan Model described in this thesis (see Figure 2.2) is partly based on several large Dutch studies and is a more recent version, than the one that was first described by Kahn and his colleagues.

The Michigan Model consists of six categories of variables. The four categories "objective environment", "subjective environment", "strains" and "sickness" form the so-called causal path. The objective environment refers to the actual working situation that is independent of individual perception. The subjective environment represents the working situation as it is perceived by the employee, and consists of several work stressors. Kahn et al. (1964) did not specify these stressors thoroughly, but in early versions of the model, role conflict and role ambiguity were the most important stressors in the model. In more recent versions, other stressors such as work overload, job insecurity and responsibility were added (Kleber, 1982). The objective environment determines the subjective environment. Further, when a person is no longer able to deal with the demands in his subjective environment, strains (physical, psychological or behavioral) may ensue. In the long term, these strains may cause sickness and disablement for work. All relationships in this causal path may be moderated by the fifth and the sixth category of variables: social support and personal characteristics. 


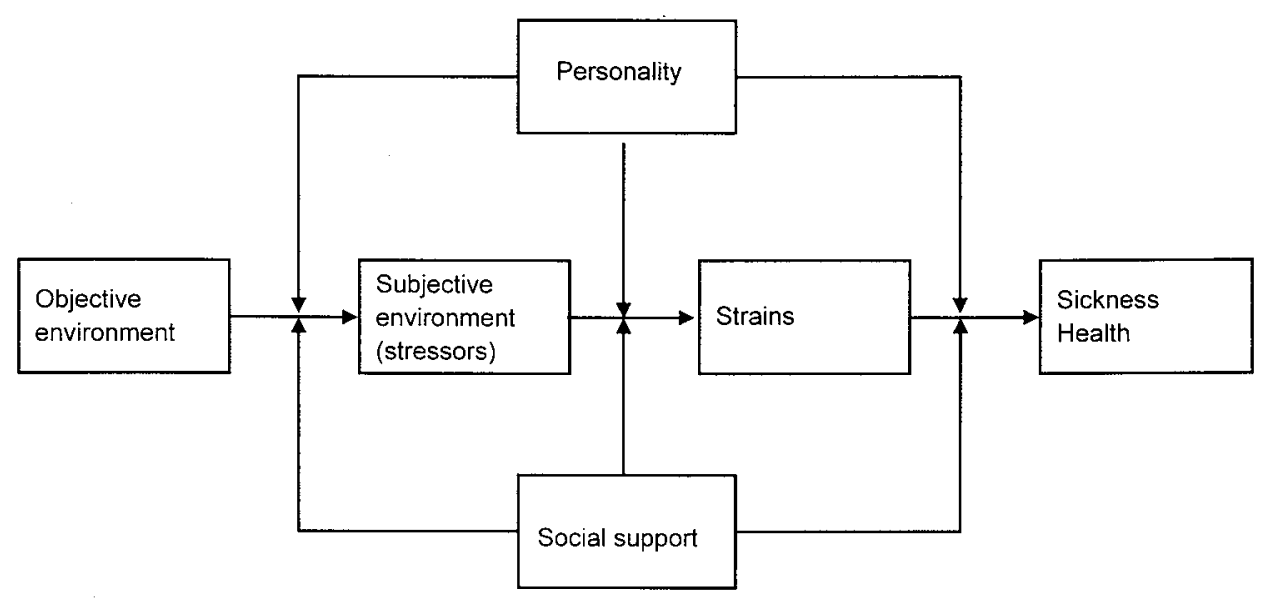

Figure 2.2 The Michigan Model (Kleber, 1982, p. 57; (c) 1982 by Van Loghum Slaterus, reprinted with permission of the publisher)

\section{Empirical evidence and insights that can be deduced from the Michigan Model}

As a result of its nature (the Michigan Model can be considered a global and comprehensive theoretical framework, and thus as a conceptual model; cf. Walker \& Avant, 1995), the Michigan Model has never been tested integrally (see also De Jonge, 1992). Several studies, however, aimed to measure as much model variables as possible, and tested the relationships between these variables. For instance, Caplan, Cobb, French, Harrison and Pinneau (1975) performed an extensive study regarding the Michigan Model (see also Marcelissen, 1987). Generally, they found support for the relationships proposed in the model: they found significant relationships between unused skills and job dissatisfaction, as well as between role ambiguity and role conflict on the one hand, and anxiety and depression on the other. However, they could not find evidence for the last relationship in the causal path, viz. the relationship between strains and sickness (i.e., the strains in their study did not lead to coronary heart diseases or stomach disorders).

With regard to the objective and subjective environment proposed in the Michigan Model, it can be concluded that in most studies it is hypothesized that the perception of the environment (i.e., the subjective environment) causes the strains, and not the objective environment (cf. De Jonge, 1992; Kleber, 1982). Marcelissen (1987) reports in this regard that in a considerable part of the studies regarding the Michigan Model, the objective environment was not measured at all. Several studies have indicated that the relationship between the subjective environment and strains is generally stronger than the relationship between the objective environment and strains (Caplan, 1971; Jessor \& Jessor, 1973; cf. De Jonge, 1992). Furthermore, Van Dijkhuizen 
(1980) has studied the causal chain proposed in the Michigan Model as well as the necessity of measuring both the objective and the subjective environment. Van Dijkhuizen found evidence for the causal chain proposed in the Michigan Model. Moreover, he found that there were hardly any significant differences between subjective and "objective" measurements (i.e., as reported by close colleagues) of the work environment. In other words, the measurement of the objective environment did not add much information to the measurement of the subjective environment. Thus, it seems that the fact that the objective environment was not measured in many studies is less problematic than some researchers suggest.

In addition, many studies investigated relationships between the stressors and strains proposed in this model. Jackson and Schuler (1985) performed a meta-analysis of studies with regard to the effects of role conflict and role ambiguity. They found, among other things, that role conflict and role ambiguity are correlated with dissatisfaction, anxiety and turnover intention. Marcelissen (1987) studied the moderating effects of social support and type $A$ behavior on the relationships between stressors and strains. He did not find moderating effects, but he showed that social support diminished several stress reactions and strains. Regarding type $A$ behavior, he found this characteristic to be a determinant of both stressors and strains. In addition, type $A$ behavior appeared to be an outcome of stressors. Based on these findings, he concluded that type $A$ behavior was rather a mediating than a moderating variable (which is not in line with the propositions of the Michigan Model).

In sum, the literature and large amount of empirical studies regarding the Michigan Model reveal that the relationships postulated in the model can be demonstrated, particularly the relationships between work stressors and stress reactions: there seems to exist a critical path leading from work stressors to strains. Furthermore, the variables social support and personal characteristics appear to have some influence on the relationships between stressors and stress outcomes, but also directly on the stress outcomes.

\section{Discussion of the Michigan Model in the light of meta-theoretical criteria and the research questions}

First, the Michigan Model is rather a conceptual model that specifies relationships between broad categories of variables, than a model that aims to predict specific outcome variables (i.e., it is not a theoretical model). Second, the Michigan Model is a process model rather than a state model. This may lead to interesting implications, but it also leads to poor testability of the model as a whole. Furthermore, the variables in the model have not been defined precisely. The model rather includes categories of variables and hence, the model can be operationalized in many ways. This implies, among other things, that the model is generalizable over different occupational groups, but it is also another factor leading to poor testability of the model. Fourth, the Michigan Model is not useful to predict specific outcome variables, but it does provide a framework for formulating predictions. The Michigan Model is important, because it has defined categories of important independent and dependent variables, and has 
described critical paths between these variables. Furthermore, the model has stimulated many empirical studies and has initiated the development of several other models in the field of Work and Organizational Psychology (see, for instance, the models in the two forthcoming subsections).

\subsubsection{The Demand-Control(-Support) Model}

At the end of the seventies, the Job Demand-Control (DC) Model was introduced (Karasek, 1979; Karasek \& Theorell, 1990). This model can be considered as a synthesis of two research traditions (cf. De Jonge, 1995): the job redesign tradition (e.g., Hackman \& Lawler, 1971; Hackman \& Oldham, 1976; Turner \& Lawrence, 1965) and the occupational stress or Michigan tradition (e.g., Caplan et al., 1975; Kahn, 1981). As such, the DC Model is a spin-off of the Michigan Model. The aim of the DC Model was to provide a theoretical framework for the development of guidelines for the enhancement of the quality of work (De Jonge, 1995).

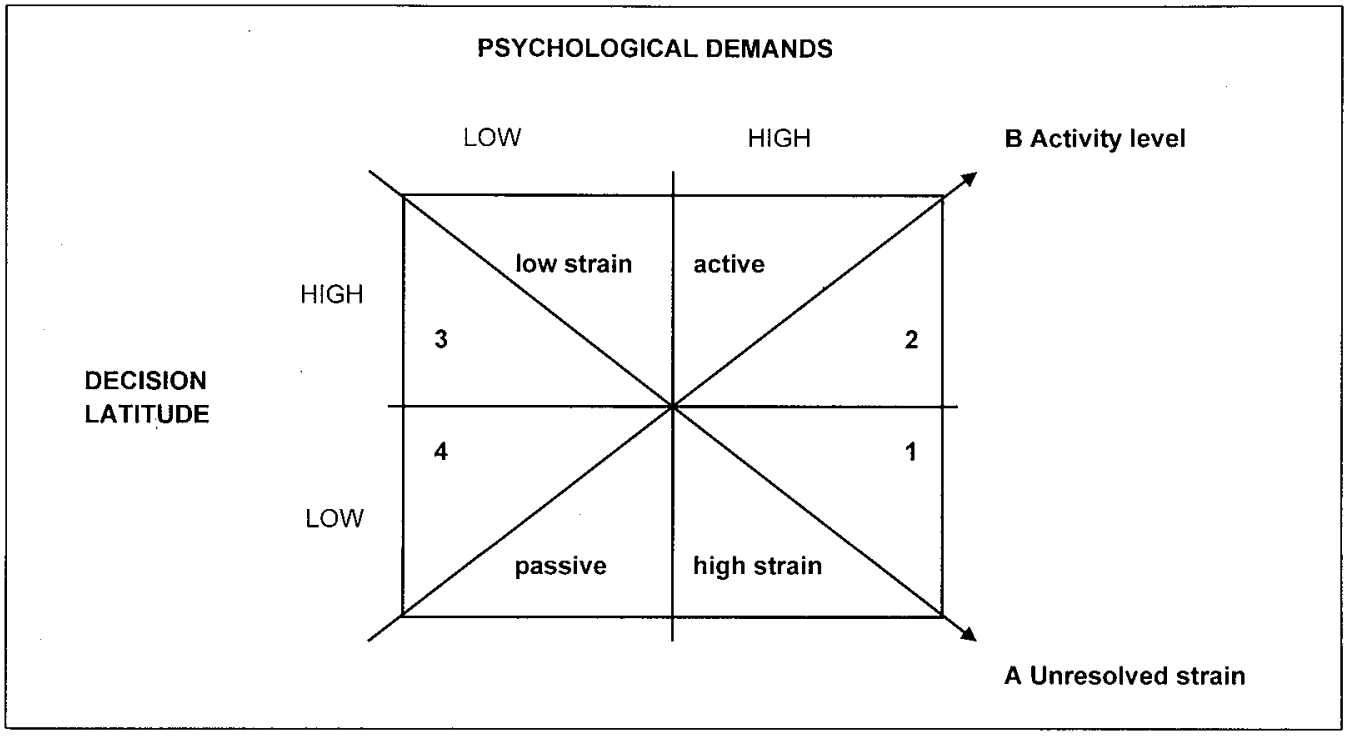

Figure 2.3 The Job Demand-Control Model (Reprinted from Karasek, R.A. (1979). Job demands, job decision latitude, and mental strain: Implications for job redesign. Administrative Science Quarterly, 24, 2, 288; with permission of Administrative Science Quarterly)

The DC Model (see Figure 2.3) postulates that stress is generally caused by two basic characteristics of the job: job demands and job control. Job demands can be defined as psychological work stressors, such as not having enough time to do the work, working hard and working fast. Job control, which has also been labeled as job decision latitude or job discretion, may be defined as the worker's potential control over his tasks and conduct during the working day (Karasek, 1979). The most 
innovative aspect of this model was that psychological strains were considered a consequence of the joint effects of the job demands and job control, that is, an interaction effect of these two variables was postulated (Karasek, 1979). The DC Model states that the different interactions of job demands and job control result in four possible work situations: (1) high strain jobs (high job demands, low job control); (2) active jobs (high job demands and high job control); (3) low strain jobs (low job demands and high job control), and (4) passive jobs (low job demands and low job control).

There are two independent diagonals in the model: the strains diagonal (A) and the active diagonal $(B)$. These two diagonals reflect the two major predictions of the DC Model. The first diagonal $(A)$ reflects the prediction that high strain jobs are most likely to result in adverse health effects. The second diagonal $(B)$ reflects the prediction that active jobs may lead to intrinsic motivation, learning and personal growth. Passive jobs, on the other hand, will result in a reduction of problem solving abilities and a passive attitude of the employee. These two psychological mechanisms can result in a variety of outcome variables. Negative outcomes (e.g., exhaustion, anxiety, psychosomatic complaints, cardiovascular diseases, absenteeism), as well as positive outcomes (motivation, satisfaction and learning) are proposed (cf. De Jonge, 1995).

As a response to criticism regarding the simplicity of the DC Model, it was extended with a third work characteristic: social support (Johnson \& Hall, 1988). This extended model was called the Demand-Control-Support Model. Karasek and Theorell (1990) defined social support as overall levels of helpful social interaction available on the job. Both the strains-diagonal and the active-diagonal are split up into isolated and collective working conditions. Accordingly, eight kinds of work situations can be distinguished: four work situations in combination with high social support and four work situations in combination with low social support.

\section{Empirical evidence and insights that can be deduced from the DC(S) Model}

With regard to the DC(S) Model, numerous empirical studies have been carried out. Generally, three kinds of studies can be distinguished (cf. De Jonge, 1995; De Jonge \& Kompier, 1997; Jones \& Fletcher, 1996): (1) epidemiological studies (multioccupation studies), which mainly focus on cardiovascular diseases as outcome variables, (2) small-scale surveys in homogeneous or heterogeneous occupational groups, which focus on attitudinal (e.g., satisfaction, motivation), behavioral (e.g., absenteeism, smoking) and physiological (e.g., blood pressure) outcome measures, and (3) monitoring studies or (quasi-) experiments, which focus on the short-term effects on physiological parameters such as the level of adrenaline. Several reviews regarding the many empirical DC(S)-studies (e.g., Ganster \& Fusilier, 1989; Karasek, 1989; Karasek \& Theorell, 1990; De Jonge, 1995; Kristensen, 1995; Theorell \& Karasek, 1996) have indicated that empirical support for this model is mixed. The epidemiological studies provide some evidence for the strains diagonal (De Jonge \& Kompier, 1997). The active diagonal has been studied to a lesser extent. Furthermore, the second group of studies (i.e., the surveys) have shown that the direct effects of job 
demands, job control and social support on health-related outcome variables, are generally confirmed: job demands are in particular related to behavioral outcome variables such as sickness absence, and job control is in particular related to attitudinal outcomes such as motivation and satisfaction (cf. De Jonge, 1995; De Jonge \& Kompier, 1997). Empirical support for the interaction hypothesis of the model, however, is rather limited. According to De Jonge (1995) this lack of evidence for the interaction hypothesis is due to factors such as the mathematical formulation of the interaction term, confounding, and sampling (samples used are often too homogeneous). In addition, comprehensive, simultaneous tests of the DC(S) Model in longitudinal studies are very scarce (cf. De Jonge, 1995; De Jonge \& Kompier, 1997).

Unlike the Michigan Model, the DC(S) Model proposes positive as well as negative outcomes of the working situation (i.e., a wider range of outcome variables is covered). This is rather unusual in the area of Work and Organizational Psychology: the number of articles examining negative states outnumbers the articles examining positive states by a ratio of approximately 17 to 1 (Diener, Suh, Lucas \& Smith, 1999; Kahn \& Byosiere, 1992). Furthermore, particularly the independent variables of the $\mathrm{DC}(\mathrm{S})$ Models have been described more precisely than the variables in the Michigan Model. That is, the Michigan Model includes categories of variables, while the DC(S) Model includes more concrete variables. As such, the DC(S) Model is more specific than the Michigan Model.

\section{Discussion of the $D C(S)$ Model in the light of meta-theoretical criteria and the research questions}

The DC(S) Model has several limitations as well. The outcome variables, for instance, still lack specificity. It appears that in the considerable amount of empirical studies with regard to the $\mathrm{DC}(\mathrm{S}) \mathrm{Model}$, many different outcome variables have been included (e.g., cardiovascular diseases, blood pressure, sickness absence, burnout, depression, anxiety, motivation, et cetera). The comparability of the diverse empirical results can therefore be questioned. In addition, the second proposition of the model (active jobs lead to learning, motivation and personal growth) has been investigated to a much lesser extent than the first proposition (De Jonge \& Kompier, 1997). Furthermore, the interaction hypothesis does not receive consistent and convincing empirical support. Finally, no personal characteristics are included in the original DC(S) Model. According to, for instance, Parkes (1991) and Furda (1995), the propositions of the model may be more salient for people with certain personal characteristics, such as an external locus of control and an active coping style.

When we consider this model in the light of the criteria for model development described in section 2.2.1, it appears that the DC(S) Model is closer to a theoretical model than the Michigan Model, and is as such better testable. Still, it has features of a conceptual model, however. For instance, despite the fact that this model is a state model and not a process model, its empirical testability is moderate. The model variables, as well as the specific nature of the (interactive) relationships between the variables are not described precisely. In the various studies regarding this model, 
several kinds of outcome variables have been included. The DC(S) model proposes more specific predictions regarding certain outcome variables and is rather parsimonious and generalizable over occupational groups, but is at the same time somewhat limited in its range.

\subsubsection{The Model of Work, Stress and Health}

The final model that will be discussed in this section, is the Dutch Model of Work, Stress and Health (Kompier \& Houtman, 1995; Kompier \& Marcelissen, 1990). This is a rather dynamic model that reflects the origination of sickness and health in the working situation. This model was developed at the end of the eighties, and was partly built on propositions of the DC(S) Model, and the Michigan Model (cf. Kompier, Van Dijk, Van Dormolen \& Meijman, 1990; Kompier \& Marcelissen, 1990; see Figure 2.4).

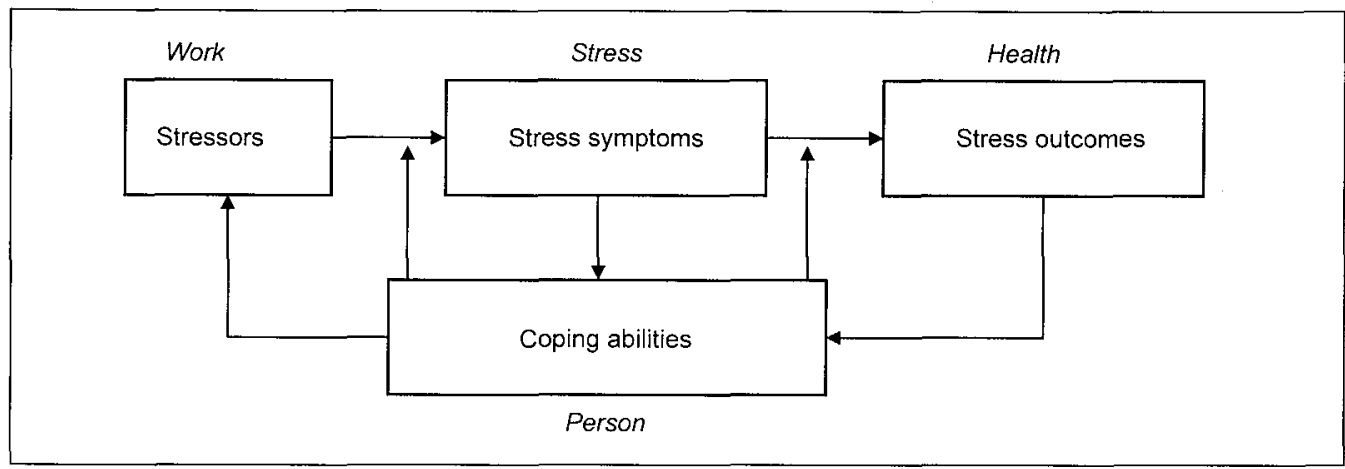

Figure 2.4 The Model of Work, Stress and Health (translated from Kompier \& Marcelissen, 1990, p. 24; (C) 1990 by TNO Arbeid, reprinted with permission of the publisher)

The causal path leading from the working situation, to stress symptoms, to stress outcomes is also recognizable in the Michigan Model (objective and subjective work environment to strains to illness; e.g., Kahn, 1981). According to the Model of Work, Stress and Health, the working situation consists of work stressors and the level of decision latitude in the working situation. This dual classification of the working situation is based on the DC Model (Karasek, 1979). However, contrary to the DC Model, the Model of Work, Stress and Health does not focus explicitly on an interaction between the stressors and decision latitude. Both work stressors and decision latitude are proposed to have an effect on stress. Contrary to the Michigan Model, which focuses on role factors as the most important stressors in the working situation, the Model of Work, Stress and Health proposes a clear classification of work stressors into four categories (Kompier \& Marcelissen, 1990): job content (e.g., task characteristics), working conditions (e.g., physical working conditions, work pressure), labor relations (e.g., relationships with colleagues and supervisors), and conditions of employment (e.g., salary and career opportunities). Furthermore, these work stressors 
can lead to several emotional, physical and behavioral stress symptoms, such as anxiety, tension, high blood pressure, higher heart rate, and irritability. When the level of work stress diminishes, these stress symptoms may disappear rather quickly (reversible symptoms). However, when the work stress is intense, or lasts for a longer period of time, these stress symptoms may become chronic and evolve into psychological sickness (i.e., stress outcomes), such as depression, fatigue and exhaustion (Kompier et al., 1990; Kompier \& Marcelissen, 1990; Kompier \& Houtman, 1995). The Model of Work, Stress and Health contains several feedback loops and interactions. For instance, when the balance between work stressors and coping abilities of a person is disturbed, stress arises in the form of stress symptoms (Kompier \& Houtman, 1995). In addition, particularly when the coping abilities of a person are low, stress symptoms may evolve into stress outcomes. An example of a feedback loop is that stress outcomes may lead to the diminishment of a person's coping abilities, which may in turn have influence on the perception of the working situation.

\section{Empirical evidence and insights that can be deduced from the Model of Work, Stress and Health}

First, it is difficult to test the model integrally, because the model does not describe specific variables and contains a rather complex network of relationships with several feedback loops. However, the relationships between stressors and job control on the one hand and stress outcomes on the other have been studied frequently. For instance, a study of Houtman, Kompier, Smulders and Bongers (1994) showed that work stressors, such a high working pace, uninteresting work, and physical and chemical stressors, are associated with higher levels of psychosomatic complaints.

Considering our research questions, the most salient feature of this model is that it provides a clear categorization of work characteristics. This may be considered a valuable supplementation to the $\mathrm{DC}(\mathrm{S})$ Model and the Michigan Model.

\section{Discussion of the Model of Work, Stress and Health in the light of meta- theoretical criteria and the research questions}

The Model of Work, Stress and Health has in common with the Michigan Model that it is rather a theoretical framework or conceptual model than a theoretical model that describes specific relationships between certain work characteristics and outcome variables (cf. Earp \& Ennett, 1991; Walker \& Avant, 1995). The model postulates a network of relationships between several categories of variables (direct, moderating, and mediating relationships, as well as feedback loops are included). In addition, this model has more features of a process model than the two models discussed above (cf. Lave \& March, 1980). However, this implies that the model is complex, and hence, the testability of the model as a whole is only moderate. The model contains several feedback loops, and the model variables (work characteristics and outcome variables) are not defined precisely. As such, the model is not very parsimonious either. The model does provide a clear classification of the working situation, but in order to be testable these variables should be elaborated more extensively. Furthermore, the 
model does not cover a wide range of possible outcome variables, in fact the model focuses on sickness and health. That is, just like in the Michigan Model, only negative outcomes are included. According to the criteria discussed in section 2.2.1, however, a model should lead to useful and meaningful implications, and be as complete as possible regarding the phenomena under study. In order to achieve this, the inclusion of more than one kind of outcome variables seems appropriate.

In sum, because the model classifies the working situation and incorporates important propositions of both the Michigan Model, and the DC(S) Model, we can conclude that this model can provide important clues for the theoretical model we aim to develop and may serve as a heuristic framework in this regard.

\subsubsection{Conclusion and implications for further model development}

In the field of Work and Organizational Psychology, several conceptual models exist that describe relationships between (categories of) work characteristics and (categories of) outcomes. The propositions of these models and the accompanying empirical studies have resulted in a considerable level of knowledge about the effects of work on the employee. However, these models do not reveal what specific effects several precisely defined work characteristics have on a meaningful set of relevant and precisely defined outcome variables. Both the Michigan Model and the Model of Work, Stress and Health are rather global models, that provide useful frameworks, but they are not suitable to describe specific relationships between work characteristics and work-related outcome variables. In addition, the variables included in these models are not described precisely. As such, integral empirical tests of these models are hardly possible. The $\mathrm{DC}(S)$ Model has a higher level of specificity, although it lacks a specific description of the outcome variables and of the specific relationships between the work characteristics and outcome variables included in the model.

Considering the limitations of the three models described in this section, we may conclude the following. A step forward in the refinement and improvement of these existing models, as well as an answer to the research questions, might be the development of a theoretical model that incorporates both the general insights regarding the influence of work on the health and well-being of employees, and more refined theories regarding specific relationships between work characteristics and outcome variables. These general insights can be deducted from the conceptual models described in this section. Furthermore, the development of such a model should meet the criteria for model development described in section 2.2.1. This implies that the work characteristics included in the model should have predictive power with regard to the outcome variables, that the model should have thorough theoretical underpinnings, should be generalizable and parsimonious (but still as complete and broad as possible) and should of course be testable in empirical research. The latter criterion implies that the model variables should be described precisely, that the model variables should not overlap, and that the model is not too complex (e.g., the model should not contain a large number of reciprocal arrows and feedback loops). Furthermore, considering the present stage of theoretical model 
development in the area of Work and Organizational Psychology, as well as the above-mentioned criteria (i.e., particularly testability and simplicity), the choice to develop a state model and not a process model, seems obvious.

In order to formulate the theoretical state model, the following steps will be taken. These steps are based on the phases in the empirical cycle (cf. Bouter \& Van Dongen, 2000) and suggestions of Earp and Ennett (1991) and Walker and Avant (1995).

1. Description of endpoints of interest (Earp \& Ennett, 1991): the outcome variables (section 2.3).

2. Description of relationships to be included: what work characteristics are important determinants of the selected outcome variables; what relationships are important, and what relationships are trivial (section 2.3)? In order to describe these relationships, we will use several more specific theories regarding the endpoints of interest.

3. Selecting important personal characteristics and describing their influence (section 2.4).

4. Deduction of testable hypotheses from the theoretical model developed in the previous steps (sections 2.3 and 2.4 ).

5. Testing the hypotheses and interpreting the results in the light of the theoretical model (chapters 4 to 6 ).

In the forthcoming section (section 2.3, the second part of this chapter), we will perform steps 1 and 2 mentioned above. That is, we aim to formulate a theoretical model that describes specific relationships between work characteristics and outcome variables. In the final part of this chapter we will address the issue of the personal characteristics.

\subsection{The selection of outcome variables, the categorization of work characteristics, and a theoretical elaboration on the specific relationships between these variables}

\subsubsection{Introduction}

In this section, we will formulate a theoretical model that describes specific relationships between work characteristics and outcome variables, by means of a literature study. For this purpose, we will reason from a pattern of relationships between work characteristics and outcome variables developed by Janssen, De Jonge and Bakker (1999), since this pattern of relationships seems quite promising in the context of this study. That is, we will take their propositions as a starting point, but elaborate on them more thoroughly.

As suggested by Earp and Ennett (1991), we will first describe a range of relevant outcome variables (subsection 2.3.2), and then provide a categorization of work characteristics (subsection 2.3.3). In the subsection thereafter (2.3.4), we will discuss the issue of specific relationships between the selected outcome variables and work 
characteristics, taking the outcome variables as a point of departure (Earp \& Ennett, 1991). More specifically, for each outcome variable, we will first discuss its content, and then narrow it to a specific, univocal concept. Second, we will discuss the most important work-related determinants of these outcome variables, based on existing theories and empirical studies. These determinants will be classified according to the categorization provided in subsection 2.3.3. At the end of this section (subsection 2.3.5), we will present the specific pattern of relationships between work characteristics and outcome variables schematically, and deduct the study hypotheses regarding specific relationships between work characteristics and outcome variables.

\subsubsection{Selection of outcome variables}

\section{Psychological outcome variables}

In the field of Work and Organizational Psychology, several types of outcome variables can be distinguished (cf. Kleber, 1982): psychological outcomes (e.g., motivation), physiological outcomes (e.g., blood pressure), and behavioral outcomes (e.g., sickness absence). Research has shown that variables measuring (the perception of) the working situation are particularly good predictors of psychological outcome variables. This finding is not considered to be the result of common method variance, but of the fact that physiological and behavioral outcomes are more distal from work characteristics than psychological outcomes (Buunk et al., 1998; see also Fried \& Ferris, 1987; Jackson \& Schuler, 1985). That is, there are many other variables, besides work characteristics, that may explain an individual's actual behavior or physiology (e.g., economic factors and lifestyle, respectively). Moreover, in the causal chain, psychological variables generally precede behavioral variables (cf. Ajzen, 1987; Ajzen \& Fishbein, 1980; De Vries, 1988). According to Earp and Ennett (1991), it is advisable to limit a theoretical model to a well-defined part of the causal chain. For these reasons, we decided to include only one kind of outcome variables, viz. psychological outcome variables. In turn, these psychological variables seem to be adequate predictors of behavior and, to a lesser extent, of physiological variables such as sickness (Ajzen, 1987; Ajzen \& Fishbein, 1980; Warr, 1996). A clear pattern of relationships between work characteristics and psychological outcome variables will simplify the development of process models, which may eventually include more distal outcome variables such as behavioral or physiological variables (cf. Warr, 1996).

\section{An existing pattern of relationships: three psychological outcome variables}

As mentioned previously, the pattern of relationships suggested by Janssen, De Jonge and Bakker (1999) seems to be a promising starting point with regard to the development of a theoretical model that reflects a pattern of specific relationships between work characteristics and outcome variables. Hence, we will use their pattern of relationships as a mould, and first try to substantiate and replicate it by means of a more extensive literature study.

With regard to outcome variables, Janssen, De Jonge and Bakker (1999) initially selected three global variables: work motivation, mental health and turnover, which 
were operationalized as intrinsic work motivation, burnout (i.e., emotional exhaustion), and turnover intention, respectively. According to Janssen and his colleagues, these three psychological outcome variables are theoretically distinct from each other, and can also be considered organizationally and socially relevant issues (see also Kompier \& Vink, 1994; Laterveer, 1996). The presence of motivated and healthy personnel with a low turnover rate, will enhance the effectiveness of organizations, the quality of the products and services rendered, and it will improve the image that organizations have with clients, potential employees, other organizations and governments (Kompier \& Vink, 1994). Furthermore, it will diminish the costs that are associated with, for instance, sickness absence and recruitment of new staff. Moreover, with regard to these three outcome variables, many theories have been developed, and many empirical studies have been performed, in several research traditions. In other words, this set of outcome variables seems to be an adequate representation of psychological effects work may have on people. Therefore, in line with Janssen, De Jonge and Bakker (1999), we will include these outcome variables in our theoretical model. In subsection 2.3.4 we will elaborate more extensively on these outcome variables, on their operationalizations, and on their work-related determinants.

\subsubsection{A categorization of possible predictors of the three outcome variables: work characteristics}

The selection of work characteristics will depend on the extent that they are associated with the selected outcome variables. A literature study must reveal whether and what work characteristics are primarily related with the outcome variables under study. The number of work characteristics to be distinguished is large, however. Therefore, in accordance with Janssen, De Jonge and Bakker (1999), we will first categorize the work characteristics. The Model of Work, Stress and Health (Kompier \& Marcelissen, 1990; see also section 2.2) offers a useful categorization of work characteristics, which seems distinct and rather complete. Four categories of work characteristics are distinguished: work content, working conditions, labor relations, and conditions of employment. Van Dijk (1990, 1992), Kruse and Grunveld (1992), Gehrels and Lemmens (1993), and Le Blanc, De Jonge and Schaufeli (2000) also used this classification. Moreover, the Dutch ARBO-law advises organizations to take these four categories of work characteristics into account in order to enhance the health, safety and well-being of their employees (cf. Laterveer, 1996; Lenderink, 1998; Kruse \& Grunveld, 1992). These four categories of work characteristics are described below. For each category we will first provide the short description of Kompier and Marcelissen (1990), and then elaborate on it somewhat more by means of additional literature.

\section{Work content}

The category of work content refers to the content and characteristics of the tasks to be performed. Kompier and Marcelissen (1990) describe this first category as "What 
should happen and how?". Examples of task characteristics in this category are monotony, difficulty, and level of responsibility (Kompier \& Marcelissen, 1990). Task characteristics are assumed to be related to, for instance, motivation and satisfaction (e.g., Hackman \& Oldham, 1980). With regard to the description or measurement of task characteristics, several perspectives can be distinguished. In the job redesign approach, a certain level of abstraction is used (e.g., Algera, 1981, 1992). This approach focuses at the intrinsic characteristics of the tasks in an organization and aims to describe these tasks in rather abstract terms (Algera, 1981, 1992). A second approach consists of a detailed exploration of all activities within a job, as is done in a job analysis. Job analysis is a technical procedure used to define the specific duties, responsibilities, and accountabilities of a job (De Cenzo \& Robbins, 1996). The results of a job analysis are very useful in Human Resources Management. However, considering the number of jobs that is usually present in an organization, such an approach seems hardly feasible in studies that aim to generate general conclusions with regard to relationships between work characteristics and outcome variables. In this regard, it seems more useful to apply the first approach and describe the work content by means of a number of core characteristics (cf. Vogelaar \& Van der Vlist, 1995). Examples of these task characteristics are autonomy and feedback from the job. Considering this description of the work content, the variable decision latitude that Kompier and Marcelissen (1990) considered to be a separate characteristic of the work situation (besides the work stressors), can also be placed in this category.

\section{Working conditions}

Kompier and Marcelissen (1990) describe this category as "the working place" and provide examples such as heavy work and dangerous work. It seems straightforward to subdivide working conditions into two global categories (cf. Dul \& Houtman, 1995; Gaillard, 1996): mental working conditions (e.g., workload) and physical working conditions (e.g., working with heavy loads or chemical agents). During the last decades, the nature of work has changed (see also chapter 1). This change has resulted in an increase of the importance of mental working conditions such as workload, while the salience of physical working conditions has relatively decreased (Kompier, 1996).

Literature suggests that mental workload is an important representative of the category of mental working conditions (cf. Kompier, 1996). Mental workload can be conceived as a product of the amount and complexity of the work to be done, and may lead to several psychosomatic and psychological complaints (Buunk et al., 1998). Kompier and Marcelissen (1990) have categorized mental workload under work content. However, in line with Gaillard (1996), we consider work content and workload to be conceptually different. In this regard, Gaillard (1996) argues, for instance, that it is not possible to determine the mental workload by means of task characteristics, because a generally accepted taxonomy of task characteristics does not exist. The amount of work that has to be done, and the time pressure are not directly related to the content of the work to be done. Therefore, mental workload has to be measured 
separately from the task characteristics. In this thesis, we consider mental workload to be part of the (working) conditions under which the tasks have to be performed.

Physical working conditions refer to the risks that originate from, for instance, working with chemical agents, unsafety or risks at the workplace, noise, vibrations, climate, static and dynamic pressure (Kompier \& Marcelissen, 1990). Physical working conditions may have effects on the physical health (e.g., cardiovascular diseases, backache, impairment of nervous system, or the "modern" disease Repetitive Strain Injury (RSI)), but also on the psychological well-being of employees (cf. Smulders, 1995).

\section{Labor relations}

The dimension of labor relations refers to the relationships employees and employers have with each other, as far as these relationships concern the working situation of the employees in the organization or the position of the factor work in society (Kluytmans \& Van Laanen, 1993). These relationships may have a formal (e.g., employee participation) or an informal nature (e.g., social contacts among colleagues and between employees and supervisors) (Kompier \& Marcelissen, 1990).

Employee participation may offer employees the opportunity to exert some influence on the decision making process in their organization. Participation may be direct or indirect. An example of direct participation is a meeting between supervisor and subordinates to discuss the work progress. An example of indirect participation is the employee council (Kluytmans \& Van Laanen, 1993). Participation may stimulate the commitment, satisfaction and health of employees.

Social support, the informal dimension of labor relations, concerns the interactions among colleagues and between employees and supervisors, and the support one gives each other in these interactions (Buunk et al., 1998). Discussing certain workrelated problems with colleagues and supervisors, may help to deal with these problems more effectively, and may thus prevent the employee from becoming distressed. There are several types of social support to be distinguished, for instance, instrumental support and emotional support (Buunk et al., 1998).

\section{Conditions of employment}

When an employee starts working for an organization, generally an employment contract is arranged that contains the agreements with regard to the conditions of employment. The conditions of employment can include many aspects such as salary (e.g., structural and flexible), career and promotion opportunities (e.g., a career development plan), job security (e.g., permanent versus temporary contract), and job perspectives (e.g., possibility to extend the contract) (Kompier \& Marcelissen, 1990). Furthermore, several secondary conditions of employment such as educational opportunities (e.g., courses within the organization or external educational opportunities, management development programs), working hours (e.g., full-time versus part-time, number of days off, flexible working hours or not, arrangements for reduction of working hours), social security (e.g., sickness insurance, pension plan), and company cars may be included in an employment contract (Hoogstad \& 
Weststeijn, 1997). Conditions of employment may enhance an employee's commitment with the organization, and may thus decrease turnover intention (e.g., Hall, 1976; Janssen, 1992). In addition, in some cases, conditions of employment may lead to extrinsic work motivation (cf. Wiersma, 1992).

\subsubsection{Work-related determinants of the selected psychological outcome variables}

Using the pattern of relationships proposed by Janssen, De Jonge and Bakker (1999) as a starting point, we have hitherto selected three outcome variables (i.e., (intrinsic) work motivation, mental health (burnout) and turnover (intention)), and we have classified the work characteristics according to four categories (i.e., work content, working conditions, labor relations and conditions of employment). In the forthcoming three subsections, we will elaborate on the pattern of relationships between these work characteristics and outcome variables. As was already outlined in section 2.3.1, we will take the three outcome variables as a starting point, in line with suggestions of Earp and Ennett (1991).

\subsubsection{Work motivation: intrinsic work motivation}

The why and whither of human behavior is one of psychology's eldest concerns (Thierry, 1998), and also in the work environment, motivation is an important issue. The concept of motivation refers to the cause, the intensity, and the direction of human behavior (Thierry, 1998). More specifically, Thierry defines motivation as the process relating to the category of outcomes an individual wants to achieve or to avoid, as well as to the specific actions necessary to attain this.

In the present thesis, we are in the first place interested in work motivation and we will limit ourselves to this specific concept. Work motivation is manifested in behavior or in an attitude towards one's work and can be defined as an individual's willingness to exert effort to achieve the organization's goals, conditioned by this effort's ability to satisfy individual needs (De Cenzo \& Robbins, 1996).

According to De Cenzo and Robbins (1996), work motivation is a major determinant of performance at the workplace (see also Cook, Hepworth, Wall \& Warr, 1981). Employees might be able to do the job, but if they are not willing to, the organization has a problem. Knowledge about the determinants of work motivation can therefore be of great interest to employers, but also to employees. What is it in work that motivates people? Is the cause of motivation located "within" the person, or is it to be found in the external environment?

\section{Theoretical models with regard to work motivation}

A concept in this context that has gained much attention both in research and practice is intrinsic work motivation (cf. Janssen, Nijhuis, Peeters \& De Jonge, 1996). This concept was first used in the job redesign tradition. Intrinsic work motivation is a construct that refers to a person's orientation towards a particular job, but it cannot 
always be inferred from one's behavior or performance. Levels of performance can also be influenced by a range of other factors such as personal abilities, machine capacity, availability of materials and so on (Cook, Hepworth, Wall \& Warr, 1981).

There is still no agreement about the definition of intrinsic work motivation. However, most descriptions of intrinsic work motivation, contain three aspects (Janssen, Nijhuis, Peeters \& De Jonge, 1996): (1) a reference to an internal factor: a "need" to perform well; (2) a reference to an external factor: the job to be done; (3) an ultimate goal: a sense of intrinsic satisfaction. The definition of Warr, Cook and Wall (1979) contains all these aspects: they define intrinsic work motivation as "the degree to which a person wants to work well in his or her job in order to achieve intrinsic satisfaction". We may conclude from this definition that intrinsic work motivation can be considered the result of an interaction between factors inside the person (internal factors) and factors outside the person (i.e., the job to be done), leading to a feeling of intrinsic satisfaction and personal growth (Janssen, Nijhuis, Peeters \& De Jonge, 1996). In the present section, we are interested in a specific category of external determinants: work characteristics. What work characteristics contribute in particular to intrinsic work motivation?

In order to answer this question, the task characteristics approach (cf. Algera, 1992; Hackman \& Oldham, 1980) can provide several clues. In particular within the framework of the job enrichment tradition, many studies have been conducted to predict intrinsic work motivation. Herzberg, Mausner and Snyderman (1959) were among the first authors who developed valuable insights into work content and task characteristics. They developed the well-known Two Factor Theory. Although this theory has not been validated totally (cf. Thierry, 1998), it has stimulated many empirical studies and has, for instance, initiated the later works of Turner and Lawrence (1965). Turner and Lawrence studied task characteristics such as task variety, autonomy, knowledge and skills, and the amount of interaction with colleagues. They found that these task characteristics lead to satisfaction.

Largely based upon the insight gained by Turner and Lawrence (1965), Hackman and Oldham $(1976,1980)$ developed their Job Characteristics Model: a model that summarizes and integrates a considerable part of the earlier work in the job redesign area (see Figure 2.5). According to this model, intrinsic work motivation is determined by characteristics of the job. Hackman and Oldham (1980) state that intrinsic work motivation will occur when three key conditions are satisfied. First, persons must have knowledge about the results of the work. Second, persons must experience responsibility for the results of their work, believing that they are personally accountable for the work outcomes. Finally, persons must experience the work as meaningful, as something that "counts" in one's own system of values. These three conditions are called "critical psychological states". It appears that even people who consider themselves lazy, are more motivated to do a good job when they experience these three psychological states (Hackman \& Oldham, 1980). The three psychological states are internal to persons and therefore not directly manipulable (Hackman \& Oldham, 1980). Research suggests that there exist five task characteristics that can activate these three psychological states (cf. Hackman \& Lawler, 1971; Hackman \& 
Oldham, 1976; Turner \& Lawrence, 1965): skill variety, task identity, task significance, autonomy, and job feedback. Skill variety, task identity and task significance are supposed to contribute to experienced meaningfulness of the work, autonomy contributes to experienced responsibility and job feedback contributes to knowledge of results (Hackman \& Oldham, 1980). The five task characteristics are combined into a single index, the Motivating Potential Score (MPS) that reflects the extent to which employees see their job as motivating (Hackman \& Oldham, 1980). This MPS is calculated as follows:

$$
\text { MPS }=[(\text { task variety }+ \text { task identity }+ \text { task significance }) / 3] \text { * autonomy * job feedback }
$$

The three critical psychological states, in turn, lead to intrinsic work motivation, satisfaction and work performance (i.e., they mediate the relationship between task characteristics and outcome variables).

In conclusion, the ways that tasks are designed and managed appear to be important determinants of intrinsic work motivation.

In the task characteristics approach it was assumed that all employees would respond similarly to certain job conditions. However, in line with other authors such as Hulin and Blood (1968), Hackman and Oldham (1980) stated that individual differences play an important role in predicting intrinsic work motivation. Hence, they included three moderating variables into their model that reflected whether a person will or will not respond positively to jobs with high motivating potential: growth need strength, knowledge and skill, and context satisfaction. These moderating variables can influence the relationships between task characteristics, critical psychological states and outcome variables, and will be discussed more extensively in section 2.4 . 


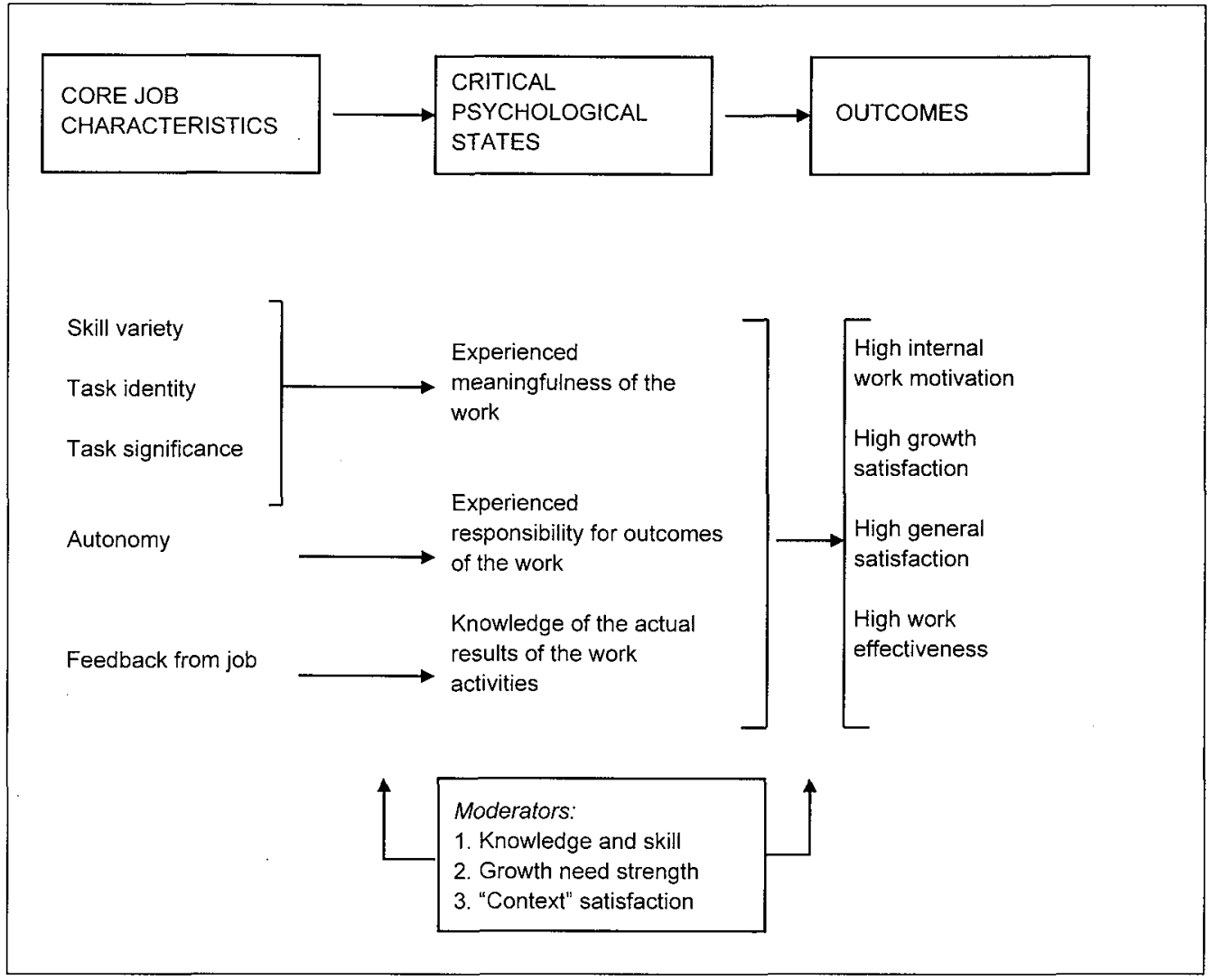

Figure 2.5 The Job Characteristics Model (Hackman \& Oldham, 1980, p. 90; (c) 1980 by Addison-Wesley; reprinted with permission of the publisher)

\section{Work-related determinants of intrinsic work motivation: empirical evidence}

With regard to the determinants of intrinsic work motivation, the Job Characteristics Model provides important clues. Many empirical studies have been conducted regarding the JCM. Hackman and Oldham $(1976,1980)$ studied the model themselves and found considerable evidence for their model. Furthermore, Fried and Ferris (1987) investigated the validity of the model. They performed a meta-analysis of 76 studies regarding the JCM and found modest support for the model. More specifically, they found that task characteristics are stronger related to psychological outcomes (e.g., intrinsic work motivation and satisfaction) than to behavioral outcome variables (e.g., performance). The Motivating Potential Score turned out to be a better predictor of the outcome variables than each task characteristic separately. However, a simple additive index of the task characteristics was even a stronger predictor of the outcome variables.

Tiegs et al. (1992) performed a study with a large, heterogeneous sample. They found significant relationships between the five task characteristics and the outcome variables intrinsic work motivation and work satisfaction. Several other researchers 
(e.g., Barnabé \& Burns, 1994; Gagné, Senécal \& Koestner, 1997; Landeweerd \& Boumans, 1994; Renn \& Vandenberg, 1995; Vogelaar \& Van der Vlist, 1995) found evidence for the relationships depicted in the JCM. With regard to the critical psychological states, it can be concluded that these are ignored in most studies. In studies that do include the critical psychological states, their hypothesized mediating role is not demonstrated (cf. Fried \& Ferris, 1987). Moreover, Vogelaar and Van der Vlist (1995) state that the critical psychological states are unimportant for the practice of work redesign.

In sum, although the influence of the critical psychological states does not receive much support, the remaining part of the JCM seems to be theoretically conceivable and receives considerable empirical support.

An ongoing discussion with regard to intrinsic work motivation is the question whether intrinsic work motivation can also be determined by factors that are extrinsic to the work itself, such as rewards and salary (cf. Janssen, Nijhuis, Peeters \& De Jonge, 1996). In this regard, Deci and Ryan (1985) hypothesize that work-extrinsic factors such as financial rewards do not enhance intrinsic work motivation. Financial rewards may even diminish the level of intrinsic work motivation, because high rewards may cause people to perform, only because of the reward. This hypothesis has, for instance, been confirmed by Deci and Ryan (1985) and Jordan (1986). Wiersma (1992) performed a meta-analyses regarding this issue and found that the motivating potential of rewards depends on the way that they are given. Particularly contingent rewards (i.e., contingent on the level of performance) can diminish the level of intrinsic work motivation. In addition, more recent studies show that intrinsic work motivation is hardly related to factors such as salary, but rather strongly to the work content (e.g., Janssen, De Jonge \& Bakker, 1999; De Jonge, Braakhuis \& Hell, 1996).

We can conclude from the several theories and empirical studies with regard to intrinsic work motivation that task characteristics (category of work content) are the most important work-related determinants of intrinsic work motivation.

\subsubsection{Mental health: burnout}

Mental health is an important issue in the current "world of work". Warr is one of the few authors who have paid attention to the theoretical description of mental health. He proposed five main components of mental health, of which affective well-being is the first. In order to measure affective well-being, Warr $(1994,1999)$ suggested three axes: satisfaction, work-related tension, and depression. An important operationalization of the third axis of affective well-being (i.e., depression) is burnout (cf. De Jonge, 1995). Burnout is a prominent issue in the field of Work and Organizational Psychology: it is of current social and scientific interest, is theoretically well underpinned, and is generally accepted as an important stress reaction in the work environment. Numerous researchers have studied this concept, as well as its correlates and consequences (Schaufeli et al., 1993; Schaufeli \& Enzmann, 1998). Moreover, in Western society burnout plays a substantial role in the prevalence rates of occupational stress, which are high and still increasing (e.g., Paoli, 1997; Schaufeli 
\& Enzmann, 1998; see also chapter 1). In sum, burnout is an important elaboration of mental health. For these reasons, we decided to concentrate on burnout as an important representative of the outcome variable mental health.

\section{Burnout}

Starting in the pioneering phase with the psychiatrist Freudenberger (1974), until now, many theories and empirical studies regarding the concept have been published (cf. Maslach, Schaufeli \& Leiter, 2001). Many reviews with regard to this concept have been performed (e.g., Lee \& Ashforth, 1996; Schaufeli, 1990; Schaufeli \& Enzmann, 1998). In addition, the number of definitions of the burnout concept is very large. Generally, state and process definitions can be distinguished, which are in fact complementary, since state definitions describe the end-state of the burnout process.

The definition of burnout that is probably most generally accepted and most widely used, was formulated by Maslach and Jackson (1986). They defined burnout as a syndrome consisting of emotional exhaustion (i.e., depletion or draining of emotional energy or resources), depersonalization (development of a negative, callous, and cynical attitude towards the recipients of one's services), and reduced personal accomplishment (i.e., the tendency to evaluate one's work with recipients negatively; it is believed that the objectives are not achieved, which is accompanied by feelings of insufficiency and poor professional self-esteem). The first dimension, emotional exhaustion, is generally considered the core dimension of burnout (Cox, Kuk \& Leiter, 1993; Maslach, 1998). The wide diffusion and acceptance of this three-dimensional definition is likely to be related to the diffusion of the Maslach Burnout Inventory (MBI), a frequently used instrument to measure burnout. Initially, Maslach and Jackson claimed that burnout exclusively occurs in occupational groups where professionals deal directly with recipients, such as patients, students and clients. However, over time Maslach expanded the concept beyond the human services. Burnout has been redefined as a crisis in the relationships with one's work and not necessarily with the people at work (cf. Maslach \& Leiter, 1997; Maslach et al., 2001).

\section{Theoretical models with regard to burnout}

It might be superfluous to state that the number of theories regarding burnout is large, and that it is not likely that all these theories will converge to one "true" theory in the near future. For a comprehensive overview of burnout theories we refer to Schaufeli and Enzmann (1998), and Schaufeli et al. (1993).

Apparently, the issue of burnout is such complicated than it cannot be explained by one or two theories. Different levels and perspectives have to be taken into account. According to Schaufeli and Enzmann (1998), the burnout theories can be classified according to at least three general theoretical perspectives: the organizational approaches, which focus on organizational and work-related factors; the interpersonal approaches, which focus on the interrelationships between professionals and their clients; and finally, the individual approaches, which mainly focus on factors and processes within the person, but also pay attention to work-related factors that initiate 
these processes within the person. Generally, the organizational approaches receive the most empirical evidence (cf. Schaufeli \& Enzmann, 1998).

Organizational approaches mainly focus on the role of work and organizational factors in the development of burnout. Two well-known, but somewhat older examples of organizational approaches, come from Cherniss (1980), who considers burnout as a reality-shock, and Golembiewski and Munzenrider (1988), who consider burnout as a virulent process that develops through eight phases. These eight phases consist of several combinations of high and low depersonalization, personal accomplishment, and emotional exhaustion. In both approaches several organizational and work-related factors are distinguished that initiate the burnout process, such as poor orientation processes within organizations, high workload, and lack of autonomy. Evidence for Chernisses approach stems from in-depth interviews with human professionals (Cherniss, 1980) and several cross-sectional studies among police officers and teachers (e.g., Burke, Shearer \& Deszca, 1984; Burke \& Greenglass, 1989). The Golembiewski and Munzenrider model has rather successfully been validated in many empirical studies (e.g., Golembiewski, Boudreau, Munzenrider \& Luo, 1996; Golembiewski \& Munzenrider, 1988; Golembiewski, Munzenrider \& Stevenson, 1986). These results indicate that poor job characteristics such as meaningfulness of work, workload, social support, autonomy, and role clarity, lead to burnout.

The most recent organizational approach regarding burnout was developed by Maslach and Leiter (1997). As opposed to their initial interpersonal views (see Maslach, 1993), they no longer consider burnout as a phenomenon that merely occurs in the human services sector. In line with the organizational approaches discussed above, they now consider the work environment to play a more prominent role than in their earlier perspectives. In this recent approach, burnout is considered a consequence of a mismatch between the job and the person. When the job demands more than a person can give, burnout may develop. This mismatch may occur anywhere in the occupational field. The three dimensions of burnout are now redefined in more general terms: exhaustion (feeling emotionally and physically overextended), cynicism (a distant and indifferent attitude towards one's work), and ineffectiveness (a sense of professional inadequacy and loss of confidence in one's abilities). These more general definitions of the three burnout-dimensions are also reflected in the third edition of the Maslach Burnout Inventory (e.g., Maslach, Jackson \& Leiter, 1996). According to Maslach and Leiter (1997) the mismatch mentioned above may occur in six domains of the work environment: work overload, lack of control, lack of rewards, lack of community (e.g., lack of social support), lack of fairness and value conflict. Preliminary research on this model has yielded support for this model. These results have shown, for instance, that the domain of values may play a mediating role for the other domains. In addition, the importance of the six domains in predicting burnout, may differ between individuals (Maslach, 1998; Maslach \& Goldberg, 1998; Maslach et al., 2001). More research on this model is needed, however. 
The use of the general definitions of the three burnout dimensions in the MBI-General Survey is by now widely accepted (e.g., Leiter, Harvie \& Frizzel, 1998; Maslach et al., 2001; Maslach et al., 1996).

Overall, the organizational approaches have in common that they identify similar, work-related factors (i.e., job demands, lack of social support, and to a lesser extent, lack of autonomy) as important correlates of burnout. Generally, these organizational approaches receive a considerable amount of empirical evidence.

Individual approaches generally emphasize the role of factors and processes within the person. These approaches attempt to explain burnout from general psychological perspectives, and generally focus on the discrepancy between a person's expectations and the reality at work. Most of the individual approaches are not supported by empirical evidence. They may, however, be used to interpret study results (Schaufeli \& Enzmann, 1998). Below, we will discuss an individual approach that seems to be more promising, and that takes several work-related factors into account: the Conservation of Resources (COR) Theory (Hobfoll \& Freedy, 1993). According to this theory, people strive to obtain or maintain things (i.e., "resources") they value. Examples of these resources are objects (e.g., a house), conditions (e.g., a supportive social network), personal characteristics (e.g., social skills) and energies (e.g., money). Stress occurs when resources are lost, threatened by demands (e.g., work overload and role stress), or when investment of resources does not reap the expected level of return. Generally, individuals deal with this stress effectively by allocating or investing new resources. However, when this way of coping is not successful, prolonged stress or eventually burnout may develop. The COR Theory defines burnout as “ ... a process of wearing out and wearing down of one's energy, or the combination of physical fatigue, emotional exhaustion and cognitive wear-out that develops gradually over time" (Hobfoll \& Shirom, 1993). This approach is worth mentioning, because several large empirical reviews were based on this theory (see next subsection). In addition, this theory was also the basis for the process model of burnout developed by Leiter (1993), which incorporates individual, interpersonal and organizational determinants of burnout, and is therefore not easy to assign to one of the three theoretical approaches regarding burnout. Leiter (1993) assumes, among other things, that job demands (i.e., workload and interpersonal demands) are related to emotional exhaustion, whereas lack of resources (i.e., lack of social support, lack of opportunities for skill enhancement, poor client cooperation, lack of autonomy and participation) are primarily related to depersonalization and reduced personal accomplishment. Thus in line with the organizational approaches discussed previously, Leiter proposes that workload and lack of resources such as social support and autonomy are associated with burnout.

In the interpersonal approaches, finally, the main focus is on daily interactions of professionals with demanding, difficult or troubled recipients. These interactions are considered to result in emotional strain and to be the root cause of burnout. This 
assumption is, however, only weakly supported by empirical evidence (Schaufeli \& Enzmann, 1998). Moreover, the primary focus on burnout as a result of interaction between professionals and their clients or patients or students, seems to be superseded by more recent perspectives on burnout, which state that burnout not merely occurs in professions where interactions with patients or clients are every day practice. The interpersonal approaches will therefore not be discussed here in more detail.

\section{Work-related determinants of burnout: empirical evidence}

The amount of empirical studies with regard to determinants and correlates of burnout is huge. Recently, three large reviews with regard to the determinants of burnout have been performed. Duquette, Kérouac, Sandhu and Beaudet (1994), Lee and Ashforth (1996), and Schaufeli and Enzmann (1998) have studied and categorized correlates of burnout.

Duquette et al. (1994) reviewed 36 burnout studies. They found that the work characteristics workload, task conflicts, and frequent client contacts were the most important work-related determinants of burnout. The resources social support, hardiness and coping were also predictive of burnout. Finally, it appeared that sociodemographic variables such as age, gender and marital status were no significant predictors of burnout.

Lee and Ashforth (1996) performed a meta-analysis of 61 (cross-sectional) burnoutstudies and studied the determinants of the three burnout-dimensions separately. They based their hypotheses on the COR Theory described above. They found that job demands (workload, role conflict) were stronger related with emotional exhaustion than with depersonalization and reduced personal accomplishment, although the relationships between job demands on the one hand, and depersonalization and reduced personal accomplishment on the other, were also significant. Resources (social support, autonomy, participation) were equally strong related with emotional exhaustion and depersonalization. Contrary to their expectations, resources were only weakly related to reduced personal accomplishment. Finally, Lee and Ashforth (1996) found a low correlation between personal accomplishment on the one hand, and depersonalization and emotional exhaustion on the other, and a stronger correlation between emotional exhaustion and depersonalization. Two more recent studies that are to a large extent in line with the findings of Lee and Ashforth (1996), were performed by Houkes and Janssen (1999) and Janssen, Schaufeli and Houkes (1999). In both these studies it was found that emotional exhaustion was particularly related to job demands, but also to the resource variable social support. In addition, Leiter and Harvie (1996) performed a review of studies that focused on mental health workers, and also found that, with regard to work-related variables, job demands and the resource variable social support (especially from supervisors) were important antecedents of emotional exhaustion. 
The third review regarding burnout studies comes from Schaufeli and Enzmann (1998). They report in the first place that many burnout-studies suffer from selection bias, common method variance, low response rates, inadequate sampling, and so on. Nonetheless, they performed a review of more than 250 studies and arrived to a large extent at similar conclusions as Duquette et al. (1994) and Lee and Ashforth (1996). The strongest correlates of burnout were found among work and organizational characteristics (i.e., workload, role conflict and ambiguity, lack of social support) but also among personal characteristics (i.e., neuroticism and hardiness). The work characteristics may be divided into two groups: demands (e.g., workload and role variables) and resources (e.g., social support). In addition, Schaufeli and Enzmann found that job related stressors (e.g., workload) are more important in predicting burnout, than client-related stressors (i.e., direct contact with clients). Further, they found that emotional exhaustion was the burnout dimension that was most strongly related to possible correlates of burnout (see also Maslach et al., 2001).

The reviews discussed above are for the greater part based on cross-sectional study results. Schaufeli and Enzmann (1998) searched explicitly for longitudinal studies with regard to burnout. However, these appeared to be rather scarce; they only found eight longitudinal studies that met the criteria they used for adequate longitudinal research. The results of these longitudinal studies are not entirely in accordance with the crosssectional findings discussed above. Either longitudinal effects were very small or not significant, or, contrary to expectations, demands seemed to be associated negatively with burnout. Even a reverse causal direction was found (emotional exhaustion leads to high workload instead of the other way around). Schaufeli and Enzmann (1998) provide some methodological explanations for these findings.

In sum, with regard to the work-related determinants of burnout, we may conclude that job demands (e.g., a high workload, work pressure, role conflict) and lack or loss of social support seem to be the most important determinants of burnout (see also Cordes \& Dougherty, 1993; Hobfoll \& Freedy, 1993; Pines, 1993). These findings also seem theoretically plausible (see, for instance, the COR Theory and Leiter's (1993) process model of burnout). The personal characteristics as determinants of burnout will be discussed more extensively in section 2.4.

As was discussed in section 2.2, we aim to include only univocal outcome variables in the present study. This will enhance the specificity and testability of the model. However, burnout is essentially a multi-dimensional concept. Therefore, below we will address the question of whether it is possible to point out a core dimension of burnout.

\section{Emotional exhaustion: the core dimension of burnout?}

Literature suggests that emotional exhaustion is the burnout dimension that is most appropriate to include as a single burnout dimension. First, according to Maslach and her colleagues (e.g., Maslach, 1998; Maslach et al., 2001), emotional exhaustion is the central quality of burnout and the most obvious manifestation of the syndrome of 
burnout, with the clearest determinants. The latter proposition is in line with the conclusion of Schaufeli and Enzmann (1998) who stated that emotional exhaustion is most strongly correlated with possible causes of burnout. This is also in line with the findings of Lee and Ashforth (1996) and Houkes and Janssen (1999) who found that emotional exhaustion was related to several work-related predictors such as workload and lack of social support, while depersonalization and particularly reduced personal accomplishment were to a much lesser extent related to the possible burnout predictors. Second, the emotional exhaustion dimension has been most widely reported and most thoroughly analyzed (Cox, Kuk \& Leiter, 1993; Maslach, 1993, 1998). Finally, in most theories regarding burnout, it is proposed that emotional exhaustion arises first, as a reaction to a demanding environment, and that depersonalization and reduced personal accomplishment develop, at least partly, as a reaction to emotional exhaustion (see, for instance, Leiter, 1993; Maslach, 1993, 1998; Schaufeli \& Enzmann, 1998).

With regard to the determinants of emotional exhaustion, we may conclude that in particular workload (category of working conditions), and to a somewhat lesser extent, lack of the resource variable social support (category of labor relations) seem to be related to emotional exhaustion.

\subsubsection{Turnover: turnover intention}

Turnover can be defined as voluntarily leaving the organization (cf. Bluedorn, 1978; Van Breukelen, 1989). As we decided to include only psychological outcome variables in this study, we will focus on the variable turnover intention (i.e., the inclination to leave an organization voluntarily). Turnover intention appears to be a very good predictor of turnover (Van Breukelen, 1989; Dougherty, Bluedorn \& Keon, 1985; Kiyak, Namazi \& Kahana, 1997; Mobley, 1977; Stedham \& Mitchell, 1996). According to Fishbein and Ajzen (1975) someone's intention to display certain behavior, is the best predictor of this behavior. Of course the relationship between turnover intention and turnover may also be influenced by factors outside the organization, such as the situation at the labor market, economic factors and the private situation (cf. Van Breukelen, 1989). This relationship and the factors that may influence this relationship, are not within the scope of this thesis, however.

High turnover rates may cause considerable damage to the production of goods and services provided by organizations. A high level of turnover is generally accompanied by high costs for recruitment, selection and coaching of new personnel (Van der Heijden, 1997; Kompier \& Vink, 1994). More and more organizations pursue a policy to prevent turnover of personnel. Especially when the labor market is tight, prevention of turnover is useful (Van Breukelen, 1989). Illustrative in this regard is the current tight labor market in The Netherlands. Employers face serious problems in recruiting and preserving qualified personnel. In combination with the huge competition, this situation can be detrimental to the effectiveness of organizations (cf. Kluytmans, 1997; 
Kompier \& Vink, 1994). A first step in preventing turnover, is to prevent turnover intention (e.g., Dougherty et al., 1985).

Below, we will first describe several theoretical models with regard to turnover intention and turnover. Second we will discuss empirical evidence regarding workrelated determinants of turnover intention.

\section{Theoretical models with regard to turnover intention}

In the early phase of research regarding turnover, attention was generally focused on actual turnover behavior, and on the individual decision making process of turnover (cf. Van Breukelen, 1989). Turnover intention and dissatisfaction were considered important precursors of turnover. Moreover, the situation at the labor market received considerable attention, because this was hypothesized to influence the decision making process in various stages.

Over time, in research regarding turnover and turnover intention, two approaches can be distinguished (Van Breukelen, 1989): the process approach, and the content or state approach.

In the first approach, the process approach, authors aim to analyze the individual decision making process that eventually leads to turnover. These process models are rather complex and do not receive much empirical support when they are tested integrally. However, these models have stimulated many empirical research regarding the concepts of turnover and turnover intention (cf. Van Breukelen, 1989).

Researchers who held the process approach considered it difficult to find strong (work-related) correlates of turnover, because there are many factors, outside the organization that may influence actual turnover. Mobley (1977) was one of the first authors who focused on turnover intention as an important predictor of turnover. Mobley based his theory on Fishbein's theory about the relationships between attitudes and behavior (e.g., Fishbein \& Ajzen, 1975). He proposed that dissatisfaction with the working situation initiates a decision making process of ten stages that starts with the evaluation of the existing job, and ends with quitting the job. Globally, the job evaluation leads to thinking about quitting, which in turn leads to the intention to search for alternative jobs. The latter intention is also predicted by the estimated chance to find adequate alternatives. This intention to search leads to turnover intention, which in turn leads to turnover. The Mobley Model has received much criticism, for instance, the precise influence of the situation at the labor market remains unclear and was never empirically validated. The influence of labor market on the turnover process is indeed very complex (Van Breukelen, 1989). Furthermore, just like many other researchers in the early phase of turnover research, Mobley (1977) focused on global dissatisfaction as the most important, work-related determinant of turnover intention. The relationship between global dissatisfaction and turnover intention is generally rather weak, however (in later studies researchers focused more on facial dissatisfaction; cf. Van Breukelen, 1989). As a whole though, Mobley's model has been important because it has stimulated many empirical studies. 
In the second approach, the content approach, researchers aim to identify workrelated and other factors that initiate turnover intention and turnover. In other words, one aims to find determinants of turnover intention and turnover. This approach has received more empirical evidence than the process approach. In research regarding determinants of turnover intention and turnover, "push-factors" and "pull-factors" can be distinguished (Van Breukelen, 1989; Pool, Meeuwsen \& Michels, 1992). Pushfactors are internal organizational and work-related factors that lead to turnover intention and turnover. Pull-factors are factors external to the organization. Examples of pull-factors are the situation at the labor market and economic factors (Pool, Meeuwsen \& Michels, 1992). In the present thesis, the focus is on work-related determinants of turnover intention, and herewith on the push-factors.

An early state model was, for instance, developed by Price (1977). Price distinguishes five organizational characteristics (i.e., pay, integration, instrumental communication, formal communication, and centralization), which lead to dissatisfaction. Satisfaction finally leads to turnover. The relationship between satisfaction and turnover can be influenced by opportunities at the labor market.

Muchinsky and Morrow (1980) summarized and ordered the results of the many turnover studies that had been performed until the beginning of the eighties, in a turnover model that distinguished three categories of antecedents of turnover: individual factors (i.e., demographic factors, values, interests, ambition, capacities); work-related and organizational factors (i.e., salary and other conditions of employment, social relationships at work, responsibility, autonomy, organizational characteristics such as size, centralization and formalization); and economic factors (e.g., situation at the labor market, the social security system). In this model turnover is considered the result of the complex interaction among these three categories of variables. According to Muchinsky and Morrow (1980), the influence of the economic factors on turnover is largest. The first two categories of factors exert most of their influence through economic factors. It is in fact known that when there is full employment, turnover is high. When employment is low, turnover is low also. The Muchinsky and Morrow Model can be considered a contingency model (Van Breukelen, 1989): the strength of the relationship between individual and work-related factors on the one hand, and turnover on the other, depends on the economic factors. It must be noted, however, that Muchinsky and Morrow did not include turnover intention in their model. We may propose in this regard that individual and workrelated factors cause turnover intention, but that turnover intention only causes turnover when employment is high. It is likely that the relationship between turnover intention and turnover is weak in times of underemployment.

A combination of the process approach and the content approach can be found in the unified model of Bluedorn (1982) who integrated the knowledge from the Price and Mobley models. Bluedorn proposes a rather large set of work-related antecedents (e.g., promotion opportunities, pay, centralization, instrumental communication, and some personal characteristics such as age and length of service). This set of 
antecedents leads to dissatisfaction. Dissatisfaction initiates the decision making process through several stages, which ends with turnover intention, and finally turnover.

As we decided to focus on the relationships between work characteristics and psychological outcomes, we are particularly interested in work-related factors that lead to turnover intention. The models described above do provide several clues regarding this matter: work-related determinants of turnover intention can be found in several categories of factors. In order to find more specific information about the work-related determinants of turnover intention, we examined the literature regarding this issue. Note that the larger part of empirical research regarding turnover intention in the eighties and in the nineties, was based on (variants of) the turnover models that were developed in the seventies and eighties (e.g., Van Breukelen, 1989; Griffeth \& Hom, 1988; Kiyak, Namazi \& Kahana, 1997; Stedham \& Mitchell, 1996).

\section{Work-related determinants of turnover intention}

First, we will describe the results of several large reviews regarding turnover and turnover intention.

Muchinsky and Morrow (1980) reviewed several studies regarding turnover and found that the work-related factors salary and human resource management were related to this outcome variable. Furthermore, they report that it is difficult to determine the influence of economic factors on the individual's decision to leave an organization, because studies that focus on economic factors generally use aggregated data and are cross-sectional.

Van Breukelen (1989) reviewed empirical studies with regard to turnover and turnover intention and found that individual factors (e.g., age and seniority) as well as workrelated factors (i.e., salary, level of integration and internal communication in the organization) were related to turnover and turnover intention. Furthermore, he found that the level of turnover is generally lower in large organization (as a result of the internal labor market in such organizations: career opportunities are usually better in large organizations).

Sager, Futrell and Varadarajan (1989) provide an overview of the empirical evidence regarding antecedents of turnover intention and turnover. With regard to work and organizational characteristics they report that pay, promotion, supervisor support, and to a lesser extent relationships with co-workers are significant predictors of both turnover and turnover intention. Generally, these factors are stronger related to turnover intention than to turnover. Finally, they report that employees with a permanent contract are less inclined to leave the organization than people with temporary contracts.

Iverson and Roy (1994) also provide an overview of turnover literature. They state that salary is generally considered to be a primary determinant of turnover intention and turnover. Employees are in the first placed linked to organizations by the pay relation. This relationship has been empirically confirmed in many studies. The importance of promotional opportunity with regard to turnover intention has also been argued for 
several decades. The latter contention is in line with the results of Manlove and Guzell (1997) who found that higher chances on career advancement elsewhere were the main reason to leave an organization in a sample of child care workers.

Lease (1998), finally, provides an overview of the literature regarding work attitudes, organizational commitment, and turnover between 1993 and 1997. She also reports that promotional opportunity, and to a lesser extent social support, are important precursors of turnover intention.

The results of these reviews are generally supported by several individual empirical studies, which were not included in the reviews described above. Rosse and Miller (1984), Lee and Mowday (1987), Stremmel (1991), Lewis and Thomas (1987) and Pool, Meeuwsen and Michels (1992) found that factors such as a lack of career and educational opportunities, a relatively low salary, no opportunities to develop oneself in one's work (dissatisfaction with work content) are related to turnover intention. With regard to salary, similar findings are reported by Stedham and Mitchell (1996), Stremmel (1991) and Francis-Felsen et al. (1996). Stremmel (1991) and FrancisFelsen et al. (1996) also report a relationship between a lack of social support from supervisors and turnover intention. This latter relationship was also reported by McFadden and Demetriou (1993) as well as Stedham and Mitchell (1996). The latter researchers provide a summary of turnover research and report that regarding the work characteristics, pay level and employee benefits are important. But also the extent to which employees can voice their opinion. Langdon (1997) found that pay, promotions, opportunities for advancement and education were important factors in predicting turnover among sales employees.

Most of the studies discussed above are cross-sectional. However, the results from these studies could be replicated in two longitudinal studies: Johnston, Griffeth, Burton and Carson (1993) performed a quasi-experimental longitudinal study with regard to the relationships between salary and promotion on the one hand, and turnover on the other. They found that both promotion and a high salary are important determinants of turnover. More specifically, they found that employees who received both a promotion and a higher salary, were most likely to stay in the organization. They also report that people who left the organization, were the least satisfied about the social relationships with their supervisors.

A second longitudinal study of Arnold and Mackenzie Davey (1999) showed that career development and pay were the strongest predictors of turnover intention. In this study the relationships between supervisor support and intrinsic work characteristics on the one hand, and turnover intention on the other, were not significant.

In sum, it may concluded from the empirical studies described above, that turnover intention is primarily related to variables that can be classified as unmet career expectations regarding salary, job security and career opportunities (i.e., variables from the category conditions of employment). These findings are theoretically plausible since job insecurity, low opportunities to obtain a better position, and low 
salary frustrate important growth needs (cf. De Cenzo \& Robbins, 1996). To a lesser extent, relationships are reported between social support and work content on the one hand, and turnover intention on the other.

\subsubsection{Study hypotheses and research model}

On the basis of the theories and empirical studies discussed in this section, the following research hypotheses may be formulated with regard to research question 1:

1. Intrinsic work motivation is primarily determined by task characteristics (category of work content).

2. Emotional exhaustion is primarily determined by workload and social support (categories of working conditions and labor relations, respectively).

3. Turnover intention is primarily determined by unmet career expectations (category of conditions of employment).

The proposed pattern of relationships between work characteristics and outcome variables is depicted in Figure 2.6.

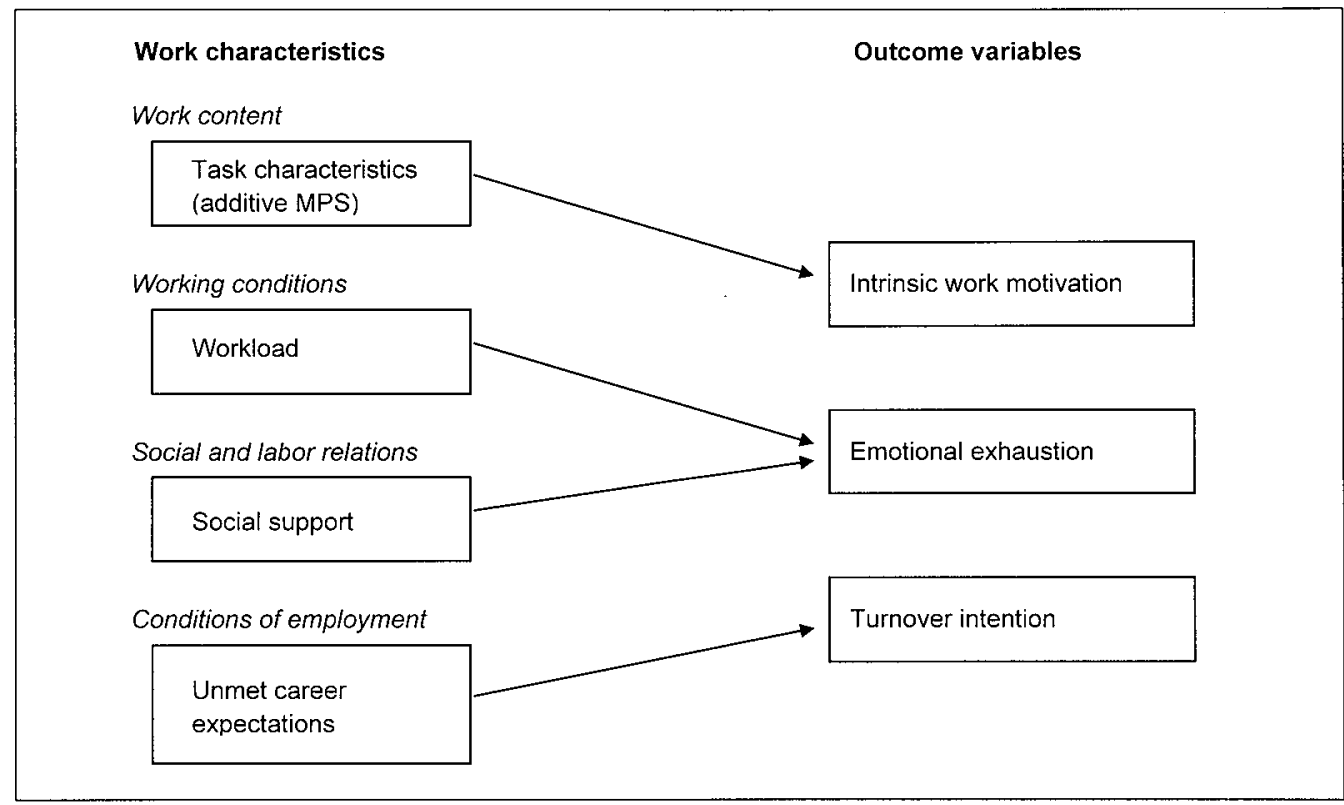

Figure 2.6 Proposed pattern of relationships between work characteristics and outcome variables (see also Janssen, De Jonge \& Bakker, 1999)

Janssen, De Jonge and Bakker (1999) tested their pattern of relationships in a sample of general nurses. They found that the proposed pattern of relationships largely holds true. They found one additional relationship, viz. the relationship between task characteristics and turnover intention. LISREL-analyses indicated, however, that the 
model fit was acceptable without this relationship and that this relationship was not significant. Important drawbacks of the study of Janssen and his colleagues, however, are that they tested this pattern of relationships in only one, rather small sample, and that they tested the pattern only cross-sectionally.

Hitherto, we have formulated three hypotheses with regard to research question 1 , but we have not paid attention to the influence of personal characteristics on the selected outcome variables, or on the relationships between work characteristics and the outcome variables yet. Literature suggests, however, that personal characteristics can contribute to the explanation of psychological outcome variables (see chapter 1, and, for instance, Kasl, 1996). Therefore, in the third and final part of this chapter (section 2.4), we will discuss the possible influence of personal characteristics on the variables and relationships discussed above, and we aim to formulate several hypotheses with regard to research question 2 .

\subsection{The specific influence of personal characteristics on the three selected outcome variables and on the relationships between work characteristics and these outcome variables}

\subsubsection{Introduction}

The many studies that have been discussed in the previous sections have shown that work characteristics such as work overload and lack of social support, can result in several outcome variables, like burnout and turnover intention (e.g., Cooper, 1998; Parker \& Wall, 1998; Schaufeli \& Enzmann, 1998). However, literature suggests that work-related variables and/or the relationships between work characteristics and outcome variables may be influenced by personal characteristics (e.g., Buunk, 1993; Furda, 1995; Kasl \& Rapp, 1991; Parkes, 1991). Hence, it appears that not all employees respond similarly to the working situation. In general, however, the precise influence of personal characteristics has not been totally clarified yet. In several cases, empirical studies concerning the influence of personal characteristics on the relationships between work stressors and outcome variables report either negative results or very diverse results (cf. Ganster \& Schaubroeck, 1995; Kasl \& Rapp, 1991; Parkes, 1994; Warr, 1987). Furthermore, in many studies, the selection of personal characteristics seems rather arbitrary (Furnham, 1992; Kasl, 1996; Kasl \& Rapp, 1991; Parkes, 1994; Warr, 1987). As stated earlier, however, knowledge about the specific role of relevant personal characteristics not only contributes to the prediction of psychological outcome variables, but may also contribute to the process of matching the right person to the right job, and to the development of efficient interventions aimed at the individual employee (cf. Cummings \& Worley, 1997; Dunnette, 1998; Furnham, 1992; Kasl, 1996; Kasl \& Rapp, 1991; Parkes, 1994).

Therefore, it is important to develop hypotheses which lead to tests of specific predictions, rather than carry out multiple analyses on an exploratory basis. According 
to Kasl (1996) and Parkes (1994), in particular personal characteristics that are relatively stable and that have a theoretically sound relationship with the variables under study, are important in research regarding relationships between work characteristics and outcome variables.

Moreover, it is not only important to know what personal characteristics are of influence, but it is also relevant to have knowledge about how these personal characteristics exert their influence. Several models exist, which describe the way in which personality can influence outcome variables (see Buunk, 1993; Parkes, 1994). In general, four models are distinguished: the additive model, the dispositional model, the tendency model, and the moderator or interactive model. Most studies that include personal characteristics and work characteristics point at additive and/or moderating (interactive) effects of personal characteristics (Frese, 1985; Parkes, 1994). The dispositional model and the tendency model seem theoretically and empirically less plausible (cf. Frese, 1985; Furnham, 1992; Parkes, 1994; Spector, 1992, 1999). For that reason, the present study will focus on the additive and interaction models. These two models are depicted in Figure 2.7.

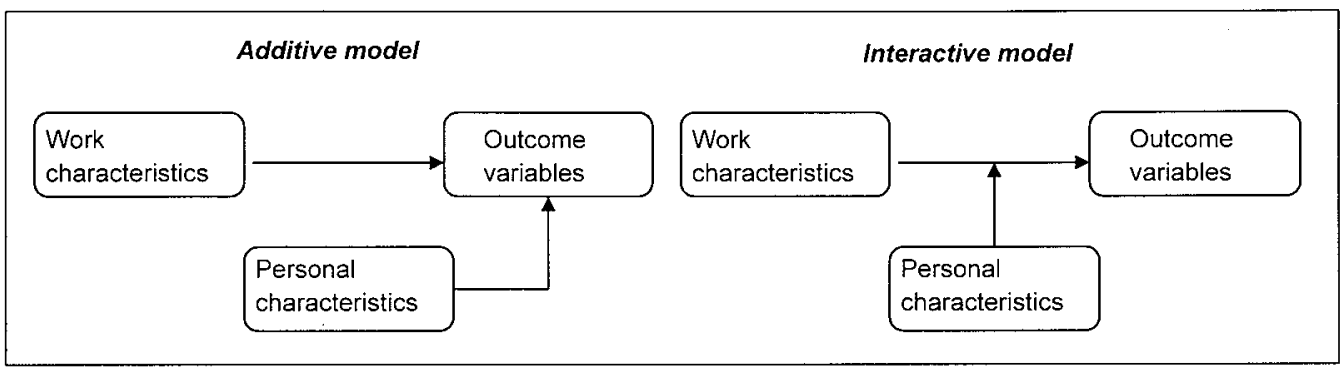

Figure 2.7 The additive model and the interactive model of personal characteristics

The additive model proposes that two variables (e.g., a work characteristic and a personal characteristic) are directly and simultaneously related to an outcome variable, each contributing independently to the explained variance (Parkes, 1994). In other words, the joined effect of work characteristics and personal characteristics equals the sum of the separate effects. The interactive model predicts that certain categories of people are more sensitive to the influence of work characteristics than others: the magnitude and/or direction of the effect of the work characteristic on the outcome variable depends on the level of the personal characteristic. In this perspective, personal characteristics moderate or alter the relationships between work characteristics and outcomes (Parkes, 1994).

In the present study, we are in the first place interested in the specific influence of personal characteristics on psychological outcome variables, over and above the influence of work characteristics. Second, we are interested in the influence of personal characteristics on the pattern of relationships between work characteristics and outcome variables, which was described in section 2.3 . The latter pattern of 
relationships might well serve as a theoretical framework to represent the specific role of personal characteristics. The usage of such a framework is recommended by Kasl (1996) and Parkes (1994). In this regard, we are interested in those personal characteristics that contribute in particular to the prediction of the three outcome variables in the theoretical model. Furthermore, we aim at testing how these personal characteristics exert their influence (i.e., additive to or in interaction with work characteristics).

\subsubsection{Selection of relevant personal characteristics for each psychological outcome variable}

In the present subsection, we aim to select several personal characteristics that contribute in particular to the prediction of the psychological outcome variables intrinsic work motivation, emotional exhaustion and turnover intention. This selection will be based on the following criteria (Earp \& Ennett, 1991; Kasl, 1996; Parkes, 1994; Walker \& Avant, 1995). First, the personal characteristics to be included should have predictive power (based on theory and empirical evidence) towards the outcome variables (Kasl, 1996; Parkes, 1994). Furthermore, in order to keep the research model testable, meaningful and parsimonious, we will limit the number of personal characteristics to one for each outcome variable (Earp \& Ennett, 1991; Walker \& Avant, 1995).

\section{Intrinsic work motivation}

We can conclude from the discussions earlier in this chapter that the Job Characteristics Model (Hackman \& Oldham, 1980) is one of the most influential and most important models with regard to intrinsic work motivation. This model states that intrinsic work motivation is determined by five task characteristics. In addition, however, Hackman and Oldham (1980) postulate that not all employees respond similarly to highly motivating jobs. Some people are better positioned to take advantage of the opportunities offered by motivating jobs than others. Hackman and Oldham (1980) mention several attributes of people that seem important in how people respond to motivating jobs. One particular important personal characteristic in this respect is Growth Need Strength (GNS). According to Hackman and Oldham (1980) people differ in their need for learning and developing themselves. Individuals with a high level of growth need strength should respond eagerly and positively to the opportunities provided by enriched work, whereas individuals scoring low on growth need strength may not value these opportunities or may even consider them as threatening. In other words, in this perspective growth need strength has a moderating effect on the relationship between task characteristics and intrinsic work motivation.

Considering the concept of growth need strength as an important predicting variable regarding intrinsic work motivation, is in line with some of the classical motivation theories. See Thierry (1998) for an overview of these classical motivation theories. For instance, Deci and Ryan (1985; Cognitive Evaluation Theory) and Locke (1991; Goal Setting Theory) mention that people have an intrinsic growth need, a need to develop 
themselves beyond where they are now. That is, people have a constant need to develop their own possibilities and capabilities and to feel competent and independent. This growth need seems to be similar to the concept of growth need strength suggested by Hackman and Oldham (1980).

Several studies regarding growth need strength report additive and/or moderating effects. Hackman and Oldham (1976, 1980) and Dwyer, Schwartz and Fox (1992) found a strong additive effect of growth need strength on intrinsic work motivation and a moderating effect of growth need strength on the relationship between work characteristics and intrinsic work motivation. Algera (1990) found a moderating effect of growth need strength on the relationship between work characteristics and intrinsic work motivation (i.e., the higher the level of growth need strength, the stronger the relationship between task characteristics and intrinsic work motivation). Fried and Ferris (1987) found in their meta-analyses that growth need strength had an additive effect on intrinsic work motivation, as well as a moderating effect on the relationship between task characteristics and intrinsic work motivation. Gaziel (1989) and Landeweerd, De Jonge and Stikvoort (1995) found a moderating effect of need for autonomy (a concept quite similar to growth need strength) on the relationships between task characteristics and intrinsic work motivation. In theory, as well as in empirical studies regarding intrinsic work motivation, other personal characteristics (e.g., "context satisfaction", "knowledge and skills") have received less attention (Fried \& Ferris, 1987; Tiegs et al., 1992). Tiegs et al. (1992), for instance, included the individual moderator "context satisfaction" in their study, but they could not find a moderating effect of this variable.

Based on the contentions and empirical studies described above, we formulated the following hypotheses with regard to growth need strength:

4. Growth need strength has an additive positive effect on intrinsic work motivation, over and above the effect of task characteristics.

5. Growth need strength moderates the relationship between task characteristics and intrinsic work motivation (the higher the level of growth need strength, the stronger the relationship between task characteristics and intrinsic work motivation).

\section{Emotional exhaustion}

With regard to emotional exhaustion, several personal characteristics have been studied, for instance, neuroticism, coping, hardiness, negative affectivity, self-esteem, self-efficacy, and type A behavior (Parkes, 1994; Schaufeli \& Enzmann, 1998). The role of personal characteristics in the development of burnout, however, is a rather complicated issue, which has not been solved fairly yet (Schaufeli \& Enzmann, 1998). In their review of more than 250 studies regarding burnout, Schaufeli and Enzmann (1998) found that the personal characteristic neuroticism (one of the "Big Five" dimensions of personality) was one of the strongest (personality) correlates of burnout, in particular of emotional exhaustion (i.e., in comparison with other personal 
characteristics, neuroticism had the largest amount of shared variance with emotional exhaustion) (see also Maslach et al., 2001). A recent variant of neuroticism is Negative Affectivity (NA). That is, neuroticism is still a widely used operationalization of negative affectivity (see, for instance, Brief et al., 1988; Moyle, 1995). Moreover, when we compare the study of Watson and Tellegen (1985), who studied markers of negative affectivity, with the study of Hofstee, De Raad and Goldberg (1992), who studied markers of neuroticism (as one of the Big Five dimensions), we can conclude that these markers concur with each other to a large extent.

Negative affectivity can be defined as a mood-dispositional dimension that reflects pervasive individual differences in the experience of negative emotions and selfconcept (Watson \& Clark, 1984). Individuals scoring high on negative affectivity tend to focus on negative aspects of themselves, other people, and the world in general (Brief et al., 1988; Watson \& Clark, 1984). Negative affectivity seems to be a stable personality trait, which is predictive of cross-situational stress (Costa \& McCrae, 1980).

Recent literature suggests that negative affectivity has a substantive direct or moderating effect on health related outcomes (rather than a confounding effect, see, for instance, Cassar \& Tattersall, 1998; Heinisch \& Jex, 1997; Jex \& Spector, 1996; Moyle, 1995; Spector, Zapf, Chen \& Frese, 2000). The moderating effect of negative affectivity has, for instance, been described by Heinisch and Jex (1997) and Spector et al. (2000). Individuals high in negative affectivity might be hyper-responsive to the environment, so that they have an exaggerated strain response to stressors. In this perspective, individuals scoring high on negative affectivity would react stronger to job-related stressors than those who are scoring low.

Literature shows that negative affectivity is not only related to burnout, but also to other health-related concepts. It seems hardly possible to select a personal characteristic that is related merely to burnout, and not to any other health-related concept, particularly because burnout has rather strong relationships with related concepts such as depression and psychological health complaints (cf. Pines, 1993). Therefore, we also discuss several studies that investigated the relationship between negative affectivity and several health-related concepts similar to burnout.

Iverson, Olekalns and Erwin (1998) found that high negative affectivity predicted high emotional exhaustion. Heinisch and Jex (1997) found a moderating effect of negative affectivity on the relationship between workload and depression (a concept related to burnout) for women. For men, they found a direct effect of negative affectivity on depression. Parkes (1990) found a strong moderating effect of negative affectivity on the relationship between work demands and psychological and psychosomatic complaints. Spector and O'Connell (1994) found negative affectivity to be predictive of job strain one year later. Moyle (1995) found multiple effects of negative affectivity on self-reported health symptoms (i.e., direct, additive and moderating effects). Cassar and Tattersall (1998) found additive and moderating effects of negative affectivity on 
stress-related outcomes and on the relationships between stressors and outcomes. Caudill (1996/1997) and Zellars, Perrewé and Hochwarter (1999) found a strong additive effect of negative affectivity on emotional exhaustion. Caudill (1996/1997) even found negative affectivity to be a stronger predictor of emotional exhaustion than the work characteristic workload.

We may conclude that negative affectivity is related to emotional exhaustion and several other health related outcomes (e.g., depression, health complaints), which are in turn related to emotional exhaustion (cf. Pines, 1993). Therefore, we believe that negative affectivity is a promising concept with regard to the prediction of emotional exhaustion. The following hypotheses were formulated:

6. Negative affectivity has an additive positive effect on emotional exhaustion, over and above the effects of workload and social support.

7. Negative affectivity moderates the relationship between workload and emotional exhaustion (the higher the level of negative affectivity, the stronger the relationship between workload and emotional exhaustion).

8. Negative affectivity moderates the relationship between social support and emotional exhaustion (the higher the level of negative affectivity, the stronger the relationship between social support and emotional exhaustion).

\section{Turnover intention}

With regard to relationships between personal characteristics and turnover intention, the amount of available literature is rather limited. Existing literature focuses at work characteristics (i.e., particularly conditions of employment) and demographic variables such as age and seniority, as the most important determinants of turnover intention. With regard to psychological personal characteristics, literature is less clear. However, one personal characteristic seemed to be in particular promising, that is Upward Striving (US) (cf. De Gilder, Ellemers, Van den Heuvel \& Blijleven, 1998; Wollack, Goodale, Wijting \& Smith, 1971). The concept of upward striving refers to the degree in which a person is focused on his or her career, upward mobility and promotion (career commitment). A lack of career possibilities within an organization may lead to turnover intention, especially for people with high upward striving (De Gilder et al., 1998; Tremblay, Roger \& Toulouse, 1995). Therefore, we expect that the relationship between unfulfilled career expectations and turnover intention is stronger for people with high upward striving than for people with low upward striving: a moderating effect. Mathieu and Zajac (1990) performed a meta-analysis of determinants, correlates and effects of organization commitment and turnover intention. They found a direct effect of upward striving on turnover intention and a moderating effect of upward striving on the relationship between career possibilities and turnover intention. They argue that for people with a high degree of upward striving, commitment will decrease and turnover intention will increase, when career possibilities in the organization are lacking. De Gilder et al. (1998) report that career possibilities have a stronger influence on turnover intention when upward striving is higher. Van den Heuvel, 
Ellemers and Seghers (1995), however, could not demonstrate a relationship between upward striving and attitude towards work.

With regard to upward striving, we formulated the following hypotheses:

9. Upward striving has an additive positive effect on turnover intention, over and above the effect of unmet career expectations.

10. Upward striving moderates the relationship between unmet career expectations and turnover intention (the higher the level of upward striving, the stronger the relationship between unmet career expectations and turnover intention).

Hypotheses 4 to 10 were all formulated with regard to research question 2 (see chapter 1).

\section{Other relationships between the selected personal characteristics and outcome variables}

In this final subsection, we will briefly address the issue of whether there exist conceivable relationships between the three selected personal characteristics and the outcome variables, other than the relationships specified in hypotheses 4 to 10 .

With regard to growth need strength it seems theoretically conceivable that this characteristic has a certain influence on turnover intention or on the relationship between unmet career expectations and turnover intention. People scoring high on growth need strength are probably rather involved in their job. When they realize that they are limited in their possibilities to develop themselves in their work (i.e., no motivating work), they might be eager to search for alternative jobs (moderating effect of growth need strength). In addition, people scoring high on growth need strength, might be searching for new challenges constantly. They might be very involved with their job or profession, but not with their organization. If they feel that it is necessary to switch jobs in order to find new challenges, they might do so without any problem (cf. Huselid \& Day, 1991; Mathieu \& Zajac, 1990). This phenomenon has, for instance, been signaled among professional workers (cf. Blau, 1989; Shore \& Martin, 1989) and would implicate that there is a direct relationship between growth need strength and turnover intention. Specific empirical results regarding this relationships were, however, not found.

A relationship between growth need strength and emotional exhaustion seems less fair, because the two concepts are rather different from each other. Growth need strength seems more likely to be related with "active" outcomes such as intrinsic work motivation and turnover intention, than with a "passive" outcome such as emotional exhaustion (cf. Watson \& Tellegen, 1985). Empirical studies with regard to emotional exhaustion (burnout) hardly ever include growth need strength (Schaufeli \& Enzmann, 1998). In sum, we expect that growth need strength is mainly related to the outcome variable intrinsic work motivation, to a lesser extent to the outcome variable turnover intention, and hardly to emotional exhaustion. 
With regard to negative affectivity we can mention the following. Although it has been stated that negative affectivity will be related to any kind of strain, research shows that the relationships between negative affectivity and non health-related outcome variables like work satisfaction, motivation and turnover intention are less clear than the relationships between negative affectivity and health-related outcomes, such as burnout (Moyle, 1995; Spector et al., 2000).

With regard to upward striving, finally, we consider it theoretically less conceivable that upward striving is related to the other selected outcomes in our study, intrinsic work motivation and emotional exhaustion. Intrinsic work motivation refers to the degree to which a person wants to work well in his or her job, in order to achieve intrinsic satisfaction. People with high upward striving, on the contrary, strive to obtain certain aspects that are extrinsic to the work itself. In addition, considering the content of upward striving and emotional exhaustion, these two concepts are not likely to be related to each other. Furthermore, empirical evidence with regard to relationships between upward striving on the one hand and intrinsic work motivation or emotional exhaustion on the other, was not found.

\subsection{Summary}

In the present chapter we have provided the theoretical outline of this study in three parts. In the first part of this chapter (section 2.2), we have described several metatheoretical issues regarding model development in order to provide a background for the discussion of existing stress models in the area of Work and Organizational Psychology, and in order to provide clues for the development of a pattern of specific relationships between work characteristics, personal characteristics and outcome variables. It appeared that there are four levels of theoretical models (Earp \& Ennett, 1991; Walker \& Avant, 1995): meta-theories (which focus on philosophical and methodological questions regarding model development), conceptual models (which provide a framework for research, but no specific hypotheses), theoretical models (which are predictive in nature, testable, but sufficiently global to be scientifically interesting), and theories (theories encompass fewer phenomena than theoretical models). We concluded that we need a theoretical model to answer the research questions that were formulated in the first chapter, and that such a model is currently not available in the field of Work and Organizational Psychology. Such a theoretical model should incorporate both the general insights regarding the influence of work on the health and well-being of employees, and the refined theoretical views regarding specific relationships between work characteristics and outcome variables. Furthermore, such a theoretical model should meet several criteria for model development, such as usefulness, meaningfulness, generalizability, parsimony, and testability. The general insights mentioned above can be deducted from existing conceptual models. We discussed three well-known examples of such models: the Michigan Model, the Demand-Control(-Support) Model, and the Model of Work, Stress and Health. These models can be considered conceptual models, which have resulted 
in a considerable level of knowledge about the effects of work on the employee. Furthermore, the Model of Work, Stress and Health proposed a useful categorization of work characteristics (i.e., work content, working conditions, labor relations, and conditions of employment). However, these models do not reveal what specific effects several precisely defined work characteristics have on a meaningful set of relevant outcome variables.

Therefore, in the second part of this chapter (section 2.3), we performed several steps to formulate a theoretical model. In this process, we used the pattern of relationships between work characteristics and outcome variables formulated by Janssen, De Jonge and Bakker (1999) as a starting point. In accordance with propositions of Earp and Ennett (1991), first several outcome variables were proposed: intrinsic work motivation, emotional exhaustion, and turnover intention. Second, based on the findings of Janssen, De Jonge and Bakker (1999), and existing theories and empirical studies, four important work-related determinants of these outcome variables were suggested. We concluded that (1) intrinsic work motivation is primarily determined by task characteristics (category of work content); (2) emotional exhaustion is primarily determined by workload (category of working conditions) and social support (category of labor relations); and (3) turnover intention is primarily determined by unmet career expectations (category of conditions of employment).

Furthermore, literature suggests that not all employees respond similarly to the working situation. Therefore, in the third part of this chapter (section 2.4), and in addition to the pattern of relationships developed by Janssen, De Jonge and Bakker (1999) and elaborated on in section 2.3, we selected three personal characteristics that seemed to contribute in particular to the prediction of the three psychological outcome variables mentioned above. We concluded that growth need strength is particularly important with regard to intrinsic work motivation, that negative affectivity is particularly important with regard to emotional exhaustion, and that upward striving is particularly important regarding turnover intention. We hypothesized that these personal characteristics would have additive effects on the outcome variables, as well as moderating effects on the relationships between the work characteristics and outcome variables.

In the forthcoming chapter we will describe the research method, procedures and samples we used to validate the proposed pattern of relationships between work characteristics and psychological outcome variables, and to test the influence of the personal characteristics. 

Chapter 3

\section{Method}




\subsection{Introduction}

In the present chapter, we will describe the research method we used for this empirical study. In order to acquire a picture of reality that is as comprehensive as possible, this study consists of a cross-sectional and a longitudinal part. The study design will be discussed more thoroughly in section 3.2. In section 3.3, we will describe several characteristics of the study populations included in this study, as well as the design of the study samples. In section 3.4, the procedures, the fieldwork and several characteristics of the respondents will be discussed. The measurement instruments we used are presented in section 3.5, and section 3.6, finally, presents some general information about the data-analyses. Section 3.7 is a summary of this chapter.

\subsection{Design of the study}

Both cross-sectional and longitudinal study designs have advantages and disadvantages (Baarda \& De Goede, 1995; Hagenaars, 1990; Kessler \& Greenberg, 1981). We decided to apply both designs in order to get a picture of reality that is as complete as possible (to a certain extent). Hence, the first part of this study involves a cross-sectional design, while the second part of the study is longitudinal.

\section{Cross-sectional part of the study}

Cross-sectional data provide valuable insights into associations between the variables under study (Kessler \& Greenberg, 1981). Furthermore, cross-sectional surveys provide the opportunity to collect data from many respondents relatively fast and easy, and statistical techniques to analyze cross-sectional data are well developed (cf. Baarda \& De Goede, 1995). A disadvantage of cross-sectional designs is that it is usually impossible to demonstrate the causal order of variables. Longitudinal designs, however, provide more opportunities to examine causality: the causal order of variables can be made plausible. Despite this advantage, there are also several problems related to longitudinal studies (Hagenaars, 1990, cf. De Jonge, 1995). The risk of losing respondents (i.e., due to attrition) is larger than in cross-sectional studies (i.e., there will be non-response in each wave). Furthermore, respondents may strive to be consistent across measurements and the initial measurement may sensitize people to the issue under investigation, which may in turn influence the answer in the second measurement. In addition, Zapf et al. (1996), mention several methodological pitfalls of longitudinal research, such as the treatment of third variables, the time lag problem and the lack of common standard procedures to analyze longitudinal data. Also for these reasons we decided to include a cross-sectional part in this study, next to the longitudinal part.

The data we used in the cross-sectional part of the study were all collected in April 1998. The theoretical hypotheses that have been formulated in chapter 2 regarding 
the research questions 1 (hypotheses 1 to 3 ) and 2 (hypotheses 4 to 10) will be tested in chapters 4 (i.e., cross-sectional analyses) and 5 (i.e., longitudinal analyses). However, both parts of the study have different points of particular interest. That is, in the cross-sectional part of the study, the focus is primarily on specific associations between the work characteristics, personal characteristics and outcome variables, while the longitudinal part of the study particularly provides the opportunity to test the stability of the pattern of relationships over time, as well as the causal order of the variables. Therefore, we decided to slightly reformulate hypotheses 1 to 10 such that they match the perspectives of both study parts. For the cross-sectional part of the study, the hypotheses were reformulated into hypotheses 1a to 10a:

1a. Intrinsic work motivation is primarily and positively related to task characteristics (combined in the additive Motivating Potential Score);

2a. Emotional exhaustion is primarily related to workload (i.e., positively) and social support (i.e., negatively);

3a. Turnover intention is primarily and positively related to unmet career expectations.

4a. Growth need strength has a positive relationship with intrinsic work motivation, in addition to the relationship between task characteristics (combined in the additive MPS) and intrinsic work motivation.

5a. Growth need strength moderates the relationship between task characteristics (combined in the additive MPS) and intrinsic work motivation (the higher the level of growth need strength, the stronger the relationship between task characteristics and intrinsic work motivation).

6a. Negative affectivity has a positive relationship with emotional exhaustion, in addition to the relationships between workload and social support on the one hand and emotional exhaustion on the other.

7a. Negative affectivity moderates the relationship between workload and emotional exhaustion (the higher the level of negative affectivity, the stronger the relationship between workload and emotional exhaustion).

8a. Negative affectivity moderates the relationship between social support and emotional exhaustion (the higher the level of negative affectivity, the stronger the relationship between social support and emotional exhaustion).

9a. Upward striving has a positive relationship with turnover intention, in addition to the relationship between unmet career expectations and turnover intention.

10a. Upward striving moderates the relationship between unmet career expectations and turnover intention (the higher the level of upward striving, the stronger the relationship between unmet career expectations and turnover intention).

Hypotheses 1a to $3 \mathrm{a}$ will be addressed in section 4.2 , and hypotheses $4 \mathrm{a}$ to $10 \mathrm{a}$ will be addressed in section 4.3 . 


\section{Longitudinal part of the study}

Despite the problems that can be associated with longitudinal designs, they provide interesting possibilities for investigating causality and for model building. First, in comparison with cross-sectional designs, they provide a better opportunity to validate theoretically hypothesized causal relationships between, for instance, work characteristics and stress outcomes, and to investigate alternative causations (Frese \& Zapf, 1988; Zapf et al., 1996). Most longitudinal studies are designed to test causal relationships between stressors $(x)$ at time 1 and outcome variables $(y)$ at time 2 (i.e., "regular causality"). We may speak of a causal effect if (a) there is covariation of the stressor with the outcome variable, (b) the stressor appeared before the outcome variable developed, and (c) if other explanations (e.g., a reverse causation of the outcome variable on the stressor) can be ruled out. In field studies, causal inference can never be proven, but can at best be made plausible by means of rejecting alternative explanations (cf. Bollen, 1989; Cook \& Campbell, 1979; Zapf et al., 1996). Alternative explanations for regular causation are reverse causation of $y$ on $x$, or reciprocal causation ( $x$ influences $y$, and $y$ influences $x$ ). Reverse causation might be explained by the "drift" hypothesis (i.e., unhealthy and unmotivated employees drifting to worse jobs) or the "true strain-stressor" hypothesis (i.e., sometimes stressors are in fact influenced by outcomes) (see Zapf et al., 1996). Empirical evidence shows that the reverse causation hypothesis receives some support, albeit less than the regular causation (see, for instance, Tharenou, 1993; cf. De Jonge, Dormann, Janssen, Dollard, Landeweerd \& Nijhuis, 2001; Zapf et al., 1996). Reciprocal relationships are also found in longitudinal studies (e.g., James \& Jones, 1980; James \& Tetrick, 1986). Bi-directional influences (which imply a sort of vicious circle) may, although they do not correspond entirely to the nature of most psychological and social systems, be present in job stress research (cf. De Jonge et al., 2001). For instance, an increase of stressors caused by emotional exhaustion may in turn contribute to even more emotional exhaustion (cf. Zapf et al., 1996).

A second advantage of longitudinal designs is that longitudinal data have more statistical possibilities regarding model building and testing (for instance, longitudinal data may produce more robust and efficient estimators) (Hagenaars, 1990; cf. De Jonge, 1995; Verbeek, 1991). Third, it is possible to follow individual changes in attitude and behavior over time. Finally, longitudinal designs provide more opportunity to treat several kinds of third variables (Zapf et al., 1996).

In a longitudinal panel design, all variables under study are measured at least twice in the same panel of subjects (Baarda \& De Goede, 1995). In this study, data were collected in April 1998 and April 1999. These longitudinal data were used complementary to our cross-sectional data in order to test our study hypotheses. With regard to the longitudinal part of the study, we formulated in the first place three general hypotheses that reflect the main purpose of this longitudinal study: 
I. The proposed pattern of relationships between work characteristics and outcome variables is stable over time.

II. Time 1 work characteristics influence time 2 outcome variables.

III. Time 1 personal characteristics influence time 2 outcome variables.

The latter two general hypotheses can be divided into ten more specific hypotheses, which are essentially reformulations of hypotheses 1 to 10 in chapter 2 . These hypotheses were reformulated into hypotheses $1 \mathrm{~b}$ to $10 \mathrm{~b}$, such that they match the longitudinal perspective of the second part of this study:

1b. Intrinsic work motivation is primarily and positively influenced by task characteristics (combined in the additive MPS).

2b. Emotional exhaustion is primarily influenced by both workload (i.e., positively) and social support (i.e., negatively).

3b. Turnover intention is primarily and positively influenced by unmet career expectations.

4b. Growth need strength has an additive positive effect on intrinsic work motivation, over and above the effect of task characteristics (combined in the additive MPS).

5b. Growth need strength has an interactive effect on the relationship between task characteristics (combined in the additive MPS) and intrinsic work motivation (the higher the level of growth need strength, the stronger the relationship between task characteristics and intrinsic work motivation).

6b. Negative affectivity has an additive positive effect on emotional exhaustion, over and above the effects of workload and social support.

7b. Negative affectivity has an interactive effect on the relationship between workload and emotional exhaustion (the higher the level of negative affectivity, the stronger the relationship between workload and emotional exhaustion).

8b. Negative affectivity has an interactive effect on the relationship between social support and emotional exhaustion (the higher the level of negative affectivity, the stronger the relationship between social support and emotional exhaustion).

9b. Upward striving has an additive positive effect on turnover intention, over and above the effect of unmet career expectations.

10b. Upward striving has an interactive effect on the relationship between unmet career expectations and turnover intention (the higher the level of upward striving, the stronger the relationship between unmet career expectations and tumover intention).

Hypotheses I, II and $1 \mathrm{~b}$ to $3 \mathrm{~b}$ will be addressed in section 5.2. Hypotheses III and $4 \mathrm{~b}$ to $10 \mathrm{~b}$ will be addressed in section 5.3 . 


\subsection{Study populations and design of the samples}

\subsubsection{Introduction}

Both Lave and March (1980) and De Groot (1981) state that, in order to provide evidence for the generalizability of a theoretical model, its validation should take place as broad and varied as possible, hence multiple occupational groups should be included in the study sample. Kristensen $(1995,1996)$, however, argues that in order to test a causal pattern of relationships within models, it is not representativeness of the sample that is important, but sufficient variation in exposure to the model variables (see also De Jonge, Dollard, Dormann, Le Blanc \& Houtman, 2000; Ganster \& Fusilier, 1989). In large heterogeneous samples there is a reduced likelihood of uncovering causality due to poor description of the jobs of the respondents, medium exposure of many respondents, superficial knowledge of individual jobs, and a tension between the diversity of individual occupations and the diversity in job characteristics. Kristensen, therefore, recommends to include only a few, but well-defined occupations.

In the present study, we aim to find evidence for both a causal pattern of relationships, as well as the generalizability of this pattern of relationships. Considering the recommendations of both Lave and March (1980) and Kristensen $(1995,1996)$ we, therefore, decided to test the proposed pattern of relationships in two well-defined, but different occupational groups. In this way, we validate the proposed causal pattern of relationships in an appropriate way, and at the same time we are able to test the generalizability of this pattern of relationships (i.e., the applicability into at least two occupational groups that are quite different from each other). More specifically, we selected the following two populations: bank employees working at the local offices of a large Dutch bank (sample 1: banking sector), and teachers working at a center for technical and vocational education for 16-18 year-olds and adults (sample 2: education). Although both populations stem from non-industrial sectors, they differ in several aspects, the most salient aspect being the fact that the banking sector is aimed at making profits (for profit) and the education sector, generally, is not (not-forprofit). There are examples of commercial activities in the education sector, such as providing courses for business companies. However, these activities nor the people that are engaged in these activities, are under investigation in the present thesis.

Below, we will discuss some general features of both populations, as well as the sample designs we used for this study. 


\subsubsection{Sample 1: banking sector}

Until the fifties, the banking sector in The Netherlands was divided into several clear categories (Bosman, 1983): trade banks, savings banks, cooperative banks, and the Post Office Bank. Since the end of the fifties, however, most of these banks have expanded their activities and the boundaries between the different categories have faded.

During the past decade, an extensive concentration process (i.e., mergers and takeovers) has taken place in the Dutch banking sector (NIBE-SVV, 1999; WGVB, 2001a). Several general banks have transformed into broad financial conglomerates, including, for instance, assurance activities, asset management, and pension funds. This tendency towards concentration is not typically Dutch, but is occurring in the banking sector throughout the world. Over time (starting already in the nineteenth century) several waves of concentration have taken place. The recent concentration process has been very voluminous, however. In the period between 1995 and 1997, 5.400 mergers have taken place world-wide.

At present, five large general banks dominate the banking sector in The Netherlands. These five banks control the largest part of the market. In addition, there are about 55 smaller banks that operate in the remaining part of the market. Of the approximately 130.000 people working in the banking sector, 115.000 people are working at one of the five large banks, and the remaining 15.000 bank employees are divided over the other smaller banks (CBS, 2000a; WGVB, 2001a).

An explanation for this concentration process in the Dutch banking sector can partly be found in (changes in) the Dutch rules and regulations regarding the banking sector (i.e., deregulation and liberalization, leading, amongst other things, to more investment possibilities), technological developments (especially regarding information and communication technologies, such like electronic commerce via the World Wide Web), and (changes in) needs of the clients. That is, clients are becoming more critical and demanding, and expect integrated financial advises (cf. NIBE-SVV, 1999).

It can be concluded from the developments described above, that the banking sector in The Netherlands is very dynamic (Lensink, 2000). A strong focus on commercial activities and the interests of clients and shareholders characterizes the banking sector. Competition in this sector is huge, not only within national boundaries, but also in international perspective. Change has become a constant factor. It is necessary to respond quickly to the market and the needs of the clients (WGVB, 2001a). This dynamic situation is likely to have consequences for the employees. Bank managers state that their employees should be very flexible and must be able to adjust to changes quickly. Employability and integrity are considered important characteristics of bank employees, which is explicitly described in the Collective Agreement on Conditions of Employment of the banking sector (WGVB, 2000, 2001a). 
At the beginning of the nineties there has been a decrease of employment in this sector (due to a decrease of banking activities). However, since the mid-nineties employment in the banking sector has increased again, as a result of a reduction of working hours and an expansion of banking activities (WGVB, 2001a).

The turnover rate in the banking sector is approximately $12 \%$ (WGVB, 2001b, personal communication). In addition, the labor market in this sector is rather tight. Recruiting and preserving qualified personnel is becoming more and more difficult (WGVB, 2001a). The number of employees leaving banking organizations, is larger than the number of employees entering. This combination of the current tight labor market, high turnover levels, and the rising employment in this sector, can cause serious problems for banks.

The percentage of sickness absence in the banking sector was $4.8 \%$ in 1998 , and $5.0 \%$ in 1999 (excluding maternity leave; CBS, 2000b: Statline). In the entire banking sector an increasing level of sickness absence can be observed. In 1999, 1.2\% of the employees working in this sector were assessed as disabled for work. $50 \%$ of these employees were assessed as disabled because of psychological disorders (31\% of all employees who were assessed as disabled in The Netherlands in 1999 had psychological disorders; LISV, 2000).

Working under time pressure is rather common in the banking sector. Approximately $68 \%$ of the employees in financial organizations indicated in 1999 that they had to work under high time pressure sometimes or often (CBS, 2000b: Statline). In comparison with other sectors, these figures are above average. Also according to figures of Van Veldhoven, Broersen and Fortuin (1999) the work pressure in this sector is above average.

The career opportunities for employees in this sector appear to be rather good. There are many different possibilities for employees, within their organizations. In the Collective Agreement on Conditions of Employment for the banking sector, it is stated that for each employee a personal career development plan should be formulated (WGVB, 2000, 2001a).

In the banking population, the percentage of female employees is approximately $50 \%$ (CBS, 2000a). A considerable part of the female employees works part-time, and in the lower functions. About $67 \%$ of the employees is between 25 and 44 years old. $24 \%$ is older than 45 years. The larger part of the bank employees is highly educated (i.e., professional education for 16-18 years olds and adults, professional education for $18+$, and university education; CBS, 2000a).

The bank that was included in our study is one of the five large Dutch banks mentioned above. In this organization $48 \%$ of the employees are female, and $69 \%$ of the workers are between 25 and 44 years old. $25 \%$ of the employees are older than 45 years. These figures resemble the demographic characteristics of the entire sector. For these reasons, we believe this organization to be an adequate representation of the Dutch banking sector. 


\section{Design of sample 1}

In mutual agreement with the board and HRM-department of the bank included in this study, 500 employees were randomly selected from all people working at the local offices of this bank on a permanent basis. These local offices are spread over the entire country. Many different banking functions were represented in this sample: clerks and tellers, account-managers, office-managers, assistant-account-managers, relationship-managers, investment-advisors et cetera. No support staff (e.g., canteen personnel, cleaning personnel, mail carriers) was included.

\subsubsection{Sample 2: education}

The educational sector is the largest public sector in The Netherlands, approximately 350.000 people are working in this sector. The Dutch education sector is divided into five sub-sectors: primary education (also including special education), secondary education, professional education for 16-18 years olds and adults, professional education for 18+, and university education (SBO, 2000). The sub-sector of professional education for 16-18 years olds and adults was included in this study. Approximately 44.000 people are working in this sub-sector.

Employees in this educational subsector are confronted with other interests and dynamics than employees in the banking sector. There is no urge to make monetary profits and schools don't have to deal with shareholders. Dynamics in this sector stem from the many rules and regulations formulated by the Dutch government. An important development in this sector is that since the nineties, the education in this subsector is for the greater part organized in the so-called "Regionale Opleidings Centra" (ROCs; Regional Education Centers). These ROCs have originated from a wave of mergers of relatively small schools into large education centers with a large geographical range. These ROCs include many study branches. Students at ROCs can be trained for technical functions, jobs in health care, administration, tourism, hotel and catering industry, construction industry, trade functions, transport, chemical analysts, social work, et cetera. This enormous expansion process has been initiated by the Dutch government, and has caused many changes for people working in this sector. There are 46 ROCs in The Netherlands (SBO, 2000).

During the last years, also several "smaller" developments such as reduction of class sizes, and the introduction of new functions have taken place. Furthermore, since the beginning of the nineties, this subsector is facing a decreasing number of students (as opposed to the other educational subsectors). This decreasing trend is likely to continue for several more years. Employment in this sector has risen slightly since 1997 , and this is mainly due to a reduction of working hours with $3 \%$.

$65 \%$ of the employees in this sector indicated that they had to work under high time pressure sometimes or often in 1999 (CBS, 2000b: Statline). Being a teacher is considered very stressful in The Netherlands; teachers report relatively many 
psychosomatic and psychological health complaints such as burnout (cf. Van Horn, Caljé, Schreurs \& Schaufeli, 1997).

The number of employees leaving the sector (turnover to other sectors) is rather low. When employees leave their organization, they usually go to another public sector (i.e., the total turnover rate in the education sector is approximately $8 \%$; SBO, 2000). People that do leave the education sector are generally rather young: Dutch teachers are aging rather fast. Due to a tight labor market, but probably also to the bad image of education, there are many vacant positions in education at the moment. It is difficult to find young people who want to work as a teacher. Research has indicated that Dutch teachers have an image problem: they are thought to have low salaries, no career opportunities and a low status. This lack of career opportunities is indeed a problem, also according to the teachers themselves (SBO, 2000). The number of people that becomes disabled for work in this sector, is comparable with the numbers in other public sectors, but is rising. Especially since the labor market for teachers is rather tight, it is difficult to replace teachers who have fallen ill.

Sickness absence in the education sector was about $7.2 \%$ in 1997 and $7.7 \%$ in 1998 (excluding maternity leave; CBS, 2000b: Statline). In 1999, 1.3\% of the employees working in this sector were assessed as disabled for work. $41 \%$ of these employees were assessed as disabled because of psychological disorders (of the total number of employees assessed as disabled in 1999 in The Netherlands, 31\% had psychological disorders; LISV, 2000).

The percentage of women in the education sector is rather large (more than $50 \%$ of the employees in the professional education sector are female), just like the number of part-timers (i.e., 54\%, mainly women). Another striking feature of employees in the education sector is that they are relatively old: $46 \%$ of the teachers is older than 45 years. $49 \%$ is between 25 and 44 years old. Employees in the education sector are in general highly educated (professional education for $18+$, and university education; CBS, 2000a; SBO, 2000).

In the present study, we included one Dutch ROC. This ROC arose in 1997 from a merger of several schools for professional training in a Dutch province, and may be considered representative for this education sector. This merger has had many consequences for the teachers working in the center, especially with regard to the management and the structure of the organization. This ROC consists of 12 units that reflect the several study branches.

In total 644 teachers are working at this education center, $40 \%$ of the teachers are female, $55 \%$ are older than 45 years, and $42 \%$ are between 25 and 44 years old.

\section{Design of sample 2}

In mutual agreement with the school board, all teachers working at the education center on a permanent basis were included in the study $(N=644)$. A part of the teachers have additional tasks besides teaching, for instance, coordinator of a unit or student mentor. No support staff was included. 
Finally, although all participants work as a bank employee or teacher, respectively, we believe that in both samples a wide enough range of occupations and work environments are covered, in order to ensure suitable variance in the work variables under study. Variance in work variables is a prerequisite to indicating causality (cf. Kristensen, 1995, 1996).

With regard to the issue of testing our theoretical hypotheses in multiple samples, we formulated two extra, methodological hypotheses:

11. The proposed pattern of relationships between work characteristics and psychological outcome variables holds over different occupational groups (i.e., bank employees and teachers).

12. The proposed pattern of relationships between personal characteristics, work characteristics and psychological outcome variables holds over different occupational groups (i.e., bank employees and teachers).

Hypothesis 11 is related to research question 1 and will be tested in chapters 4 and 5 . Hypothesis 12 is related to research question 2, and will be tested in chapter 4 .

\subsection{Procedure, fieldwork and respondents}

In order to collect data, we used the following procedure. First of all, meetings were arranged with the boards of both the bank and the education center. The boards were informed about the research topic and purpose, and the data collection procedure. In the education center, we also had meetings with several staff members and with the employees council.

In both samples, we used self-report questionnaires to collect the data. In sample 1, we sent the questionnaires to the private addresses of the subjects. The board of the bank agreed that we would receive 500 private addresses of employees, which were randomly selected from all employees working at the local offices of this bank. We used these addresses merely to distribute the questionnaires (at two measurement points) and the reminders. After the second measurement, the file containing the addresses was destroyed. In sample 2, the questionnaires were distributed by the internal mail system. The questionnaires were sent to the subjects in sealed envelopes with their names on it. Each envelope contained a questionnaire, the administration instruction, a stamped and addressed return envelope, and finally, a letter written and signed by the management of the bank and the education center, respectively. In this letter the importance of the study was explained, the merits for the organization were described, and subjects were urged to fill out and return the questionnaires.

Two weeks after we sent the questionnaire, the subjects received a reminder in which we explained the goal of the study once again, and urged the subjects to fill out the questionnaire and return it. 
As we already mentioned in section 3.2 , this study had two waves. For both samples, the first measurement took place in April 1998, and the second measurement took place in April 1999. Hence, the time interval we used was one year. This time period seems long enough to measure possible changes in individual scores, and not too long with regard to non-response. Furthermore, this one year interval ensures that seasonal influence is stable (cf. Frese \& Zapf, 1988; Vermaat, 1994; Zapf et al., 1996). In April 1999 (the second measurement), all subjects who received a questionnaire at the first measurement (April 1998) and who were still working at the organization, received the second questionnaire, which was exactly the same as the first one. The procedure we used, was the same as in the first wave. At both time 1 and time 2, the questionnaires contained a code, in order to identify subjects in the second wave and to connect the data from both waves. The purpose of this code was explained in the administration instruction, and anonymity of the subjects was guaranteed. The lists that connected the codes on the questionnaires with the names of the subjects, were only available to the researcher and were destroyed immediately after the second measurement.

All respondents of the first wave who returned usable questionnaires, were included in the cross-sectional part of the study (we will call this group "the cross-sectional group" throughout this thesis). The respondents that responded at both time 1 and time 2 (the so-called "panel group") were included in the longitudinal part of the study.

Figure 3.1 shows a schematic overview of the samples and the response rates in the two waves. 

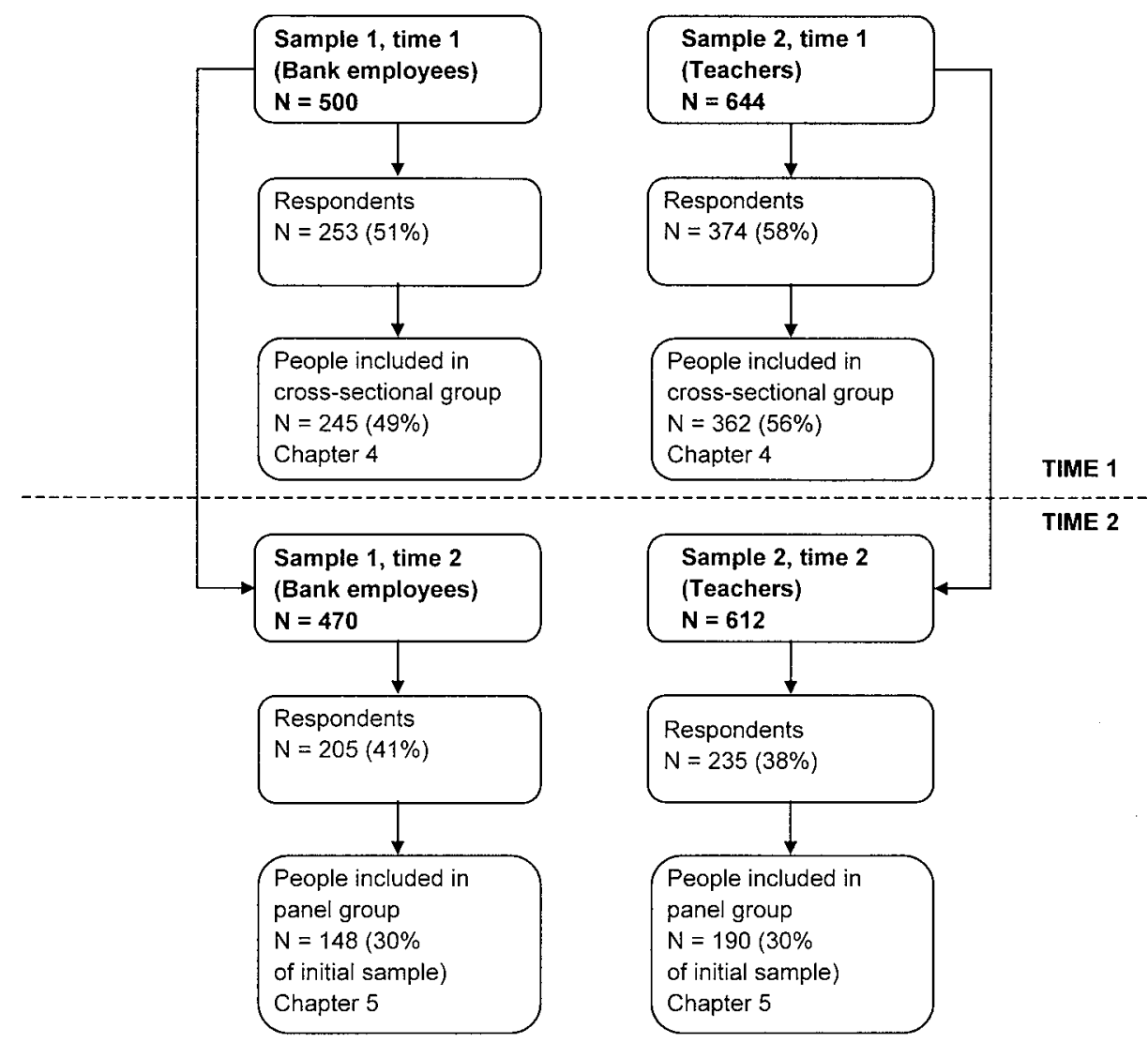

Figure 3.1 Response rates at time 1 and time 2 in sample 1 and sample 2

It can be concluded from Figure 3.1 that the response was highest at time 1 (in both samples). In the second wave, the response was a bit lower. Unfortunately, due to wave non-response (i.e., subjects who do not respond at one or two measurements) and attrition (i.e., subjects who participate in the first measurement, but not in the second), the panel group finally consisted of $30 \%$ of the initial group in both sample 1 and sample 2. The number of dropouts in sample 1 is 97 , and in sample 2 this number is 172. Losing a substantial part of the initial sample is, however, a common feature of many panel studies (cf. Hagenaars, 1990; Kessler \& Greenberg, 1981; Verbeek, 1991).

Table 3.1 shows some demographic characteristics of the cross-sectional group and the panel group (of both samples 1 and 2). 
Table 3.1 Description of the cross-sectional group and the panel group in sample 1 and sample 2

\begin{tabular}{lcccc}
\hline & $\begin{array}{c}\text { Cross-sectional } \\
\text { group sample 1 } \\
(N=245)\end{array}$ & $\begin{array}{c}\text { Cross-sectional } \\
\text { group sample } 2 \\
(N=362)\end{array}$ & $\begin{array}{c}\text { Panel group sample 1 } \\
(N=148)\end{array}$ & $\begin{array}{c}\text { Panel group sample 2 } \\
(N=190)\end{array}$ \\
\hline Mean age & $38.4(S D=8.4)$ & $46.3(S D=6.1)$ & $39.3(S D=8.7)$ & $47.4(S D=5.8)$ \\
Percentage of men & $55 \%$ & $61 \%$ & $60 \%$ & $70 \%$ \\
Percentage full-time & $80 \%$ & $55 \%^{\mathrm{a}}$ & $83 \%$ & $62 \%^{\mathrm{a}}$ \\
\hline
\end{tabular}

Note. All values depicted in this Table are measured at time 1.

${ }^{3}$ Among the part-time employed teachers only $14 \%$ (cross-sectional group) $/ 17 \%$ (panel group) were contracted for less then 18 hours a week.

The cross-sectional groups of both sample 1 and sample 2, appeared not to differ significantly from the total working populations at the bank and at the education center, respectively, with regard to the demographic characteristics gender (sample 1: $\chi^{2}(1)=.40$, n.s.; sample $2: \chi^{2}(1)=.13$, n.s.) and age (sample $1: t=.65$, n.s.; sample 2 : $t=.93$, n.s.).

With regard to non-response due to attrition (dropout), $t$-tests indicate that, at time 1 , in both samples the panel group was somewhat older than the dropouts (bank employees: $t=2.05, p \leq .05$; and teachers: $t=3.45, p \leq .05)$. The mean differences were, however, less than one quarter of the standard deviation in both samples. Furthermore, the panel group of sample 2 (teachers) included slightly more male employees than the dropouts in this sample $\left(\chi^{2}(1)=11.51, p \leq .05\right)$. We believe, however, that these are rather minor demographic differences, which will not cause serious selection problems. The non-response due to attrition and wave non-response will be discussed more thoroughly in chapter 5 . In the latter chapter, we will discuss the question whether dropout is a result of a certain causal dynamic that is different from that of the panel group, and several other threats of internal validity in more detail (cf. Daniels \& De Jonge, 2001).

\subsection{Measures}

\subsubsection{Introduction}

In order to measure the study variables, we used self-report questionnaires. Some authors point at several drawbacks of self-report measures, such as the disturbing influence of factors such as social cues, attitudes and personal characteristics, and common method variance (cf. Spector, 1992; Zapf, 1989). In this light, these authors recommend to use more "objective" measures such as observation and registration (see, for instance, Zapf, 1989). However, there are also many arguments that legitimate the use of more subjective measures. First, in many studies the correlations between "objective" and "subjective" measures are moderate to high (Boumans \& Landeweerd, 1993; Farh \& Scott, 1983; Fried \& Ferris, 1987; Spector, 1992; Taber \& 
Taylor, 1990; Vogelaar \& Van der Vlist, 1995). Spector (1992, p. 143), for instance, summarizes the research that has been carried out with regard to this matter as follows: "There is considerable evidence that perceptual measures reflect the objective environment. ..., there is surprisingly little evidence that observed relations are attributable to the self-report method. There is also considerable doubt that social cues invalidate these self-reports." According to Spector (1992), a subjective measurement of work characteristics even adds something to an objective measurement: that is the impact of a working situation on the employee. Second, an objective measurement of the work has its own problems and difficulties (Van Veldhoven \& Meijman, 1994): observations of experts may, in common with the selfreport of employees, be affected by cognitive and emotional processes. Furthermore, employees may behave differently when they know that they are being observed. Thus, we may conclude that the objectivity of objective measures may at least be questioned. The third argument to use self-report questionnaires is of a practical nature: the use of objective measures is laborious, and time and money consuming. Questionnaires, on the contrary, provide the possibility to collect a large amount of data relatively cheap and fast.

For all these reasons, we decided to use self-report questionnaires. In order to prevent common method variance, we used measures in which work characteristics (independent variables) were formulated in different terms from the outcome (dependent) variables. Furthermore, we used different response formats and scales throughout the questionnaire.

The remaining part of this section gives an overview of the measurement instruments (i.e., operationalizations) that were used in this study. The selection of the variables is based on the pattern of relationships that was depicted in chapter 2. In order to measure these variables, we decided to use existing and generally well-known measurement instruments that have proven to be valid and reliable in previous studies (e.g., De Jonge, 1995; Janssen, De Jonge \& Bakker, 1999; Vermaat, 1994; Watson et al., 1988). The measurement instruments are reproduced integrally in the Appendix.

The operationalizations of the four work characteristics will be preceded by a short description of these variables. The personal characteristics and psychological outcome variables have extensively been described in chapter 2 .

\subsubsection{Work characteristics}

\section{Task characteristics}

In the previous chapter, we concluded that the five task characteristics described by Hackman and Oldham (1980) are among the most important determinants of intrinsic work motivation. These five task characteristics can be described as follows.

1. Skill variety: the degree to which a job requires a variety of different activities, involving the use of a number of different skills and talents. 
2. Task identity: the degree to which a job requires completion of a "whole" and identifiable piece of work, that is, doing a job from beginning to end with a visible outcome.

3. Task significance: the degree to which the job has a substantial impact on the lives of other people, whether those people are in the immediate organization or the world at large.

3. Autonomy: the degree to which the job provides substantial freedom, independence, and discretion to the individual in scheduling the work and in determining the procedures to be used in carrying out the work.

4. Job feedback: the degree to which carrying out the work activities required by the job provides the individual with direct and clear information about the effectiveness of his or her performance.

The task characteristics were measured by means of a Dutch translation of several scales of the Job Diagnostic Survey (JDS; Hackman \& Oldham, 1980). Together, these scales consist of 16 items, measuring the five task characteristics mentioned above: autonomy (three items), task variety (five items), job feedback (two items), task identity (three items) and task significance (three items). The response scale ranged from 1 "strongly disagree" to 7 "fully agree". An example item is: "The job gives me considerable opportunity for independence and freedom in how I do the work". In line with suggestions of Fried and Ferris (1987), we combined these five task characteristics into a single, unweighted, additive index that reflects the motivating potential of a job (Motivating Potential Score-additive index). According to Fried and Ferris (1987), this simple additive index is a better predictor of work outcomes than the multiplicative MPS index, which has been suggested by Hackman and Oldham (1980). In addition, the multiplicative MPS contains two cross-product terms, which may unnecessarily increase measurement error (Evans, 1991). Second-order factor analysis of the five task characteristics in this additive index (Principal Axis Factoring) showed that a one-factor solution was admissible at both measurement points and in both samples, indicating that it is permitted to combine the five task characteristics into one index (explained variance ranged between $40 \%$ and $45 \%$ ).

\section{Workload}

The previous chapter has shown that (mental) workload is an important determinant of burnout, and in particular of emotional exhaustion. Workload appeals to the information processing and emotional capabilities of the brain (Kompier, 1995). It may be described as the level to which job demands occupy the information processing capacity of a person (Zij]stra \& Mulder, 1989). However, there is no agreement about the definition of workload in the literature (Gaillard, 1996). Workload might be considered as a rather objective concept that indicates the amount of work to be done (Grunveld, 1992). However, workload might also be considered as a somewhat more "subjective" concept in which the perceived amount of work to be done is combined with time pressure, other circumstances at the work place, and the capacity of the worker. In the present thesis we use the term workload to indicate the perceived 
amount of work to be done in combination with factors such as time pressure. The latter concept of workload can be divided into qualitative workload (e.g., task complexity, difficulty) and quantitative workload (e.g., number of requirements within limited time space) (cf. De Jonge, 1995; Muntaner \& O'Campo, 1993; Warr, 1987).

Workload was measured by means of an eight-item scale that was developed by De Jonge, Landeweerd and Nijhuis (1993). The response scale ranged from 1 "never" to 5 "always". This scale consists of a relatively wide range of both quantitative and qualitative demanding aspects in the work situation, like working under time pressure, working hard, and strenuous work. An example item is: "In the organization where I work, too much work has to be done".

\section{Social support}

Just like workload, a lack of social support may also be related to emotional exhaustion (see chapter 2). Social support at work refers to overall levels of social transactions available on the job, from both supervisors and colleagues (Karasek \& Theorell, 1990). Buunk et al. (1998) distinguish four kinds of social support:

- Emotional support: the expression of affection, acceptance, empathy and trust.

- Instrumental support: practical support, the exchange of services and goods or properties.

- Informative support: the exchange of information that may solve personal and/or work-related problems. The exchange of experiences and personal advice.

- Appreciative support: the expression of appreciation and respect. The exchange of information that may help somebody to value himself and/or his work.

Buunk and Verhoeven (1991) mention a fifth kind of social support, viz. companionship: having informal conversations with colleagues, characterized by pleasantness and fun.

Social support was measured by means of a ten-item scale, derived from a Dutch questionnaire on organizational stress (Vragenlijst Organisatie Stress-Doetinchem; Bergers, Marcelissen \& De Wolff, 1986). Except for instrumental support, all kinds of social support described above were included in this scale. The response scale ranged from 1 "never" to 4 "always". An example item is: "If there are problems at work, can you talk about them with your colleagues?".

\section{Unmet career expectations}

The previous chapter has shown that unmet expectations regarding salary, job security, and career opportunities are the most important determinants of turnover intention.

For many people, financial rewards (i.e., salary) are very important, because in contemporary Western society, money provides the opportunity to satisfy many needs (cf. Hoogstad \& Weststeijn, 1997). For organizations, salaries are an important human resources management-instrument, which may be used for recruiting and preserving personnel for the organization (Moorhead \& Griffin, 1995). 
Second, when employees are not certain about their job security within the organization, they might be inclined to leave the organization. In light of the increasing competition, organizations have to be able to adjust to their environments very fast. Therefore, many organizations strive to make their work force as flexible as possible. Flexibility of the work force enables organizations to adjust the amount of human resources to the demands of the environment (De Jonge \& Geurts, 1997). This leads to an increasing use of flexible (i.e., temporary) employment contracts. As a result, many employees have to deal with insecurity about their job perspectives. According to Van Vuuren (1991), however, a certain level of job security is important to preserve employees for the organization.

The factor career opportunities, finally, may refer to educational opportunities, promotion and career development. With regard to turnover intention, particularly a lack of career opportunities seems to be important (cf. Van Breukelen, 1989; Janssen \& Buunk, 1990; Janssen, 1992; Pool, Van Elburg \& Nusselder, 1992). A lack of career opportunities may, for instance, be due to a flat organization and the organizational culture with regard to careers and internal mobility (Pool, Van Elburg \& Nusselder, 1992). According to Hall (1976), a career may defined as a sequence of jobs a person fulfills during his working life. In popular usage, the term career generally means advancement (upward mobility). Careers are important to individuals because they provide the opportunity to satisfy the needs of the employee, such as personal growth and the development of a positive self-concept (De Cenzo \& Robbins, 1996; Schein, 1978).

Unmet career expectations were measured by means of a scale that reflects the unmet expectations regarding salary, responsibility, opportunities to develop knowledge and skills, job security and position. This scale consists of five items that were derived from an existing eight-item questionnaire (cf. Buunk \& Janssen, 1992; Janssen, 1992). For reasons of item overlap with other measures, the three remaining items (i.e., unmet expectations regarding support, self determination and creativity) were not included. The response scale ranged from 1 "strongly disagree" to 5 "fully agree". An example item is: "I want to have a higher salary than I have now".

\subsubsection{Personal characteristics}

\section{Growth need strength}

Growth need strength was measured by means of a Dutch translation of a six-itemscale from the Job Diagnostic Survey (JDS; Hackman \& Oldham, 1980). The six items had a seven-point response scale, ranging from 1 "strongly disagree" to 7 "fully agree". An example item is: "I would like to have stimulating and challenging work".

\section{Negative affectivity}

Negative affectivity was measured by means of a ten-item-scale derived from the Positive Affectivity Negative Affectivity Scale (PANAS; Watson et al., 1988). Subjects were asked to rate on a five-point response scale (ranging from 1 "very slightly" to 5 
"extremely") the extent to which they, in general, experienced several mood states. Examples of the mood states are: "guilty", "ashamed", "nervous" and "distressed".

\section{Upward striving}

Upward striving was measured by means of a nine-item-scale developed by Wollack, Goodale, Wijting and Smith (1971). The response scale ranged from 1 "strongly disagree" to 5 "fully agree". An example item is: "A worker who turns down a promotion is probably making a mistake". Factorial and reliability analysis indicated that the reliability and factorial validity of this scale were much better when one item was left out. Inspection of this item revealed that it was non-monotonous (see Appendix). That is, both people who are high on upward striving and people who are low on upward striving might agree with the proposition in this item. Therefore, we decided to omit this item from the scale.

\subsubsection{Outcome variables}

\section{Intrinsic work motivation}

Intrinsic work motivation was measured by means of a six-item scale derived from a questionnaire developed by Warr, Cook and Wall (1979) and translated by Janssen, De Jonge and Bakker (1999). The response scale ranged from 1 "strongly disagree" to 7 "fully agree". An example item is: "I take pride in doing my job as well as I can".

\section{Emotional exhaustion}

Emotional exhaustion was measured by means of a five-item subscale of the Maslach Burnout Inventory - General Survey (Schaufeli, Leiter, Maslach \& Jackson, 1996). The response scale ranged from 1 "never" to 7 "always". This version of the Maslach Burnout Inventory is suitable for use in all professions and not merely the human services. An example item is: "I feel tired when I get up in the morning and have to face another day on the job".

\section{Turnover intention}

Turnover intention was measured by means of a four-item scale derived from a Dutch questionnaire on the experience of work (Questionnaire on the Experience and Evaluation of Work; Van Veldhoven \& Meijman, 1994). The response scale ranged from 1 "no" to 2 "yes". An example item is: "I intend to leave this organization this year".

The internal reliability coefficients (Cronbach's alphas and KR20) of the measurement instruments described above, are depicted in Table 3.2 (for both samples and both measurement points). The test-retest reliabilities of the measurement instruments will be discussed in chapter 5. Furthermore, for all variables (i.e., work characteristics, personal characteristics and outcome variables) we computed the mean scores (sumscore divided by the number of items in the scale). These mean scores were included in the further analyses (chapters 4 and 5). 
Finally, we measured the background variables gender and age. These variables may confound the results (Furnham, 1992; Karasek \& Theorell, 1990; Zapf et al., 1996) and we included them in order to control for their possible influence.

Table 3.2 Reliability coefficients of the measurement instruments (sample 1 and sample 2)

\begin{tabular}{|c|c|c|c|c|c|c|c|c|}
\hline Measures & $\begin{array}{c}\text { sample } 1 \\
\text { total } \\
\text { time } 1 \\
N=243\end{array}$ & $\begin{array}{c}\text { sample } 2 \\
\text { total } \\
\text { time } 1 \\
N=361\end{array}$ & $\begin{array}{c}\text { sample } 1 \\
\text { panel } \\
\text { time } 1 \\
N=148\end{array}$ & $\begin{array}{c}\text { sample } 1 \\
\text { panel } \\
\text { time } 2 \\
N=148\end{array}$ & $\begin{array}{c}\text { sample } 2 \\
\text { panel } \\
\text { time } 1 \\
N=188\end{array}$ & $\begin{array}{c}\text { sample } 2 \\
\text { panel } \\
\text { time } 2 \\
N=188\end{array}$ & $\begin{array}{c}\text { sample } 1 \& 2 \\
\text { panel } \\
\text { time } 1 \\
N=323\end{array}$ & $\begin{array}{c}\text { sample } 1 \& 2 \\
\text { panel } \\
\text { time } 2 \\
N=323\end{array}$ \\
\hline MPS (add.) & .76 & .75 & .78 & .79 & .70 & .80 & .74 & .79 \\
\hline Workload & .87 & .89 & .89 & .87 & .88 & .90 & .89 & .88 \\
\hline Social support & .83 & .82 & .83 & .80 & .83 & .85 & .83 & .83 \\
\hline Unm. car. exp. & .80 & .72 & .79 & .70 & .76 & .68 & .74 & 68 \\
\hline GNS & .89 & .89 &.$^{a}$ & -- & -- & -- & .88 & .91 \\
\hline NA & .85 & .85 & - & -- & -- & - & .86 & .86 \\
\hline US & .67 & .65 & - & -- & -- & - & 66 & .63 \\
\hline Intr. work mot. & .67 & .74 & 67 & .63 & .68 & .76 & .67 & .71 \\
\hline Emotional exh. & .90 & .90 & .90 & .91 & .90 & .89 & .90 & .90 \\
\hline Turnover int. ${ }^{\mathbf{b}}$ & .72 & .78 & .63 & .72 & .79 & .78 & .73 & .76 \\
\hline
\end{tabular}

${ }^{a}$ For the longitudinal analyses regarding personal characteristics we combined sample 1 and sample 2 into one larger sample (see chapter 5 for a further explanation). Therefore, the Cronbach's alphas of the personal characteristics were only computed for this combination of sample 1 and sample 2, and not for the panel groups of both samples separately.

${ }^{b}$ For turnover intention, we computed KR20 instead of Cronbach's alpha (KR20 is a measure of internal reliability that is particularly appropriate for dichotomous items. Its interpretation is equal to the interpretation of Cronbach's alpha).

It may be concluded from Table 3.2 that the internal reliabilities of the scales we used were all higher than .65 (which is acceptable), and most of them were higher than .70 (which is good) (cf. Nunnally, 1978). There is one exception: the personal characteristic upward striving has a Cronbach's alpha of .63 at time 2. At time 1, however, Cronbach's alpha of upward striving is higher than .65. A second variable that showed Cronbach's alphas lower than .70, is intrinsic work motivation. With regard to this variable, alphas of approximately .66 have previously been reported by Janssen, De Jonge and Bakker (1999) and Berkhout (2000).

\subsection{Data analyses}

\subsubsection{Introduction}

In this section, we will discuss several general issues with regard to the statistical techniques we used to analyze the data in this study.

In both the cross-sectional part and the longitudinal part of the study, we analyzed the data in several steps. First, we carried out several preliminary analyses in order to gain a first insight into the data (i.e., means, standard deviations, and zero-order Pearson correlations). Next, we performed more sophisticated analyses, which were 
all executed by means of Structural Equation Modeling (SEM) using the LISREL (LInear Structural RELations) computer program, version 8.20. In the cross-sectional part of the study we mainly used multi-sample analysis (MSA), a special feature of SEM, in order to analyze data in multiple samples simultaneously. In the longitudinal part of the study, we used a cross-lagged panel design (also by means of SEM). To analyze the effects of the personal characteristics in both the cross-sectional and the longitudinal part of the study, finally, we used several techniques to test interaction effects by means of SEM.

To summarize, we used multi-sample analyses and cross-lagged panel designs with regard to research question 1 , and several techniques to test interaction effects by means of SEM, with regard to research question 2. Below, we will first provide some general information about SEM, and next we will pay attention to the specific SEM techniques mentioned above.

\subsubsection{Structural Equation Modeling (SEM)}

\section{The why and what of Structural Equation Modeling (SEM)}

SEM, which has also been labeled as covariance structure modeling, is a multivariate technique that combines methodological and statistical contributions from the psychometric theory as well as the econometric theory (Diamantopoulos, 1994; Scott Long, 1983). Generally, in SEM the difference between the sample covariances and the covariances predicted by the model, is minimized (Bollen, 1989). The observed covariances minus the predicted covariances form the residuals. The fundamental hypothesis for this structural equation procedure is that the sample covariance matrix $S$ is a function of a set of parameters. If the model were correct and if we knew the parameters, the population covariance matrix would be exactly reproduced (Bollen, 1989).

A full covariance structure model basically consists of two components: (1) the measurement or factor-analytic model, which reduces observed measured variables (e.g., items of the workload scale) to a smaller number of latent variables or factors (e.g., workload), and (2) the structural equation model, which defines (causal) relationships among these latent variables (cf. Jöreskog \& Sörbom, 1993b). The present study simplifies the covariance structure model by assuming that the latent and observed variables are identical (i.e., each construct had only one operationalization). In other words, there are no specified measurement models in the analyses. We made this decision because of the large number of items used to operationalize all the variables in our model: simultaneous consideration of all observed variables (i.e., items) would result in unreliable parameter estimates and insufficient power (cf. Anderson \& Gerbing, 1988; Jaccard \& Wan, 1996; cf. De Jonge et al., 2001; cf. Schumacker \& Lomax, 1996). Once latent variables are adequately defined (measured), it makes sense to examine the latent-variable relationships in a structural equation model (Schumacker \& Lomax, 1996). This procedure seems justified because the measures used in this study have generally proven to be valid and reliable in the current study and/or in previous research. 
The basic objective of SEM is to provide a means of simultaneously testing hypothesized substantive models to account for a pattern of covariation among the latent variables (Jöreskog \& Sörbom, 1993b; Scott Long, 1983; cf. De Jonge, 1995). Accordingly, the general latent variable model can be written as:

$\eta=\mathrm{B} \eta+\Gamma \xi+\zeta$

where $\mathrm{B}$ is a matrix of structural parameters relating the endogenous variables to one another, $\Gamma$ is a matrix of structural parameters relating the exogenous variables to the endogenous variables, and $\zeta$ is a vector of random disturbance terms, sometimes called errors in equations. The latter represent a summary of all known and unknown influences of the $\eta s$ which are uncorrelated with the $\xi s$. Furthermore, $\Phi$ represents the covariance matrix of $\xi$, and $\Psi$ reflects the covariance matrix of $\zeta$ (Jöreskog \& Sörbom, 1993b; Scott Long, 1983). The exogenous variables and the errors in equations are assumed to be uncorrelated. Exogenous ("independent") variables are latent variables that are determined by variables that lie outside the model. Endogenous ("dependent") variables are latent variables that are determined by variables within the model (Bollen, 1989). Before estimation of the parameters can proceed, it is necessary to determine whether a unique solution exists for each parameter in the matrices. This is called the problem of identification (cf. Hayduk, 1987; Scott Long, 1983; cf. De Jonge, 1995). The most recent LISREL versions provide a $99 \%$ security about whether a structural equation model is identified (personal communication, Van Breukelen, 1999, cf. Jöreskog \& Sörbom, 1993b). Once a structural equation model is identified, the parameters of the model can be estimated (cf. Diamantopoulos, 1994; Hayduk, 1987). LISREL can perform several methods of estimation. In the present study we used Maximum Likelihood (ML) estimation. ML maximizes the likelihood of the parameters, given the data. The ML estimator is approximately unbiased, has as small a sampling variance as other estimators, and is approximately normally distributed. As the sample size gets larger, the expected values of the sample estimates get closer and closer to the true population parameters (which is a desirable asymptotic property; Scott Long, 1983; Schumacker \& Lomax, 1996). It is, however, unclear how large a sample must exactly be in order to take advantage of these desirable asymptotic properties (Scott Long, 1983). ML is scale invariant, which means that if the scale of one or more of the observed variables is transformed, the untransformed and transformed variables will yield estimates that are properly related (Schumacker \& Lomax, 1996). ML estimation assumes that all variables are multinormally distributed, although this method is rather robust against non-normally distributed variables (cf. Bollen, 1989; Hayduk, 1987). The method is iterative and requires approximations of the parameters in order to begin the computations. In most cases, it is sufficient to specify only the non-zero fixed values, and leave it to the program to compute estimates of all the free parameters (Jöreskog \& Sörbom, 1993b). 
According to, for instance, Jöreskog and Sörbom (1993a, 1993b), SEM should primarily be theory-driven, and to a much lesser extent data-driven, which means that structural paths that are specified in the structural equation model, should be formulated prior to the data analyses, and should be based on theoretical hypotheses. Thus, SEM is primarily confirmatory in nature: it is investigated to what extent a postulated structure of relationships is actually consistent with the data.

\section{Indicators of the fit of structural equation models}

In order to determine the fit of a specified model to the data, fit indices are used. Generally, it is recommended to use a mixture of fit indices. More specifically, Schumacker and Lomax (1996) suggest to use various goodness of fit criteria to assess model fit, model comparison, and model parsimony. Criteria to assess model fit are, for instance, the chi-square statistic $\left(\chi^{2}\right)$ and the adjusted goodness-of-fit index (AGFI). The chi-square statistic is the only fit index that has a statistical test of significance (Schumacker \& Lomax, 1996). Chi-square is a measure of overall fit of the model to the data. It tests the null hypothesis that the observed covariance matrix fits the hypothesized model. A small, non-significant chi-square corresponds to a good fit. Chi-square is, however, very sensitive to sample size: as sample size increases, chi-square has a tendency to become significant. AGFI is an overall measure of fit, which takes the number of degrees of freedom into account. This fit index estimates the extent to which the sample variances and covariances fit the hypothesized model, while taking parsimony into account (cf. De Jonge, 1995). When AGFI is .85 or higher, the model fit is acceptable. Values around .95 indicate a good fit (Verschuren, 1991). Just as the chi-square statistic, AGFI is sensitive to sample size.

Fit criteria to compare models are, for instance, the non-normed fit index (NNFI; also known as the Tucker-Lewis index), and the comparative fit index (CFI) (cf. Schumacker \& Lomax, 1996). By means of the NNFI, models can be compared regardless of whether or not they can be ordered in a nested sequence. NNFI measures how much better a model fits than an independent model (i.e., the null model, assuming zero relationships between variables). The value of NNFI should be higher than .90 (Bentler, 1990). An advantage of NNFI is that this index is not sensitive to sample size. The CFI measures the improvement in non-centrality in going from the least restrictive to the saturated model. CFI is also not sensitive to sample size and should be higher than .90 (cf. Schumacker \& Lomax, 1996).

Fit criteria to assess model parsimony are the Akaike information criterion (AIC) and the root mean square error of approximation (RMSEA). Parsimony refers to the number of estimated coefficients required to achieve a specific level of fit (the more parsimonious the model, the larger the number of degrees of freedom). AlC takes into account the number of degrees of freedom. The AIC is always positive, but the lower the value of the AIC, the more parsimonious the model. The RMSEA, finally, can be used as a measure of the discrepancy per degree of freedom of the model. The RMSEA can provide useful information for the assessment of the degree of approximation in the population, and has the tendency to reward more parsimonious models (cf. De Jonge, 1995). A value lower than .05 indicates a close fit of the model 
in relation to the degrees of freedom. Values between .05 and .10 indicate acceptable fit (cf. Bentler, 1990; Browne \& Cudeck, 1993; Hu \& Bentler, 1998; Jöreskog, 1993; Jöreskog \& Sörbom, 1993a; Schumacker \& Lomax, 1996; Verschuren, 1991).

All fit criteria discussed above, will be used throughout this thesis. All criteria but the chi-square statistic, will be referred to as practical fit indices.

In order to validate the results of a SEM-analysis, it is generally recommended to replicate the study either by obtaining a second data set, or by splitting the existing sample and running the analysis in two smaller samples. In the present study, we already use multiple samples. In addition, Browne and Cudeck (1989) proposed a single-sample expected cross validation index (ECVI) for comparing alternative models using only one sample of data. The alternative model that results in the smallest ECVI should be the most stable in the population.

\section{Individual relationships within structural equation models}

With regard to specific relationships within structural equation models, LISREL provides beta and gamma coefficients (in the beta and gamma matrices, respectively). Beta coefficients indicate the strength of the relationships among the endogenous variables, and gamma coefficients indicate the strength of the relationships between the exogenous and the endogenous variables (Jöreskog \& Sörbom, 1993a, 1993b). In addition, LISREL provides $t$-values and modification indices. T-values indicate the significance of the specified relationships. A $t$-value of 1.96 or higher indicates that the relationship is significant (a $t$-value of 1.96 corresponds to an alpha level of .05; Jöreskog \& Sörbom, 1993b). The modification indices provide information as to what specific relationships should be added to the model, when theoretically plausible, in order to improve the fit between the hypothesized model and the data (Hayduk, 1987; Jöreskog \& Sörbom, 1993a). A modifjcation index indicates how much the model fit will improve when a parameter which was fixed to a specific value (e.g., zero) is set free and estimated from the data. The process of respecification based on the Mls, can be repeated until the model fit is acceptable. However, the adjustment of structural equation models should be theoretically plausible (cf. Hayduk, 1987). A rule of thumb is that modification indices larger than 5.00 are worth considering.

\section{Comparison of structural equation models}

In order to compare different, nested, structural equation models, a chi-square difference test (or: likelihood ratio test; Bentler \& Bonett, 1980) can be performed. A model is nested in another (original) model, when the nested model is derivable from the original model, by adding constraints to this original model. In other words, a nested model is a special case of the original model. When models are nested, they can be ordered according to increasing number of degrees of freedom (Bentler \& Bonett, 1980; Jöreskog \& Sörbom, 1993b). The difference in loglikelihood between nested models has itself a chi-square distribution, with the number of degrees of freedom equal to the corresponding difference in degrees of freedom of the separate 
models. Critical values of the chi-square distribution are taken as evidence that additional constraints are preferred or not.

\subsubsection{Multi-Sample Analysis (MSA) using SEM}

In the present study, we aim to test a proposed pattern of relationships in multiple samples. Multi-sample analysis (MSA) is particularly useful to test a pattern of relationships in multiple samples simultaneously. By means of MSA it is possible to investigate to what extent a postulated pattern of relationships is actually consistent with the observed data in two or more samples (Jöreskog \& Sörbom, 1993b; Schumacker \& Lomax, 1996). Moreover, it is possible to investigate whether a proposed pattern of relationships is invariant (i.e., the structural paths have the same strength and direction) across two or more different samples, thus providing a powerful validation of this pattern of relationships (see Byrne, 1991, 1994, 1998).

In addition, MSA provides the possibility to test whether differences exist between the samples: one can specify certain relationships as invariant, and at the same time specify additional relationships for each sample separately, where appropriate (Schumacker \& Lomax, 1996). Testing for invariance involves specifying a model in which certain parameters are constrained to be equal across the groups under study, and then comparing that model with a less restrictive model in which these parameters are free to take on any value. These nested competing models can be compared by means of the chi-square difference test discussed above. A non-significant difference in chi-square indicates invariance (Byrne, 1991).

As a prerequisite to testing for invariance of relationships, Byrne (1998) advises to consider a baseline model that is estimated separately for each group first (Byrne, 1998). This procedure offers the opportunity to detect a priori group-specific differences. In a second step, invariance of the paths that are found in both separate samples, can be tested.

\subsubsection{Cross-lagged panel designs using SEM}

In the present study, the longitudinal data will be tested by means of cross-lagged panel designs using Structural Equation Modeling. Other statistical techniques to analyze panel data, are cross-lagged panel correlational analysis (CLPC) and hierarchical regression analysis (HRA) (see, for instance, Rogosa, 1980, 1987). CLPC is a method that compares the lagged zero-order correlations of two variables in a causal study. HRA aims to provide evidence for causal predominance by performing two hierarchical regression analyses: $X 1$ and $Y 1$ on $Y 2$, and subsequently, $X 1$ and $Y 1$ on $Y 2$. Then, the standardized regression coefficients (of $X 1$ on $Y 2$, and of $Y 1$ on $X 2$ ) are compared. However, the latter two techniques have several important disadvantages (Hagenaars, 1990; cf. De Jonge, 1995; Kessler \& Greenberg, 1981; Rogosa, 1980). CLPC, to begin with, ignores the stability of the variables under study. As a result, CLPC tends to favor the variables with the lowest stabilities as the cause. Furthermore, cross-lagged effects might in fact be synchronous effects (i.e., 
misspecified causal lags can create significant cross-lagged correlational differences, even when do not exist in reality). In addition, when the relationship between two variables (i.e., a causal process) is not stable over time, the cross-lagged correlations will attenuate in ways that are not related to causal influences. Finally, using CLPC it is not possible to test more than two variables simultaneously. HRA meets some of the shortcomings of CLPC. For instance, it is possible in HRA to include more than one independent variable, to control for third variables, and to take stability into account. However, in HRA it is still not possible to take into account all (dependent and independent) variables and equations, and test the model fit as a whole (cf. De Jonge, 1995). Therefore, in the present study we decided to use used a cross-lagged panel design, using SEM (e.g., Finkel, 1995; Kessler \& Greenberg, 1981).

Figure 3.2 shows an example of a general cross-lagged panel design, including the work characteristics and outcome variables of this study.

In this longitudinal structural equation model, all work characteristics and outcome variables are measured twice (time 1 and time 2). Furthermore, time 1 gender and age are controlled for. These demographic variables are consequently labeled as exogenous, and all other variables are labeled as endogenous (cf. Bollen, 1989).

This structural equation model further consists of the following parameters: regression coefficients representing the differential synchronous (arrows 1 and 2 in Figure 3.2) and cross-lagged structural paths (arrows 3 and 4 in Figure 3.2); temporal stability coefficients between the measurement scales of the work characteristics and the outcome variables; covariances between the background variables; and residual covariances between the work characteristics, and between the outcome variables (cf. De Jonge et al., 2001). In addition, because the endogenous variables might partly be predicted by variables that are not included in the present study, the error variances of the endogenous variables themselves and the error variances regarding the relationships between the endogenous variables were set free (cf. De Jonge et al., 2001; MacCallum, Wegener, Uchino \& Fabrigar, 1993). 


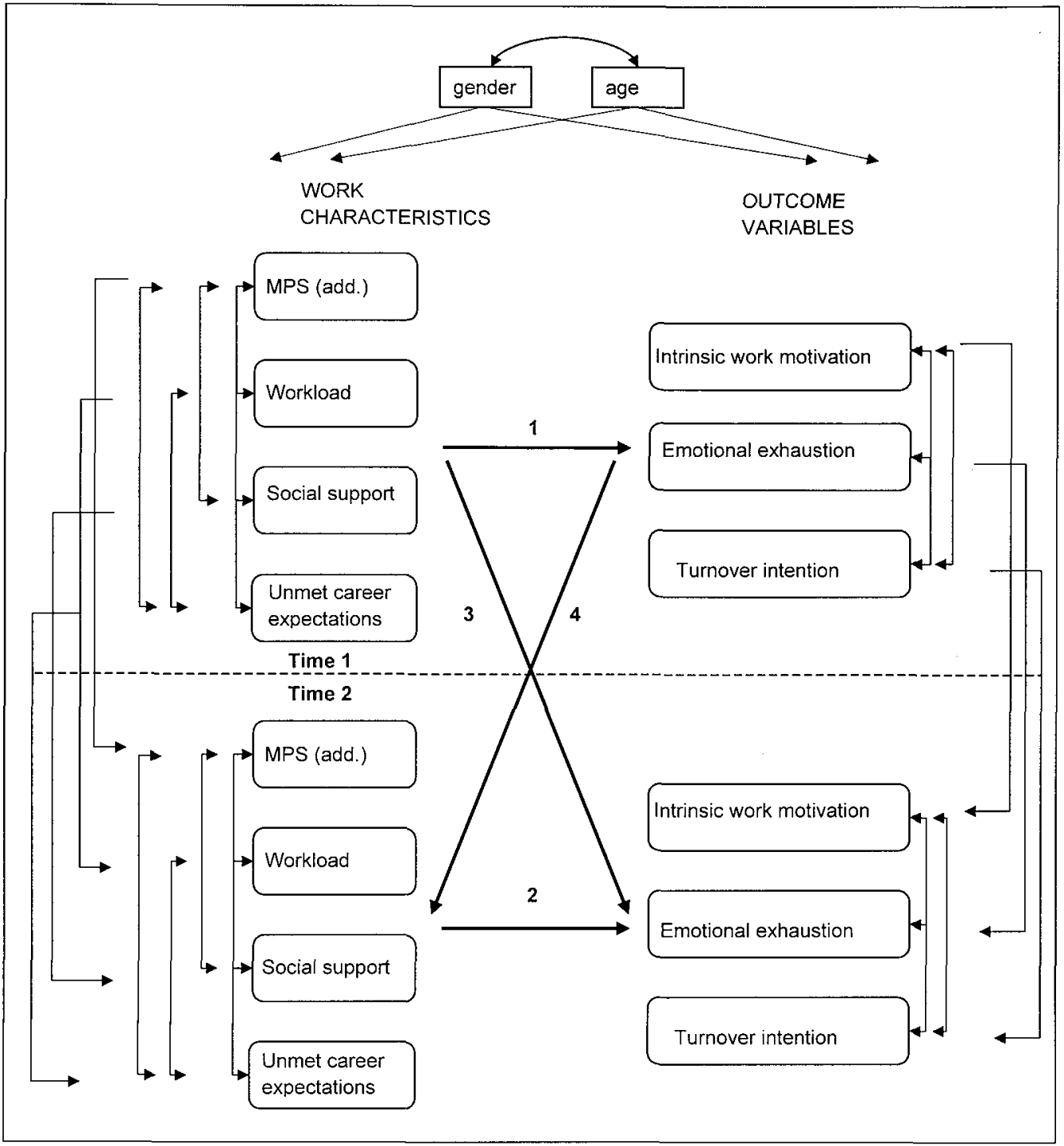

Figure 3.2 Cross-lagged structural panel model

By means of SEM (using maximum likelihood estimation) it is possible to test the fit of this model. More specifically, it is possible to test a sequence of competing, nested structural equation models by means of the chi-square difference test discussed previously (cf. Hom \& Griffith, 1991; Jöreskog \& Sörbom, 1993b; De Jonge et al., 2001):

M1: a model with synchronous paths (arrows 1 and 2 in Figure 3.2) and temporal stabilities, but without cross-lagged structural paths. 
M2: a model that is identical to M1, but also includes cross-lagged paths from time 1 work characteristics to time 2 outcome variables (i.e., regular causation, reflected by arrow 3 in Figure 3.2).

M3: a model that is identical to M1, but also includes cross-lagged paths from time 1 outcome variables to time 2 work characteristics (i.e., reverse causation, reflected by arrow 4 in Figure 3.2).

M4: a model that is identical to M1, but also includes both cross-lagged patterns (i.e., reciprocal causation, reflected by arrows 3 and 4 in Figure 3.2).

If M2 turns out to be the best model, there is considered to be support for regular causation. If $\mathrm{M} 3$ appears to be the best model, there is support for reverse causation, and if M4 is the best model, there is support for reciprocal causation. In the case M4 is the best model, it is possible to examine which causal pattern (i.e., regular or reverse causation) has predominance. In order to do so, one specifies an extra model (M5) in which both cross-lagged patterns are constrained to be equal. If the chi-square difference test between the model with (M5) and without equality constraints (M4) is significant, M5 is not better than M4: the patterns are not equal: one of them is causally predominant. In this case the practical fit indices of models M2 and M3 can be examined in order to find support for one of the two causal patterns.

In addition to the investigation of causal predominance, it is also informative to look at specific cross-lagged effects and measures of strength of individual relationships (betas) in this longitudinal structural equation model (cf. De Jonge et al., 2001; Rogosa, 1980).

\subsubsection{Testing interaction effects using SEM}

In SEM, there are several ways to test interaction effects. In the present study we used two techniques: adding multiplicative interaction terms to the structural equation model (see, for instance, Schumacker \& Lomax, 1996), and subgroup analysis (see, for instance, Jaccard \& Wan, 1996).

\section{Adding multiplicative interaction terms}

In order to test the interactions in the cross-sectional part of the study, product terms can be added to a structural equation model (personal characteristic * work characteristic) (cf. Kenny \& Judd, 1984; Schumacker \& Lomax, 1996). Since the correlations of the product terms with their component predictors are usually rather high, all predictor variables should be centered in order to reduce multicollinearity (cf. Aiken \& West, 1991; Kleinbaum, Kupper \& Muller, 1988). This technique permits models with additive effects of the personal characteristics to be tested against models with interaction effects, by means of the chi-square difference test for nested models (Bentler \& Bonett, 1980). More specifically, three nested models can be compared: $M 1$ (basic model), which includes only relationships between work 
characteristics and outcome variables; $M 2$ (additive model), which also includes a direct relationship between the personal characteristics under study and the outcome variable it is hypothesized to predict; and $M 3$ (interactive model), which is similar to M2, but also includes the interactive relationship(s). Finally, in order to interpret an interaction effect (direction), it is suggested to plot the regression equations (Aiken \& West, 1991; Cohen \& Cohen, 1983).

\section{Subgroup analysis}

In order to test interactive effects of the personal characteristics in the longitudinal part of the study, it does not seem feasible to use multiplicative interaction terms: it is theoretically hardly defensible to specify structural paths between time 1 outcome variables, and time 2 interaction terms. In other words, to test causal relationships, a first order model, that is a model with only linear effects over time, seems most appropriate (see also De Jonge, 1995). Therefore, we used subgroup analyses to test the longitudinal interaction effects of the personal characteristics (see Jaccard \& Wan, 1996; Schumacker \& Lomax, 1996). Subgroup analysis consists of the following procedure. In the first step, a multi-group procedure is performed in which LISREL derives parameter estimates for two groups: a group scoring high on a certain personal characteristic, and a group scoring low on this characteristic. Before proceeding to the second step, it is advisable to have a model with an adequate fit at step 1. The step 1 analysis provides perspectives on how well the model fits the data when LISREL is permitted to estimate coefficients in each group separately and without constraints across groups. In step 2, however, the constraint that a specific path (i.e., the path that is hypothesized to be moderated by the personal characteristic under study) is invariant over the high and the low scoring group is imposed. If this constraint adversely affects model fit, there is supposed to be an interaction effect. By means of the chi-square difference test it is possible to test whether the worsening of the model fit is significant.

\subsection{Summary}

In the present chapter, several parts of the research method have been discussed. The research design of this study includes a cross-sectional design (i.e., one measurement point) as well as a longitudinal panel design (i.e., two measurement points with a time interval of one year). We included two study populations: bank employees working at the local offices of a large Dutch bank (a random sample of 500 employees was drawn from this population) and teachers working at an education center for 16-18 years olds and adults.

At time 1 , approximately $50 \%$ of both samples responded. These employees were all included in the cross-sectional part of the study. At time 2, we also had a response rate of about $50 \%$. It appeared that about $30 \%$ of the initial sample responded at both time 1 and time 2 . These employees are called the panel group, and were included in the longitudinal part of the study. Comparison of the dropouts with the panel group 
showed that, with regard to demographic characteristics, the differences between these two groups were not very large. In chapter 5 we will perform a more extensive non-response analysis.

Furthermore, we discussed the measurement instruments we used to measure the variables under study. Generally, these measurement instruments have proven to be valid and reliable in this and/or in previous studies. Finally, we discussed some general issues with regard to the statistical techniques we used to analyze the data from both the cross-sectional and the longitudinal parts of this study (i.e., Structural Equation Modeling (SEM), multi-sample analysis using SEM, testing cross-lagged panel designs using SEM, and testing interaction effects using SEM). 


\section{Chapter 4}

\section{Cross-sectional analyses}

Parts of section 4.2 have been published under the title:

Houkes, I., Janssen, P.P.M., Jonge, J. de \& Nijhuis, F.J.N. (2001). Specific relationships between work characteristics and intrinsic work motivation, burnout and turnover intention: A multi-sample analysis. European Journal of Work and Organizational Psychology, 10, 1-23.

Parts of section 4.3 have been published under the title:

Houkes, I., Janssen, P.P.M., Jonge, J. de, \& Nijhuis, F.J.N. (2001). Work and individual determinants of intrinsic work motivation, emotional exhaustion and turnover intention. A multi-sample analysis. International Journal of Stress Management, 8, 257-283. 

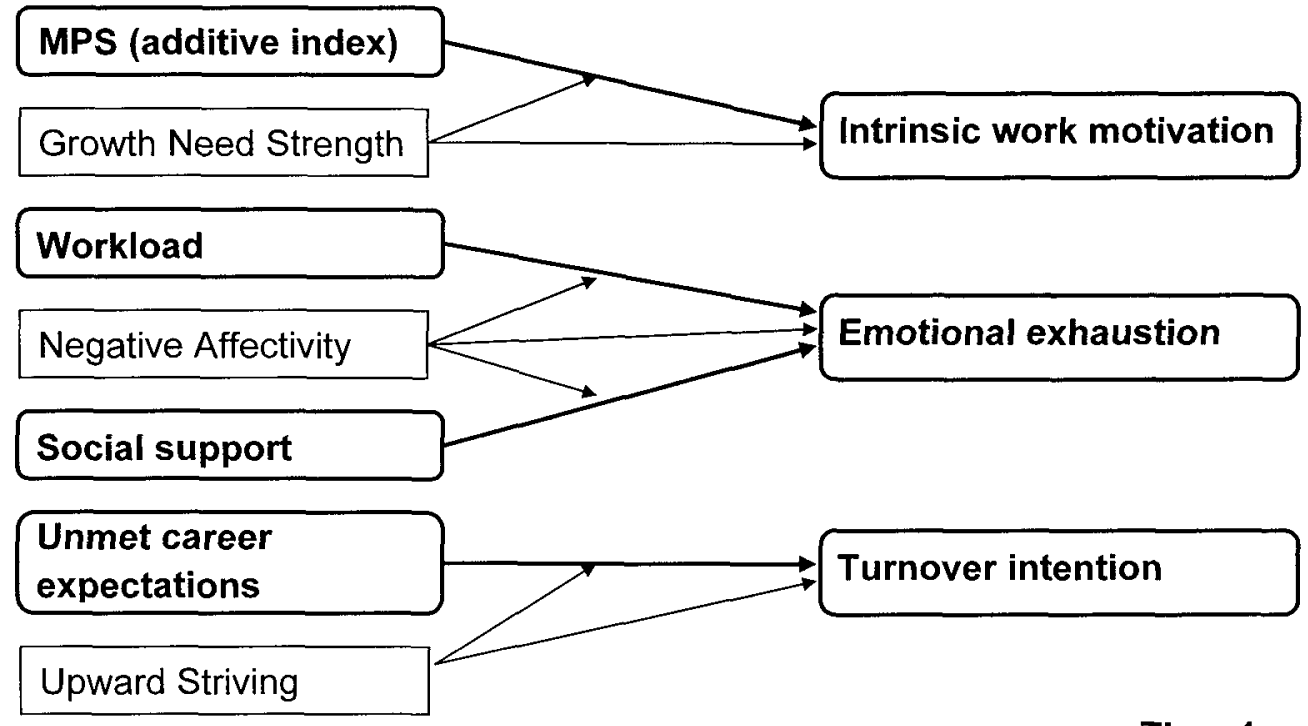

Time 1

Time 2
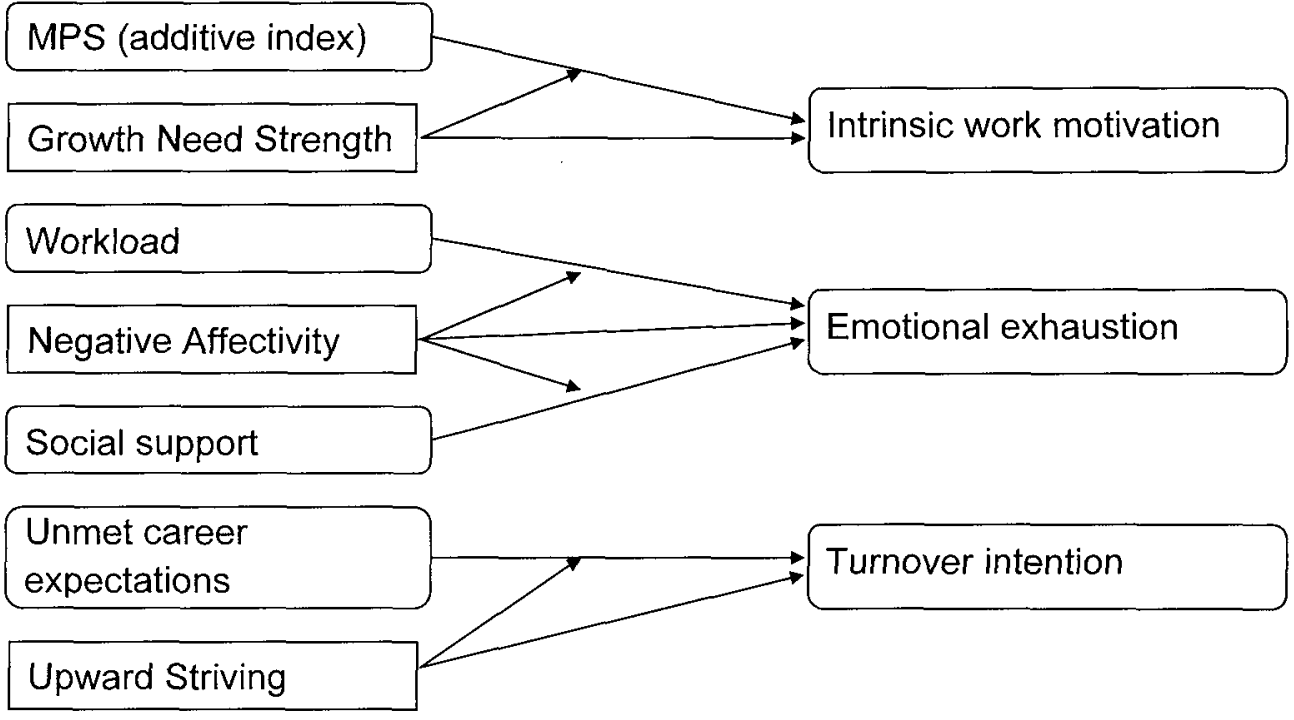

Figure I Schematic representation of the part of the research model that is under investigation in section 4.2 


\subsection{Introduction}

This chapter presents the results of the cross-sectional part of this study. In the analyses described in this chapter, we will use the data of all bank employees and teachers who participated in the first measurement (April 1998; see also chapter 3).

This chapter will be structured as follows. Section 4.2 addresses the background and results of the cross-sectional validation of the proposed pattern of specific relationships between work characteristics and outcome variables in multiple samples. The background and results of the cross-sectional analysis of the influence of the personal characteristics growth need strength, negative affectivity and upward striving on the these outcome variables, and on the relationships between work characteristics and outcome variables, are described in section 4.3.

Section 4.4, finally, presents the main conclusions of the cross-sectional part of this study, and summarizes the contents of this chapter.

\subsection{Specific relationships between work characteristics and intrinsic work motivation, emotional exhaustion and turnover intention: a multi-sample analysis}

\subsubsection{Hypotheses, background and data analyses}

In this section, we will present the results of the cross-sectional analyses regarding research question 1; the issue of specific relationships between the work characteristics (i.e., task characteristics, workload, social support and unmet career expectations) on the one hand, and the outcome variables (i.e., intrinsic work motivation, emotional exhaustion and turnover intention) on the other. Figure 2.6 shows the proposed pattern of relationships between these work characteristics and outcome variables.

Figure I shows a schematic representation of all variables measured in this entire study (at both time 1 and time 2). The part of this research model that is under investigation in the present section is printed bold.

The pattern of relationship depicted in Figure 2.6, was preliminary validated by Janssen, De Jonge and Bakker (1999) (see also chapter 2). Janssen and his colleagues, however, tested the model in only one, relatively small sample. In chapter 3 , we argued that a test of this model in multiple, well-defined samples seems appropriate (see, for instance, Kristensen, 1995, 1996; Lave \& March, 1980). Hence, we selected two study populations: bank employees and teachers.

In chapter 3, we formulated three hypotheses with regard to the cross-sectional analyses regarding specific relationships between work characteristics and psychological outcome variables: 
1a. Intrinsic work motivation is primarily and positively related to task characteristics (combined in the additive Motivating Potential Score);

2a. Emotional exhaustion is primarily related to workload (i.e., positively) and social support (i.e., negatively);

3a. Turnover intention is primarily and positively related to unmet career expectations.

With regard to the test of these hypotheses in two samples, we formulated an extra, methodological hypothesis:

11. The proposed pattern of relationships between work characteristics and psychological outcome variables holds over different occupational groups (i.e., bank employees and teachers).

In the analyses and results described in this section, 245 bank employees and 362 teachers were included. Table 3.1 represents some demographic characteristics of both samples. Table 3.2 shows the reliability coefficients of the measurement instruments.

In order to test the hypotheses, we applied multi-sample analysis (MSA) using Structural Equation Modeling (Jöreskog \& Sörbom, 1993b; Schumacker \& Lomax, 1996). MSA is particularly useful to test all these hypotheses simultaneously (see also section 3.6.3). In line with suggestions of Byrne (1991, 1994, 1998) we first tested and fitted the proposed pattern of relationships for each sample separately (i.e., a baseline model). In the second step of analyses, we tested for invariance.

\subsubsection{Results}

\subsubsection{Preliminary analyses}

Prior to the multi-sample analysis, several preliminary analyses were carried out in order to gain a first insight into the data. Accordingly, the means, standard deviations, percentage of employees scoring negative on each variable, and zero-order Pearson correlations of the model variables were calculated for both samples (see Tables 4.1 and 4.2). 
Table 4.1 Means (M), standard deviations (SD), and percentage of employees scoring negative (\% neg.) of sample 1 (bank employees) and sample 2 (teachers) in the cross-sectional analyses

\begin{tabular}{lcccccc}
\hline Variables (range) & \multicolumn{3}{c}{ Sample 1 $(N=245)$} & \multicolumn{3}{c}{ Sample 2 $(N=362)$} \\
\hline & $M$ & $S D$ & $\%$ neg. $^{2}$ & $M$ & SD & $\%$ neg. $^{{ }^{a}}$ \\
\hline 1. MPS (additive index) (1-7) & 5.22 & .63 & 3.7 & 5.03 & .66 & 9.6 \\
2. Workload (1-5) & 3.35 & .59 & 44.0 & 3.38 & .62 & 46.5 \\
3. Social support (1-4) & 3.13 & .37 & 6.4 & 2.97 & .43 & 14.7 \\
4. Unmet career expectations (1-5) & 3.37 & .78 & 33.1 & 3.32 & .78 & 43.9 \\
5. Intrinsic work motivation (1-7) & 5.99 & .59 & .4 & 6.03 & .63 & .5 \\
6. Emotional exhaustion (1-7) & 2.57 & 1.03 & 5.6 & 3.06 & 1.20 & 14.7 \\
7. Turnover intention (1-2) & 1.31 & .31 & 12.4 & 1.30 & .33 & 13.8 \\
\hline
\end{tabular}

${ }^{a}$ In order to determine whether a respondent scores negative on a scale, we specified cut off points. These cut off points were specified as follows: 1.5 for a $1-2$ scale, 2.5 for a $1-4$ scale, 2.5 and 3.5 for a $1-5$ scale, and 3.5 and 4.5 for a 1-7 scale.

${ }^{b}$ For these variables a relatively high mean score should be interpreted positively, for the other variables a relatively high mean score should be interpreted negatively.

Table 4.1 shows that the mean scores on the study variables do not differ much between the samples. In order to provide some information about the possible existence of problems in the working situation, we reported the percentage of employees scoring negative on the study variables. In this regard, it is difficult to establish cut off points (cf. Schaufeli \& Enzmann, 1998). When is there really a problem? A rule of thumb is that a problem exists when $20 \%$ or more of the employees scores negative. From 15\% and higher, a problem seems to be developing. However, there are cases in which $1 \%$ of the employees scoring negative, is already too high (cf. Janssen, Nijhuis, Lourijsen \& Schaufeli, 1996). Table 4.1 shows that in sample 1 (bank employees), a high workload and a high level of unmet career expectations are the most salient problems in the working situation. Turnover intention is not a problem yet, but is getting close. In sample 2 (teachers), the level of workload, and the level of unmet career expectations are problematic. Social support, emotional exhaustion and turnover intention are almost problematic. Note that with regard to emotional exhaustion clinical cut off points have been proposed also (Schaufeli \& Van Dierendonck, 1995, 2000; Schaufeli \& Enzmann, 1998). With regard to the use of these cut off points, Schaufeli and Enzmann (1998) argue that they should be used with caution, and that they are specific for nations.

Comparison of our results with these clinical cut off points, shows that $20.6 \%$ of the bank employees scores high, and $5.2 \%$ scores very high on emotional exhaustion. For teachers, these percentages are $31.6 \%$ and $6.7 \%$, respectively. We may conclude from these figures that the cut off points we have applied in Table 4.1 are rather conservative with regard to emotional exhaustion. 
Table 4.2 Zero-order Pearson correlations of the study variables in the crosssectional analyses for sample 1 (bank employees, $N=245$, left-lower corner) and sample 2 (teachers, $N=362$, right-upper corner)

\begin{tabular}{|c|c|c|c|c|c|c|c|}
\hline Variables & Correlat & & & & & & \\
\hline & 1 & 2 & 3 & 4 & 5 & 6 & 7 \\
\hline 1. MPS (additive index) & -- & -.08 & $36^{\star \star}$ & -.08 & $.19^{\star \star}$ & $-.34^{* *}$ & $-.18^{\star \star}$ \\
\hline 2. Workload & .09 & -- & $-.25^{\star \star}$ & .10 & .10 & $.44^{* *}$ & .06 \\
\hline 3. Social support & $.16^{\star}$ & $-.14^{*}$ & -. & $-.18^{\star \star}$ & .04 & $-.39^{\star \star}$ & $-.24^{\star \star}$ \\
\hline 4. Unmet career expectations & $.14^{*}$ & $.15^{\star}$ & -.11 & -- & .04 & .03 & $28^{* \star}$ \\
\hline 5. Intrinsic work motivation & $.22^{\star \star}$ & $.16^{\star}$ & .03 & -.00 & - & .04 & $-.13^{*}$ \\
\hline 6. Emotional exhaustion & -.07 & $.52^{\star \star}$ & $-.25^{\star \star}$ & .01 & .06 & -- & $.16^{* \star}$ \\
\hline 7. Turnover intention & $-.13^{*}$ & .05 & $-.24^{* *}$ & $.22^{\star *}$ & $-.14^{*}$ & .09 & -- \\
\hline
\end{tabular}

Note. Correlations that reflect the hypothesized pattern of relationships (see Figure 2.6) are printed bold. Missing values were handled by listwise deletion.

${ }^{*} p \leq .05,{ }^{* *} p \leq .01$.

Table 4.2 suggests that the hypothesized pattern of relationships between work characteristics and psychological outcome variables (printed bold) largely holds true in both samples, and that the relationships point in the expected direction. That is, all relationships hypothesized had significant correlations at an alpha level of .01. Some unpredicted relationships were found, however. In both samples, the relationship between social support and turnover intention was significant. In sample 2, the relationship between the additive MPS index and emotional exhaustion was significant, and rather strong also.

These correlational analyses only provide insight in the bivariate relationships between the variables. In order to test the hypothesized pattern of relationships simultaneously, we applied multi-sample analysis.

\subsubsection{Multi-sample analysis}

As was suggested by Byrne $(1991,1994)$, we first tested and fitted a baseline structural equation model for each sample separately. Next, we tested for invariance of the proposed pattern of relationships over two samples.

\section{Testing and fitting a baseline model for each sample separately (hypotheses 1a to $3 a)$}

In both samples, we introduced gender and age as potential confounders. Consequently, these two variables were labeled as exogenous (see Bollen, 1989, p. 126) and all other variables were labeled as endogenous (i.e., the four work characteristics and the three outcome variables). We simplified the covariance structure by assuming that the latent and observed variables were identical (see also section 3.6.2). The error variances of the endogenous variables themselves and the error variances regarding the relationships between the three endogenous variables were set free. This decision was made because the model is probably not exhaustive (MacCallum et al., 1993). The endogenous variables thus might in part be predicted by (related) variables that are not taken into account (MacCallum et al., 1993; cf. Schumacker \& Lomax, 1996). Furthermore, the structural paths between the work 
characteristics and the outcome variables (beta-matrix), were specified according to hypotheses $1 \mathrm{a}, 2 \mathrm{a}$ and $3 \mathrm{a}$.

\section{Sample 1 (bank employees)}

The results of the baseline analysis of sample 1 are shown in Table 4.3 (basic model: relationships were specified according to hypotheses $1 \mathrm{a}$ to $3 \mathrm{a}$ ). It can be seen that this model did not fit. The chi-square statistic was significant, and the practical fit indices were not within acceptable limits. Inspection of the $t$-values of the structural paths revealed that all specified relationships between work characteristics and outcome variables were significant. Although the significance of the proposed relationships implies that the expected pattern of relationships seems to be valid, several improvements of the overall model appear to be necessary. Therefore, we examined the modification indices provided by LISREL. It appeared that the modification index of the path between social support and turnover intention was highest (modification index is 19.32). The preliminary analyses discussed previously have already indicated that the bivariate correlation between social support and turnover intention was significant. This relationship has been reported before, although not systematically (see, for instance, McFadden \& Demetriou, 1993; Stremmel, 1991). Nonetheless, we decided to modify the model according to this suggestion and performed another LISREL analysis. Table 4.3 shows the results of this analysis (modified model 1a). It can be concluded that the model fit improved considerably. However, chi-square was still significant and especially the NNFI was somewhat low. Now LISREL suggests to add a path between workload and intrinsic work motivation (modification index is 7.02). When we add this relationship to the model, the model fit is good (modified model $1 \mathrm{~b}$; see Table 4.3). In addition, all modeled relationships are significant. We will discuss the additional relationships more extensively in section 6.4.1.

Table 4.3 Fit measures of the baseline analysis in sample 1 (bank employees)

\begin{tabular}{lcccccc}
\hline Fit measures & $\chi^{2}(d f)$ & AGFI & RMSEA & AlC & NNFI & CFI \\
\hline Basic model & $36.94^{*}(8)$ & .82 & .12 & 109.47 & .47 & .88 \\
Modified model (1a) & $16.62^{*}(7)$ & .90 & .08 & 92.37 & .80 & .96 \\
Modified model (1b) & $9.43(6)$ & .94 & .05 & 87.29 & .92 & .99 \\
\hline
\end{tabular}

${ }^{\star} p \leq .05$

In order to examine the robustness of a structural equation model, generally a crossvalidation procedure is recommended (i.e., splitting the sample in two subsamples and replicating the findings of the first subsample in the second subsample; cf. Schumacker \& Lomax, 1996). In the present study, we already use multiple samples. However, in section 3.6 we have described a single sample cross validation index: the Expected Cross Validation Index (ECVI) (Browne \& Cudeck, 1989). This index can be used to examine the stability of estimates and models within a single sample of data. The model that results in the smallest ECVI-value should be the most stable in the population. The ECVI of modified model $1 \mathrm{~b}$ is .36 , which is lower than the ECVIs of the other models $(E C V I s>.38)$ and of the saturated model $(E C V I=.38$; a saturated 
model is a model in which all possible effects are introduced and in which the number of degrees of freedom is equal to zero: the number of covariances is equal to the number of parameters that have to be estimated; see Saris \& Stronkhorst, 1984). Thus, model $1 b$ seems to be the most stable model in this sample.

\section{Sample 2 (teachers)}

The results of the baseline analyses of sample 2 are shown in Table 4.4 .

Table 4.4 Fit measures of the baseline analysis in sample 2 (teachers)

\begin{tabular}{lcccccc}
\hline Fit measures & $\chi^{2}(d f)$ & AGFI & RMSEA & AIC & NNFI & CFI \\
\hline Basic model & $54.52^{\star}(8)$ & .82 & .13 & 126.58 & .44 & .88 \\
Modified model (2a) & $32.27^{\star}(7)$ & .88 & .10 & 107.44 & .65 & .93 \\
Modified model (2b) & $14.65^{\star}(6)$ & .93 & .07 & 92.51 & .86 & .98 \\
Modified model (2c) & $7.95(5)$ & .96 & .04 & 87.91 & .94 & .99 \\
\hline
\end{tabular}

${ }^{*} p \leq .05$.

It can be concluded from Table 4.4 that the model fit of the basic model (i.e., relationships are specified according to hypothesis 1a to 3a) was statistically not acceptable (the chi-square was significant, and especially the NNFI was rather low). Inspection of the $t$-values of the structural paths indicated, however, that all specified relationships were significant. Thus, the basic pattern of relationships also seems to be valid in this sample. Again, LISREL provides some suggestions to improve the model fit. The largest modification index concerned the relationship between the additive MPS index and emotional exhaustion (modification index is 21.17). Adding this path to the model yielded the fit indices as shown in Table 4.4 (modified model 2a). It can be concluded that the model fit has increased substantially. However, as in sample 1, the chi-square statistic and the NNFI were not satisfying. Inspection of the LISREL output revealed that the model fit could still improve when the relationship between social support and turnover intention was added to the model (modification index is 17.07). Table 4.4 (modified model $2 \mathrm{~b}$ ) shows that most fit indices have improved to adequate values after this modification. However, it was still possible to improve the model fit (modification index of the relationship between workload and intrinsic work motivation is 6.60). When this relationship was added to the model, the model fit was good (modified model $2 \mathrm{c}$ ). Although all modeled relationships were significant, the latter relationship between workload and intrinsic work motivation was not very strong (beta coefficient is .14; all other beta coefficients were higher than .20). The ECVI of model $2 \mathrm{c}$ was .25, which was lower than the ECVIs of the other models $(E C V I s>.26)$ and the $E C V I$ of the saturated model $(E C V I=.26)$. Hence, model $2 \mathrm{C}$ appears to have the best model fit, and is the most stable model in this sample.

In sum, these baseline analyses in both samples separately have indicated that the proposed pattern of relationships between work characteristics and outcome variables, as it is formulated in hypotheses $1 \mathrm{a}$ to $3 \mathrm{a}$, seems to be valid. All these relationships have significant beta coefficients in the structural equation models. At the 
same time, in both samples, several relationships had to be added in order to acquire optimal model fit.

In order to find evidence for hypothesis 11 (i.e., "The proposed pattern of relationships between work characteristics and psychological outcome variables holds over different occupational groups"), we will continue testing for invariance of this pattern of relationships.

\section{Testing for invariance (hypothesis 11)}

Following the suggestions of Byrne $(1991,1994,1998)$, our next step was to test for invariance of the proposed pattern of relationships across two samples. Therefore, we performed multi-sample analysis in which we compared three nested models by means of the chi-square difference test (cf. Bentler \& Bonett, 1980; Jöreskog \& Sörbom, 1993b). According to Byrne (1991, 1994), testing for invariance involves specifying a model in which certain parameters are constrained to be equal across groups and then comparing that model with a less restrictive model in which these parameters are free to take on any value. More specifically, we compared three nested models:

$M 1$ (invariant, basic model): the basic pattern of relationships as formulated in hypotheses 1a to $3 a$ is specified as invariant (i.e., relationships have the same strength and direction in both samples) across the two samples. No additional relationships are specified.

M2 (invariant, modified model): the basic pattern of relationships as formulated in hypotheses $1 a$ to $3 a$ is specified as invariant (i.e., relationships have the same strength and direction in both samples) across the two samples. Furthermore, the relationship between social support and turnover intention is specified as invariant across the two samples. The other additional relationships we found in the first step are specified for each sample separately (i.e., in sample 1 we specified a relationship between workload and intrinsic work motivation, and in sample 2 we specified a relationship between the additive MPS index and emotional exhaustion). We decided not to specify the additional relationship between workload and intrinsic work motivation in sample 2, because we aim to find a model that is as parsimonious as possible. Moreover, model $2 b$ proved to have several acceptable fit indices in sample 2. Thus, the test of invariance concerns both the basic pattern of relationships and the relationship between social support and turnover intention. We decided to include the latter relationship in the test of invariance, because this relationship emerged in both samples in the baseline analyses, and there exists some theoretical and empirical evidence for this relationship (e.g., Francis-Felsen et al., 1996; Stremmel, 1991). This procedure is in line with Byrne (1994), who suggests that relationships that are common for multiple groups should be included in a test of invariance. Accordingly, we considered the other additional relationships as sample-specific and did not include them in the test of invariance. 
M3 (non-invariant, modified model): the basic pattern of relationships as formulated in hypotheses $1 \mathrm{a}$ to $3 \mathrm{a}$, and the relationship between social support and turnover intention are specified as non-invariant across the two samples. The other two additional relationships we found in the first step are specified for each sample separately. Hence, M3 is the least restrictive model.

The results of these model comparisons are shown in Table 4.5.

Table 4.5 Fit measures and chi-square difference tests of the nested structural equation models in the multi-sample analysis

\begin{tabular}{lccccc}
\hline Model & $\chi^{2}$ & $d f$ & comparison & $\Delta \chi^{2}$ & $d f$ \\
\hline Invariant model, basic (M1) & $95.24^{*}$ & 20 & & & \\
Invariant model, modified (M2) & 27.48 & 17 & M1 vs. M2 & $67.76^{*}$ & 3 \\
Non-invariant model, modified (M3) & $24.08^{*}$ & 12 & M2 vs. M3 & 3.40 & 5 \\
\hline Model & AGFI & RMSEA & AlC & NNFI & CFI \\
\hline Invariant model, basic (M1) & .93 & .11 & 231.53 & .57 & .88 \\
Invariant model, modified (M2) & .97 & .05 & 173.09 & .93 & .98 \\
Non-invariant model, modified (M3) & .96 & .06 & 179.80 & .88 & .98 \\
\hline
\end{tabular}

${ }^{*} p \leq .05$.

Let us first consider M1 (invariant, basic model) and M2 (invariant, modified model). It appears from Table 4.5 that the difference in chi-square between M1 and M2 was significant, which means that $M 2$ better accounts for the data than $M 1$. The modifications of the model (in the form of additional paths in both samples) appear to improve the model fit significantly in this MSA. The difference in chi-square between M2 (invariant, modified model) and M3 (non-invariant, modified model) was not significant, which means that $M 3$ does not fit better than $M 2$. We conclude from these results that $\mathrm{M} 2$ shows the best combination of model fit and parsimony of the three competing models: the proposed basic pattern of relationships and the relationship between social support and turnover intention are invariant across the two samples, but additional sample-specific relationships have to be added in order to reach optimal model fit (this, however, decreases parsimony). Table 4.5 further presents the practical fit measures of the three nested models. In general, M2 also has the best fit when these measures are taken into account (i.e., AGFI and NNFI are highest, and RMSEA and AIC are lowest). Figure 4.1 shows the modified structural equation models for sample 1 and sample 2 simultaneously (i.e., M2: common metric standardized solution). 


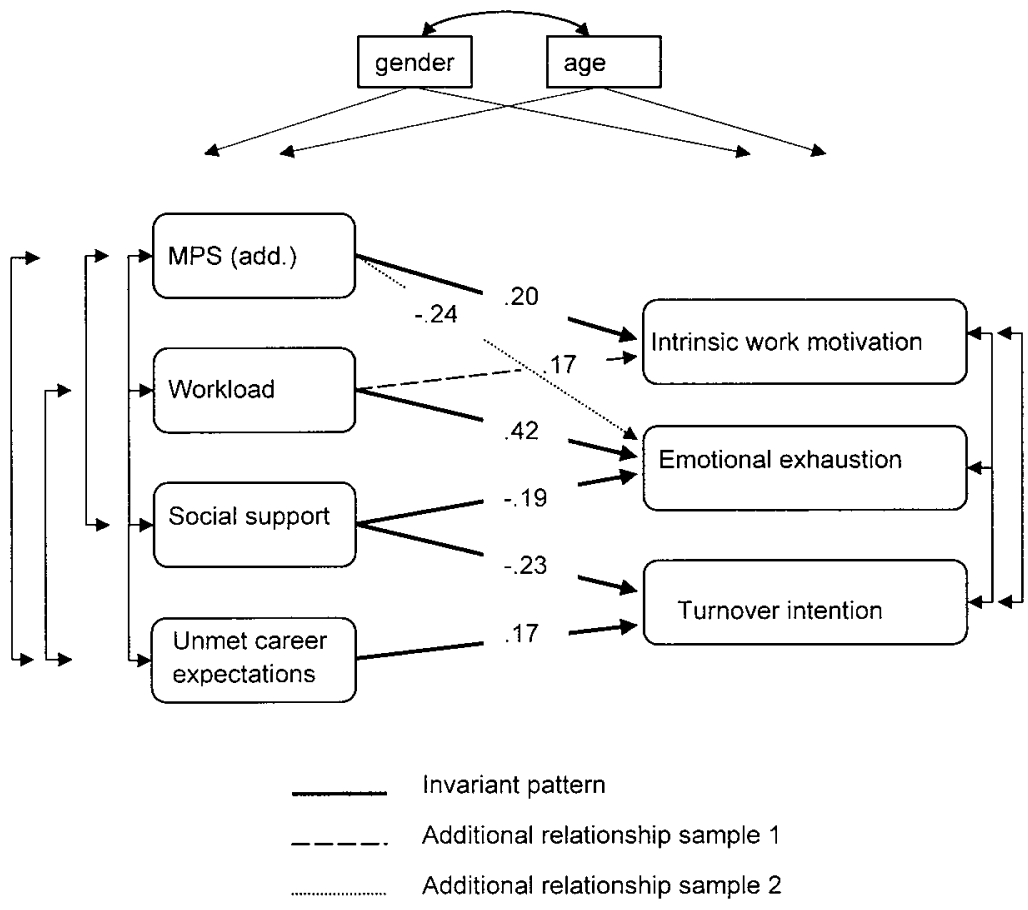

Figure 4.1 Final structural equation model (M2) for sample 1 (bank employees, $N=$ 245) and sample 2 (teachers, $N=362$ )

It can be concluded from Figure 4.1 that all modeled relationships are significant and point in the expected direction. The higher the Motivating Potential Score (additive index) of a job, the more employees are intrinsically motivated to perform well. in addition, both a high workload, and a low level of social support, lead to high levels of emotional exhaustion, and finally, the higher the level of unmet career expectations, the higher the level of turnover intention. These relationships appear to be invariant across our two samples. That is, they have the same strength and direction among bank employees and teachers. These results confirm hypotheses 1a to $3 \mathrm{a}$, and hypothesis 11. Apparently, the proposed specific pattern of relationships between work characteristics and outcome variables is valid in multiple samples.

In addition, however, we found two additional relationships in both samples. For instance, we found in both samples that turnover intention is not only related to unmet career expectations, but also to social support: the lower the level of social support, the higher the level of turnover intention. Moreover, the best model in terms of model fit and parsimony proved to be the model in which the basic pattern of relationships and the relationship between social support and turnover intention were specified as 
invariant, and the other two additional relationships were specified for each sample separately. These additional relationships will be discussed in chapter 6 .

Now that we have found evidence for the proposed pattern of relationships between work characteristics and outcome variables, we can continue examining the influence of personal characteristics on this pattern of relationships and on the psychological outcome variables. In the next section we will address this issue, and present the cross-sectional analyses of the influence of the personal characteristics.

\subsection{Work and individual determinants of intrinsic work motivation, emotional exhaustion and turnover intention: a multi-sample analysis}

\subsubsection{Hypotheses, background and data analyses}

In the present section we will present the results of the cross-sectional analyses regarding research question 2 . We aim to test the specific influence of personal characteristics on the proposed pattern of relationships between work characteristics and psychological outcome variables (i.e., moderating effect) as well as directly on these psychological outcome variables (i.e., additive effect, over and above the effects of work characteristics).

Figure II shows schematically which part of the research model is under investigation in the present section.

In chapter 3, we formulated seven hypotheses with regard to the cross-sectional analyses of the specific influence of personal characteristics:

4a. Growth need strength has a positive relationship with intrinsic work motivation, in addition to the relationship between task characteristics (combined in the additive MPS) and intrinsic work motivation.

5a. Growth need strength moderates the relationship between task characteristics (combined in the additive MPS) and intrinsic work motivation (the higher the level of growth need strength, the stronger the relationship between task characteristics and intrinsic work motivation).

6a. Negative affectivity has a positive relationship with emotional exhaustion, in addition to the relationships between workload and social support on the one hand and emotional exhaustion on the other.

7a. Negative affectivity moderates the relationship between workload and emotional exhaustion (the higher the level of negative affectivity, the stronger the relationship between workload and emotional exhaustion).

8a. Negative affectivity moderates the relationship between social support and emotional exhaustion (the higher the level of negative affectivity, the stronger the relationship between social support and emotional exhaustion). 


\section{MPS (additive index)}

Growth Need Strength

Intrinsic work motivation

\section{Workload}

Negative Affectivity

Social support

\section{Unmet career \\ expectations}

Upward Striving
Emotional exhaustion

Time 1

Time 2
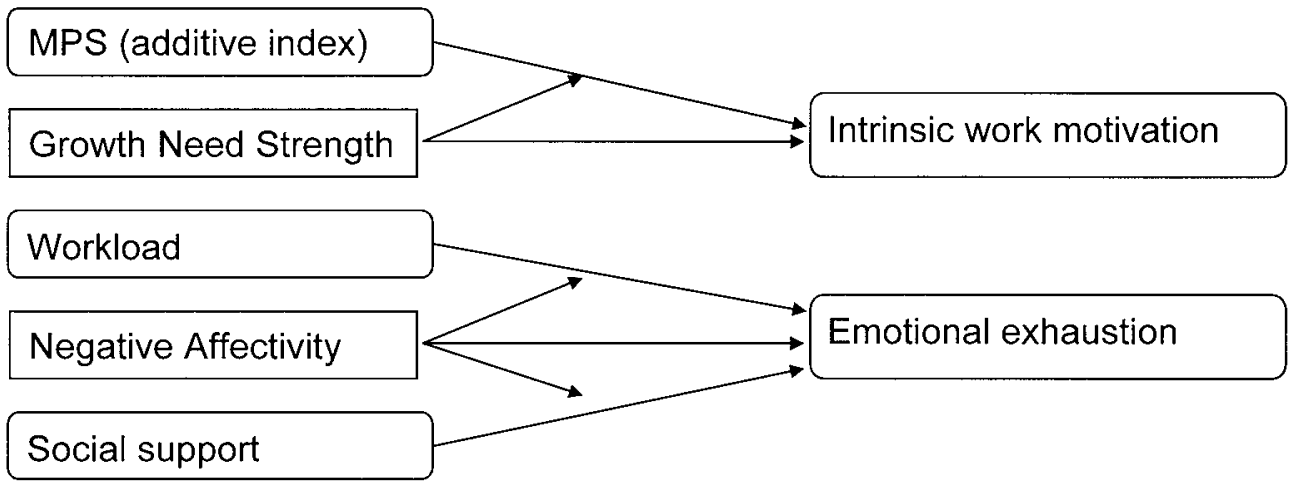

Unmet career
expectations

Upward Striving

Figure II Schematic representation of the part of the research model that is under investigation in section 4.3 
9a. Upward striving has a positive relationship with turnover intention, in addition to the relationship between unmet career expectations and turnover intention.

10a. Upward striving moderates the relationship between unmet career expectations and turnover intention (the higher the level of upward striving, the stronger the relationship between unmet career expectations and turnover intention).

With regard to the test of these hypotheses in two samples, we formulated an extra, methodological hypothesis.

12. The proposed pattern of relationships between personal characteristics, work characteristics and psychological outcome variables holds over different occupational groups (i.e., bank employees and teachers).

In the analyses described in this section, 243 bank employees and 361 teachers were included. These figures are slightly lower than the numbers in section 4.2 , due to listwise deletion of missing values in all analyses. Table 3.2 shows the reliability coefficients of the measurement instruments we used.

Generally, in order to test the hypotheses, we applied multi-sample analysis (MSA) using SEM (Jöreskog \& Sörbom, 1993b; Schumacker \& Lomax, 1996). In order to test the moderating effects of the personal characteristics, we added product terms to the structural equation models (e.g., Schumacker \& Lomax, 1996; see also section 3.6.5). Prior to testing the additive and moderating effects of the personal characteristics, we performed several preliminary analyses.

\subsubsection{Results}

\subsubsection{Preliminary Analyses}

The means, standard deviations, and percentages of employees scoring negative for the work characteristics and the three psychological outcome variables, are depicted in Table 4.1 (see section 4.2). The means, standard deviations, and percentage of employees scoring negative on the personal characteristics are depicted in Table 4.6, for both sample 1 and sample 2 .

Table 4.6 Means $(M)$, standard deviations (SD), and percentage of employees scoring negative (\% neg.) of sample 1 (bank employees) and sample 2 (teachers) in the cross-sectional analyses of personal characteristics

\begin{tabular}{|c|c|c|c|c|c|c|c|}
\hline \multirow{2}{*}{\multicolumn{2}{|c|}{ Personal characteristics (range) }} & \multicolumn{3}{|c|}{ Sample $1(N=243)$} & \multicolumn{3}{|c|}{ Sample $2(N=361)$} \\
\hline & & $\vec{M}$ & SD & $\%$ neg. $^{2}$ & $M$ & SD & $\%$ neg. $^{a}$ \\
\hline 1. & Growth need strength $(1-7)^{\mathrm{b}}$ & 5.81 & .79 & 2.0 & 5.86 & 71 & 5 \\
\hline 2. & Negative affectivity $(1-5)$ & 2.00 & .60 & 2.4 & 2.25 & 65 & 3.5 \\
\hline 3. & Upward striving $(1-5)^{\mathrm{b}}$ & 3.03 & .49 & 18.3 & 2.77 & 50 & 34.0 \\
\hline
\end{tabular}

\footnotetext{
a In order to determine whether a respondent scores negative on a scale, we specified cut off points. These cut off points were specified as follows: 2.5 and 3.5 for a 1-5 scale, and 3.5 and 4.5 for a 1-7 scale.

b For these variables a relatively high mean score should be interpreted positively, for the other variables a relatively high mean score should be interpreted negatively.
} 
Table 4.6 shows that both bank employees and teachers have rather high scores on the personal characteristic growth need strength, although teachers score higher. Furthermore, it appears that teachers score somewhat higher on negative affectivity than bank employees. Finally, bank employees appear to be more eager for upward mobility than teachers. The percentage of teachers scoring negative on upward striving is rather high, but this might not be conceived of as problematic. Rather, when a considerable part of teachers scores high on upward striving, a problem may ensue, considering the limited possibilities for upward career mobility in teaching (cf. Van Horn et al., 1997).

Table 4.7 shows the correlation matrix (i.e., Pearson correlations) of the variables under study in the present section.

Table 4.7 Zero-order Pearson correlations of the study variables in the crosssectional analyses of personal characteristics for sample 1 (bank employees, $N=243$; left-lower corner) and sample 2 (teachers, $N=362$; right-upper corner)

\begin{tabular}{|c|c|c|c|c|c|c|c|c|c|c|c|}
\hline & \multirow[t]{2}{*}{ Variables } & \multicolumn{10}{|c|}{ Correlations } \\
\hline & & 1 & 2 & 3 & 4 & 5 & 6 & 7 & 8 & 9 & 10 \\
\hline 1. & MPS - additive index & - & -.09 & $.36^{\star \star}$ & -.08 & .08 & $-.32^{\star \star}$ & -.10 & $.19^{* *}$ & $-.34^{\star \star}$ & $-.19^{\star \star}$ \\
\hline 2. & Workload & .09 & -- & $-.25^{\star *}$ & .10 & $.17^{* *}$ & $.30^{\star *}$ & .00 & .10 & $.43^{\star \star}$ & .07 \\
\hline 3. & Social support & $.16^{*}$ & $-.14^{*}$ & -- & $-.18^{\star \star}$ & $-.12^{\star}$ & $.42^{\star \star}$ & -.04 & .04 & $-.40^{\star \star}$ & $-.25^{\star \star}$ \\
\hline 4. & Unmet career expectations & $.14^{\star}$ & $.15^{\star}$ & -.11 & - & $.48^{* *}$ & -.00 & $.37^{* *}$ & .05 & .03 & $.28^{\star *}$ \\
\hline 5. & Growth need strength & $.29^{* *}$ & $.19^{\star *}$ & .01 & $46^{\star \star}$ & - & .01 & $.26^{\star *}$ & $.22^{\star \star}$ & .03 & $.22^{\star x}$ \\
\hline 6. & Negative affectivity & $-.19^{\star \star}$ & $.36^{\star \star}$ & $-.26^{\star *}$ & -01 & -.08 & -- & -.03 & .03 & $.59^{\star \star}$ & $.17^{\star \star}$ \\
\hline 7. & Upward striving & $.20^{\star \star}$ & $.15^{\star}$ & -.06 & $.37^{\star \star}$ & $.35^{\star \star}$ & -.10 & -- & -.04 & -.00 & $.21^{\star \star}$ \\
\hline 8. & Intrinsic work motivation & $.21^{* *}$ & $.16^{*}$ & .03 & -.01 & .08 & .06 & -.04 & -- & .04 & $-.13^{\star}$ \\
\hline 9. & Emotional exhaustion & -.07 & $.52^{\star \star}$ & $-.25^{\star \star}$ & .01 & .02 & $.50^{\star \star}$ & -.02 & .06 & -- & .00 \\
\hline 10. & Turnover intention & -.12 & .05 & $-.24^{\star *}$ & $.23^{\star \star}$ & $.22^{\star \star}$ & $.13^{\star}$ & $.13^{*}$ & $-.14^{\star}$ & .10 & -- \\
\hline
\end{tabular}

Note. Correlations that reflect the hypothesized pattern of relationships are printed bold. Missing values were handled by listwise deletion.

${ }^{*} p \leq .05,{ }^{* *} p \leq .01$.

The results of the correlational analyses (Table 4.7) show that most hypothesized relationships are significant and point in the expected direction, especially in sample 2 (teachers) ${ }^{1}$. With regard to the relationships between personal characteristics and outcome variables, it appears that in sample 1 growth need strength is not significantly correlated with intrinsic work motivation. Growth need strength is, however, significantly correlated with turnover intention. In sample 2, the proposed pattern of relationships is more clear, although in this sample some additional relationships

NOTE

\footnotetext{
${ }^{1}$ Some authors might suggest that part of the relationship between negative affectivity and emotional exhaustion is due to overlap between both constructs (cf. Judge, Erez, \& Thoresen, 2000; Spector et al., 2000). However, the fact that the correlations of the relationship between negative affectivity and emotional exhaustion were not extremely high is inconsistent with this explanation. Furthermore, factor analysis (principle axis factoring with oblique rotation) of the negative affectivity and emotional exhaustion items refuted this possibility for the greater part. A two factor structure emerged in both samples, with negative affectivity and emotional exhaustion each forming clear and distinct factors. This indicates that, although the factors are related, they are not isomorphic.
} 
between personal characteristics and outcome variables were found, for instance, the relationships between growth need strength and turnover intention, and between negative affectivity and turnover intention were significant.

Although the theory and empirical studies discussed in section 2.4, as well as the correlational analyses described above, have provided important clues regarding specific relationships between personal characteristics and outcome variables, they were not conclusive in all respects (for instance, additional relationships were found). Therefore, as a prerequisite to testing the personal characteristics in combination with the work characteristics, we tested a structural equation model that only contained personal characteristics and outcome variables (i.e., testing the direct effects of the personal characteristics). That is, we simplified the structural equation model (see Saris \& Stronkhorst, 1984). This procedure provides the opportunity to gain a clear insight in the unique effects of the personal characteristics on the outcome variables. Only personal characteristics that have a significant relationship with the outcome variables they are hypothesized to predict, will be included in the further analyses. A possible drawback of this procedure, however, might be that the work characteristics and the personal characteristics are mutually correlated, and hence, that their separate contributions to the explained variance of the outcome variables are not completely independent from each other (see also Saris \& Stronkhorst, 1984). This situation has two conceivable effects (cf. Spector et al., 2000). First, work characteristics may inflate the direct relationship between personal characteristics and outcome variables, and as a result, this relationship may be overestimated. In this case, the problem will "solve itself" when work characteristics are included in the further analysis. A second conceivable effect is that the direct relationships between the personal characteristics and outcome variables are attenuated (i.e., underestimated). That is, the correlation between these two variables can be attenuated by the work characteristics (cf. Spector et al., 2000). In this case, the personal characteristics might erroneously be excluded from further analyses.

According to Williams and Brown (1994) (cf. Spector et al., 2000), the relationship between an independent and a dependent variable will be inflated (which is not a serious problem in this study) when the correlation between the work characteristics and the personal characteristics and the correlation between the work characteristic and the outcome, have the same sign. Attenuation will only occur, when the correlation between the work characteristic and the personal characteristic and the correlation between the work characteristic and the outcome, have a different sign. As can be concluded from Table 4.7, the latter situation is not present in this study. Hence, the direct relationships between personal characteristics might be overestimated, but this problem will be corrected in the further analyses. Therefore, we believe that the chance that these preliminary analyses lead to erroneous conclusions, is small.

In accordance with the procedure in the previous section, we introduced gender and age as potential confounders. The structural relationships were specified as follows: 
growth need strength is positively related to intrinsic work motivation, negative affectivity is positively related to emotional exhaustion, and upward striving is positively related to turnover intention. We performed this SEM-analysis for both samples separately. The results are shown in Table 4.8.

Table 4.8 Fit indices of the preliminary structural equation models of the direct relationships between personal characteristics and outcome variables for sample 1 (bank employees) and sample 2 (teachers)

\begin{tabular}{lcccccc}
\hline Fit measures & $\chi^{2}(d f)$ & AGFI & RMSEA & AlC & NNFI & CFI \\
\hline Sample 1 & & & & & & \\
\hline Basic model & $19.80^{*}(6)$ & .88 & .10 & 79.14 & .70 & .93 \\
Modified model (1a) & $8.92(5)$ & .94 & .06 & 70.82 & .90 & .98 \\
\hline Sample 2 & & & & & & .71 \\
\hline Basic model & $25.18^{*}(6)$ & .90 & .09 & 84.50 & .84 & .94 \\
Modified model (2a) & $13.87^{*}(5)$ & .93 & .07 & 75.70 & .97 \\
Modified model (2b) & $3.65(4)$ & .98 & .00 & 67.63 & 1.01 & 1.00 \\
\hline
\end{tabular}

${ }^{*} p \leq .05$.

The structural relationships between personal characteristics and outcome variables specified in the basic model were all significant (i.e., all $t$-values were higher than 1.96). It can, however, be concluded from Table 4.8 that in both samples the basic model did not have a satisfactory model fit. The highest modification indices in both samples concerned the relationship between negative affectivity and turnover intention (i.e., modification index is 10.50 in sample 1 , and 11.05 in sample 2). The fit indices of these modified models are shown in Table 4.8 (i.e., modified models $1 \mathrm{a}$ and $2 \mathrm{a}$ ). In sample 1, the model fit is now adequate. However, in sample 2, LISREL suggests to add the relationship between growth need strength and turnover intention (i.e., modification index is 10.01). After this modification the model fit is good (see modified model $2 b$ in Table 4.8).

We entered these modified structural equation models ( $1 \mathrm{a}$ and $2 \mathrm{~b}$ ) into a multi-sample analysis. We compared the following models:

M1 (invariant, basic model): the basic pattern of relationships between personal characteristics and outcome variables is specified as invariant (i.e., relationships have the same strength and direction in both samples) across the two samples. No additional relationships are specified.

M2 (invariant, modified model): this model is equal to M1. However, additional relationships are specified for each sample (i.e., a relationship between negative affectivity and turnover intention in sample 1 , and relationships between growth need strength and negative affectivity on the hand, and turnover intention on the other in sample 2).

M3 (non-invariant, modified model): the basic pattern of relationships is specified as non-invariant across the two samples. The other additional relationships we found in 
the first step are specified for each sample separately. Hence, M3 is the least restrictive model.

The results of these model comparisons are shown in Table 4.9.

Table 4.9 Fit measures and chi-square difference tests of the nested structural equation models in the preliminary multi-sample analysis of personal characteristics

\begin{tabular}{lccccc}
\hline Model & $\chi^{2}$ & $d f$ & comparison & \multicolumn{1}{c}{$\Delta \chi^{2}$} & $d f$ \\
\hline Invariant model, basic (M1) & $53.47^{*}$ & 15 & & & \\
Invariant model, modified (M2) & 19.11 & 12 & M1 vs. M2 & $34.36^{*}$ & 3 \\
Non-invariant model, modified (M3) & 12.57 & 9 & M2 vs. M3 & 6.54 & 3 \\
\hline Model & AGFI & RMSEA & AlC & NNFI & CFI \\
\hline Invariant model, basic (M1) & .95 & .09 & 165.79 & .72 & .93 \\
Invariant model, modified (M2) & 1.00 & .04 & 138.88 & .94 & .99 \\
Non-invariant model, modified (M3) & 1.00 & .03 & 138.45 & .96 & .99 \\
\hline
\end{tabular}

${ }^{*} p \leq 05$.

The results of this MSA revealed that the proposed pattern of relationships was invariant (i.e., has the same strength and direction) across the two samples, but that additional relationships had to be added in order to reach optimal model fit: M2 appears to be the best model. All modeled relationships are significant. When we consider the individual relationships, it appears that the relationship between negative affectivity and turnover intention (beta is .22 in sample 1, and .15 in sample 2) is much weaker than the relationship between negative affectivity and emotional exhaustion (beta is .55 in the common metric standardized solution). The relationship between growth need strength and turnover intention in sample 2 (beta is .18) is, however, stronger than the relationship between upward striving and turnover intention (beta is .15 in the common metric standardized solution) and similar to the relationship between growth need strength and intrinsic work motivation (beta is .19 in the common metric standardized solution).

Overall, we may conclude that the three selected personal characteristics are related to the three outcome variables according to our preliminary expectations. That is, growth need strength is primarily related to intrinsic work motivation, negative affectivity is primarily related to emotional exhaustion, and upward striving is primarily related to turnover intention. Hitherto, the results are rather promising. All personal characteristics will be included in the further analyses.

Furthermore, we found some additional, unexpected relationships, the most salient being the relationship between negative affectivity and turnover intention (i.e., this relationship was found in both samples). This relationship was, however, considerably weaker than the hypothesized relationship between negative affectivity and emotional exhaustion. Finally, we found an additional relationship between growth need strength and turnover intention in sample 2 (teachers). We have seen in chapter 2 that this relationship might be theoretically plausible. 
Now that we have gained some preliminary insights in the data, we can continue testing the study hypotheses formulated at the beginning of this section. In order to do so, we performed structural equation modeling in multiple samples. The procedure we used is similar to the procedure described in section 4.2 , that is, we first tested and fitted a baseline model in both samples separately (see Byrne, 1991, 1994, 1998) (section 4.3.2.2). Second, we performed multi-sample analysis (MSA) to test for invariance of the findings in the first step (section 4.3.2.3).

\subsubsection{Testing hypotheses $4 \mathrm{a}$ to $10 \mathrm{a}$ in both samples separately}

In order to test whether and how personal characteristics influence outcome variables (over and above the influence of work characteristics: additive effects) or the relationships between work characteristics and outcome variables (i.e., moderating effects), we added these personal characteristics to the proposed pattern of relationships between work characteristics and outcome variables one by one. In this way, we were able to test the influence of each specific personal characteristic separately. In addition, including all personal characteristics, work characteristics, interaction terms and outcome variables in the structural analysis simultaneously, would yield a complex structural equation model with (too) many variables, considering the sample sizes (cf. Saris \& Stronkhorst, 1984; Schumacker \& Lomax, 1996). This procedure implies that we analyzed three different structural equation models (one for each personal characteristic).

In order to test the interactions, product terms were added to the three structural equation models (personal characteristic * work characteristic) (cf. Kenny \& Judd, 1984; Schumacker \& Lomax, 1996). Since the correlations of the product terms with their component predictors are usually quite high, all predictor variables (i.e., work characteristics and personal characteristics) were centered in order to reduce multicollinearity (see, for instance, Aiken \& West, 1991; Kleinbaum, Kupper \& Muller, 1988). This technique permits models with additive effects of the personal characteristics to be tested against models with interaction effects, by means of the chi-square difference test for nested models (cf. Bentler \& Bonett, 1980).

Again, we simplified the covariance structure by assuming that the observed and latent variables were identical. We introduced gender and age as potential confounders. We did not specify relationships between gender and age on the one hand, and interaction terms on the other, because this does not seem theoretically plausible. The relationships between the work characteristics and the outcome variables were specified according to the pattern of relationships depicted in Figure 2.6. The relationships between the personal characteristics (and their interaction terms) and the outcome variables were specified according to hypotheses $4 \mathrm{a}$ to $10 \mathrm{a}$. In both samples, and for each personal characteristic (structural equation model) we compared three nested models: 
$M 1$ (basic model), which includes only relationships between work characteristics and outcome variables, according to the relationships specified in Figure 2.6. No effects of personal characteristics are specified.

M2 (additive model), which also includes a direct relationship between one of the three selected personal characteristics and the outcome variable it is hypothesized to predict. In this model, an additive effect of the personal characteristic is specified.

M3 (interactive model), which is similar to $\mathrm{M} 2$, but also includes the interactive relationship(s), that is the relationship between the product term and outcome variable under study.

The sample 1 results are depicted in Table 4.10. The sample 2 results are depicted in Table 4.11.

Table 4.10 Chi-square difference tests and practical fit measures of nested structural equation models for each personal characteristic separately for sample 1 (bank employees)

\begin{tabular}{|c|c|c|c|c|c|c|c|c|c|c|}
\hline Model & $x^{2}$ & $d f$ & Comparison & $\Delta z^{2}$ & $d f$ & $A G F I$ & RMSEA & $A / C$ & NNFI & $\mathrm{CFI}$ \\
\hline \multicolumn{11}{|c|}{ Growth need strength } \\
\hline M1 & $58.02^{\star}$ & 16 & & & & .84 & .10 & 155.12 & .62 & .89 \\
\hline M2 & $56.47^{*}$ & 15 & M1 vs. M2 & 1.55 & 1 & .83 & .10 & 155.67 & .60 & .89 \\
\hline M3 & $53.69^{*}$ & 14 & M2 vs. M3 & 2.78 & 1 & .82 & .11 & 155.23 & .59 & .90 \\
\hline \multicolumn{11}{|c|}{ Negative affectivity } \\
\hline M1 & $82.22^{\star}$ & 21 & & & & .81 & 11 & 190.54 & .46 & .83 \\
\hline $\mathrm{M} 2$ & $50.91^{\star}$ & 20 & M1 vs. M2 & $31.31^{\star}$ & 1 & .87 & .08 & 164.93 & .71 & .91 \\
\hline M3 & $44.98^{*}$ & 18 & M2 vs. M3 & 5.93 & 2 & .87 & .08 & 163.17 & .72 & .92 \\
\hline \multicolumn{11}{|c|}{ Upward striving } \\
\hline M1 & $50.72^{\star}$ & 16 & & & & .86 & .09 & 148.34 & .61 & .89 \\
\hline M2 & $50.27^{*}$ & 15 & M1 vs. M2 & .45 & 1 & .85 & .10 & 149.87 & .58 & .89 \\
\hline M3 & $48.23^{\star}$ & 14 & M2 vs. M3 & 2.04 & 1 & .84 & .10 & 150.17 & .56 & .89 \\
\hline
\end{tabular}


Table 4.11 Chi-square difference tests and practical fit measures of nested structural equation models for each personal characteristic separately for sample 2 (teachers)

\begin{tabular}{|c|c|c|c|c|c|c|c|c|c|c|}
\hline Model & $x^{2}$ & $d f$ & Comparison & $\Delta \chi^{2}$ & $d f$ & $A G F I$ & RMSEA & $A / C$ & NNFI & CFI \\
\hline \multicolumn{11}{|c|}{ Growth need strength } \\
\hline M1 & $79.15^{*}$ & 16 & & & & .85 & .10 & 175.61 & .58 & .88 \\
\hline M2 & $59.69^{*}$ & 15 & M1 vs. M2 & $19.46^{*}$ & 1 & .87 & .09 & 159.48 & .68 & .91 \\
\hline M3 & $59.22^{*}$ & 14 & M2 vs. M3 & .47 & 1 & .87 & .10 & 161.01 & .66 & .91 \\
\hline \multicolumn{11}{|c|}{ Negative affectivity } \\
\hline M1 & $143.17^{\star}$ & 21 & & & & .79 & .12 & 240.74 & .47 & .83 \\
\hline M2 & $53.95^{\star}$ & 20 & M1 vs. M2 & $89.22^{*}$ & 1 & .91 & .07 & 168.43 & .85 & .95 \\
\hline M3 & $51.03^{*}$ & 18 & M2 vs. M3 & 2.92 & 2 & .90 & .07 & 169.56 & .83 & .95 \\
\hline \multicolumn{11}{|c|}{ Upward striving } \\
\hline M1 & $68.00^{*}$ & 16 & & & & .86 & .09 & 165.16 & .60 & .88 \\
\hline M2 & $60.09^{*}$ & 15 & M1 vs. M2 & $7.91^{*}$ & 1 & .87 & .09 & 159.79 & .63 & .90 \\
\hline M3 & $55.69^{*}$ & 14 & M2 vs. M3 & $4.40^{*}$ & 1 & .87 & .09 & 157.76 & .64 & .91 \\
\hline
\end{tabular}

We will describe the results for each personal characteristic separately.

\section{Growth need strength}

In sample 1 (bank employees) the difference in chi-square between $\mathrm{M} 1$ and $\mathrm{M} 2$ was not significant, which means that M2 (additive model) did not have a better fit than M1. In sample 2 (teachers), the difference in chi-square between $M 1$ and $M 2$ was significant: M2 (additive model) had a better fit than M1. The difference in chi-square between $M 2$ and $M 3$ was not significant in both samples: M3 (interactive model) did not fit better than M2 (additive model). It can be concluded from these model comparisons that in sample 1, M1 (basic model) is the best fitting model, and in sample 2, M2 (additive model) is the best fitting model. These findings imply that, in sample 2, growth need strength had a significant, additive effect on intrinsic work motivation, over and above the effect of the additive MPS index. In sample 1, no additive effect of growth need strength was found. When we consider the $t$-value of the relationship between growth need strength and intrinsic work motivation in M2 of sample 1, however, it appears that this relationship was significant at the liberal alpha level of .10 .

\section{Negative affectivity}

It appears from Tables 4.10 and 4.11 that the difference in chi-square between M1 and M2 (additive model) was significant in both samples, and that the difference in chisquare between M2 and M3 (interactive model) was not significant. These findings imply that M2 was the best fitting model in both samples. Negative affectivity had a significant, additive effect on emotional exhaustion, over and above the effects of the work characteristics workload and social support. 


\section{Upward striving}

Table 4.10 shows that in sample 1 , the difference in chi-square between M1 and M2 (additive model) was not significant. The difference in chi-square between M2 and M3 (interactive model) was also not significant in this sample. It can be seen, however, that the difference in chi-square between $M 2$ and $M 3$ is larger than the difference in chi-square between $M 1$ and M2. Thus, there are indications for interaction in this sample. When we consider the $t$-value of the relationship between the interaction term (upward striving * unmet career expectations) and turnover intention in sample 1, it appears that this relationship is significant at the liberal alpha level of . 10 .

In sample 2, the difference in chi-square between $M 1$ and $M 2$, as well as the difference in chi-square between $M 2$ and $M 3$ was significant (see Table 4.11). These findings imply that in sample 2, M3 (interactive model) had the best fit. We may conclude that upward striving moderates the relationship between unmet career expectations and turnover intention in this sample (teachers).

Now that we have performed some baseline analyses for each sample separately, we can continue with multi-sample analysis, using the results discussed above as input.

\subsubsection{Testing hypothesis 12: multi-sample analysis of the personal characteristics}

In our next analytical step, we performed multi-sample analysis for each personal characteristic separately (i.e., we used three structural equation models). In order to test the influence of the personal characteristics in both samples simultaneously, we compared similar structural equation models as in the previous analyses (i.e., M1: basic model, M2: additive model, M3: interactive model). However, in this case, we specified the pattern of relationships as equal in both samples. For the final, best fitting model, we also tested whether a more restrictive and parsimonious model with more degrees of freedom (i.e., an invariant model: same pattern and same strength of relationships) did not significantly worsen the model fit. These more parsimonious models were labeled $\mathrm{M}^{\mathrm{a}}, \mathrm{M}^{\mathrm{a}}$ and $\mathrm{M} 3^{\mathrm{a}}$. By means of this procedure, we aimed at finding the best model in terms of total fit (over both samples) and parsimony, as well as testing hypothesis 12 .

Although the sample 1 results in our previous step of analyses were not all significant at an alpha level of .05 , we decided to continue with multi-sample analysis for two reasons. First, it is in line with our theoretical study hypotheses, and second, also in sample 1 there were indications for an additive effect of growth need strength and an interactive effect of upward striving.

The results of the multi-sample analyses are presented in Table 4.12. 
Table 4.12 Chi-square difference tests and fit measures of nested structural equation models for each personal characteristic separately (MSA)

\begin{tabular}{|c|c|c|c|c|c|c|c|c|}
\hline Model & $\chi^{2}(d f)$ & comparison & $\Delta z^{2}(d f)$ & $A G F I$ & RMSEA & $A / C$ & NNFI & $C F I$ \\
\hline \multicolumn{9}{|c|}{ Growth need strength } \\
\hline M1 & $140.94^{*}(36)$ & & & .92 & .10 & 326.12 & .64 & .88 \\
\hline$M 2$ & $119.80^{\star}(34)$ & M1 vs. M2 & $21.14^{*}(2)$ & .92 & .09 & 310.19 & .69 & .90 \\
\hline M3 & $116.36^{\star}(32)$ & $M 2$ vs. M3 & $3.44(2)$ & .92 & .09 & 311.41 & .68 & .91 \\
\hline$M 2^{\mathrm{a}}$ & $123.66^{\star}(35)$ & $\mathrm{M} 2$ vs. $M 2^{\mathrm{a}}$ & $3.86^{\star}(1)$ & .92 & .09 & 312.03 & .69 & .90 \\
\hline M2 ad. & $52.86^{*}(30)$ & & & .96 & .05 & 255.59 & .91 & .97 \\
\hline \multicolumn{9}{|c|}{ Negative affectivity } \\
\hline M1 & $229.18^{*}(46)$ & & & .92 & .11 & 426.22 & .52 & .83 \\
\hline$M 2$ & $107.31^{*}(44)$ & M1 vs. M2 & $121.87^{\star}(2)$ & 95 & .07 & 327.61 & .83 & .94 \\
\hline M3 & $98.34^{\star}(40)$ & M2 vs. M3 & $8.97(4)$ & .94 & .07 & 326.94 & .82 & .95 \\
\hline$M 2^{a}$ & $111.54^{*}(45)$ & $\mathrm{M} 2$ vs. $M 2^{a}$ & $4.23^{*}(1)$ & .93 & .07 & 329.58 & .82 & .94 \\
\hline M2 ad. & $51.36(40)$ & & & .96 & .03 & 282.60 & .97 & .99 \\
\hline \multicolumn{9}{|c|}{ Upward striving } \\
\hline$M 1$ & $123.87^{\star}(36)$ & & & .92 & .09 & 310.27 & .65 & .89 \\
\hline $\mathrm{M} 2$ & $114.97^{*}(34)$ & M1 vs. M2 & $8.90^{*}(2)$ & .92 & .09 & 305.92 & .66 & .89 \\
\hline M3 & $108.39^{*}(32)$ & M2 vs. M3 & $6.58^{*}(2)$ & .94 & .09 & 304.02 & .66 & .90 \\
\hline$M 3^{a}$ & $109.81 *(34)$ & $M 3$ vs. $M 3^{a}$ & $1.35(2)$ & .92 & .08 & 301.35 & .68 & .90 \\
\hline $\mathrm{M}^{\mathrm{a}}$ ad. & $43.65(30)$ & & & .96 & .04 & 246.98 & .93 & .98 \\
\hline
\end{tabular}

Note. ad. = adjusted (indicating the best fitting final adjusted structural equation model for each personal characteristic).

${ }^{*} p \leq .05$.

Again, we will describe the results for each personal characteristic separately.

\section{Growth need strength}

It appears from Table 4.12 that M2 (additive model) had a better fit than M1 (no effect of personal characteristic specified). M3 (interactive model) did not show a better fit than M2 (the difference in chi-square is not significant). This means that an additive model, which includes a relationship between growth need strength and intrinsic work motivation, had the best model fit over two samples. However, no interactive effects of growth need strength were found.

Finally, we compared $M 2$ and $M 2^{a}$. Table 4.12 shows that an extra restriction on $M 2$ (viz., specifying the additive relationships between growth need strength and intrinsic work motivation as invariant over both samples: $\mathrm{M}^{\mathrm{a}}$ ) significantly worsened the model fit (chi-square difference is significant). It should be mentioned, however, that the chisquare difference is very close to non-significance. To summarize, the relationship between growth need strength and intrinsic work motivation is present in both samples, but is not invariant over the two samples (that is, the strength of this relationship is different in both samples).

\section{Negative affectivity}

It appears from Table 4.12 that M2 (additive relationship between negative affectivity and emotional exhaustion) had a better fit than M1. In addition, M3 (interactive relationships) did not have a better fit than $\mathrm{M} 2$ (the chi-square difference was not significant). These results indicate that there is no interactive effect of negative 
affectivity on the relationships between workload and social support on the one hand and emotional exhaustion on the other. Next, we compared $\mathrm{M} 2$ and $\mathrm{M} 2^{\mathrm{a}}$. Table 4.12 shows that the difference in chi-square between $\mathrm{M} 2$ and $M 2^{\mathrm{a}}$ was significant. This means that addition of an extra parameter significantly worsened the model fit (the relationship between negative affectivity and emotional exhaustion was not invariant over both samples). These results indicate that negative affectivity had an additive effect on emotional exhaustion in both samples (over and above the effects of the work characteristics workload and social support), but that this relationship did not necessarily have the same strength in both samples.

\section{Upward striving}

Table 4.12 shows that M2 (additive model) had a better fit than M1 (basic model). In addition, M3 (interactive model) had a better fit than M2. Comparison of M3 and $M 3^{a}$ showed that addition of extra parameters (by specifying the relationships between upward striving and the interaction term on the one hand, and turnover intention on the other as invariant across samples) did not significantly worsen the model fit. These findings imply that the model with an interactive, invariant relationship $\left(M 3^{a}\right)$ was the best model. Upward striving had an interactive effect on the relationship between unmet career expectations and turnover intention, which was invariant across the two samples.

Considering the practical fit indices shown in Table 4.12, it appeared that the best fitting models (i.e., M2 for growth need strength, M2 for negative affectivity and $M 3^{a}$ for upward striving) did not have perfect fit yet (i.e., in all models RMSEA was somewhat high, and NNFI was somewhat low). In order to improve the model fit, we studied the modification indices of the best fitting models for each personal characteristic. We revised the models stepwise (we added relationships one by one, until the model fit was acceptable; when theoretically acceptable, we freed the parameters with the largest modification indices first; cf. De Jonge \& Schaufeli, 1998; Jöreskog \& Sörbom, 1993a). In all three structural equation models (i.e., M2 for growth need strength, M2 for negative affectivity and $\mathrm{M}^{\mathrm{a}}$ for upward striving), the following relationships were added: a relationship between workload and intrinsic work motivation in sample 1 (bank employees), a relationship between the additive MPS index and emotional exhaustion in sample 2 (teachers), and, finally, a relationship between social support and turnover intention in both sample 1 and sample 2. We may conclude that these additional relationships concur with the relationships we added in the previous section (4.2).

The fit indices of the final, adjusted, structural equation models for each personal characteristic are shown in Table 4.12 (i.e., labeled as M2 ad., M2 ad., and M3 ${ }^{\mathrm{a}}$ ad., respectively), and the structural models themselves are shown in Figures 4.2 to 4.4 (i.e., common metric standardized solution). 


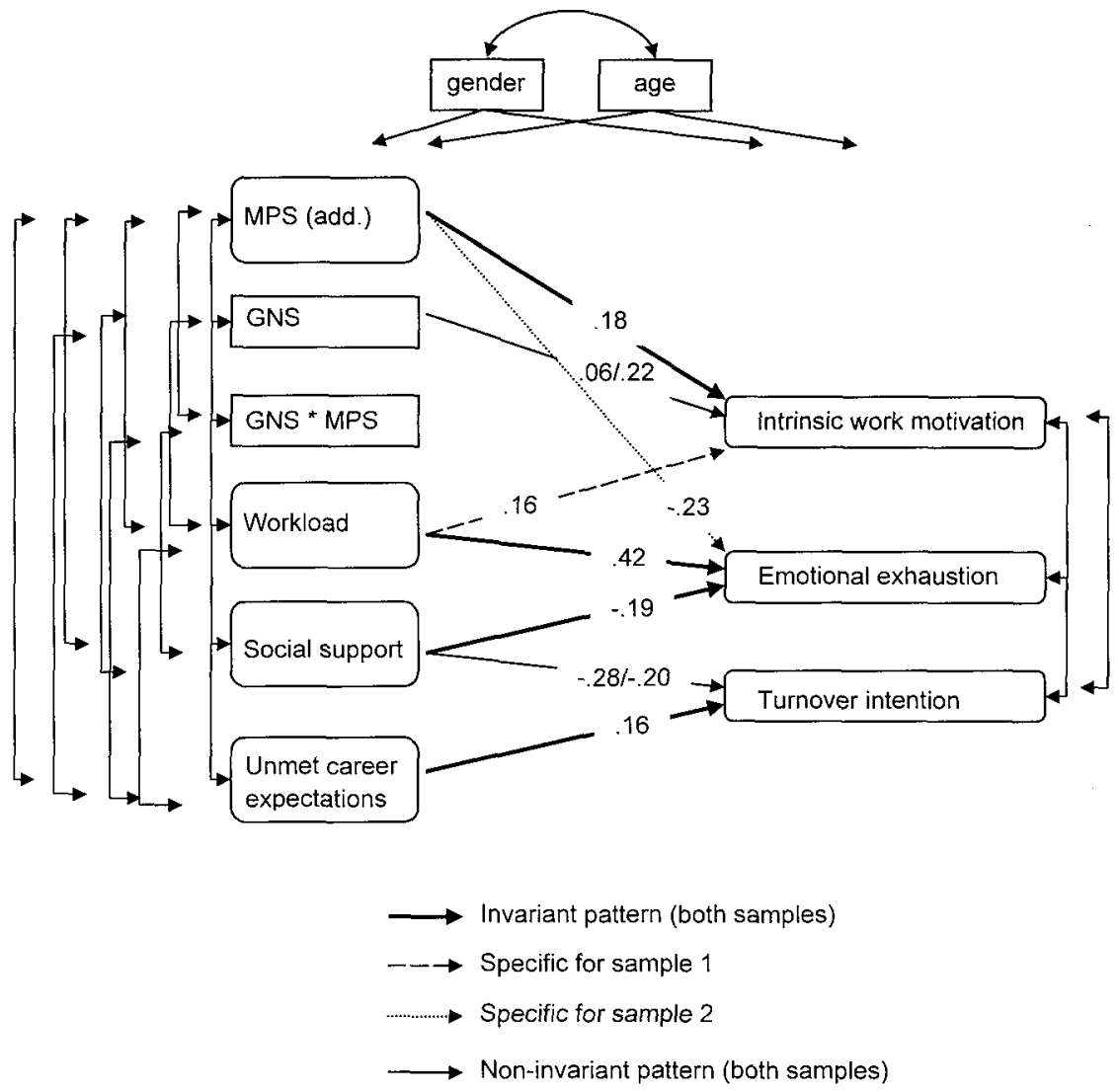

Figure 4.2 Final adjusted structural equation model for growth need strength 


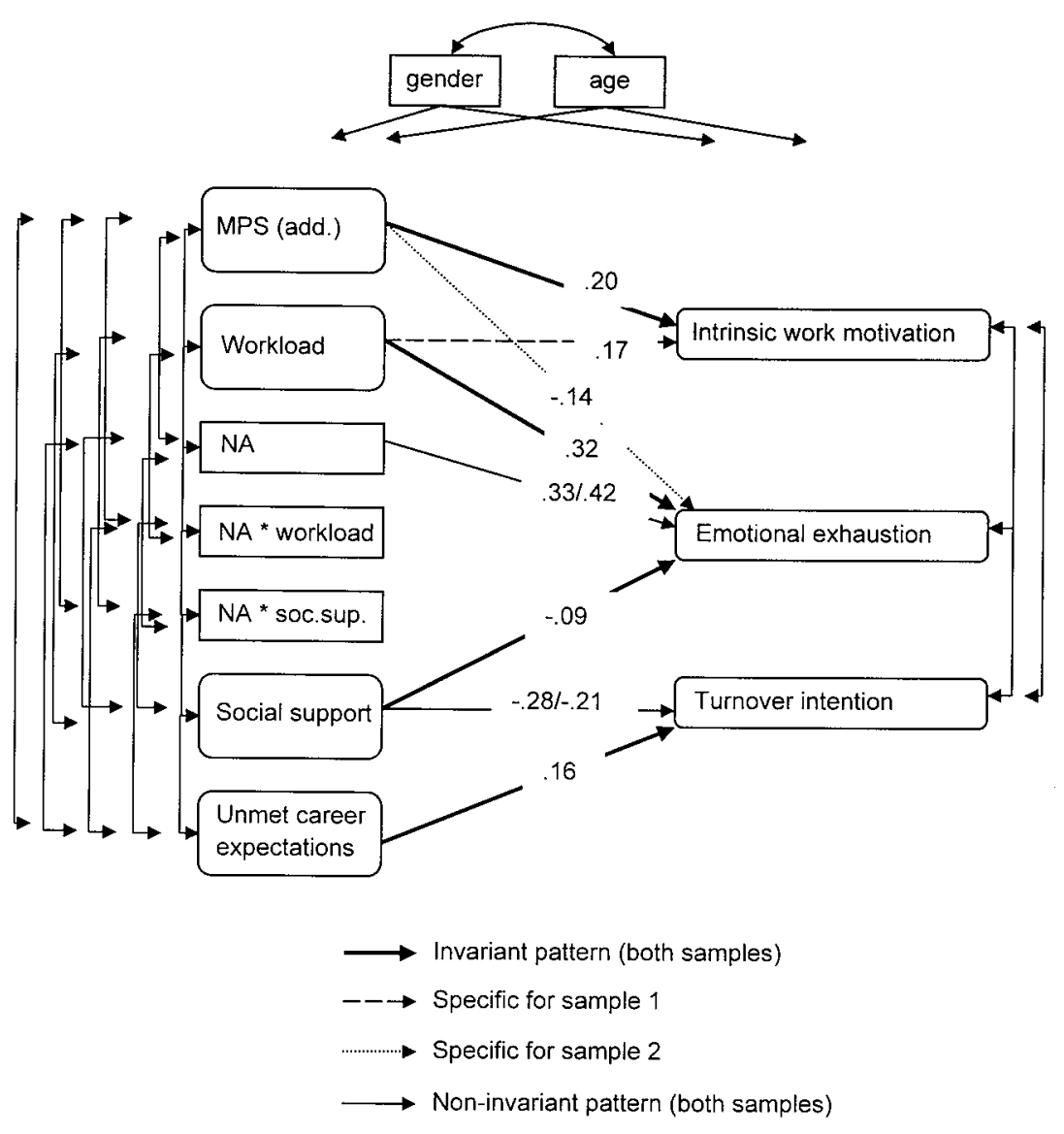

Figure 4.3 Final adjusted structural equation model for negative affectivity 


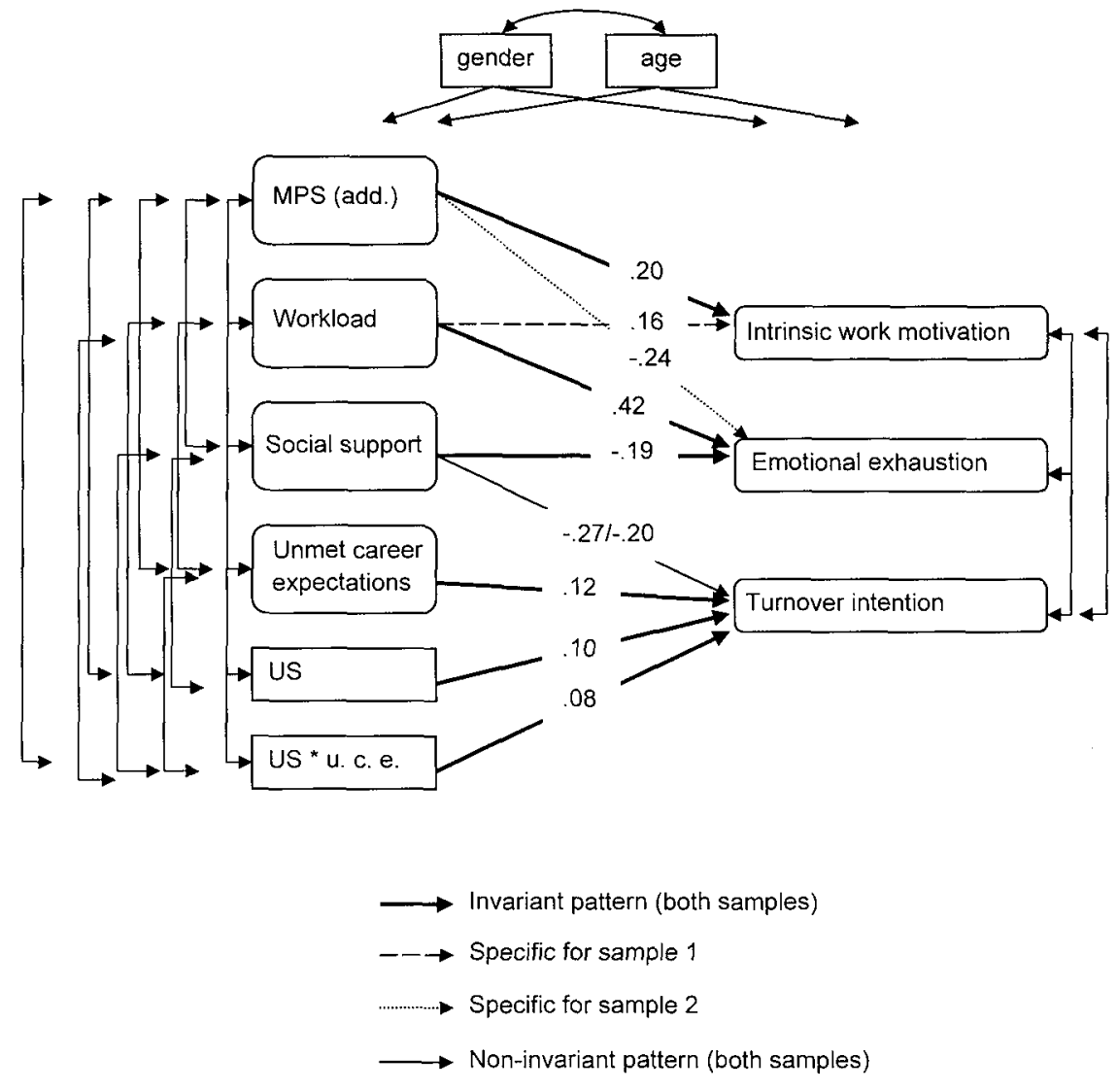

Figure 4.4 Final adjusted structural equation model for upward striving

It may be concluded from Figures 4.2 to 4.4 that the relationships between the personal characteristics and work characteristics on the one hand and the outcome variables on the other point in the expected direction: The higher the levels of growth need strength and the additive MPS index, the higher the level of intrinsic work motivation. Both workload and negative affectivity are positively related to emotional exhaustion, while social support is negatively related to emotional exhaustion. In addition, the higher the levels of unmet career expectations and upward striving, the higher the level of turnover intention.

Finally, in order to interpret the interaction effect of upward striving, we plotted the equations (cf. Aiken \& West, 1991). Values of the predictor variables were chosen one standard deviation below and above the mean (Cohen \& Cohen, 1983). Simple regression lines were then generated by entering these values in the regression equation. The results of this procedure are depicted in Figure 4.5. 


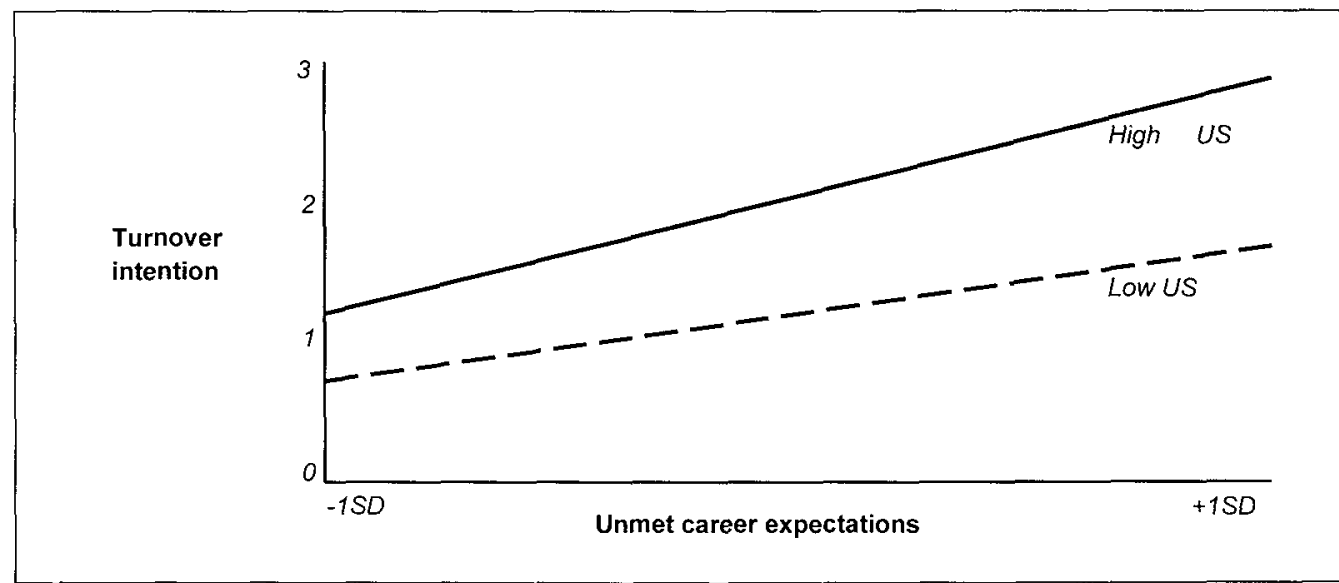

Figure 4.5 Graphical representation of the interactive effect of upward striving on the relationship between unmet career expectations and turnover intention

It can be concluded from Figure 4.5, that for people with high upward striving, the relationship between unmet career expectations and turnover intention, is stronger than for people with low upward striving (the regression line is somewhat steeper for the high upward striving-group). However, for both groups the relationship between unmet career expectations and turnover intention is positive and significant. Hence, the interaction effect is significant, but does not seem strong.

Overall, these findings support hypothesis 12. The effects of the personal characteristics are found in both samples, although not all effects are invariant across both samples.

\subsection{Summary}

The present chapter discussed the results of the cross-sectional part of this study. All bank employees $(N=245)$ and teachers $(N=362)$ who participated in the first measurement of this study were included in the analyses described in this chapter.

In section 4.2, we tested the proposed pattern of relationships between the four work characteristics and three outcome variables described in chapter 2 . By means of multisample analysis (MSA) we tested this pattern of relationships integrally and simultaneously in two samples. This MSA revealed that this pattern of relationships was invariant across the two samples. That is, the direction and strength of the relationships was equal in both samples. This finding may be considered a rather strong validation of the proposed pattern of relationships (cf. Byrne, 1994, 1998) and is in line with the findings of Janssen, De Jonge and Bakker (1999) who tested this pattern of relationships in a preliminary single-sample study among nurses. We can 
conclude that hypotheses $1 \mathrm{a}$ to $3 a$ (regarding the specific relationships between the work characteristics and psychological outcome variables), and hypothesis 11 (regarding the invariance of the pattern of relationships over occupational groups), have been confirmed. Challenging work is positively related to intrinsic work motivation, workload and social support are related to emotional exhaustion (i.e., positively and negatively, respectively), and finally, frustrated career expectations lead to turnover intention. These results suggest that more accurate predictions regarding the associations between work characteristics and psychological outcome variables are possible.

We did however, also find several additional relationships. In sample 1, we found a relationship between workload and intrinsic work motivation, and between social support and turnover intention. In sample 2, we found additional relationships between the additive MPS index and emotional exhaustion, and also between social support and turnover intention. The latter relationship proved to be consistent across samples. The other two relationships were considered sample-specific (see also chapter 6).

In section 4.3, we examined the influence of the personal characteristics growth need strength, negative affectivity and upward striving on the pattern of relationships between work characteristics and outcome variables, and directly on the outcome variables. We first performed several preliminary analyses (by means of structural equation modeling) and found that, according to our hypotheses, growth need strength was primarily related to intrinsic work motivation, negative affectivity was primarily related to emotional exhaustion, and upward striving was primarily related to turnover intention. Furthermore, in both samples, we found an additional relationship between negative affectivity and turnover intention. This relationship was relatively weak, however. Because these results were very promising, we went on testing the additive and moderating effects of the personal characteristics. Again, we performed multisample analysis. These MSA showed that growth need strength had a positive additive effect on intrinsic work motivation (over and above the effect of task characteristics). This additive effect of growth need strength was more prone among bank employees than among teachers. Negative affectivity had a positive additive effect on emotional exhaustion, over and above the effects of workload and social support. The latter two effects were, however, not invariant across the two samples (i.e., these relationships had the same sign, but the strength of the relationships was not equal in both samples). Upward striving, finally, had an additive and interactive effect upon turnover intention and upon the relationship between unmet career expectations and turnover intention, respectively. People scoring high on upward striving, are more prone to leave the organization voluntarily than people scoring low on this personal characteristic, especially when career opportunities are low. In addition, for people scoring high on upward striving, the relationship between unmet career expectations and turnover intention was stronger than for people scoring low on upward striving. This effect was invariant across the two samples. 
The results we found in section 4.3 are a partial confirmation of our hypotheses. We found additive effects of all personal characteristics, hence hypotheses $4 a, 6 a$ and $9 a$ have been confirmed. We could, however, demonstrate only one moderating effect: only hypothesis 7 a was confirmed. Hypothesis 12 was confirmed to a large extent. In sum, we may conclude that the personal characteristics we selected have specific effects on the outcome variables under study.

The theoretical and practical implications of the results of these cross-sectional analyses, as well as some methodological issues regarding these analyses, will be discussed in chapter 6 .

Strictly speaking, the cross-sectional part of the study described in this chapter and summarized above, has provided evidence for the specific associations among work characteristics, personal characteristics and outcome variables. We cannot be sure, however, about the causal direction of these relationships. Based on theory, we expect that work characteristics and personal characteristics influence the outcome variables, and not the other way around. In the following chapter, we will describe a panel study that addresses this issue. That is, panel studies provide, more than crosssectional studies, the opportunity to indicate causality. Furthermore, we will examine in the forthcoming chapter whether the proposed pattern of relationships between work characteristics and outcome variables, as well as the additional relationships between work characteristics and outcome variables we found in section 4.2, are stable over time. 


\section{Chapter 5}

\section{Panel study}

Parts of section 5.2 have been submitted under the title:

Houkes, I., Janssen, P.P.M., Jonge, J. de \& Bakker. A.B. (2001b). Specific determinants of intrinsic work motivation, emotional exhaustion and turnover intention: A multi-sample longitudinal study. Manuscript submitted for publication.

Parts of section 5.3 have been submitted under the title:

Houkes, I., Janssen, P.P.M., Jonge, J. de \& Bakker, A.B. (2001a). Personality, work characteristics, and employee well-being. A longitudinal analysis of additive and moderating effects. Manuscript submitted for publication. 


\subsection{Introduction}

The present chapter addresses the results of the panel study. In the analyses described in this chapter we will use the data from the so-called panel group: bank employees and teachers who participated twice (i.e., at both the first and the second measurement: April 1998 and April 1999).

This chapter is outlined as follows. In section 5.2 we will first examine the stability of the proposed pattern of relationships between work characteristics and outcome variables over time and over samples. Second, we aim to find evidence for the causal direction within the proposed pattern of relationships between work characteristics and outcome variables. Are work characteristics the cause of the outcome variables, or are there alternative explanations? We will examine these issues in both samples (i.e., bank employees and teachers) separately.

In section 5.3, we will pursue the issue of the longitudinal effects of the personal characteristics. For methodological reasons it was not possible to use interaction terms to analyze the longitudinal interactive effects of the personal characteristics. ${ }^{2}$ Hence, we had to use subgroup analyses.

Analyzing the data for both our study samples separately, using subgroup analyses, would result in very small subgroups (consisting of about 50-65 subjects). According to Ding, Velicer and Harlow (1995) (cf. Schumacker \& Lomax, 1996), however, a minimum sample size of 100 is advisable in order to acquire accurate parameter estimates. Therefore, in section 5.3 we combined our two study samples into one larger sample consisting of bank employees and teachers. We believe that this procedure is admissible because previous results have indicated that the relationships between work characteristics, personal characteristics and outcome variables are to a large extent similar for both samples. In section 5.4, finally, the summary and main conclusions of this chapter will be presented.

2 In a longitudinal structural panel model it does not seem feasible to use multiplicative interaction terms, because a structural path between a time 1 outcome variable and a time 2 interaction term is difficult to interpret theoretically and statistically. Hence, we used a first order model, that is a model with only linear effects over time, to test the causal moderating effects (see also De Jonge, 1995). 

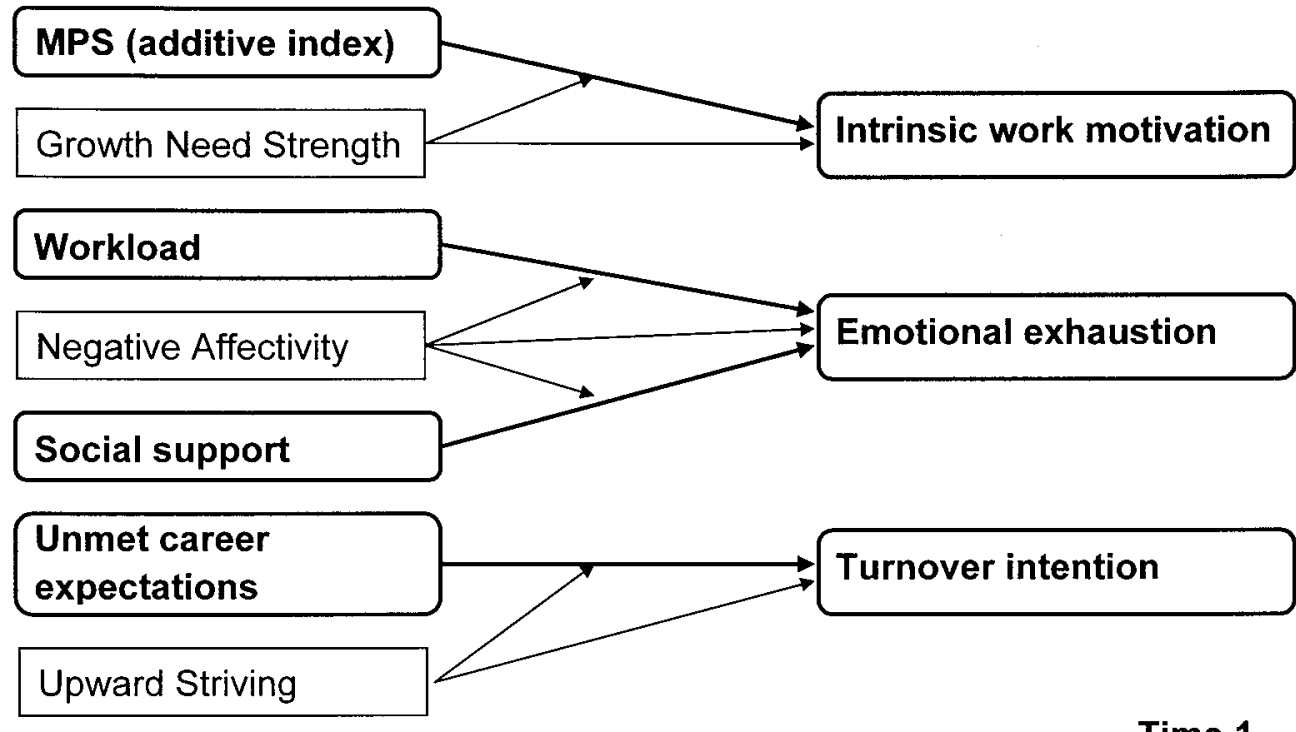

Time 1

Time 2
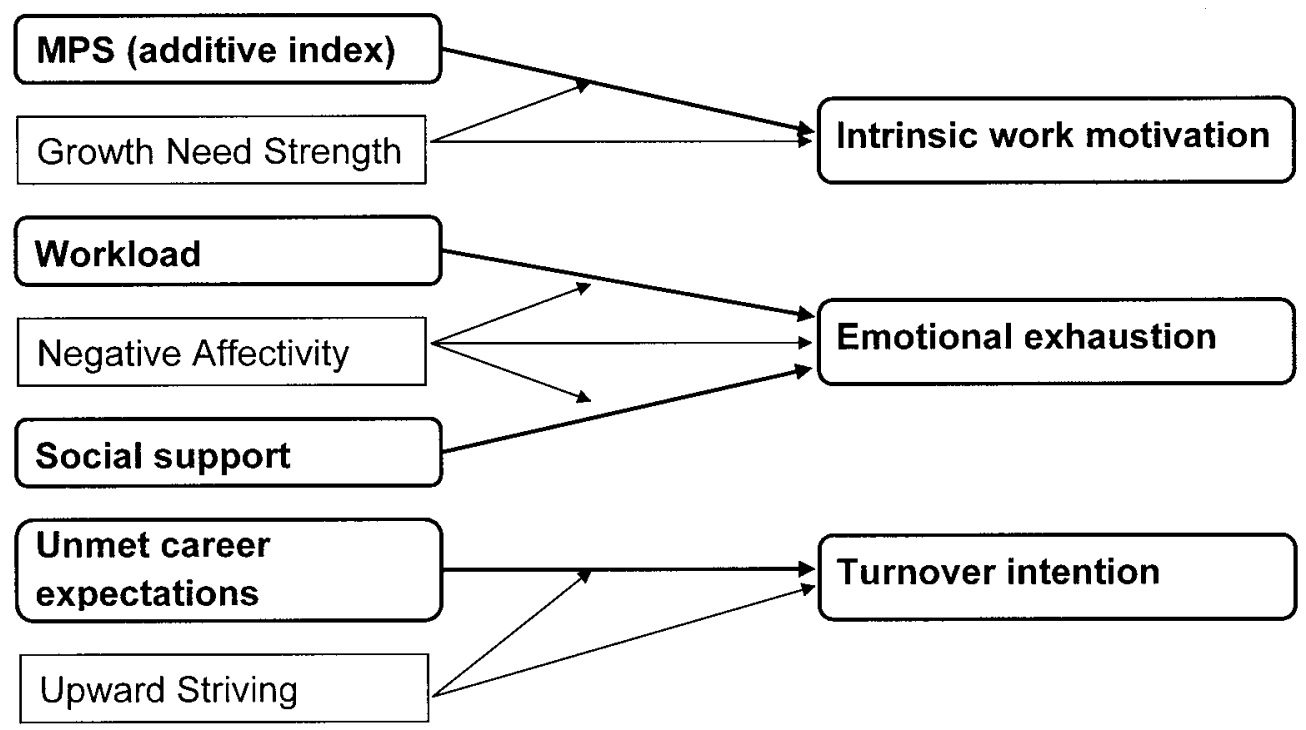

Figure III Schematic representation of the part of the research mode/ that is under investigation in section 5.2 


\subsection{Specific determinants of intrinsic work motivation, emotional exhaustion and turnover intention: A multi- sample longitudinal study}

\subsubsection{Hypotheses, background and data analyses}

In this section we will present the longitudinal analyses regarding research question 1. That is, the issue of specific relationships between the work characteristics (i.e., task characteristics, workload, social support and unmet career expectations) on the one hand, and the outcome variables (i.e., intrinsic work motivation, emotional exhaustion and turnover intention) on the other.

The part of the research model that is under investigation in the present section is schematically depicted in Figure III.

In the previous chapter (4) we found cross-sectional evidence for the proposed pattern of relationships between work characteristics and outcome variables. Furthermore, we found several additional relationships in both samples. In this section we aim to examine in the first place whether this pattern of relationships and the additional relationships are stable over time, but also over samples. Second, we aim to find support for the causal direction of the relationships between the work characteristics and the psychological outcome variables.

In chapter 3, we formulated two general hypotheses and three more specific hypotheses regarding the longitudinal relationships between work characteristics and outcome variables. Because of the finding of additional relationships in section 4.2 , in the present section hypothesis I will be extended with the question regarding stability over samples.

I. The proposed pattern of relationships between work characteristics and outcome variables is stable over time and over samples.

II. Time 1 work characteristics influence time 2 outcome variables.

1b. Intrinsic work motivation is primarily and positively influenced by task characteristics (combined in the additive MPS).

2b. Emotional exhaustion is primarily influenced by both workload (i.e., positively) and social support (i.e., negatively).

3b. Turnover intention is primarily and positively influenced by unmet career expectations.

With regard to the test of the study hypotheses in two samples, we formulated an extra, methodological hypothesis in chapter 3 :

11. The proposed pattern of relationships between work characteristics and psychological outcome variables holds over different occupational groups (i.e., bank employees and teachers).

This hypothesis has already been confirmed in the cross-sectional analyses (chapter 4). In the present section, we will test in this regard whether the causal order of variables is stable over samples. 
The hypotheses regarding the causal direction of relationships are in line with the expectations of Janssen, De Jonge and Bakker (1999), with the expectations formulated in the previous chapter, and with, for example, the propositions of the Demand-Control-Support model (Johnson \& Hall, 1988; Karasek \& Theorell, 1990) and the Job Characteristics Model (Hackman \& Oldham, 1980). Both these models propose that work characteristics are a direct cause of outcome variables such as intrinsic work motivation, satisfaction and health, and not the other way around.

\section{Data analyses}

We analyzed the data in four steps. In the first step we performed a non-response analysis: we tested whether panel mortality and wave non-response have threatened the internal validity of this study. In this regard, several biases may occur (Daniels \& De Jonge, 2001). First, there is attrition bias (due to the so-called "dropouts": people who participate in the first measurement, but not in the second). In order to test whether this has occurred, we determined whether there were differences between employees in the panel group and the dropouts with regard to variable means as well as the pattern of relationships between variables. Other conceivable biases are multiple testing bias (to be tested by means of comparing the scores of the panel group at time 2, with the scores of the people who only participated at the second wave); history effects (to be tested by means of comparing the scores of the dropouts with the scores of the people who only participated at the second wave); regression to the mean (to be tested by means of comparing the scores of the panel group at time 1 and time 2); and finally, non-response bias at time 1 (to be tested by means of comparing the scores of the panel group at time 1 with the scores of the people who only participated at time 2 ).

In the second step we performed several preliminary analyses. We computed the means, standard deviations, percentage of employees scoring negative on each variable, test-retest reliabilities of the study variables and zero-order Pearson correlations among the variables. Third, in order to test hypothesis 1, we performed multi-sample analysis (MSA). First, we tested whether the proposed pattern of relationships (see Figure 2.6) was stable over the two study samples (bank employees and teachers) at both time 1 and time 2 . In addition, in order to test the stability of the proposed pattern of relationships over time, we compared two models with and without equivalent synchronous correlations (cf. De Jonge, 1995). Synchronous correlations are the associations between variables at the same time point (time 1 work characteristics and time 1 outcome variables, for instance). Testing for equivalent synchronous correlations implies testing whether the association between a time 1 work characteristic and a time 2 outcome variable is equal to this very same association at time 2. While performing this analysis, we are actually testing for stationarity: is the structure of relationships between variables stable over time? In our fourth, final step, we analyzed the panel data by means of SEM in order to test hypothesis II, as well as hypotheses $1 \mathrm{~b}$ to $3 \mathrm{~b}$. We used a cross-lagged panel design (e.g., Finkel, 1995; Kessler \& Greenberg, 1981) and we compared a sequence of competing, nested structural equation models in several steps by means of the chi- 
square difference test (cf. Hom \& Griffith, 1991; Jöreskog \& Sörbom, 1993b; De Jonge et al., 2001). This cross-lagged panel design has already been discussed in chapter 3 (see also Figure 3.2).

Just like in chapter 4 , we simplified the covariance structure by assuming that the latent and observed variables were identical (see also section 3.6.2), and introduced the demographic variables gender and age as potential confounders (cf. Karasek \& Theorell, 1990).

\subsubsection{Results}

\subsubsection{Non-response analysis}

In order to rule out selection problems due to panel loss (i.e., attrition), we first determined whether there were differences between employees in the panel group and the dropouts with regard to the means of the job variables (the four work characteristics and three outcome variables). We have already discussed in chapter 3 that the samples differed somewhat with respect to the demographic variables gender (in sample 2) and age (in both samples), but we concluded that this would not cause serious selection problems, because the differences were rather small.

The results of the $t$-tests of the job characteristics are shown in Table 5.1.

Table 5.1 T-tests of mean differences of time 1 work characteristics and outcome variables between dropouts and the panel group for sample 1 (bank employees) and sample 2 (teachers)

\begin{tabular}{llccccc}
\hline \multicolumn{2}{l}{ Variables } & \multicolumn{3}{c}{ Sample 1 } & \multicolumn{3}{c}{ Sample 2 } \\
\hline & \multicolumn{1}{c}{$t$} & $d f$ & $p$ & $t$ & $d f$ & $p$ \\
\hline 1. MPS (additive index) & 1.68 & 242 & .09 & .08 & 364 & .94 \\
2. Workload & .20 & 247 & .84 & .77 & 372 & .44 \\
3. Social support & .16 & 248 & .87 & .42 & 366 & .67 \\
4. Unmet career expectations & 1.13 & 249 & .26 & 1.22 & 369 & .22 \\
5. Intrinsic work motivation & -.67 & 249 & .50 & .69 & 372 & .49 \\
6. Emotional exhaustion & .34 & 250 & .74 & -.79 & 371 & .43 \\
7. Turnover intention & -1.44 & 249 & .15 & -.84 & 368 & .40 \\
\hline
\end{tabular}

Note. Significant $p$-levels are printed in italics (alpha was set at .10).

In order to evaluate the differences between the groups, Daniels and De Jonge (2001) suggest to set alpha at .10 , because the statistical tests are being used to assess absence of differences. It can be concluded from Table 5.1 that there exist no significant differences between the panel group and the dropouts with regard to the mean values of the time 1 work characteristics and the time 1 outcome variables (i.e., all $p$-values are higher than .10), except for the additive MPS index in sample 1 . The $p$-value of the $t$-test of the latter work characteristic was close to .10, though.

This verification of mean differences between respondents and non-respondents is important, but not sufficient to exclude selection problems. Kessler and Greenberg (1981) additionally recommend to investigate whether the causal relationships among 
all study variables are similar for the panel group and the dropouts. In order to examine this so-called causal homogeneity, they suggest to use information from the waves where responses have been obtained. However, in our study the dropouts only responded in one wave (time 1), hence, an absolute test of causal homogeneity is hardly possible (only cross-sectional data were available from the dropouts). Therefore, we examined at time 1 whether the interrelationships among the study variables were homogeneous for the dropouts and the panel group. In order to test this, we first verified whether the intercorrelations among all study variables were equal (i.e., invariant) for both the dropouts and the panel group (in both samples). We performed a cross-sectional, multi-group structural equation analysis using two corresponding correlation matrices (one matrix for the panel cases and one matrix for the dropouts), for both sample 1 and sample 2 (Jöreskog \& Sörbom, 1993b). More specifically, for both samples we compared a model in which we specified the intercorrelations between the study variables as invariant (same pattern and same strength of the relationships) for both the dropouts and the panel group, with a model in which we specified the intercorrelations as non-invariant (i.e., same pattern of relationships but not the same strength) across both groups, by means of the chisquare difference test (Bentler \& Bonett, 1980; Jöreskog \& Sörbom, 1993b). In both samples, the invariant model appeared to fit better than the non-invariant model (sample 1: $\Delta \chi^{2}(28)=35.66$, n.s.; sample 2: $\Delta \chi^{2}(28)=36.12$, n.s.): no significant differences were found regarding the intercorrelations among the study variables between the panel group and the dropouts.

Second, we tested whether the theoretically proposed pattern of relationships (see Figure 2.6) was equal (i.e., invariant) for the panel group and the dropouts (again, in both samples; see also De Jonge et al., 2001). More specifically, for both samples, we tested whether a model in which the relationships were specified as non-invariant (i.e., same pattern of relationships but not the same strength) in the dropouts and the panel group, fitted better than a model in which the relationships were specified as invariant across the dropouts and the panel group (same pattern and same strength of the relationships). The difference in chi-square was not significant in both samples (sample 1: $\Delta \chi^{2}(6)=6.75$, n.s.; sample 2: $\Delta \chi^{2}(6)=1.73$, n.s.). These findings imply that the pattern of relationships was invariant across the dropouts and the panel group in both sample 1 and sample 2. Therefore, we may conclude that in both samples the panel group and the dropouts are quite comparable with regard to the intercorrelations among the study variables and with regard to the pattern of relationships, and that in this regard no serious selection problems seem to have occurred.

In order to test whether other biases due to wave non-response (i.e., multiple testing bias, history effects, regression to the mean, and non-response bias at time 1) have occurred, we performed several other comparisons for both study samples (Daniels \& De Jonge, 2001). See Tables 5.2 and 5.3. 
Table 5.2 Comparison of several groups of participants for sample 1 (bank employees) in order to exclude biases due to wave non-response

\begin{tabular}{|c|c|c|c|c|c|c|c|c|c|c|c|c|}
\hline \multirow[t]{2}{*}{ Variables } & \multicolumn{3}{|c|}{ G1\&2 T2 vs. G2 } & \multicolumn{3}{|c|}{ G1 vs. G2 } & \multicolumn{3}{|c|}{ G1\&2 T1 vs. T2 } & \multicolumn{3}{|c|}{ G1\&2 T1 vs. G2 } \\
\hline & $t \chi^{2 \mathrm{a}}$ & $d f$ & $p$ & $t \chi^{2 a}$ & $d f$ & $p$ & $t / \chi^{2 a}$ & $d f$ & $p$ & $t x^{2 a}$ & $\overline{d f}$ & $\bar{p}$ \\
\hline Gender $^{a}$ & .88 & 1 & .35 & .06 & 1 & .81 & .02 & 1 & .89 & 1.06 & 1 & .30 \\
\hline Age & 30 & 180 & .02 & 36 & 136 & .72 & -.95 & 292 & .34 & 1.71 & 180 & .09 \\
\hline MPS (add & 45 & 18 & .15 & .07 & 34 & .95 & -.37 & 288 & .71 & 1.19 & 176 & .24 \\
\hline Workload & 69 & 18 & .09 & 31 & 135 & .76 & -1.97 & 293 & .05 & .40 & 180 & .68 \\
\hline Soc. sup. & -.02 & 181 & .99 & -.41 & 136 & .69 & -.50 & 293 & .62 & -.31 & 180 & .76 \\
\hline Unmet & -.34 & 181 & .73 & -.34 & 137 & .74 & 1.26 & 293 & .21 & .45 & 180 & .65 \\
\hline Intr. work mot. & 1.94 & 181 & .06 & 2.31 & 137 & .02 & .03 & 293 & .98 & 1.75 & 180 & .08 \\
\hline Emot. exh. & 1.02 & 180 & .31 & .31 & 137 & .76 & -.85 & 293 & .40 & .56 & 181 & .58 \\
\hline Turnover int. & -.53 & 179 & .60 & 19 & 137 & .91 & -.55 & 291 & .58 & -.92 & 180 & .36 \\
\hline
\end{tabular}

Note. G1 $=$ People who only participated at time $1 ; G 2=$ people who only participated at time $2 ; G 1 \& 2=$ panel group; $T 1=$ time $1 ; T 2=$ time 2 . Significant p-levels are printed in italics (alpha was set at .10).

${ }^{\text {a }}$ For gender we performed a chi-square test instead of a $t$-test.

Table 5.3 Comparison of several groups of participants for sample 2 (teachers) in order to exclude biases due to wave non-response

\begin{tabular}{|c|c|c|c|c|c|c|c|c|c|c|c|c|c|}
\hline \multirow{2}{*}{\multicolumn{2}{|c|}{ Variables }} & \multicolumn{3}{|c|}{ G1\&2 T2 vs. G2 } & \multicolumn{3}{|c|}{ G1 vs. G2 } & \multicolumn{3}{|c|}{ G1\&2T1 vs. T2 } & \multicolumn{3}{|c|}{ G1\&2 T1 vs. G2 } \\
\hline & & $t / \chi^{2 \mathrm{a}}$ & $d f$ & $p$ & $t x^{2 \mathrm{a}}$ & $d f$ & $p$ & $t^{2} \chi^{2 \mathrm{a}}$ & $d f$ & $p$ & $t x^{2 a}$ & $d f$ & $p$ \\
\hline 1. & Gend & 1.66 & 1 & .20 & 7.69 & 1 & .01 & .01 & 1 & .94 & .66 & 1 & 42 \\
\hline 2. & Age & 1.40 & 230 & .16 & -1.70 & 223 & .09 & -1.66 & 374 & .10 & .41 & 228 & 68 \\
\hline 1. & MPS (add.) & .43 & 229 & .67 & -.68 & 221 & .49 & -1.28 & 370 & .20 & -.50 & 225 & 63 \\
\hline 2 & Workload & -1.11 & 230 & .27 & -1.89 & 226 & .06 & -.56 & 374 & .57 & -1.41 & 228 & .16 \\
\hline 3. & Soc. sup. & .15 & 228 & .88 & -1.46 & 220 & .15 & -2.01 & 372 & .05 & -1.13 & 226 & .26 \\
\hline 4. & Unmet car. & -.65 & 229 & .52 & -.28 & 223 & .78 & 1.98 & 373 & .05 & .49 & 228 & .63 \\
\hline 5. & Intr. work mot. & -.11 & 229 & .91 & -.01 & 226 & .99 & .90 & 373 & .37 & .42 & 228 & .67 \\
\hline 6. & Emot exh. & -1.10 & 229 & .27 & -.20 & 226 & .84 & .41 & 372 & .69 & .67 & 227 & .50 \\
\hline 7. & Turnover int. & -1.19 & 226 & .24 & -.70 & 223 & .48 & -.12 & 369 & .10 & -1.20 & 225 & .23 \\
\hline
\end{tabular}

Note. $\mathrm{G}_{1}=$ People who only participated at time $1 ; \mathrm{G} 2=$ people who only participated at time $2 ; \mathrm{G} 1 \& 2$ = panel group; $T 1=$ time $1 ; \mathrm{T} 2=$ time 2 . Significant $p$-levels are printed in italics (alpha was set at .10 ).

${ }^{a}$ For gender we performed a chi-square test instead of a $t$-test.

Generally, Tables 5.2 and 5.3 indicate that, in both samples, the scores on the demographic variables gender and age, the work characteristics and outcome variables did not differ significantly between the several groups. However, there were some exceptions (i.e., in some instances the groups differ with regard to mean scores on gender, age, workload, social support, unmet career expectations and intrinsic work motivation). We conclude that some selection bias may have occurred. However, considering the finding that the number of significant $p$-values in Tables 5.2 and 5.3 is very low, as well as the results of the LISREL-analyses regarding the comparisons of the dropouts and the panel groups, we believe that these biases have not influenced the study results severely.

\subsubsection{Preliminary analyses}

In the second step, we performed several preliminary analyses (means, standard deviations, percentage of employees scoring negative on each variable, test-retest 
reliabilities, zero-order Pearson correlations). The results of these analyses are depicted in Tables 5.4 and 5.5 .

Table 5.4 Means (M), standard deviations (SD) and percentage scoring negative (\% neg.) of sample 1 (bank employees) and sample 2 (teachers) in the panel study

\begin{tabular}{|c|c|c|c|c|c|c|c|}
\hline \multicolumn{2}{|c|}{ Variables (range) } & \multicolumn{3}{|c|}{ Sample $1(N=148)$} & \multicolumn{3}{|c|}{ Sample 2(N=188) } \\
\hline & & $\bar{M}$ & SD & $\%$ neg. $^{a}$ & $M$ & $S D$ & $\%$ neg. $^{a}$ \\
\hline 1. & MPS (additive index) $(1)(1-7)^{6}$ & 5.30 & .66 & 3.4 & 5.00 & .65 & 7.4 \\
\hline 2. & Workload (1) (1-5) & 3.37 & .64 & 46.3 & 3.42 & 63 & 50.3 \\
\hline 3. & Social support (1) $(1-4)^{b}$ & 3.13 & .38 & 8.2 & 2.98 & .45 & 16.5 \\
\hline 4. & Unmet career expectations (1) (1-5) & 3.41 & .76 & 44.2 & 3.37 & .77 & 48.7 \\
\hline 5. & Intrinsic work motivation (1) $(1-7)^{\mathrm{b}}$ & 5.96 & .63 & .7 & 6.05 & .63 & 1.1 \\
\hline 6. & Emotional exhaustion (1) (1-7) & 2.59 & 1.02 & 5.4 & 3.02 & 1.21 & 13.8 \\
\hline 7. & Turnover intention (1) (1-2) & 1.29 & .28 & 7.5 & 1.29 & 33 & 13.4 \\
\hline 8. & MPS (additive index) (2) $(1-7)^{\mathrm{b}}$ & 5.32 & 63 & 3.4 & 5.11 & .70 & 5.8 \\
\hline 9. & Workload (2) (1-5) & 3.51 & .58 & 56.8 & 3.46 & .62 & 51.9 \\
\hline 10. & Social support (2) $(1-4)^{b}$ & 3.15 & .35 & 4.7 & 3.07 & .46 & 12.8 \\
\hline 11. & Unmet career expectations (2) (1-5) & 3.31 & .64 & 39.9 & 3.23 & .72 & 38.8 \\
\hline 12. & Intrinsic work motivation (2) $(1-7)^{b}$ & 5.96 & .54 & .4 & 5.99 & .64 & 1.6 \\
\hline 13. & Emotional exhaustion (2) (1-7) & 2.69 & 1.12 & 8.8 & 2.97 & 1.08 & 8.0 \\
\hline 14. & Turnover intention (2) (1-2) & 1.31 & .31 & 12.3 & 1.29 & .33 & 12.4 \\
\hline
\end{tabular}

Note. (1) = Time 1, (2) = Time 2 .

a In order to determine whether a respondent scores negative on a scale, we specified cut off points. These cut off points were specified as follows: 1.5 for a 1-2 scale, 2.5 for a $1-4$ scale, 2.5 and 3.5 for a $1-5$ scale, and 3.5 and 4.5 for a 1-7 scale.

bor these variables a relatively high mean score should be interpreted positively, for the other variables a relatively high mean score should be interpreted negatively.

It can be concluded from Table 5.4 that a high workload and a high level of unmet career expectations, are the most salient problems in both samples and at both measurement points. It appears that with regard to the percentage of employees scoring negative on the study variables, there exist no striking differences between time 1 and time 2. The variable social support seems to be a problem in sample 2 (teachers). When the clinical cut off points with regard to emotional exhaustion suggested by Schaufeli and Van Dierendonck $(1995,2000)$ are applied, it appears that in sample $1,22 \%$ of the employees score high on emotional exhaustion at both time 1 and time $2.3 .4 \%$ and $5.4 \%$ score very high on time 1 and time 2 , respectively. For sample 2, these figures are the following: $35 \%$ score high, and $9.6 \%$ score very high at time 1 . At time $2,41 \%$ score high, and $5 \%$ score very high. 
Table 5.5 Zero-order Pearson correlations of the study variables in the panel study for sample 1 (bank employees, $N=148$, left-lower corner) and sample 2 (teachers, $N=188$, right-upper corner)

\begin{tabular}{|c|c|c|c|c|c|c|c|c|c|c|c|c|c|c|c|}
\hline \multicolumn{2}{|c|}{ Variables } & \multicolumn{14}{|c|}{ Correlations } \\
\hline & & 1 & 2 & 3 & 4 & 5 & 6 & 7 & 8 & 9 & 10 & 11 & 12 & 13 & 14 \\
\hline 1. & MPS (add. ind & -- & $-.19^{* \star}$ & $49^{* *}$ & -.11 & .12 & $-.42^{\star *}$ & -.13 & $.62^{\star \star}$ & $-.16^{*}$ & $.32^{\star *}$ & -.07 & .13 & $-.31^{\star \star}$ & $-.16^{*}$ \\
\hline 2. & Worklo & .09 & - & $-.21^{\star *}$ & $.15^{\star}$ & $.16^{\star}$ & $.43^{* *}$ & $.15^{*}$ & $-.16^{\star}$ & $.71^{* *}$ & $-18^{*}$ & .04 & .01 & $37^{\star * *}$ & .13 \\
\hline 3. & Socia & $.19^{*}$ & -.11 & -- & $-.20^{\star \star}$ & .04 & $-.42^{\star \star}$ & $-.27^{\star \star}$ & $.37^{\star \star}$ & -.10 & $.56^{\star \star}$ & -.14 & .06 & $-.29^{* *}$ & $-.19^{* *}$ \\
\hline 4. & Unme & 10 & $.23^{\star \star}$ & -.14 & -- & .07 & -.02 & $.29^{* \star}$ & .02 & .09 & -.14 & $.74^{\star *}$ & .01 & .00 & $.21^{* *}$ \\
\hline 5. & Intrin & $.23^{\star \star}$ & .16 & -.01 & -.02 & - & .12 & -.09 & $.15^{*}$ & $.18^{*}$ & -.04 & -.04 & $.47^{\star \star}$ & .05 & -.01 \\
\hline 6. & Emo & .02 & $.45^{\star \star}$ & $-.21^{\star}$ & .10 & .09 & -- & $-.18^{\star}$ & $-.27^{\star *}$ & $.34^{\star \star}$ & $-.31^{\star *}$ & -.06 & .07 & $.69^{* *}$ & .12 \\
\hline 7. & Turn & -.09 & .06 & $-.19^{\star \star}$ & $.20^{*}$ & -.10 & .11 & - & -.07 & $.20^{\star \star}$ & $-.17^{\star}$ & $.34^{\star *}$ & -.06 & .12 & $.62^{\star \star}$ \\
\hline 8. & MPS & $.49^{\star \star}$ & .14 & .08 & .08 & $.25^{\star \star}$ & -.14 & -.14 & -- & $-.25^{\star *}$ & $.38^{\star *}$ & .00 & $.22^{* *}$ & $-.38^{* *}$ & $-.30^{*}$ \\
\hline 9. & Work & .06 & $.57^{\star \star}$ & -.15 & $.17^{\star}$ & .08 & $31^{\star *}$ & .05 & -.00 & -- & $-.28^{\star \star}$ & .01 & .03 & $.50^{\star \star}$ & $.25^{\star}$ \\
\hline 10. & Socia & $.29^{\star *}$ & -.01 & $.53^{\star \star}$ & -.08 & .00 & $-.20^{*}$ & -.07 & $.17^{*}$ & $-.26^{\star *}$ & - & -.12 & .06 & $-.36^{\star \star}$ & -.28 \\
\hline 11. & Unme & .01 & .14 & -.11 & $.56^{\star \star}$ & $-.19^{*}$ & .04 & $17^{*}$ & -.04 & $18^{*}$ & $-.22^{\star \star}$ & -- & -.04 & -.04 & $.29^{\star}$ \\
\hline 12. & Intrins & $24^{\star \star}$ & .15 & .06 & -.02 & $.49^{\star \star}$ & .14 & -.15 & $.29^{\star \star}$ & .13 & .06 & -.09 & -- & -.01 & -.08 \\
\hline 13. & Emotional exh. (2) & -.02 & $.18^{* *}$ & $-.17^{\star}$ & .04 & .06 & $.66^{\star *}$ & .06 & $-.26^{\star \star}$ & $.40^{\star \star}$ & $-.28^{\star \star}$ & .07 & .07 & - & $22^{*}$ \\
\hline 14. & Turnover int. (2) & -.15 & -.05 & -.06 & $.17^{\star}$ & -.08 & -.09 & $.45^{\star \star}$ & $-.27^{\star \star}$ & .05 & -.16 & $.33^{\star \star}$ & $-.17^{\star}$ & .03 & -. \\
\hline
\end{tabular}

Note. Correlations that reflect the hypothesized pattern of relationships, as well as the test-retest reliabilities are printed bold. Missing values were handled by listwise deletion. (1) = Time 1, (2) = Time 2 .

${ }^{\star} p \leq .05,{ }^{\star \star} p \leq .01$

A problem of the test-retest approach is that work characteristics and outcome variables may change over time (i.e., the true score may change over time), regardless of test-retest reliability of the measurement instrument used. Consequently, test-retest-reliabilities tend to be higher in short-term retests than in long-term retests. A rule of thumb is that test-retest reliabilities higher than .50 are acceptable (cf. Bollen, 1989; De Jonge, 1995). Table 5.5 shows that the test-retest reliabilities of most variables were moderate to high, with somewhat higher stabilities for sample 2 .

Furthermore, Table 5.5 shows that the cross-sectional correlations (i.e., time 1 work characteristics to time 1 outcome variables, and time 2 work characteristics to time 2 outcome variables) show that in both samples and at both measurement points the associations between work characteristics and outcome variables generally meet our expectations (as they are depicted in Figure 2.6). An exception is the relationship between the additive MPS index and intrinsic work motivation, which is not significant in sample 2 (teachers) at time 1 . At time 2 , however, this relationship is significant.

\subsubsection{Testing hypothesis I: the stability of the proposed pattern of relationships}

In order to test the stability of the pattern of relationships depicted in Figure 2.6 over samples, we performed a multi-sample analysis (MSA) for bank employees and teachers at time 1, and a MSA for bank employees and teachers at time 2. In addition, in order to test the stability of the proposed pattern of relationships over time, we compared two models with and without equivalent synchronous paths for both bank employees and teachers. In all analyses, the model relationships (betas) were 
specified according to the pattern of relationships depicted in Figure 2.6 (i.e., intrinsic work motivation is primarily related to task characteristics; emotional exhaustion is primarily related to workload and social support; and turnover intention is primarily related to unmet career expectations).

\section{Testing the stability of the proposed pattern of relationships over samples at time 1}

The results of the MSA at time 1 indicate that the basic pattern of relationships (Figure 2.6) holds in both samples (i.e., the proposed relationships are significant in both samples as is indicated by the $t$-values). The overall model fit (the fit of all models over all samples) was, however, not optimal. LISREL provides some suggestions to improve the model fit (modification indices). The following relationships were added stepwise. In sample 1 (bank employees) we added a relationship between social support and turnover intention. In sample 2 (teachers), we added relationships between the additive MPS index and emotional exhaustion, between workload and intrinsic work motivation, and also between social support and turnover intention. We added these relationships because we did not consider them theoretically unlikely (see also chapter 6 ). After these modifications the model fit appeared to be acceptable $\left(\chi^{2}=32.13, \mathrm{df}=26, \mathrm{n} . \mathrm{s}\right.$; $\mathrm{AGFI}=.96 ; \mathrm{RMSEA}=.04 ; \mathrm{AIC}=159.68 ; \mathrm{NNFI}=.95 ; \mathrm{CFI}=$ .98 ). These results imply that the pattern of relationships proposed in Figure 2.6 is stable across the two samples at time 1.

In order to find more evidence for the stability of the basic pattern of relationships over samples at time 1, we compared a model M1, in which the basic pattern of relationships (Figure 2.6) was specified as invariant (i.e., same strength and same direction) across the two samples and the additional relationships mentioned above were specified for each sample separately, with a less restrictive model, M2, in which the basic pattern of relationships was specified as non-invariant (i.e., same pattern but not the same strength) and the additional relationships were specified for each sample separately. It appeared that the difference in chi-square between M1 and M2 was not significant $\left(\Delta \chi^{2}(4)=2.25\right.$, n.s.), indicating that $M 2$ has no better fit than $M 1$ : the proposed basic pattern of relationships is invariant across both samples at time 1 . In addition, the chi-square value of M1 was not significant $\left(\chi^{2}=34.38, \mathrm{df}=30, \mathrm{n} . \mathrm{s}\right.$.) and the practical fit indices of $M 1$ also showed adequate values (RMSEA $=.03 ; A G F I=$ $.97 ; \mathrm{AlC}=153.97 ; \mathrm{NNFI}=.97 ; \mathrm{CFI}=.99$ ).

\section{Testing the stability of the proposed pattern of relationships over samples at time 2}

The MSA results for time 2 also showed that the basic pattern of relationships holds in both samples (i.e., significant $t$-values of the proposed relationships). Again, however, the model fit was not optimal when only the basic pattern of relationships was specified. This time, we added relationships between the additive MPS index on the one hand, and emotional exhaustion and turnover intention on the other hand in sample 1. In sample 2, we added relationships between the additive MPS index and 
social support on the one hand, and turnover intention on the other, and between the additive MPS index and emotional exhaustion (these relationships were added stepwise; see also chapter 6 ). After these modifications, the model fit was acceptable $\left(\chi^{2}=36.14, \mathrm{df}=25, \mathrm{n} . \mathrm{s}\right.$; $\mathrm{AGFI}=.93 ; \mathrm{RMSEA}=.05 ; \mathrm{AIC}=165.06 ; \mathrm{NNFI}=.91 ; \mathrm{CFI}=$ .97). Furthermore, we tested for invariance of the basic pattern of relationships by means of comparing the same models M1 (invariant model) and M2 (non-invariant model) as for time 1. It appeared that the difference in chi-square between $M 1$ and $M 2$ was not significant $\left(\Delta \chi^{2}(4)=.74, n . s\right.$. $)$, indicating that $M 2$ has no better fit than $M 1$ : the proposed basic pattern of relationships was invariant across both samples at time 2 . In addition, the chi-square value of $M 1$ was not significant $\left(\chi^{2}=36.88\right.$, $\mathrm{df}=29, \mathrm{n} . \mathrm{s}$.) and the practical fit indices of $M 1$ also showed adequate values (RMSEA $=.04 ; A G F I=$ $.97 ; \mathrm{AlC}=157.70 ; \mathrm{NNFI}=.95 ; \mathrm{CFI}=.98$ ).

In conclusion, the proposed basic pattern of relationships (Figure 2.6) seems to be invariant across the two study samples at both time 1 and time 2 .

\section{Testing the stability of the proposed pattern of relationships over time}

In order to find evidence for the stability of the proposed pattern of relationships over time, we tested for stationarity of relationships over time for each sample separately. We compared two models with (M1) and without (M2) an equivalent basic pattern of relationships. For sample 1 (bank employees), the results of the model comparison between M1 (model with an equivalent pattern of relationships over time) and M2 (model with a non-equivalent pattern of relationships over time) show that the difference in chi-square between these models is not significant $\left(\Delta \chi^{2}(4)=6.71\right.$, n.s.). This indicates that $M 2$ is not better than $M 1$ : for sample 1 (bank employees) the pattern of relationships is stable over time. For sample 2 (teachers), we also found that the difference in chi-square between $M 1$ and $M 2$ was not significant $\left(\Delta \chi^{2}(4)=\right.$ 8.80 , n.s.). $M 1$ appears to be the best model and the proposed pattern of relationships seems to be stable over time.

In sum, we may conclude that the first hypothesis (I) of this section has largely been confirmed. The proposed basic pattern of relationships as it is depicted in Figure 2.6 is stable over both time points and over both study samples. We were, however, not able to fully replicate the findings of chapter 4 regarding the additional relationships. That is, the relationships that were added in the current chapter are not exactly similar to the relationships that were added in section 4.2. In the present chapter, we added the following relationships once or twice: the relationships between the additive MPS index on the one hand and emotional exhaustion and turnover intention on the other, and the relationship between workload and intrinsic work motivation. The precise meaning of these relationships is not entirely clear (see chapter 6).

\subsubsection{Panel analyses: testing hypotheses II and $\mathbf{1 b}$ to $\mathbf{3 b}$}

In order to test hypothesis II ("Time 1 work characteristics influence time 2 outcome variables"; regular causation), we used structural equation modeling for longitudinal analyses. Covariance matrices were used as input for these analyses. The general 
panel model we used and its properties have been described in chapter 3 (see Figure 3.2) (see also De Jonge et al., 2001).

We compared the following nested structural equation models:

M1: a model with synchronous paths (arrows 1 and 2 in Figure 3.2) and temporal stabilities, but without cross-lagged structural paths. The pattern of synchronous paths is specified according to the findings in the previous step (section 5.2.2.3).

M2: a model that is identical to M1, but also includes cross-lagged paths from time 1 work characteristics to time 2 outcome variables, according to the pattern of relationships depicted in Figure 2.6 (regular causation, reflected by arrow 3 in Figure 3.2).

M3: a model that is identical to M1, but also includes cross-lagged paths from time 1 outcome variables to time 2 work characteristics, according to the pattern of relationships depicted in Figure 2.6 (reverse causation, reflected by arrow 4 in Figure 3.2).

M4: a model that is identical to M1, but includes both cross-lagged patterns (reciprocal causation, reflected by arrows 3 and 4 in Figure 3.2).

Models M3 and M4 were included in order to test the alternative explanations for a regular causal pattern of relationships between time 1 work characteristics and time 2 outcome variables. If model M2 appears to be the best model, there is considered to be support for hypothesis II. If M3 (reverse causation) appears to be the best model, hypothesis II will be rejected. When M4 is found to be the best model, reciprocal causation seems to exist, and hypothesis II will be confirmed only partially.

Testing causal predominance (hypothesis II) in sample 1: model comparisons The results of the model comparisons for sample 1 are shown in Table 5.6. 
Table 5.6 Fit measures and chi-square difference tests of nested structural equation models in sample 1 (bank employees, $N=148$ )

\begin{tabular}{|c|c|c|c|c|c|c|c|c|c|c|}
\hline Model & $\bar{\chi}^{2}$ & $d f$ & comp. & $\Delta x^{2}$ & $d f$ & $R M S E A$ & $A / C$ & $A G F I$ & NNFI & $\mathrm{CFI}$ \\
\hline M1: no cr & $82.85^{\star}\left(82.81^{\star}\right)$ & 55 & & & & .05 & 239.20 & .84 & .89 & .95 \\
\hline$M 2$ cross $W_{T 1}{ }^{a}-O V_{T 2}{ }^{a}$ & $64.10(64.04)$ & 51 & M1 & $18.75^{\star}$ & 4 & .03 & 228.42 & 87 & .95 & .98 \\
\hline$M 3:$ cross $O V_{T 2}-W C_{T 1}$ & $78.26^{*}\left(78.22^{*}\right)$ & 51 & M1 vs. M3 & 4.59 & 4 & .06 & 243.19 & 84 & .88 & .95 \\
\hline M4: both $\mathrm{c}$ & $59.51(59.45)$ & 47 & M1 vs. M4 & $23.36^{\star}$ & 8 & .03 & 232.43 & .87 & .94 & .98 \\
\hline & & & M2 vs. M4 & 4.59 & 4 & & & & & \\
\hline
\end{tabular}

\footnotetext{
${ }^{a} \mathrm{WC}=$ work characteristics, $\mathrm{OV}=$ outcome variables.

${ }^{b}$ For the likelihood ratio tests concerning the reciprocal model M4 (i.e., M1 vs. M4, M2 vs. M4, and M3 vs. M4) correlation matrices instead of covariance matrices were used (cf. De Jonge, 1995). The disadvantage of covariance matrices is that they do not have a standardized unit of measurement (cf. Jöreskog \& Sörbom, 1993). In the case of reciprocal relationships, the models have to be scale invariant in order to provide a precise hypothesis test. The chi-square-values that were computed using correlation matrices are presented between brackets. The practical fit measures were all computed using covariance matrices.
}

${ }^{*} p \leq .05$.

First, we compared M1 (no cross-lagged paths) and M2 (cross-lagged paths from time 1 work characteristics to time 2 outcomes). The chi-square difference between M1 and M2 was significant. This means that a model with cross-lagged relationships between work characteristics at time 1 and outcome variables at time 2 (M2) fits better to the data than a model without cross-lagged relationships (M1). Next, we compared M1 and $\mathrm{M} 3$ (cross-lagged paths from time 1 outcomes to time 2 work characteristics). The chi-square difference between M1 and M3 was not significant, indicating that M3 has no better fit than M1: time 1 outcome variables apparently do not exert a unique causal inference upon time 2 work characteristics. Furthermore, the chi-square difference between $\mathrm{M} 1$ and M4 was significant. A model with reciprocal cross-lagged relationships (M4) has a better statistical fit than a model without cross-lagged relationships (M1). However, the chi-square difference between the models $M 2$ and M4 was not significant. The latter finding implicates that addition of the reversed crosslagged paths between time 1 outcome variables and time 2 work characteristics does not improve the fit of a model with cross-lagged paths between time 1 work characteristics and time 2 outcome variables (M2).

We may conclude that in terms of chi-square relative to the degrees of freedom (parsimony), model $\mathrm{M} 2$ has the best fit of the four competing models in our analyses. When we consider the practical fit indices, model M2 also appears to have the best model fit (see Table 5.6): The NNFI and CFI are highest, and the AIC is lowest.

Considering the ECVIs of the various models (see chapter 4 for an explanation of this cross validation index), it appears that the ECVI of M2 is 1.66, which is lower than the ECVIs of the other models (ECVIs $\geq 1.68$ ) and the ECVI of the saturated model (ECVI $=1.97)$. Thus, $\mathrm{M} 2$ also seems to be the most stable model in this sample.

In conclusion, in sample 1, we have found support for hypothesis II: time 1 work characteristics seem to influence time 2 outcome variables. Alternative explanations have been ruled out. 


\section{Specific causal effects in sample 1 (hypotheses $1 \mathrm{~b}$ to $3 \mathrm{~b}$ ): cross-lagged relationships}

In addition to the determination of causal predominance, we examined the specific causal effects and measures of strength of individual relationships (cf. De Jonge et al., 2001; Rogosa, 1980). Figure 5.1 represents the estimated structural coefficients of the best fitting model in sample 1 (i.e., M2; the parameters have been standardized and only significant cross-lagged relationships and temporal stabilities are shown). It appears from Figure 5.1 that the cross-lagged relationships between the time 1 additive MPS index and time 2 intrinsic work motivation, and between time 1 workload and time 2 emotional exhaustion were significant, even after controlling for stability effects. The relationship between the time 1 additive MPS index and time 2 intrinsic work motivation was positive (as expected). However, the cross-lagged relationship between time 1 workload and time 2 emotional exhaustion appeared to be negative, which is contrary to expectations, and does not line up with the sign of the synchronous paths between workload and emotional exhaustion. This negative direct effect of time 1 workload on time 2 emotional exhaustion might be due to the so-called "suppressor" phenomenon, more precisely, negative suppression (i.e., a statistical artifact; see Maassen \& Bakker, 2000; Tzelgov \& Henik, 1991). Negative suppression occurs when two or more independent variables have positive predictive validity and intercorrelate positively, and one of the predictors receives a negative path coefficient. According to Maassen and Bakker (2000), there is a fair chance on a suppressor situation in a structural equation model that includes variables that are measured at two time points, and in which the stability coefficients and synchronous path coefficients are substantially larger than the cross-lagged path coefficients. It is likely that this situation has occurred in this panel study and has blurred the results. Maassen and Bakker (2000) suggest that we should not instantly move to the conclusion that there is a negative effect of time 1 workload on time 2 emotional exhaustion, because the negative sign of the cross-lagged relationship only occurs when time 2 workload and time 1 emotional exhaustion are included in the model (i.e., the bivariate relationship between time 1 workload and time 2 emotional exhaustion was positive, see Table 5.5). 


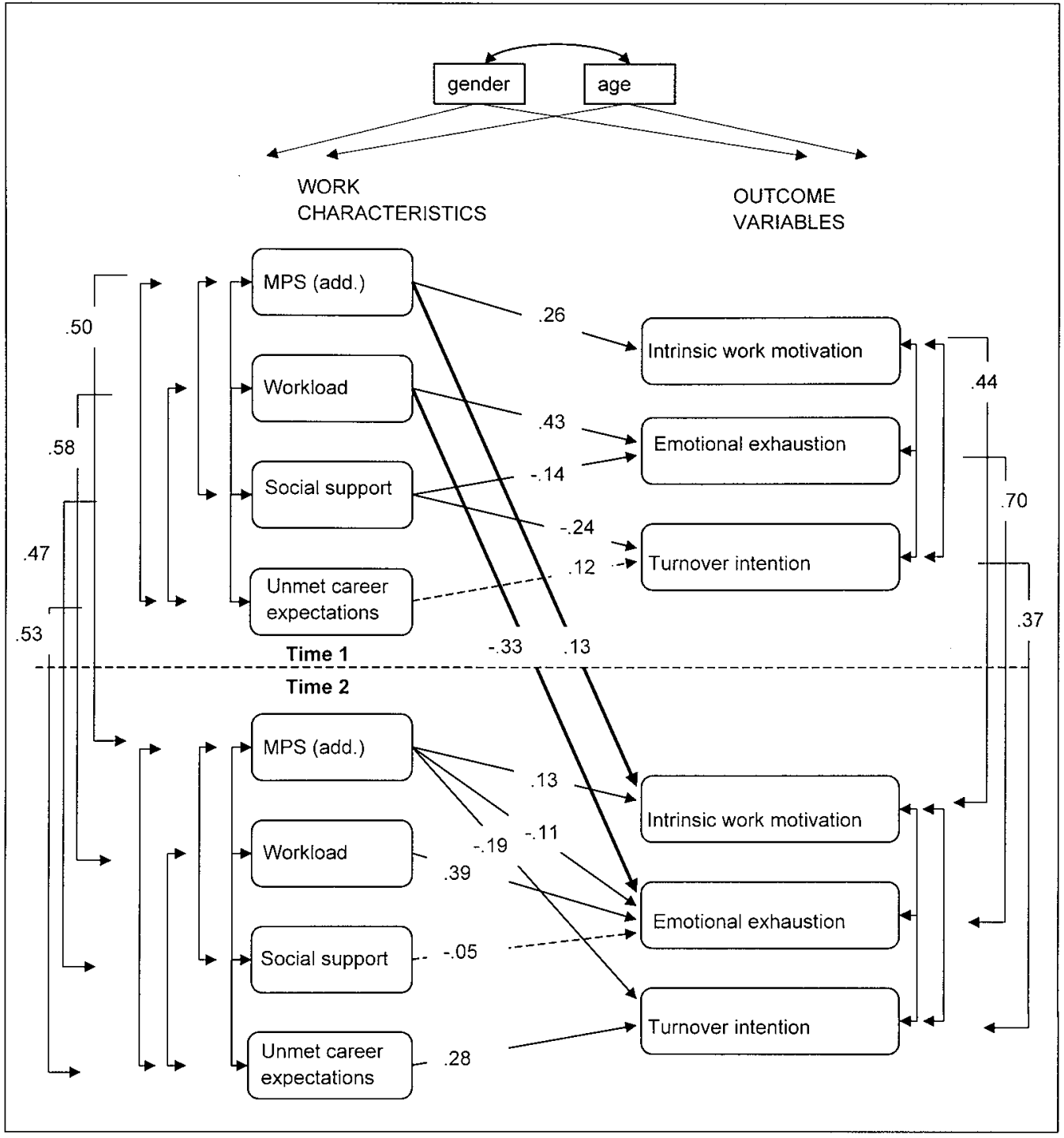

Figure 5.1 The final longitudinal structural equation model with standardized coefficients and significant cross-lagged relationships for sample 1 (bank employees, $N=148$ )

A possible way to interpret these results, might be to take the total effect of time 1 workload on time 2 emotional exhaustion into account (cf. De Jonge, 1995; Jöreskog \& Sörbom, 1993b; Saris \& Stronkhorst, 1984; Schumacker \& Lomax, 1996). Saris and Stronkhorst (1984), for instance, recommend to take both direct and total effects of variables into account. When only direct effects are considered, it is possible to overlook certain relevant effects, especially when the direct effect and total effect do not have (approximately) the same magnitude. It can be concluded from Figure 5.1 
that the indirect effect of time 1 workload on time 2 emotional exhaustion consists of two pathways: (1) time 1 workload $=>$ time 2 workload $=>$ time 2 emotional exhaustion, and (2) time 1 workload => time 1 emotional exhaustion => time 2 emotional exhaustion. The sum of the indirect effects was .52. Thus, the total effect of time 1 workload on time 2 emotional exhaustion was .19: higher levels of workload at time 1 lead to higher levels of emotional exhaustion at time 2. The total effect of time 1 MPS (additive index) on time 2 intrinsic work motivation was .28: higher levels of MPS, lead to higher levels of intrinsic work motivation. We can conclude from these results that hypotheses $1 b$ and $2 b$ have been confirmed. Hypothesis $3 b$ has not been confirmed ${ }^{3}$.

\section{Testing causal predominance (hypothesis II) in sample 2: model comparisons}

For sample 2 (teachers), we compared the same models (i.e., M1 to M4) as for sample 1 (bank employees). The results of the model comparisons for sample 2 (teachers) are shown in Table 5.7.

Table 5.7 Fit measures and chi-square difference tests of nested structural equation models in sample 2 (teachers, $N=188$ )

\begin{tabular}{|c|c|c|c|c|c|c|c|c|c|c|}
\hline Model & $x^{2}$ & $d f$ & comp. & $\Delta \chi^{2}$ & $d f$ & RMSEA & $\overline{A I C}$ & $A G F I$ & NNFI & CFI \\
\hline M1: no cross-lagged & $79.31^{*}\left(79.28^{*}\right)$ & 53 & & & & .05 & 241.12 & .87 & .94 & .97 \\
\hline$M 2$ : cross $W_{C}{ }_{T 1}{ }^{a}-O V_{T 2}{ }^{a}$ & $69.65^{\star}\left(69.64^{\star}\right)$ & 49 & M1 vs. M2 & $9.66^{\star}$ & 4 & .05 & 242.12 & .87 & .95 & .98 \\
\hline$M 3:$ cross $O V_{T 1}-W_{T 2}$ & $69.04^{*}\left(69.02^{*}\right)$ & 49 & M1 vs. M3 & $10.27^{*}$ & 4 & .04 & 238.47 & .88 & .95 & 98 \\
\hline \multirow[t]{3}{*}{ M4: both cross ${ }^{b}$} & $59.37(59.37)$ & 45 & M1 vs. M4 & $19.91^{*}$ & 8 & .04 & 239.70 & .88 & .96 & .99 \\
\hline & & & M2 vs. M4 & $10.27^{*}$ & 4 & & & & & \\
\hline & & & M3 vs. M4 & $9.65^{\star}$ & 4 & & & & & \\
\hline M5: equal cross ${ }^{\mathrm{b}}$ & $76.96^{\star}\left(75.04^{\star}\right)$ & 49 & M4 vs. M5 & $15.67^{*}$ & 4 & .05 & 246.55 & .87 & .93 & .97 \\
\hline
\end{tabular}

"WC = work characteristics, OV = outcome variables.

${ }^{b}$ For the likelihood ratio tests concerning the reciprocal models M4 and M5 (i.e., M1 vs. M4, M2 vs. M4, M3 vs. M4, and M4 vs. M5) correlation matrices instead of covariance matrices were used (cf. De Jonge, 1995). The disadvantage of covariance matrices is that they do not have a standardized unit of measurement (cf. Jöreskog \& Sörbom, 1993). In the case of reciprocal relationships, the models have to be scale invariant in order to provide a precise hypothesis test. The chi-square-values that were computed using correlation matrices are presented between brackets. The practical fit measures were all computed using covariance matrices.

${ }^{*} p \leq .05$.

First, we compared $M 1$ and $M 2$. The chi-square difference between $M 1$ and $M 2$ was significant. This finding indicates that a model with cross-lagged relationships between time 1 work characteristics and time 2 outcome variables (M2) fits the data better than a model without cross-lagged relationships (M1). Next, we compared M1 and M3

NOTE

${ }^{3}$ Some researchers may argue that the finding of regular causation to be predominant was partly based on a cross-lagged relationship that is subject to negative suppression. However, in several additional analyses we performed the test of causal predominance for both sample 1 and sample 2 in cross-lagged panel models in which the synchronous paths were not specified (only covariances were specified among the time 1 variables, and among the time 2 variables). With regard to causal predominance, the results of these analyses point in the same direction as the results above, and negative suppression did not occur in these analyses. We decided to report the models with synchronous paths, however, because we believe that these models are theoretically better interpretable. 
(cross-lagged paths from time 1 outcomes to time 2 work characteristics). The chisquare difference between $\mathrm{M} 1$ and $\mathrm{M} 3$ was also significant. This means that there also exists support for reverse causation: a model with cross-lagged relationships between time 1 outcome variables and time 2 work characteristics (M3) fits the data better than a model without cross-lagged relationships (M1). Furthermore, both types of cross-lagged patterns might be valid: The chi-square difference between $\mathrm{M} 1$ and M4 (model with both cross-lagged patterns) was significant, and the chi-square difference between $M 2$ and $M 4$ was also significant, just like the chi-square difference between M3 and M4. Apparently, a model with reciprocal causation fits better than a model with only regular or only reverse causation. To examine which pattern (regular or reverse) has causal predominance, we tested the equality of the cross-lagged patterns as is shown in Table 5.7 (model M5 versus M4). The chi-square difference between a model with (M5) and without equality constraints (M4) is significant, which means that M5 is not better than M4. The patterns are not equal: one of them is causally predominant. It may be concluded from Table 5.7 that M3 fits somewhat better than $\mathrm{M} 2$, the difference in fit is, however, not very clear. The CFI and NNFI fit measures, for instance, are equal for both $\mathrm{M} 2$ and M3. But still, in terms of chi-square relative to the degrees of freedom (parsimony), model M4 has the best fit of the four competing models. When we consider the practical fit measures, it appears that M4 shows the best combination of NNFI and CFI and the lowest RMSEA. When we consider the cross-validation indices (ECVIs) in sample 2, it appears that the ECVI of M4 is 1.35, which is lower than or equal to the ECVIs of the alternative models (ECVIs $\geq 1.35$ ) and lower than the ECVI of the saturated model (ECVI = 1.53). Thus, in sample 2, M4 appears to be the most stable model. Therefore, we conclude that M4 is the best model. Time 1 work characteristics seem to influence time 2 outcome variables, and time 1 outcome variables may have an effect on time 2 work characteristics.

We may conclude from these findings that hypothesis II (regular causation) has been supported in sample 2 also. At the same time, however, we were not able to exclude the alternative explanation of reverse causation. The sample 2 results provide no clear answer as to which pattern has causal predominance. There is some indication for reverse causation, however, the model including regular and reverse causation (M4) fitted the data better than a model with only reverse causation. 


\section{Specific causal effects in sample 2 (hypotheses $1 b$ to $3 b$ ): cross-lagged relationships}

Figure 5.2 represents the estimated structural coefficients of the best fitting model in sample 2 (i.e., M4; the parameters have been standardized and only significant crosslagged relationships and temporal stabilities are shown).

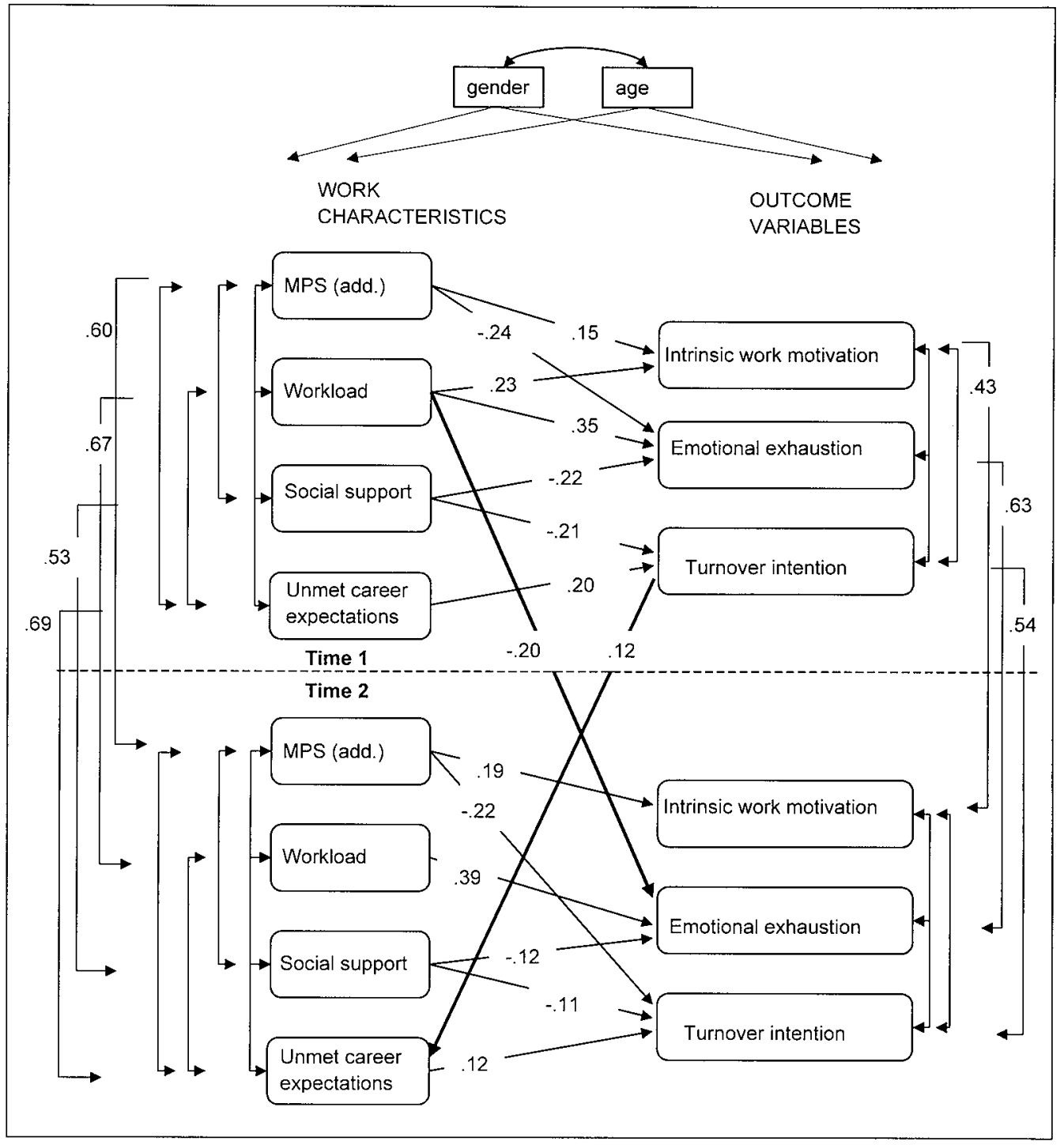

Figure 5.2 The final longitudinal structural equation model with standardized coefficients and significant cross-lagged relationships for sample 2 (teachers, $N=188$ ) 
It appears from Figure 5.2 that the cross-lagged relationships between time 1 workload and time 2 emotional exhaustion, and between time 1 turnover intention and time 2 unmet career expectations were significant. The direct effect of time 1 workload on time 2 emotional exhaustion is negative (i.e., -.20) (it is likely that this negative sign is due to negative suppression, see also sample 1). In order to interpret the results, we computed the total effects (cf. Saris \& Stronkhorst, 1984). The total effect of time 1 workload on time 2 emotional exhaustion is .29 (the sum of the indirect effects is .49). Thus, a higher level of workload leads to higher levels of emotional exhaustion. In addition, a higher level of turnover intention at time 1 leads to a higher level of unmet career expectations at time 2: the total effect is equal to the direct effect (i.e., .12). Hence, for sample 2, hypothesis $2 b$ has been confirmed, and hypotheses $1 b$ and $3 b$ have not been confirmed.

With regard to hypothesis 11 , it may be concluded that the causality of the proposed pattern of relationships appeared not to be completely stable over the two samples. In sample 1 , the cross-lagged pattern of relationships between time 1 work characteristics and time 2 outcome variables is predominant, and in sample 2, a reciprocal pattern of relationships is predominant. Thus, hypothesis 11 has only been confirmed partially in this panel study.

The implications of the results of this longitudinal analyses of the relationships between work characteristics and psychological outcome variables will be discussed more extensively in chapter 6 .

In the next section, we will examine the longitudinal influence of personal characteristics on the pattern of relationships between work characteristics and psychological outcome variables.

\subsection{A longitudinal analysis of the additive and moderating influence of personality on the relationships between work characteristics and psychological well-being}

\subsubsection{Hypotheses, background and data analyses}

In the present section, we will present the results of the longitudinal analyses regarding research question 2 . We aim to test the specific causal influence of the three personal characteristics growth need strength, negative affectivity, and upward striving, on the proposed pattern of relationships between work characteristics and psychological outcome variables, as well as their direct influence on the outcome variables. In section 4.3, we examined the cross-sectional data with regard to the personal characteristics. In the present section, we will use the panel data.

The part of the research model that is under investigation in this section, is schematically shown in Figure IV. 

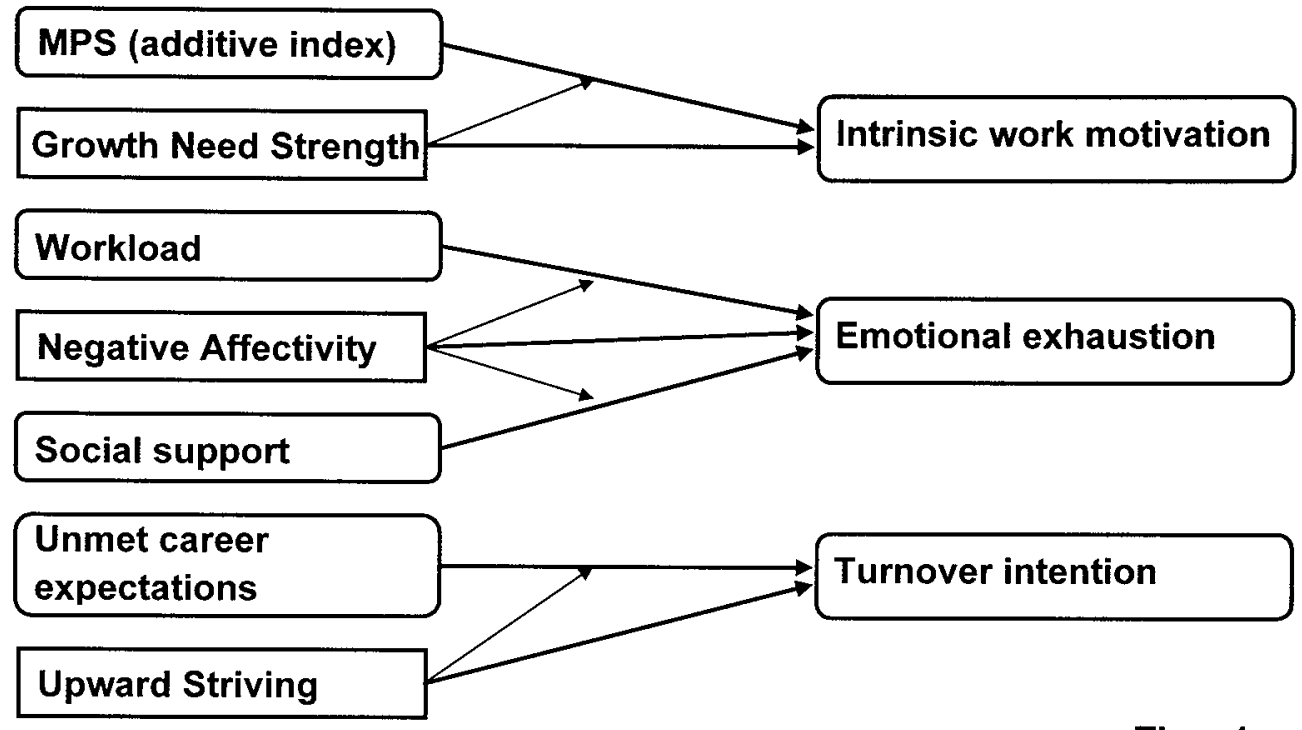

Time 1

Time 2
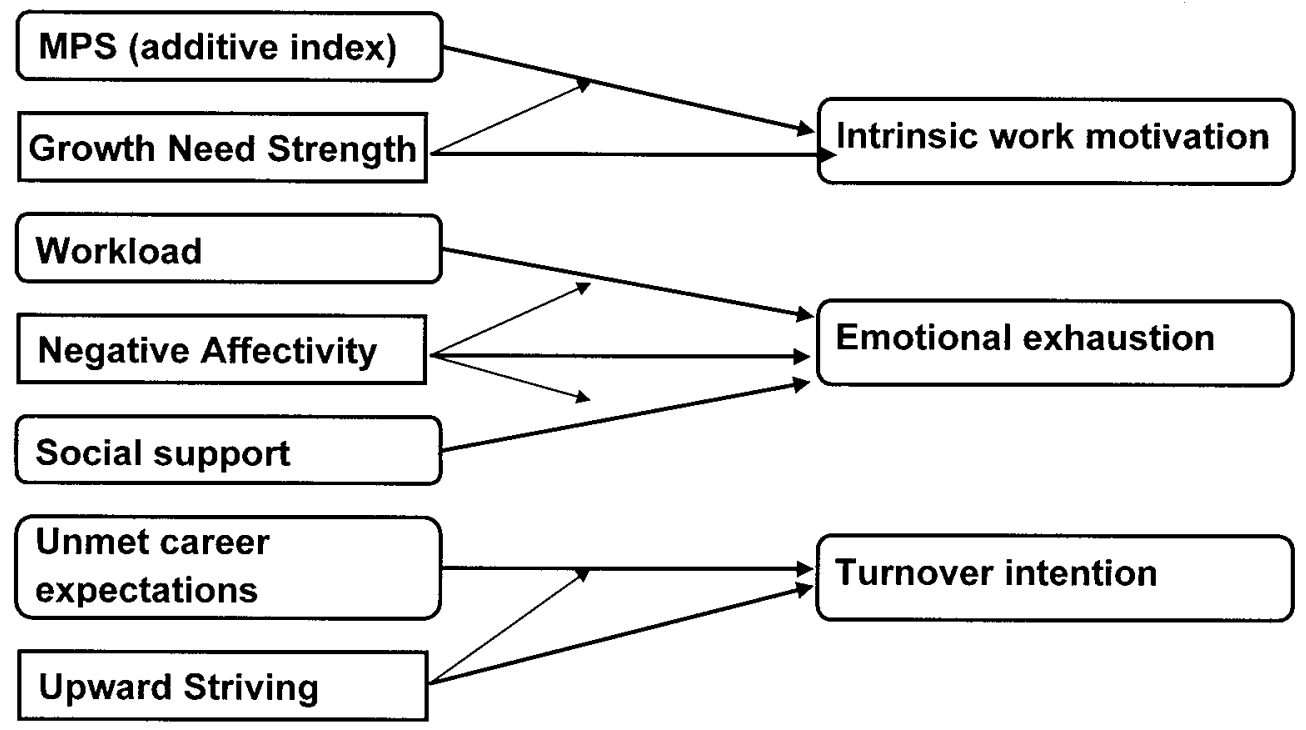

Figure IV Schematic representation of the part of the research model that is under investigation in section 5.3 
In chapter 3, we formulated one general and seven more specific hypotheses regarding the longitudinal influence of personal characteristics:

III. Time 1 personal characteristics influence time 2 outcome variables.

4b. Growth need strength has an additive positive effect on intrinsic work motivation, over and above the effect of task characteristics (combined in the additive MPS).

5b. Growth need strength has an interactive effect on the relationship between task characteristics (combined in the additive MPS) and intrinsic work motivation (the higher the level of growth need strength, the stronger the relationship between task characteristics and intrinsic work motivation).

6b. Negative affectivity has an additive positive effect on emotional exhaustion, over and above the effects of workload and social support.

7b. Negative affectivity has an interactive effect on the relationship between workload and emotional exhaustion (the higher the level of negative affectivity, the stronger the relationship between workload and emotional exhaustion).

8b. Negative affectivity has an interactive effect on the relationship between social support and emotional exhaustion (the higher the level of negative affectivity, the stronger the relationship between social support and emotional exhaustion).

9b. Upward striving has an additive positive effect on turnover intention, over and above the effect of unmet career expectations.

10b. Upward striving has an interactive effect on the relationship between unmet career expectations and turnover intention (the higher the level of upward striving, the stronger the relationship between unmet career expectations and turnover intention).

As we have mentioned in section 5.1, we will analyze the data from both samples simultaneously. That is, we combined the two samples into one large sample consisting of all bank employees and teachers who participated at both measurement points.

Our study sample in this section (the panel group) consists of 338 employees (150 bank employees and 188 teachers) who filled out both questionnaires (i.e., $30 \%$ of the initial group). The mean age in the panel group at time 1 was 43.80 years $(S D=8.3)$. Sixty-five percent of this group were male and $73 \%$ were employed full-time.

The number of dropouts (bank employees and teachers who participated at the first wave, but not at the second) was 289 .

\section{Data analyses}

We analyzed the data in four steps. Step one is a preliminary step in which we performed the non-response analyses: that is, we determined whether there were differences between employees in the panel group and the dropouts with regard to variable means as well as the interrelationships among variables. Furthermore, we investigated several other threats to the internal validity of the study results. In addition, in this first step, we performed several preliminary analyses of the panel data (means, standard deviations, percentage of employees scoring negative on the 
variables, test-retest reliabilities and zero-order Pearson correlations among the study variables).

In step two, we tested the direct longitudinal effects of the personal characteristics on the outcome variables, as a prerequisite to testing the additive effects (see also section 4.3). We decided to perform this analysis, in order to find preliminary evidence for the causal inference of personal characteristics on outcome variables. When direct effects are indeed found to be present, we can go on testing for additive effects of personal characteristics over and above the effects of work characteristics. If the direct effects of personal characteristics on the outcome variables appear not to be significant, it seems meaningless to go on testing for additive longitudinal effects (cf. Jöreskog \& Sörbom, 1993a). Furthermore, hypothesis III was tested in this step.

In the third step, we tested the additive effects of the personal characteristics that proved to have significant direct effects (hypotheses $4 b, 6 b$, and $9 b$ ). In the fourth step, finally, we tested the moderating effects (hypotheses $5 b, 7 b, 8 b$, and $10 b$ ) of all personal characteristics on the relationships between the work characteristics and the outcome variables (the absence of direct effects, does not necessary imply that there are no moderating effects; cf. Aiken \& West, 1991).

Just like in previous sections, we simplified the covariance structure by assuming that the latent and observed variables were identical (see also section 3.6.2), and we controlled for the demographic variables gender and age (cf. Schumacker \& Lomax, 1996).

\subsubsection{Results}

\subsubsection{Non-response analysis and preliminary analyses Non-response analysis}

First, we determined whether there were mean differences between employees in the panel group and the dropouts with regard to the demographic and job variables by means of $t$-tests (and a chi-square test for the demographic variable gender). The results of these analyses are shown in Table 5.8. 
Table 5.8 T-tests of mean differences of time 1 demographic and job variables between dropouts and the panel group for the combined sample

\begin{tabular}{|c|c|c|c|c|}
\hline \multirow{2}{*}{\multicolumn{2}{|c|}{ Variables }} & \multicolumn{3}{|c|}{ Combined sample } \\
\hline & & $t / x^{2 a}$ & $d f$ & $p$ \\
\hline 1. & Gender $^{a}$ & 13.50 & 1 & .00 \\
\hline 2. & Age & 2.55 & 584 & .01 \\
\hline 1. & MPS (additive index) & 1.39 & 584 & .17 \\
\hline 2. & Workload & .63 & 584 & .53 \\
\hline 3. & Social support & .95 & 584 & .34 \\
\hline 4. & Unmet career expectations & 1.46 & 584 & .14 \\
\hline 5. & Growth need strength & 1.63 & 584 & .10 \\
\hline 6. & Negative affectivity & -2.44 & 584 & .02 \\
\hline 7. & Upward striving & -.94 & 584 & .35 \\
\hline 8. & Intrinsic work motivation & .21 & 584 & .84 \\
\hline 8. & Emotional exhaustion & -1.04 & 584 & .30 \\
\hline 10. & Turnover intention & -1.52 & 584 & .13 \\
\hline
\end{tabular}

Note. Significant p-levels are printed in italics (alpha was set at .10).

${ }^{a}$ For gender we performed a chi-square test instead of a $t$-test.

It can be concluded from Table 5.8 that there exist no significant differences between the panel group and the dropouts with regard to the mean values of work characteristics, two of the three personal characteristics and all outcome variables (for these variables the $p$-values are higher than or equal to .10). With regard to negative affectivity, the dropouts scored somewhat higher than the panel group, the mean difference was rather small, however (less than one quarter of the standard deviation). Furthermore, some minor demographic differences were found between the panel group and the dropouts: It appeared that the panel group was somewhat older than the dropouts (i.e., 1.7 years, which is less than one quarter of the standard deviation) and the panel group included slightly more males than the dropouts $\left(\chi^{2}(1)=13.50, p \leq\right.$ $.05)$.

In addition, we tested whether the intercorrelations among the study variables and causal relationships among the study variables are equal for the panel group and the dropouts (i.e., causal homogeneity; Kessler \& Greenberg, 1981). First, we performed a cross-sectional, multi-group structural equation analysis using two corresponding correlation matrices (one matrix for the panel group and one matrix for the dropouts). We compared a model in which we specified the intercorrelations among the study variables as invariant for both the dropouts and the panel group, with a model in which these intercorrelations were specified as non-invariant across both groups (Bentler \& Bonett, 1980; Jöreskog \& Sörbom, 1993b). The invariant model appeared to fit better than the non-invariant model. The results showed no significant differences regarding the intercorrelations among the study variables between the panel group and the dropouts $\left(\Delta \chi^{2}(55)=62.24\right.$, n.s. $)$.

Second, we tested whether the theoretically proposed pattern of relationships between work characteristics and personal characteristics on the one hand, and psychological outcome variables on the other (see Figure 2.6 and the hypotheses $4 b, 6 b$, and 9b) was invariant for the panel group and the dropouts. Again, we compared a model in which these relationship were specified as invariant, with a model in which these 
relationships were specified as non-invariant. It appeared that the difference in chisquare was not significant $\left(\Delta \chi^{2}(10)=9.93\right.$, n.s.). This implies that the pattern of relationships is invariant across the panel group and the dropouts. Thus, we conclude that the dropouts were comparable with the panel group and that, in this respect, no serious selection problems due to panel loss have occurred.

Finally, in order to test whether other biases due to wave non-response (i.e., multiple testing bias, history effects, regression to the mean, and non-response bias at time 1) have occurred, we performed several other comparisons for this combined sample.

Table 5.9 Comparison of several groups of participants for the combined sample in order to exclude biases due to wave non-response

\begin{tabular}{|c|c|c|c|c|c|c|c|c|c|c|c|c|}
\hline \multirow[t]{2}{*}{ Variables } & \multicolumn{3}{|c|}{ G1\&2 T2 vs. G2 } & \multicolumn{3}{|c|}{ G1 vs. G2 } & \multicolumn{3}{|c|}{ G1\&2 T1 vs. T2 } & \multicolumn{3}{|c|}{ G1\&2 T1 vs. G2 } \\
\hline & $t / \chi^{2 a}$ & $d f$ & $p$ & $t / \chi^{2 a}$ & $d f$ & $p$ & $t / \chi^{2 \mathrm{a}}$ & $d f$ & $p$ & $t / \chi^{2 a}$ & $d f$ & $p$ \\
\hline Gender $^{a}$ & 01 & 1 & .94 & 4.48 & 1 & .03 & .03 & 1 & .87 & .03 & 1 & .86 \\
\hline Age & 2.46 & 410 & .02 & .07 & 361 & .94 & -1.53 & 668 & .13 & 1.53 & 410 & .13 \\
\hline MPS & 1.13 & $4 c$ & .26 & -.53 & 363 & 60 & .98 & 666 & .3 & 56 & 409 & .58 \\
\hline Worklc & 21 & 411 & .76 & -1.20 & 36 & .23 & -1.73 & 669 & .09 & -.73 & 10 & .47 \\
\hline Soc. & .01 & 409 & .99 & -1.64 & 358 & .10 & -1.91 & 667 & .06 & -1.13 & 408 & .26 \\
\hline 4. Unmet car. & -.81 & 410 & .42 & -.48 & 362 & .63 & 2.31 & 668 & .02 & 66 & 410 & .51 \\
\hline GNS & -.87 & 407 & .38 & -.18 & 365 & .85 & 2.54 & 666 & .01 & .69 & 411 & .49 \\
\hline NA & .53 & 407 & .59 & 1.79 & 363 & .07 & -.29 & 666 & .77 & .35 & 411 & .73 \\
\hline US & 02 & 407 & .00 & -1.49 & 364 & .14 & 1.47 & 667 & .14 & -2.01 & 410 & .05 \\
\hline Intr. w & -1.16 & 410 & .25 & 1.45 & 365 & .15 & .71 & 668 & .48 & 1.52 & 410 & .13 \\
\hline Emot. exh. & 01 & 409 & .99 & .40 & 365 & .69 & -.23 & 667 & .82 & -.15 & 410 & .88 \\
\hline 10. Turnover int. & 1.19 & 405 & .23 & -.49 & 362 & .62 & -.44 & 662 & 66 & -1.51 & 407 & 13 \\
\hline
\end{tabular}

Note. $G 1=$ People who only participated at time $1 ; G 2=$ people who only participated at time $2 ; G 1 \& 2=$ panel group; $T 1=$ time $1 ; T 2=$ time 2 . Significant $p$-levels are printed in italics (alpha was set at 10 ).

${ }^{a}$ For gender we performed a chi-square test instead of a $t$-test

It can be concluded from Table 5.9 that almost all $t$-tests and chi-square tests are not significant. Exceptions are found with regard to the personal characteristics upward striving, and with regard to several work and personal characteristics in the third comparison (i.e., panel group at T1 versus panel group at T2). We conclude that some bias due to regression to the mean may have occurred, but that there is no serious bias due to multiple testing, history effects or wave non-response (cf. Daniels \& De Jonge, 2001).

\section{Preliminary analyses of the panel data}

In order to gain a first insight in the panel data we computed the means, standard deviations, percentage of employees scoring negative on the study variables, testretest-reliabilities, and zero-order Pearson correlations among the study variables. The results of these analyses are shown in Tables 5.10 and 5.11. 
Table 5.10 Means (M), standard deviations (SD) and percentage scoring negative (\% neg.) of the combined sample in the panel study

\begin{tabular}{|c|c|c|c|c|}
\hline \multicolumn{2}{|c|}{ Variables (range) } & \multicolumn{3}{|c|}{ Combined sample $(N=338)$} \\
\hline & & $M$ & SD & $\%$ neg. $^{a}$ \\
\hline 1. & MPS (additive index) (1) $(1-7)^{6}$ & 5.14 & .67 & 6.0 \\
\hline 2. & Workload (1) (1-5) & 3.40 & .63 & 48.5 \\
\hline 3. & Social support (1) $(1-4)^{b}$ & 3.05 & .42 & 12.8 \\
\hline 4. & Unmet career expectations (1) (1-5) & 3.39 & .76 & 46.7 \\
\hline 5. & GNS (1) $(1-7)^{\mathrm{b}}$ & 5.88 & .71 & 2.4 \\
\hline 6. & $N A(1)(1-5)$ & 2.10 & 62 & 2.7 \\
\hline 7. & US (1) $(1-5)^{b}$ & 2.87 & .49 & 26.7 \\
\hline 8. & Intrinsic work motivation (1) $(1-7)^{b}$ & 6.00 & .63 & .9 \\
\hline 9. & Emotional exhaustion (1) (1-7) & 2.83 & 1.29 & 10.1 \\
\hline 10. & Turnover intention (1) (1-2) & 1.29 & 31 & 11.1 \\
\hline 11. & MPS (additive index) (2) $(1-7)^{\mathrm{b}}$ & 5.21 & .68 & 4.7 \\
\hline 12. & Workload (2) (1-5) & 3.48 & .60 & 46.9 \\
\hline 13. & Social support (2) $(1-4)^{\mathrm{b}}$ & 3.11 & .42 & 9.2 \\
\hline 14. & Unmet career expectations (2) (1-5) & 3.27 & .68 & 39.0 \\
\hline 15. & GNS (2) $(1-7)^{\mathrm{b}}$ & 5.73 & .85 & 3.9 \\
\hline 16. & $N A(2)(1-5)$ & 2.11 & .60 & 2.4 \\
\hline 17. & US (2) $(1-5)^{\mathrm{b}}$ & 2.81 & .47 & 27.8 \\
\hline 18. & Intrinsic work motivation $(2)(1-7)^{b}$ & 5.98 & 60 & .4 \\
\hline 19. & Emotional exhaustion (2) (1-7) & 2.84 & 1.11 & 8.4 \\
\hline 20. & Turnover intention (2) $(1-2)$ & 1.30 & .32 & 12.7 \\
\hline
\end{tabular}

Note. (1) = Time 1, (2) = Time 2 .

a In order to determine whether a respondent scores negative on a scale, we specified cut off points. These cut off points were specified as follows: 1.5 for a $1-2$ scale, 2.5 for a $1-4$ scale, 2.5 and 3.5 for a $1-5$ scale, and 3.5 and 4.5 for a $1-7$ scale.

${ }^{b}$ For these variables a relatively high mean score should be interpreted positively, for the other variables a relatively high mean score should be interpreted negatively.

In accordance with previous results, Table 5.10 shows that also for the combined sample, the most salient problems occur with regard to workload and unmet career expectations. When we apply the clinical cut off points suggested by Schaufeli and Van Dierendonck $(1995,2000)$ to emotional exhaustion, it appears that at time $1,30 \%$ score high, and $6 \%$ score very high on this variable. At time 2 these figures are $30 \%$ and $5 \%$, respectively. With regard to the personal characteristics, we can conclude that the percentage of employees scoring high on negative affectivity is rather moderate. The percentage of employees scoring negative on upward striving is rather high, but as we have argued in section 4.3 , this might not be a problem. Finally, over time no striking changes seem to have occurred in any of the study variables. 


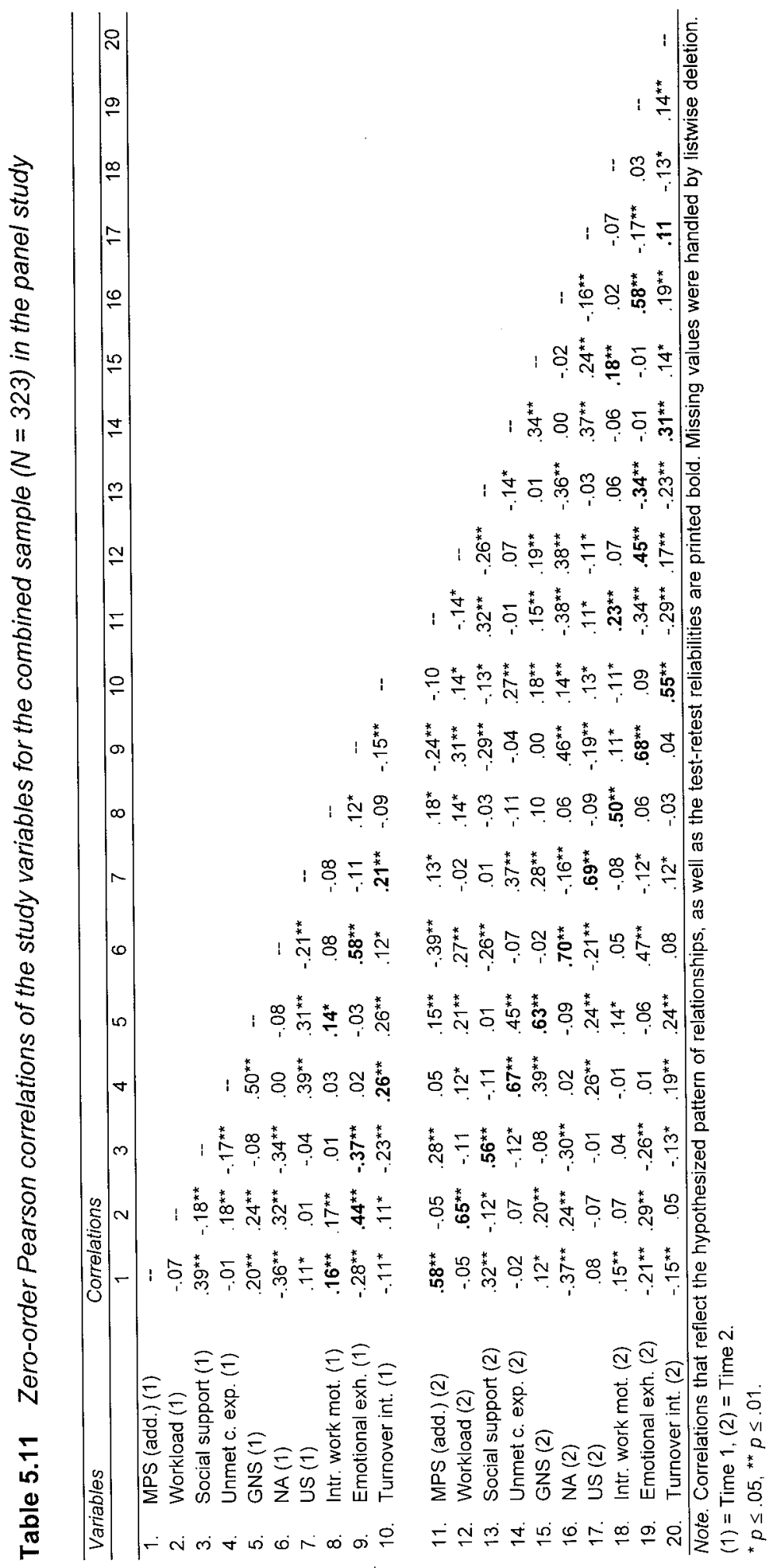


Table 5.11 shows that the test-retest reliabilities of most variables were moderate to high, with somewhat higher stabilities for the personal characteristics. The crosssectional correlations (i.e., time 1 work and personal characteristics to time 1 outcome variables, and time 2 work and personal characteristics to time 2 outcome variables) showed that the associations between work characteristics and personal characteristics on the one hand and psychological outcome variables on the other, generally meet our expectations. That is, at both measurement points, growth need strength is correlated with intrinsic work motivation, and negative affectivity is correlated with emotional exhaustion. At time 1, upward striving is correlated with turnover intention. One salient additional relationship, is that growth need strength is at both time points significantly correlated with turnover intention (see also section 4.3).

\subsubsection{Testing hypothesis III: the direct longitudinal effects of personal characteristics on the outcome variables}

Our second step concerns a test of the direct longitudinal effects of the personal characteristics on the outcome variables. Testing all longitudinal additive effects of all personal characteristics at once (i.e., including the longitudinal effects of the work characteristics) would yield a very complex structural equation model (with two exogenous and twenty endogenous variables, spread over two time points). A suchlike model can hardly be interpreted (cf. Saris \& Stronkhorst, 1984). Moreover, considering our sample size, the power of the test of such a complex model, would be limited (cf. Schumacker \& Lomax, 1996). In section 4.3, we have argued that testing a model including only personal characteristics and outcomes (i.e., testing direct effects) prior to testing the additive effects over and above the effects of the work characteristics (that is, simplifying the theory or model, see Saris \& Stronkhorst, 1984; see also section 4.3.2.1), might be a possible solution to this problem. This procedure provides the opportunity to gain a clear insight in the unique effects of the personal characteristics on the outcome variables. In the present section we use this second step to select personal characteristics for the third step (i.e., testing the additive effects).

In section 4.3.2.1, we have already seen that this procedure may lead to attenuation (i.e., underestimation) or inflation (i.e., overestimation) of the direct relationships between the personal characteristics and outcome variables. In the case of attenuation, the personal characteristic may erroneously be excluded from further analyses in this section (cf. Spector et al., 2000). In the case of inflation, there is not really a problem, because in further analyses, the work characteristics will be included. According to Williams and Brown (1994), however, attenuation will only occur, when the correlation between the work characteristic and the personal characteristic and the correlation between the work characteristic and the outcome, have a different sign. As can be concluded from Table 5.11, this situation is not present in this study. Therefore, we believe that the chance that the test of the direct effects of the personal characteristics leads to erroneous conclusions, is very small eventually. 
In order to test the direct longitudinal influence of the personal characteristics on the outcome variables, we used a cross-lagged panel model consisting of personal characteristics and outcome variables at time 1 and time 2 (see Figure 5.3). The model relationships (betas) were specified as follows. Growth need strength influences intrinsic work motivation, negative affectivity influences emotional exhaustion, and upward striving influences turnover intention.

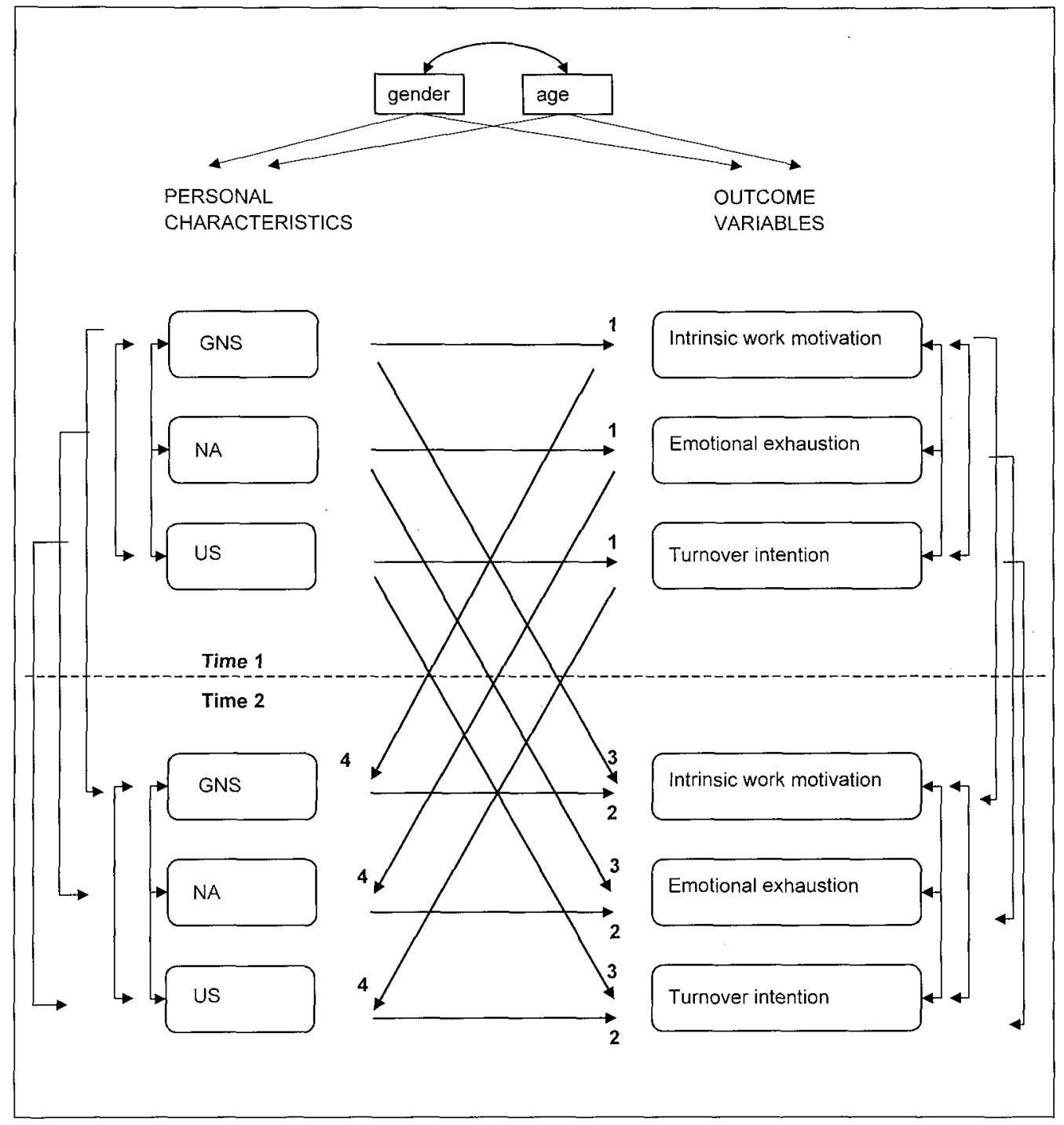

Figure 5.3 Cross-lagged structural panel model of personal characteristics and psychological outcome variables

We compared the following nested structural equation models: 
M1: a model with synchronous paths (from time 1 personal characteristics to time 1 outcomes, and from time 2 personal characteristics to time 2 outcomes) and temporal stabilities, but without cross-lagged structural paths (reflected by arrows 1 and 2 in Figure 5.3).

M2: a model that is identical to $M 1$, but that also includes cross-lagged paths from time 1 personal characteristics to time 2 outcomes (regular causation, reflected by arrows 3 in Figure 5.3).

M3: a model that is identical to M1, but that also includes cross-lagged paths from time 1 outcome variables to time 2 personal characteristics (reverse causation, reflected by arrows 4 in Figure 5.3).

M4: a model that is identical to $M 1$, but that also includes both cross-lagged patterns of relationships (reciprocal causation, reflected by arrows 3 and 4 in Figure 5.3).

Models M3 and M4 were included in order to test the alternative explanations for a regular causal pattern of relationships between time 1 personal characteristics and time 2 outcome variables. The results of the model comparisons are depicted in Table 5.12 .

Table 5.12 Fit measures and chi-square difference tests of nested structural equation models in step 2 (testing direct longitudinal effects of personal characteristics in the combined sample)

\begin{tabular}{|c|c|c|c|c|c|c|c|c|c|c|}
\hline Model & $x^{2}$ & $d f$ & comp. & $\Delta \chi^{2}$ & $d f$ & RMSEA & $A I C$ & $A G F I$ & NNFI & $C F I$ \\
\hline M1: no cross-lagged & $95.87^{*}$ & 42 & & & & .06 & 218.36 & .90 & .92 & .96 \\
\hline$M 2:$ cross $\mathrm{PC}_{\mathrm{T} 1}{ }^{\mathrm{a}}-\mathrm{OV}_{\mathrm{T} 2}{ }^{\mathrm{a}}$ & $85.14^{*}$ & 39 & M1-M2 & $10.73^{*}$ & 3 & .06 & 212.13 & .91 & .92 & .97 \\
\hline M3: cross $O \mathrm{~V}_{\mathrm{T} 2}-\mathrm{PC}_{\mathrm{T} 1}$ & $93.23^{\star}$ & 39 & M1-M3 & 2.64 & 3 & .06 & 222.31 & .90 & .91 & .96 \\
\hline M4: both cross & $82.50^{*}$ & 36 & $\begin{array}{l}M 1-M 4 \\
\text { M2-M4 }\end{array}$ & $\begin{array}{l}13.37^{*} \\
2.64\end{array}$ & $\begin{array}{l}6 \\
3\end{array}$ & .06 & 216.44 & .90 & .92 & .97 \\
\hline
\end{tabular}

${ }^{a} \mathrm{PC}=$ Personal Characteristics, OV $=$ Outcome Variables

${ }^{*} p \leq .05$.

First, we compared M1 (no cross-lagged paths) and M2 (cross-lagged paths from time 1 personal characteristics to time 2 outcome variables: regular causation). Table 5.12 shows that the chi-square difference between $M 1$ and M2 was significant. M2 has a better fit than M1. Furthermore, the chi-square difference between $M 1$ and $M 3$ (reverse causation) was not significant. The chi-square difference between M1 and M4 (reciprocal causation) was significant, but the chi-square difference between M2 (regular causation) and M4 (reciprocal causation) was not: this means that the addition of reversed cross-lagged paths to a model with only regular paths between personal characteristics and outcome variables does not significantly improve model fit: M2 (i.e., regular causation) appears to be the best model. Time 1 personal characteristics seem to influence time 2 outcome variables. Although the chi-square statistic of M2 was still significant, fit indices that are less sensitive to sample size 
indicated a good fit (i.e., the NNFI of M2 was .92). Therefore, we decided not to adjust the model any further (cf. Bentler, 1990; De Jonge, 1995; Schumacker \& Lomax, 1996).

It has appeared hitherto that a regular causation pattern between personal characteristics and outcome variables is predominant. Hence, hypothesis III seems to be confirmed by the data. In order to provide preliminary evidence for our hypotheses regarding additive effects $(4 b, 6 b$ and $9 b)$, however, we examined the specific crosslagged effects and measures of strength of individual relationships (cf. De Jonge et al., 2001). All synchronous relationships we specified in $M 2$, were significant at both time points. In addition, the cross-lagged path between time 1 negative affectivity and time 2 emotional exhaustion was significant, even after controlling for stability effects. The beta coefficients of the significant structural paths are depicted in Table 5.13.

Table 5.13 Beta coefficients of the significant paths in model M2 in step 2 (regular causation model of personal characteristics and outcome variables)

\begin{tabular}{lc}
\hline \multicolumn{1}{c}{ Structural path } & Beta coefficient $^{\text {a }}$ \\
\hline Time 1 GNS to time 1 intrinsic work motivation & .17 \\
Time 1 NA to time 1 emotional exhaustion & .55 \\
Time 1 US to time 1 turnover intention & .13 \\
Time 2 GNS to time 2 intrinsic work motivation & .15 \\
Time 2 NA to time 2 emotional exhaustion & .42 \\
Time 2 US to time 2 turnover intention & .07 \\
Time 1 NA to time 2 emotional exhaustion & -.17 \\
\hline
\end{tabular}

${ }^{a}$ These beta coefficients are all significant at an alpha level of .05.

Table 5.13 shows that the beta coefficient of the cross-lagged relationship between time 1 negative affectivity and time 2 emotional exhaustion is negative, which is contrary to our expectations and does not line up with the sign of the synchronous paths between negative affectivity and emotional exhaustion. This negative direct effect of time 1 negative affectivity on time 2 emotional exhaustion might again be due to negative suppression. In section 5.2, we have argued that negative suppression may easily occur in cross-lagged panel models with two waves (see also Maassen \& Bakker, 2000). The negative sign of the cross-lagged relationship between negative affectivity and emotional exhaustion only occurs when time 2 negative affectivity and time 1 emotional exhaustion are included in the model (i.e., the bivariate relationship between time 1 negative affectivity and time 2 emotional exhaustion was positive, see also table 5.11). In order to interpret the results, we computed the total effect of time 1 negative affectivity on time 2 emotional exhaustion. The sum of the indirect effects was .63. Thus, the total effect of time 1 negative affectivity on time 2 emotional exhaustion was $.63-.17=.46$ : higher levels of negative affectivity at time 1 lead to higher levels of emotional exhaustion at time 2 .

In sum, we may conclude from the findings in this second step, that the only significant cross-lagged relationship, was the relationship between time 1 negative affectivity and time 2 emotional exhaustion. Hypotheses $4 \mathrm{~b}$ and $9 \mathrm{~b}$ can be rejected. Therefore, in step 3 , we focused at testing the additive effect of negative affectivity (hypothesis $6 \mathrm{~b}$ ). 


\subsubsection{Testing hypothesis $6 \mathrm{~b}$ : the longitudinal additive effect of negative affectivity}

In order to test the longitudinal additive effect of negative affectivity on emotional exhaustion (third step of analyses), over and above the effects of the work characteristics workload and social support, we added this personal characteristic to a structural equation model containing work characteristics and outcome variables (as proposed by Janssen, De Jonge \& Bakker, 1999) at both time 1 and time 2. We compared the following nested models by means of the chi-square difference test:

M1: a model with synchronous and reciprocal cross-lagged paths between work characteristics and outcome variables. No paths between negative affectivity and emotional exhaustion are specified.

M2: a model that is identical to M1, but also includes the synchronous paths between negative affectivity and emotional exhaustion (at both time 1 and time 2).

M3: a model that is identical to $\mathrm{M} 2$, and also includes the cross-lagged relationship between time 1 negative affectivity and time 2 emotional exhaustion (regular causation of negative affectivity).

M4: a model that is identical to $M 2$, but also includes the cross-lagged relationship between time 1 emotional exhaustion and time 2 negative affectivity (reverse causation of negative affectivity).

M5: a model that is identical to M2, but also includes both cross-lagged relationships between negative affectivity and emotional exhaustion (reciprocal causation of negative affectivity).

The results of the model comparisons are presented in Table 5.14.

Table 5.14 Model comparisons in step 3: testing the additive effects of negative affectivity

\begin{tabular}{|c|c|c|c|c|c|}
\hline Model & $x^{2}$ & $d f$ & comp. & $d \chi^{2}$ & $d f$ \\
\hline$M 1: n o N A^{a}$ & $282.07^{\star}$ & 70 & & & \\
\hline M2: NA synchronous & $173.73^{*}$ & 68 & $\mathrm{M} 1-\mathrm{M} 2$ & $108.34^{*}$ & 2 \\
\hline$M 3: M 2+N A_{T 1}-E U_{T 2}{ }^{a}$ & $167.37^{\star}$ & 67 & M2-M3 & $6.36^{\star}$ & 1 \\
\hline$M 4: M 2+E U_{T 1}-N A_{T 2}$ & $170.78^{*}$ & 67 & M2-M4 & 2.95 & 1 \\
\hline M5: M2 + both cross NA - EU & $164.42^{*}$ & 66 & M2-M5 & $9.31^{*}$ & 2 \\
\hline & & & M3-M5 & 2.95 & 1 \\
\hline
\end{tabular}

$\mathrm{NA}=$ negative affectivity, $\mathrm{EU}=$ emotional exhaustion.

${ }^{\star} p \leq .05$.

Table 5.14 shows that the chi-square difference between $M 1$ and $M 2$ was significant, meaning that that negative affectivity had a synchronous, additive effect on emotional exhaustion, over and above the synchronous effects of workload and social support. The chi-square difference between M2 and M3 was also significant. This means that 
addition of the cross-lagged relationship between time 1 negative affectivity and time 2 emotional exhaustion improves the fit of the model: negative affectivity has a significant longitudinal additive effect on emotional exhaustion, over and above the effects of workload and social support. In order to exclude alternative causation patterns, we performed several other comparisons. The chi-square difference between M2 and M4 was not significant. This means that addition of the cross-lagged relationship between time 1 emotional exhaustion on time 2 negative affectivity does not improve the model fit: there is no reverse causation of negative affectivity. The chisquare difference between M2 and M5 is significant, indicating that there might be evidence for reciprocal causation of negative affectivity. However, the chi-square difference between M3 and M5 is not significant, indicating that addition of a reverse relationship between emotional exhaustion and negative affectivity does not improve the fit of a model including the regular relationship between negative affectivity and emotional exhaustion. Hence, we conclude that $M 3$ is the best model: negative affectivity has a longitudinal effect on emotional exhaustion, over and above the effects of workload and social support. The practical fit indices of model M3 were within acceptable limits (i.e., RMSEA $=.07 ; \mathrm{AIC}=371.92 ; \mathrm{AGFI}=.86 ; \mathrm{NNFI}=.89 ; \mathrm{CFI}$ $=.95$ ). Therefore, we decided not to adjust the model any further. $M 3$ is depicted in Figure 5.4 (only significant cross-lagged paths are shown, and we left out the arrows connecting the error variances between the endogenous variables). 


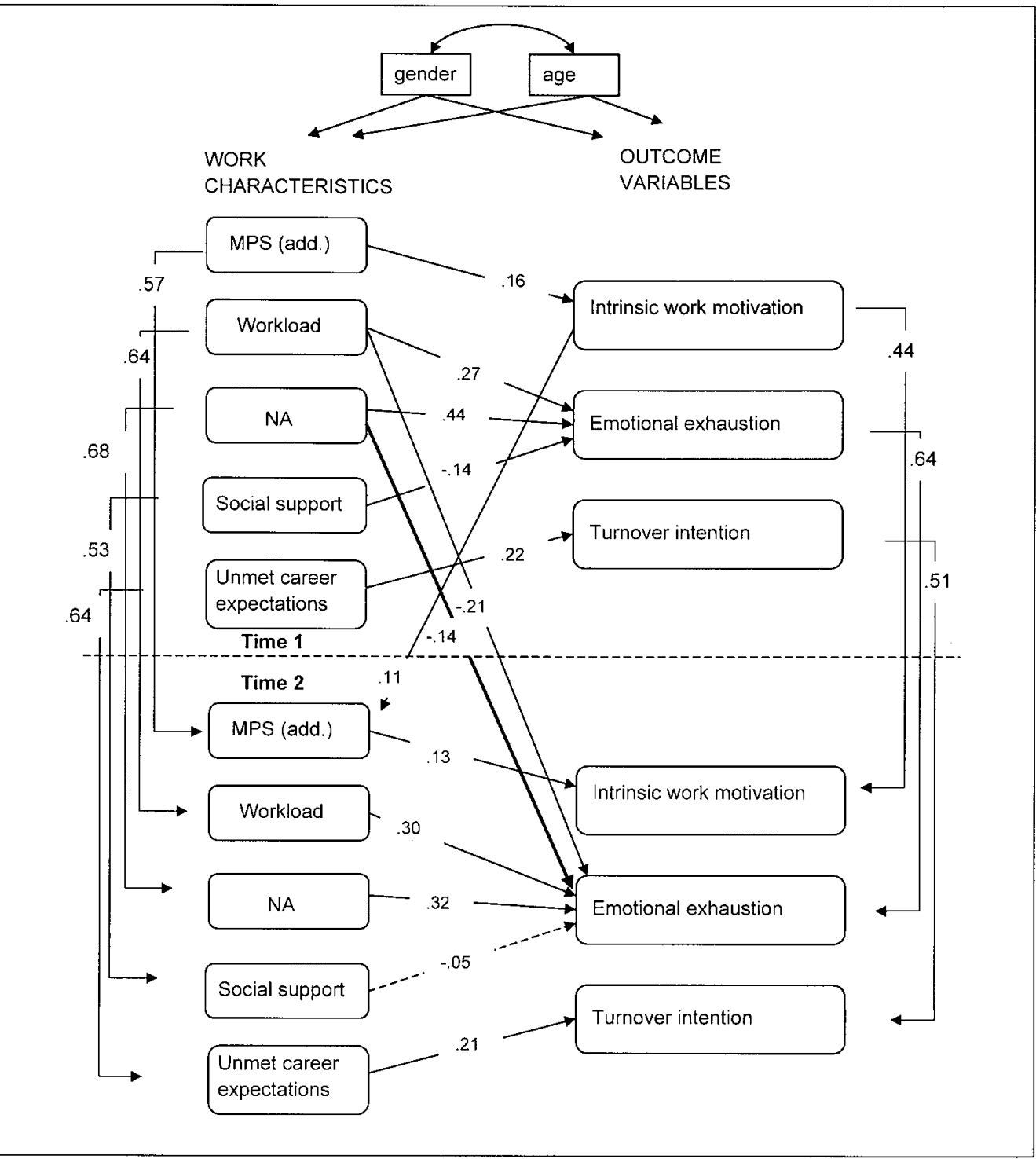

Figure 5.4 Final longitudinal structural equation model of the longitudinal additive effect of negative affectivity (i.e., M3, combined sample)

It can be concluded from Figure 5.4 that both regular cross-lagged relationships have a negative sign, which is opposite to our expectations. It is likely that negative suppression has occurred again (see also the step 2 results, and section 5.2). In order to interpret these results, we computed the total effect of time 1 negative affectivity on time 2 emotional exhaustion. This total effect was .36 (indirect effect is .50). The higher the level negative affectivity at time 1 , the higher the level of emotional exhaustion at time 2. In addition, the total effect of time 1 workload on time 2 
emotional exhaustion was .15 (indirect effect is .37). The higher the level of workload at time 1, the higher the level of emotional exhaustion at time 2.

\subsubsection{Testing hypotheses $5 b, 7 b, 8 b$, and $9 b$ : the moderating effects of personal characteristics}

In chapter 3 , we argued that it is not feasible to use multiplicative interaction terms in cross-lagged panel models, because a structural path between a time 1 outcome variable and a time 2 interaction term is difficult to interpret theoretically as well as practically. Hence, we used a first order model, that is a model with only linear effects over time, to test the causal moderating effects (see also De Jonge, 1995). More specifically, in this subsection (fourth step of analyses), we used subgroup analyses to test the longitudinal moderating effects of the personal characteristics (see section 3.6.5 for a description of this procedure; see Jaccard \& Wan, 1996; Schumacker \& Lomax, 1996).

The analyses were performed for each personal characteristic separately. Hence, for each personal characteristic, we divided the main sample into three subgroups, based on the values of the tertiles (i.e., we used the time 1 values of each personal characteristic to divide the main sample), thus creating three subgroups: a group scoring high, middle and low on this personal characteristic. This means that each group consisted of about 110 subjects. The high and the low group were used in the multi-group analyses.

The procedure further consisted of two steps. Prior to testing the moderating effects of the personal characteristics, we tested the causal direction of the relationships between work characteristics and outcome variables in the different subgroups. In this first step, we entered a cross-lagged panel model with work characteristics and outcome variables at both time 1 and time 2 into the multi-group structural equation model (see Figure 3.2) (cf. Jaccard \& Wan, 1996; Schumacker \& Lomax, 1996). We specified the structural paths between work characteristics and outcome variables according to the propositions made in Figure 2.6. Next, we compared several nested structural equation models:

M1: no cross-lagged paths between work characteristics and outcomes, only synchronous paths are specified.

M2: a model with regular causation: time 1 work characteristics influence time 2 outcome variables.

M3: a model with reverse causation: time 1 outcome variables influence time 2 work characteristics.

M4: a model with reciprocal causation: both types of cross-lagged causation patterns are specified. 
The model that appears to be the best model in this first step, will be called Ma, and entered into the second step of analysis.

In this second step, we compared the following models:

Ma: the model that appeared to be the best model in step 1, no invariance constraints are entered.

$M b$ : the synchronous paths between the work characteristic and outcome variable the personal characteristic under study is hypothesized to moderate, are specified as invariant across the high and the low group. For instance, when growth need strength is examined, the relationship between the additive MPS index and intrinsic work motivation is specified as invariant across the high growth need strength group and the low growth need strength group.

Mc: both the synchronous and the cross-lagged paths between the work characteristics and outcome variable under study are specified as invariant across the high and the low group.

In other words, it is tested whether these invariance constraints significantly worsened the model fit of $\mathrm{Ma}$. In the case of negative affectivity, two additional models are tested ( $M d$ and $\mathrm{Me}$ ), because negative affectivity is hypothesized to moderate two relationships: the relationship between workload and emotional exhaustion, and the relationship between social support and emotional exhaustion.

\section{Testing the moderating effect of growth need strength (hypothesis 5b)}

With regard to the causality of the relationships between work characteristics and outcome variables, the step 1 results showed that M2 (regular causation of the work characteristics on the outcome variables) was the best model in the low as well as in the high growth need strength group. This means that time 1 work characteristics influence time 2 outcome variables and not vice versa.

In the second step, we used M2 from step 1 as input model (Ma). The step 2 results showed that the difference in chi-square between Ma and Mb was not significant $\left(\Delta \chi^{2}\right.$ $(2)=.37$, n.s.). In addition, the chi-square difference between Ma and Mc was not significant either $\left(\Delta \chi^{2}(3)=1.50\right.$, n.s.). These results imply that the paths between the additive MPS index and intrinsic work motivation are invariant over both groups (in other words, setting these structural relationships free does not significantly improve the fit of the model), and that growth need strength has no moderating effect on the relationship between the additive MPS index and intrinsic work motivation. Table 5.15 shows the beta coefficients of the structural paths between the additive MPS index and intrinsic work motivation for both the high and the low growth need strength group (Mc; common metric standardized solution). We can conclude that the relationship between the additive MPS index and intrinsic work motivation has the same strength, and is positive for both the high and the low growth need strength group. 
Table 5.15 Beta coefficients of the paths between work characteristics and outcome variables that are hypothesized to be moderated, for each personal characteristic separately

\begin{tabular}{|c|c|c|c|c|c|c|}
\hline Structural path & $\begin{array}{l}\text { LoW } \\
\text { GNS }\end{array}$ & $\begin{array}{l}\text { High } \\
\text { GNS }\end{array}$ & $\begin{array}{l}\text { Low } \\
\text { NA }\end{array}$ & $\begin{array}{c}\text { High } \\
\text { NA }\end{array}$ & $\begin{array}{c}\text { Low } \\
\text { US }\end{array}$ & $\begin{array}{l}\text { High } \\
\text { US }\end{array}$ \\
\hline Time 1 MPS add. to time 1 intrinsic work motivation & .08 & .08 & & & & \\
\hline Time 1 workload to time 1 emotional exhaustion & & & 12 & .44 & & \\
\hline Time 1 social support to time 1 emotional exhaustion & & & -.13 & -.22 & & \\
\hline Time 1 unmet career expectations to time 1 turnover intention & & & & & .21 & 21 \\
\hline Time 2 MPS add. to time 2 intrinsic work motivation & 11 & 11 & & & & \\
\hline Time 2 workload to time 2 emotional exhaustion & & & 31 & .43 & & \\
\hline Time 2 social support to time 2 emotional exhaustion & & & -.20 & -.05 & & \\
\hline Time 2 unmet career expectations to time 2 turnover intention & & & & & 21 & 21 \\
\hline Time $1 \mathrm{MPS}$ add to time 2 intrinsic work motivation & 08 & .08 & & & & \\
\hline Time 1 workload to time 2 emotional exhaustion & & & -.27 & -.20 & & \\
\hline Time 1 social support to time 2 emotional exhaustion & & & .10 & .08 & & \\
\hline Time 1 unmet career expectations to time 2 turnover intention & & & & & -.06 & -.06 \\
\hline
\end{tabular}

\section{Testing the moderating effect of negative affectivity (hypotheses $7 \mathrm{~b}$ and $8 \mathrm{~b}$ )}

In step 1, we compared the same nested models as in step 1 for growth need strength. Once again, it appeared that M2 (regular causation) was the best model. Time 1 work characteristics influence time 2 outcome variables. M2 was used as input model for step 2 (i.e., as Ma).

With regard to the moderating effect of negative affectivity on the relationship between workload and emotional exhaustion (using $\mathrm{Mb}$ and $\mathrm{Mc}$ ), the results showed that the difference in chi-square between $\mathrm{Ma}$ and $\mathrm{Mb}$ was significant $\left(\Delta \chi^{2}(2)=7.93, p \leq .05\right)$, just like the difference in chi-square between Ma and $M c\left(\Delta \chi^{2}(3)=10.02, p \leq .05\right)$. These results indicate that negative affectivity moderates the synchronous and crosslagged relationships between workload and emotional exhaustion.

With regard to the relationship between social support and emotional exhaustion (using $\mathrm{Md}$ and $\mathrm{Me}$ ), the results showed that the differences in chi-square between $\mathrm{Ma}$ and $M d\left(\Delta \chi^{2}(2)=2.21\right.$, n.s. $)$, and between $M a$ and $M e\left(\Delta \chi^{2}(3)=2.39\right.$, n.s.) were not significant. Thus, it can be concluded that negative affectivity has no moderating effect on the relationship between social support and emotional exhaustion. Table 5.15 shows the beta coefficients of the structural paths between workload and social support on the one hand and emotional exhaustion on the other, for both the high and the low negative affectivity group (Ma; common metric standardized solution). We can conclude from this Table that the relationship between workload and emotional exhaustion is stronger for people with high negative affectivity, than for people with low negative affectivity. In both groups, however, the relationship between workload and emotional exhaustion has the same sign.

\section{Testing the moderating effect of upward striving (hypothesis 10b)}

Again, the step 1 results showed that M2 (regular causation of time 1 work characteristics on time 2 outcome variables) was the best model for both the high and the low upward striving group. M2 was used as input model for the second step (Ma). 
In step 2, the results showed that the chi-square difference between $\mathrm{Ma}$ en $\mathrm{Mb}$ was not significant $\left(\Delta \chi^{2}(2)=2.47\right.$, n.s.). The chi-square difference between $M a$ and $M c$ was not significant either $\left(\Delta \chi^{2}(3)=2.47, n . s\right.$. $)$. Imposing invariance constraints on the synchronous and cross-lagged relationships between unmet career expectations and turnover intention does significantly worsen the model fit. Therefore, we conclude that upward striving has no moderating effect on the relationship between unmet career expectations and turnover intention (see Table 5.15). Table 5.15 shows that the relationship between unmet career expectations and turnover intention has the same strength and is positive for both the high and the low upward striving group.

In sum, we may conclude that the personal characteristics growth need strength, negative affectivity, and upward striving have significant synchronous effects on the outcome variables intrinsic work motivation, emotional exhaustion and turnover intention, respectively. These results are in line with the cross-sectional results described in chapter 4. Furthermore, it appeared that longitudinally, a regular causation pattern of personal characteristics is predominant: time 1 personal characteristics seem to influence time 2 outcome variables (i.e., hypothesis III seems to be confirmed). However, with regard to the additive and moderating effects over time, we only found significant results with regard to the personal characteristic negative affectivity. Negative affectivity has a longitudinal additive effect on emotional exhaustion, over and above the effects of workload and social support. In addition, negative affectivity moderates the relationship between workload and emotional exhaustion. Hence, hypotheses $6 b$ and $7 b$ have been confirmed. Hypotheses $4 b, 5 b$, $8 \mathrm{~b}, 9 \mathrm{~b}$ and $10 \mathrm{~b}$ have not been confirmed. The implications of these results will be discussed more extensively in chapter 6 .

\subsection{Summary}

The present chapter described the results of the panel study. All bank employees and teachers who participated at both measurement points (April 1998 and April 1999), the so-called "panel group" were included in the analyses described in this chapter.

In section 5.2, we tested the proposed pattern of relationships between the four work characteristics and outcome variables longitudinally, in both samples separately. First, we tested whether the basic pattern of relationships, as well as the additional relationships that were found in section 4.2, were stable over time and over samples. The LISREL-analyses revealed that the basic pattern of relationships was stable over time and over samples: intrinsic work motivation is particularly related to the motivating potential score of the task characteristics, emotional exhaustion is particularly related to workload and a lack of social support, and turnover intention is particularly related to unmet career expectations. These relationships appeared to be invariant across both samples, and stationary across both measurement points: hypothesis I has been confirmed. With regard to the additional relationships, we found 
that these were not stable over samples or over time. Several relationships were added, but these were not similar for the two samples and time points (i.e., they might be specific for samples or time points). Therefore, we considered them as less salient, even the more so because the proposed pattern of relationships (Figure 2.6) did prove to be stable (see also chapter 6 ). In the second part of section 5.2, we tested the causal direction within the proposed pattern of relationships. For sample 1 (bank employees), the results revealed that time 1 work characteristics influence time 2 outcome variables. In sample 2, there was evidence for reciprocal causation: time 1 work characteristics influence time 2 outcome variables, and time 1 outcome variables influence time 2 work characteristics. With regard to specific cross-lagged relationships it was found that in sample 1, the relationships between the time 1 additive MPS index and time 2 intrinsic work motivation (i.e., hypothesis $1 \mathrm{~b}$ ), and between time 1 workload and time 2 emotional exhaustion (i.e., hypothesis $2 \mathrm{~b}$ ) were significant. In sample 2, we found significant relationships between time 1 workload and time 2 emotional exhaustion (i.e., hypothesis $2 \mathrm{~b}$ ), and between time 1 turnover intention, and time 2 unmet career expectations. Hence, hypothesis II (i.e., "Time 1 work characteristics influence time 2 outcome variables") seems to be confirmed, although in sample 2 alternative explanations could not be ruled out. This implies that hypothesis 11 (i.e., regarding the stability of the proposed pattern of relationships over samples) has been confirmed partially in the panel study. Hypothesis $3 b$ (i.e., regarding the cross-lagged relationship between time 1 unmet career expectations and time 2 turnover intention) could not be confirmed.

In section 5.3, we tested the longitudinal influence of the personal characteristics growth need strength, negative affectivity and upward striving on the proposed pattern of relationships between work characteristics and outcome variables, by means of a cross-lagged panel design using SEM. For methodological reasons, we combined sample 1 and sample 2 into one larger sample consisting of bank employees and teachers. The results revealed that the synchronous paths between the personal characteristics and outcome variables were all significant at both measurement points: growth need strength is particularly related to intrinsic work motivation, negative affectivity is particularly related to emotional exhaustion, and upward striving is particularly related to turnover intention. The causal direction within this pattern of relationships appeared to be regular: generally, time 1 personal characteristics seem to influence time 2 outcome variables. Hence, hypothesis III (i.e., "Time 1 personal characteristics influence time 2 outcome variables") seems to be confirmed. With regard to specific cross-lagged paths, it appeared that only the relationship between time 1 negative affectivity and time 2 emotional exhaustion was significant. Moreover, negative affectivity had a longitudinal additive effect on emotional exhaustion, over and above the effects of workload and social support (i.e., hypothesis 6b). Furthermore, negative affectivity moderated the relationship between workload and emotional exhaustion over time (i.e., hypothesis $7 b$ ). Hypotheses $4 b, 5 b$ and $8 b$ to $10 b$ could not be confirmed: Growth need strength and upward striving had no significant effects over time. 
The theoretical and practical implications of the results of this chapter, will be discussed in chapter 6 . In addition, in this chapter the cross-sectional and longitudinal study results will be compared. 
Chapter 6

General conclusion and discussion 


\subsection{Introduction}

This thesis generally focused on two issues. First, we aimed to develop and validate a pattern of specific relationships between relevant characteristics of a work setting (i.e., task characteristics, workload, social support, and unmet career expectations), and three important psychological outcome variables (i.e., intrinsic work motivation, emotional exhaustion, and turnover intention). Second, we were interested in the influence of three personality characteristics (i.e., growth need strength, negative affectivity, and upward striving) on these psychological outcome variables (i.e., additive effects), as well as on the pattern of specific relationships between work characteristics and psychological outcome variables (i.e., moderating effects). These issues are reflected in the research questions that were formulated in chapter 1 . We investigated these issues by means of an empirical study consisting of two parts: a cross-sectional survey, and a panel study with two waves. In this final chapter, the general conclusions to be drawn from this study will be presented and discussed. This chapter is outlined as follows. Section 6.2 presents the summary and conclusions of the main findings. Section 6.3 reflects on several methodological issues regarding this study, and points at some cautions in interpreting the study results. In section 6.4 , we will elaborate on the theoretical and practical implications of the results of this study. Section 6.5 , finally, provides several recommendations for future research.

\subsection{Summary and conclusions of the main findings}

\subsubsection{Study hypotheses}

The general research questions of this thesis were formulated as follows:

\section{What are the specific relationships between work characteristics and work- related outcome variables? \\ 2. What is the specific influence of personal characteristics on the work- related outcome variables, as well as on the specific relationships between work characteristics and these outcome variables?}

Based on meta-theoretical insights (Earp \& Ennett, 1991; Walker \& Avant, 1995) we concluded that in order to answer these research questions, there is a need for a theoretical model that incorporates both the general insights regarding the influence of work on the health and well-being of employees, and the refined theoretical views regarding specific relationships between work characteristics, personal characteristics, and outcome variables. Using the pattern of relationships between work characteristics and psychological outcome variables developed by Janssen, De Jonge and Bakker (1999) as a starting point, we performed a literature study to formulate such a theoretical model. This literature study has resulted in a number of theoretical and methodological hypotheses, which were tested in two samples (i.e., bank 
employees and teachers) by means of a study consisting of two parts: a crosssectional survey and a panel study.

The hypotheses that were formulated for the cross-sectional part of the study are shown in the following box.

1a. Intrinsic work motivation is primarily and positively related to task characteristics (combined in the additive Motivating Potential Score, MPS).

2a. Emotional exhaustion is primarily related to both workload (i.e., positively) and social support (i.e., negatively).

3a. Turnover intention is primarily and positively related to unmet career expectations.

4a. Growth need strength has a positive relationship with intrinsic work motivation, in addition to the relationship between task characteristics (combined in the additive MPS) and intrinsic work motivation.

5a. Growth need strength moderates the relationship between task characteristics (combined in the additive MPS) and intrinsic work motivation (the higher the level of growth need strength, the stronger the relationship between task characteristics and intrinsic work motivation).

6a. Negative affectivity has a positive relationship with emotional exhaustion, in addition to the relationships between workload and social support on the one hand and emotional exhaustion on the other.

7a. Negative affectivity moderates the relationship between workload and emotional exhaustion (the higher the level of negative affectivity, the stronger the relationship between workload and emotional exhaustion).

8a. Negative affectivity moderates the relationship between social support and emotional exhaustion (the higher the level of negative affectivity, the stronger the relationship between social support and emotional exhaustion).

9a. Upward striving has a positive relationship with turnover intention, in addition to the relationship between unmet career expectations and turnover intention.

10a. Upward striving moderates the relationship between unmet career expectations and turnover intention (the higher the level of upward striving, the stronger the relationship between unmet career expectations and turnover intention).

11. The proposed pattern of relationships between work characteristics and psychological outcome variables holds over different occupational groups (i.e., bank employees and teachers).

12. The proposed pattern of relationships between personal characteristics, work characteristics and psychological outcome variables holds over different occupational groups (i.e., bank employees and teachers).

The hypotheses that were formulated for the panel study are shown in the box below.

I. The proposed pattern of relationships between work characteristics and outcome variables is stable over time and over samples.

II. Time 1 work characteristics influence time 2 outcome variables.

III. Time 1 personal characteristics influence time 2 outcome variables.

The latter two hypotheses can be divided into ten more specific hypotheses:

1b. Intrinsic work motivation is primarily and positively influenced by task characteristics (combined in the additive MPS).

2b. Emotional exhaustion is primarily influenced by both workload (i.e., positively) and social support (i.e., negatively).

3b. Turnover intention is primarily and positively influenced by unmet career expectations.

4b. Growth need strength has an additive positive effect on intrinsic work motivation, over and above the effect of task characteristics (combined in the additive MPS). 
5b. Growth need strength has an interactive effect on the relationship between task characteristics (combined in the additive MPS) and intrinsic work motivation (the higher the level of growth need strength, the stronger the relationship between task characteristics and intrinsic work motivation).

6b. Negative affectivity has an additive positive effect on emotional exhaustion, over and above the effects of workload and social support.

7b. Negative affectivity has an interactive effect on the relationship between workload and emotional exhaustion (the higher the level of negative affectivity, the stronger the relationship between workload and emotional exhaustion).

8b. Negative affectivity has an interactive effect on the relationship between social support and emotional exhaustion (the higher the level of negative affectivity, the stronger the relationship between social support and emotional exhaustion).

9b. Upward striving has an additive positive effect on turnover intention, over and above the effect of unmet career expectations.

10b. Upward striving has an interactive effect on the relationship between unmet career expectations and turnover intention (the higher the level of upward striving, the stronger the relationship between unmet career expectations and turnover intention).

With regard to hypothesis 11 , we paid in the panel study special attention to the stability of the longitudinal pattern of relationships over occupational groups (note that this hypothesis was also formulated for the cross-sectional study).

11. The proposed longitudinal patiern of relationships between work characteristics and psychological outcome variables holds over different occupational groups (i.e., bank employees and teachers).

For the test of hypotheses III and $4 \mathrm{~b}$ to $10 \mathrm{~b}$, we combined the two samples of this study into one larger sample (see section 5.1).

\subsubsection{Main findings of the cross-sectional study}

\section{Mean scores on the work characteristics and the personal characteristics}

In chapter 4, we provided the mean scores and percentages of employees scoring negative on the work characteristics and personal characteristics.

First, it appeared that teachers, generally, score lower on the additive MPS index than bank employees. This finding implies that teachers are less satisfied with, for instance, the level of autonomy and task variety in their work than bank employees. The negative scores of the teachers on this variable might be explained by the erosion of the work content of teachers in The Netherlands (cf. Van Horn et al., 1997). Recent changes in the Dutch education system have, among other things, diminished the level of professional autonomy of teachers.

Second, with regard to workload, both samples have very high, comparable mean scores. Approximately $45 \%$ of both the bank employees and the teachers score negative on this work characteristic. As we have already outlined in chapter 1 , a high workload is a huge problem in the Western world of work. The results of this study are in line with this observation.

With regard to the level of received social support, teachers score worse than bank employees. This is in line with the results of the interviews that were held with several teachers in our sample (see also chapter 3 ). Social relationships, particularly with supervisors, were classified as rather bad by participants in this sample. 
With regard to unmet career expectations, both samples score rather negative, but teachers score worse. As we have seen in chapter 3 , career opportunities for teachers in The Netherlands are limited. This phenomenon is reflected in the study results for this sample.

With regard to the personal characteristics, we may conclude that teachers generally score higher on growth need strength than bank employees. Teachers might be more intrinsically driven than bank employees. The scores with regard to negative affectivity are comparable. With regard to upward striving bank employees score higher: they are more eager for upward mobility than teachers. The latter finding seems plausible in the sense than people who are interested in upward career mobility, will probably not choose to become a teacher.

\section{Specific relationships between work characteristics, personal characteristics and outcome variables}

The first important finding of the cross-sectional study was that the pattern of specific relationships between work characteristics and outcome variables that was formulated in chapter 2 (hypotheses 1a-3a) is significant in and invariant across both samples (hypothesis 11). These findings have the following implications for both bank employees and teachers: characteristics that make a job challenging and worthwhile (e.g., autonomy, task variety, task significance and task identity) are associated with feelings of intrinsic work motivation. In addition, demanding aspects of the job (i.e., a high workload: working hard, and performing complex tasks), as well as a lack of social support from both supervisor and colleagues, are associated with feelings of emotional exhaustion. Turnover intention finally, is primarily associated with unmet career expectations regarding salary, job security, and career opportunities. The finding of invariance implies that these relationships have the same strength and direction in both study samples, which is a powerful validation of this pattern of relationships (cf. Byrne, 1991, 1994). Moreover, our findings are in line with the prior results of Janssen, De Jonge and Bakker (1999) who tested this pattern of relationships among a sample of nurses working in a general hospital. We may, therefore, conclude that this pattern of relationships seems to be quite stable in several occupational groups. Furthermore, this pattern of relationships is in line with the existing theories and empirical evidence discussed in chapter 2 (e.g., Hackman \& Oldham, 1980; Lee \& Ashforth, 1996; Rosse \& Miller, 1984; Schaufeli \& Enzmann, 1998; Tiegs et al., 1992).

However, we must also consider several additional relationships. In the first step of the analysis, we found two additional relationships in both samples. In sample 1 (bank employees), we found that an increase in workload was associated with a increase in intrinsic work motivation (i.e., a positive relationship), and in sample 2 (teachers) we found that a decrease in the motivating potential of a job (e.g., a decrease in the level of autonomy), was associated with an increase in feelings of emotional exhaustion (i.e., a negative relationship). Furthermore, we found a relationship between lack of social support and turnover intention in both samples. We decided to add the latter 
additional relationship to the test of invariance in the multi-sample analysis, because there exists some theorizing and empirical evidence regarding this relationship, and because it was found in both samples. The best model in terms of model fit and parsimony proved to be the model in which the basic pattern of relationships (see Figure 2.6) and the relationship between social support and turnover intention were specified as invariant, and the other two additional relationships were specified for each sample separately.

The cross-sectional analyses regarding the influence of the personal characteristics showed that growth need strength had a significant, positive relationship with intrinsic work motivation, over and above the relationship between task characteristics and intrinsic work motivation (i.e., hypothesis 4a). High levels of internal growth need are associated with feelings of intrinsic work motivation. This relationship was more salient among teachers than among bank employees. Moreover, in sample 2 (teachers), we found an additional relationship between growth need strength and turnover intention. Furthermore, the results showed that negative affectivity had, in both samples, an additive, positive relationship with emotional exhaustion (over and above the associations of workload and social support with emotional exhaustion) (i.e., hypothesis 6a). Employees with high levels of negative affectivity report higher levels of emotional exhaustion. Upward striving had a significant, positive additive relationship with turnover intention, over and above the relationship between unmet career expectations and turnover intention, in both samples (i.e., hypothesis $9 \mathrm{a}$ ). In addition, we found that upward striving moderated the relationship between unmet career expectations and turnover intention, in both samples (i.e., hypothesis 10a). The higher the level of upward striving, the stronger the relationship between unmet career expectations and turnover intention. Based on the abovementioned results we may state that hypothesis 12 (i.e., regarding the stability of the influence of the personal characteristics over occupational groups) has been confirmed to a large extent.

\subsubsection{Main findings of the panel study}

\section{Stability of proposed pattern of relationships between work characteristics and outcome variables}

Our first general hypothesis (I) was that the pattern of relationships as it is depicted in Figure 2.6 is stable over time and over samples. Our results indicated that this proposed pattern of relationships was invariant (i.e., had the same strength and direction) across the two samples at both time 1 and time 2. In addition, our results showed that for both samples, the proposed pattern of relationships was stable over time. That is, the specific pattern of relationships between the four work characteristics on the one hand, and intrinsic work motivation, emotional exhaustion and turnover intention on the other that was found in the cross-sectional study (i.e., at time 1), could be replicated in the longitudinal study (i.e., at time 2). This finding implicates an extra validation of the proposed pattern of relationships. 
However, in each group and at each measurement point, some additional relationships had to be added to the model in order to reach adequate model fit.

Table 6.1 shows an overview of the additional relationships that were added in these analyses, and also of the additional relationships we found in the cross-sectional study (see section 6.2.2).

Table 6.1 Schematic overview of the additional relationships in sample 1 and sample 2

\begin{tabular}{|c|c|c|c|}
\hline & Cross-sectional study & Time 1 panel study & Time 2 panel study \\
\hline Sample 1 (bank employees) & $\begin{array}{l}\text { Social support to turnover } \\
\text { intention } \\
\text { Workload to intrinsic work } \\
\text { motivation }\end{array}$ & $\begin{array}{l}\text { Social support to turnover } \\
\text { intention }\end{array}$ & $\begin{array}{l}\text { MPS index to emotional } \\
\text { exhaustion } \\
\text { MPS index to turnover } \\
\text { intention }\end{array}$ \\
\hline Sample 2 (teachers) & $\begin{array}{l}\text { Social support to turnover } \\
\text { intention } \\
\text { MPS index to emotional } \\
\text { exhaustion }\end{array}$ & $\begin{array}{l}\text { Social support to turnover } \\
\text { intention } \\
\text { MPS index to emotional } \\
\text { exhaustion } \\
\text { Workload to intrinsic work } \\
\text { motivation }\end{array}$ & $\begin{array}{l}\text { Social support to turnover } \\
\text { intention } \\
\text { MPS index to emotional } \\
\text { exhaustion } \\
\text { MPS index to turnover } \\
\text { intention }\end{array}$ \\
\hline
\end{tabular}

It can be concluded from Table 6.1 that, generally, these additional relationships were not very stable across time points or samples. An exception is the relationship between social support and turnover intention, which was added in almost all groups. In addition, the relationship between the additive MPS index and emotional exhaustion seems to be quite salient among teachers. We conclude the other additional relationships to be less salient (i.e., time and/or sample specific).

\section{Longitudinal relationships between work characteristics and outcome variables}

Our second general hypothesis (II) of the panel study was that time 1 work characteristics influence time 2 outcome variables. Comparison of four competing structural equation models (by means of the chi-square difference test) indicated that in sample 1 (bank employees) the regular causation pattern was predominant. Generally, time 1 work characteristics seem to influence time 2 outcome variables. Hence, hypothesis II was confirmed in this sample. More specifically, we found two significant cross-lagged relationships: first, we found that the relationship between the time 1 additive MPS index and time 2 intrinsic work motivation was significant (the direct as well as the total effect were positive: a higher MPS index at time 1 leads to higher intrinsic work motivation at time 2). Hypothesis $1 \mathrm{~b}$ was confirmed in sample 1. Among bank employees, challenging work appears to enhance feelings of intrinsic work motivation, in the short run as well as in the long run (see also Hackman \& Oldham, 1980). The second significant cross-lagged relationship we found in sample 1 , was the relationship between time 1 workload and time 2 emotional exhaustion. The direct effect was negative, but the total effect was positive. We may conclude from this finding that a high level of workload may lead to an increase in emotional exhaustion even one year later (i.e., hypothesis $2 b$ was confirmed in this sample). 
In sample 2 (teachers), the comparison of four competing structural equation models indicated that in this sample reciprocal relationships between work characteristics and outcome variables seem to exist. First, in line with the findings in sample 1 , it was found that, generally, time 1 work characteristics influence time 2 outcome variables (i.e., regular causation, in line with expectations). However, at the same time it seems possible that in this sample, time 1 outcome variables influence time 2 work characteristics (i.e., reverse causation). This finding is not in line with our expectations. Hence, in this sample hypothesis II was confirmed, but alternative hypotheses could not be rejected. More specifically, just like in sample 1 , we found a significant cross-lagged relationship between time 1 workload and time 2 emotional exhaustion (hypothesis $2 \mathrm{~b}$ was confirmed in sample 2 also). A high workload leads to higher levels of emotional exhaustion one year later. In addition, we found a significant reversed cross-lagged relationship between time 1 turnover intention and time 2 unmet career expectations. Higher levels of turnover intention at time 1, lead to higher levels of unmet career expectations at time 2 . These cross-lagged relationships will be discussed in section 6.4 .

With regard to hypothesis 11 we aimed to investigate whether the longitudinal pattern of relationships was stable over different occupational groups (i.e., bank employees and teachers). We did not explicitly test this hypothesis in the longitudinal study (e.g., by means of MSA), because this would yield a very complex structural equation model, which is hardly interpretable. However, we may conclude from the results discussed above, that in both samples we found support for a regular causation pattern (time 1 work characteristics influence time 2 outcome variables). However, in sample 2 (teachers), we also found support for a reverse causation pattern.

\section{Longitudinal influence of personal characteristics}

The main findings of the longitudinal analyses regarding the influence of the personal characteristics were the following (note that we used the combined sample for these analyses). The results showed that overall a regular causation pattern was predominant: the time 1 personal characteristics influence the time 2 outcome variables and not vice versa (i.e., hypothesis III seems to be confirmed). With regard to specific relationships we found that all synchronous relationships we specified were significant, at both time 1 and time 2: growth need strength was associated with intrinsic work motivation, negative affectivity was associated with emotional exhaustion, and upward striving was associated with turnover intention. These results are in line with the cross-sectional results described in chapter 4.

The relationship between time 1 negative affectivity and time 2 emotional exhaustion was the only significant cross-lagged relationship (the higher the level of negative affectivity, the higher the level of emotional exhaustion one year later). It further appeared that time 1 negative affectivity had an additive longitudinal effect on time 2 emotional exhaustion, over and above the effects of workload and social support (hypothesis $6 \mathrm{~b}$ was confirmed). Moreover, negative affectivity appeared to be the only personal characteristic with a significant longitudinal moderating effect in the panel 
study: For people scoring high on negative affectivity, the relationship between workload and emotional exhaustion was stronger than for people scoring low on negative affectivity. This effect appeared to exist in the short run (synchronous effects at both time 1 and time 2) as well as in the long run (cross-lagged effects): hypothesis $7 \mathrm{~b}$ was confirmed, but hypothesis $8 \mathrm{~b}$ was not. That is, negative affectivity did not moderate the relationship between social support and emotional exhaustion. Hypotheses $4 b, 5 b, 9 b$ and $10 b$ (i.e., regarding the longitudinal additive and moderating effects of growth need strength and upward striving, respectively) could not be confirmed either.

Figure 6.1 depicts a graphical summary of the results of this study. Relationships between work characteristics and personal characteristics on the one hand, and outcome variables on the other are shown. The upper half of this figure (time 1) replicates the results of the cross-sectional study. For reasons of comprehensibility, we did neither include stability effects nor the beta coefficients of the relationships. In addition, we did not include interaction terms in this model. Interaction effects are shown by means of arrows leading from personal characteristics to paths between work characteristics and outcome variables. Overall, it can be concluded from this Figure that the synchronous and cross-lagged effects were generally in accordance with our hypotheses, and that the number of significant cross-lagged relationships was rather limited. 


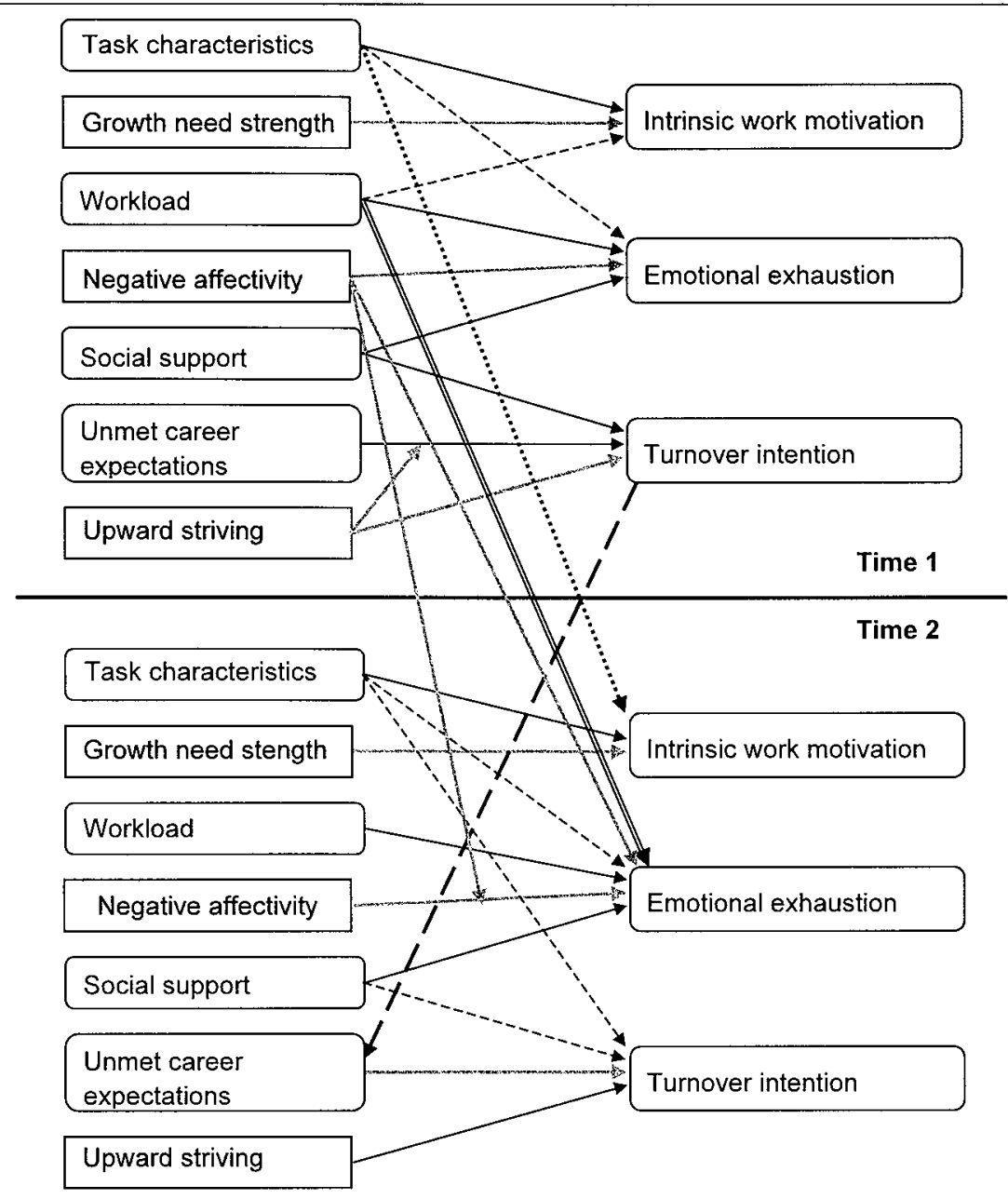

Relationships between work characteristics and outcomes that are invariant across both samples
in the cross-sectional study and over time 1 and time 2
Additional relationships between work characteristics and outcomes in either sample 1 or 2
found in the cross-sectional study and/or in the panel study
Significant cross-lagged relationship in both sample 1 and sample 2
Significant cross-lagged relationship sample 1
Significant cross-lagged relationship sample 2
Effects of personal characteristics (effects indicated at time 1 replicate the cross-sectional results
for sample 1 and 2 ; effects indicated at time 2 and the cross-lagged effects replicate the results of
the panel studv Icombined samblel)

Figure 6.1 Graphical representation of the results of this study 


\subsection{Methodological reflections}

The hypotheses of this study were tested in two different, but well defined samples (i.e., bank employees and teachers). Although both samples represent non-industrial sectors, it may be concluded from the population descriptions in chapter 3 that both samples have quite different characteristics. For instance, banks are commercial and clearly aimed at making profits, while education is not primarily oriented towards financial gains. Hence, invariance of relationships across both samples, provides at least some confidence in the generalizabilty of the proposed pattern of relationships over occupations.

Second, in both samples different jobs and hierarchical levels were represented, and, therefore, we concluded that there is sufficient variation in the study variables (cf. Kristensen, 1995, 1996). However, in order to gain more insight into the variance in our study samples, Table 6.2 shows the variability coefficients (standard deviation divided by the mean; see Ganster \& Fusilier, 1989) of the work and personal characteristics (i.e., the independent study variables) for the cross-sectional groups of sample 1 and sample 2, as well as the variability coefficients of several comparison groups.

Table 6.2 Variability coefficients of work characteristics and personal characteristics of the cross-sectional groups at $T 1$ for sample $1(\mathrm{~N}=$ 243), sample $2(N=362)$ and several comparison groups

\begin{tabular}{lccc}
\hline Samples & Sample 1 & Sample 2 & Comparison groups $^{a}$ \\
\hline Variables & M/SD & M/SD & M/SD \\
\hline Autonomy (additive MPS) & .19 & .25 & $.19 / .24$ \\
Task variety (additive MPS) & .16 & .14 & $.19 / .28$ \\
Feedback (additive MPS) & .15 & .25 & $.21 / .23$ \\
Task identity (additive MPS) & .25 & .31 & $.23 / .25$ \\
Task significance (additive MPS) & .18 & .16 & $.17 / .18$ \\
Workload & .18 & .18 & $.15 / .18$ \\
Social support & .12 & .15 & $.09 / .11$ \\
Unmet career expectations & .23 & .23 & $.21 / .19$ \\
Growth need strength & .14 & .12 & $.13 / .13$ \\
Negative affectivity & .30 & .29 & .29 \\
Upward striving & .17 & .18 & .16 \\
\hline The & & & \\
\hline
\end{tabular}

${ }^{a}$ The variability coefficients for the comparison groups were derived from Hackman and Oldham (1980), De Jonge (1995), Janssen, De Jonge and Bakker (1999), Janssen, Schaufeli and Houkes (1999), Watson et al. (1988) and Wollack et al. (1971).

It may be concluded from Table 6.2 that the variability in work and personal characteristics in both our study samples is generally comparable with, or higher than the variability in several single-occupation comparison groups. Thus, in line with the recommendations of Kristensen $(1995,1996)$, we believe that there is sufficient variation in the work characteristics and personal characteristics in our samples (which is necessary to demonstrate causality).

A third pro of the present study is that we combined the insights and advantages from both cross-sectional and longitudinal research. Fourth, we used sophisticated and up- 
to-date statistical techniques to analyze the data. For instance, a rather unique aspect of this study is the multi-sample analysis of the data by means of structural equation modeling. This possibility of studying a theoretical model using more than one sample simultaneously is an elegant feature of this technique, though not frequently used (Schumacker \& Lomax, 1996). We tested the proposed pattern of relationships across two samples simultaneously, in order to test the invariance of the relationships over populations. This is a rather strict test of a pattern of relationships. Invariance of relationships implies that a statistical comparison of parameters revealed that this pattern of relationships is equivalent across groups. This invariance indicates that the pattern of relationships is generalizable to at least two groups. In addition, in line with recommendations of Zapf et al. (1996), we used a cross-lagged panel model, using SEM, to analyze the longitudinal data. Finally, we selected measurement instruments that have proven to be valid and reliable in this and/or in previous studies (e.g., Hackman \& Oldham, 1980; De Jonge, 1995, Van Veldhoven \& Meijmann, 1994).

However, this study has several limitations that must be taken into account.

\section{Study design}

The present study consisted of a cross-sectional part and a panel study. Of course an important drawback of cross-sectional research is that causality of relationship cannot be proven. Thus, we performed a panel study in order to find support for the causal direction of the relationships we found in the cross-sectional analyses. However, also longitudinal designs are not able to prove causality and have their own methodological pitfalls and difficulties (Finkel, 1995; Zapf et al., 1996).

First, there is the time lag problem. We measured the study variables at two fixed time points, while the processes we observed are continuous. Thus, if the time lag between the two measurements moments does not match with the actual lag between a cause and an effect, it is possible that the results are not completely valid (cf. Kessler \& Greenberg, 1981). This time lag problem is very difficult to solve and is intrinsic to longitudinal research in general. For instance, in a study that uses a time lag of one year, a true three-months time lag, might be better represented by the synchronous effects than by the lagged effects (Zapf et al., 1996). Moreover, in our study, the time lag problem is even more pronounced, because we studied several different relationships simultaneously. It is, for instance, theoretically plausible that the true time lag between the additive MPS index and intrinsic work motivation is shorter than the true time lag between workload and negative affectivity on the one hand, and emotional exhaustion on the other. Emotional exhaustion develops after a prolonged period of stress. One week of hard work does not immediately lead to emotional exhaustion (Schaufeli \& Enzmann, 1998). In terms of Frese and Zapf (1988), this effect is an example of a so-called "sleeper effect". On the contrary, when a job is challenging, intrinsic work motivation is likely to develop rather soon. There might in fact exist processes at the workplace that are rather momentaneous, and which are as such difficult to study longitudinally (see also Zapf et al., 1996). Examples of such relationships might be the effect of a certain interesting task (within a job) at a certain moment on work motivation, or the effect of a pleasant conversation with colleagues 
or supervisor (formal or informal) on an employee's mood. In terms of Frese and Zapf (1988) such effects are called "initial impact" effects, implying that the time between the causes and the effects is relatively short. In order to investigate such processes, very short time lags or even cross-sectional analyses should be applied. Another possibility might be to include time itself in the model as a variable (cf. Marcoulides \& Schumacker, 1996).

The second problem of longitudinal research is attrition (i.e., panel loss). In our study, we lost a considerable part of our respondents. In the first wave, somewhat more than $50 \%$ of the employees responded. These response rates were, although satisfactory, somewhat lower than we might have wished for. In the second wave, we again lost about $50 \%$ of the sample, resulting in panel groups that consisted of $30 \%$ of the initial samples. If this non-response has occurred completely at random, only the statistical conclusion validity may be threatened. If, however, non-response did not occur completely at random, the conclusions drawn from the study, may not be valid for the total population (i.e., no external validity) (Hagenaars, 1990).

Our non-response analyses (see chapters 3 and 5) showed in the first place that, with regard to gender and age, our study samples were representative for the total working populations of the bank and the education center, respectively. Second, chapter 5 showed that, generally, the panel group did not differ from the dropouts with regard to the means of the variables under study, as well as with regard to the interrelationships among these variables. In addition, we performed several other comparisons between the dropouts, panel groups, and people who only participated at the second measurement, in order to identify other possible threats to internal validity of the study results (Daniels \& De Jonge, 2001). These comparisons showed that for a relatively small number of variables, some biases such as history effects and non-response bias at time 1, may have occurred. However, overall the occurrence of bias was limited, and we concluded that no serious selection problems seem to be present in this study.

\section{Samples}

First, as has already been discussed previously, we used two different study samples in order to find evidence for the generalizability of the results (cf. Walker \& Avant, 1995). We have seen that these samples were rather different from each other. When we also take the validation of the pattern of relationships among nurses (Janssen, De Jonge \& Bakker, 1999) into account, we may conclude that the proposed pattern of relationships is stable over different occupational groups. However, at the same time we see that the proposed pattern of relationships between work characteristics and outcome variables has hitherto been validated in three non-industrial samples. Thus, although almost $80 \%$ of the Dutch working population are working in non-industrial sectors (CBS, 2000a), the testing of the generalizability of the results into an industrial sector might be a next step in this specific research area (see also section 6.5).

Second, considering the variability coefficients depicted in Table 6.2, and the fact that in both samples many different jobs were included, we may also conclude that the variance in the work characteristics was sufficient (cf. Kristensen, 1995). The 
presence of different jobs might, however, be less salient in sample 2, which merely consists of teachers. But also in this sample, we have seen that there is sufficient variability in the work characteristics. This might be due to the fact that the sample of teachers we included, contained many different kinds of teachers (e.g., practice teachers from very different areas such as nursing and construction; theoretical teachers in areas such as foreign languages and social studies). In addition, a considerable part of the teachers in our sample had additional tasks besides teaching, such as mentoring students, co-coordinating and supervising departments. Moreover, these teachers worked at many different locations.

Finally, each study that uses samples that are composed of the active working population, can be influenced by the "healthy worker effect" (cf. Frese, 1985; De Jonge \& Landeweerd,1993). As all the participants in our study were still working at the time the questionnaires were distributed, this effect may also have influenced our study results. It might be that bank employees or teachers with very adverse health outcomes were underrepresented, because they were absent from their work. The consequence of this effect is that relationships between work characteristics and certain outcome variables are underestimated as a result of restriction of variance in the outcome variables. For practical reasons, it was not possible to include absent bank employees or teachers in our sample. Moreover, the validity of the answers of employees who have been absent from work for several months on questions concerning work characteristics, may at least be questioned (i.e., due to recall bias) (Bouter \& Van Dongen, 2000).

\section{Measurement instruments}

This study relied on self-report questionnaires to measure the variables under study (i.e., work characteristics, personal characteristics, and psychological outcome variables). Some authors (e.g., Zapf, 1989) argue that this procedure may lead to common method variance (i.e., the finding of spurious relationships between work characteristics and outcome variables). However, many other authors argue that there is very little evidence for common method variance in self-report studies (e.g., Boumans \& Landeweerd, 1993; Spector, 1992, 1999). Moreover, in the present study we took several actions to limit this problem as much as possible, for instance, we selected self-report stressors that were as objective as possible (i.e., items were not affective in tone) and that were formulated in different terms from the outcome variables (cf. Spector et al., 2000), and we used different scale ranges (i.e., scale ranges varied between 1-2 and 1-7). Therefore, we do not expect that common method variance caused serious problems in this study.

\section{Statistical analyses}

For almost all analyses described in this thesis, we used structural equation modeling, which has several restrictions. First, structural equation models can be rejected, but it can never be proven that a structural equation is the one true reflection of reality (Bollen, 1989; cf. De Jonge, 1995). Second, when using interaction terms, the multinormality assumption is violated (Kenny \& Judd, 1984). However, the maximum 
likelihood estimation of the parameters we used throughout this theses is rather robust against this violation of multinormality (cf. Hayduk, 1987; De Jonge, 1995).

In addition, in our panel study we used the method of analyses recommended by Zapf et al. (1996) and Finkel (1995). We used SEM, full panel designs, and we corrected for the background variables gender and age. However, despite all these precautions, problems such as negative suppression still occur. When the stability of the endogenous variables is high (i.e., a high test-retest-reliability), the chance on negative suppression increases. This seems to be a paradoxical situation. A high testretest reliability is generally considered desirable, and simultaneously high test-retest reliability leads to undesirable negative suppression (Maassen \& Bakker, 2000). Moreover, the application of SEM to longitudinal data results in very complex models, which are difficult to interpret (cf. Saris \& Stronkhorst, 1984). Hence, challenges for future research may be found in refining the currently available techniques to analyze longitudinal data.

Despite these methodological issues, we believe that the results of this study are noteworthy and provide challenges for future research, theoretically and methodologically. Below, we will the discuss the results of this study in the light of the methodological reflections presented above.

\subsection{Theoretical discussion and practical implications}

\subsubsection{Theoretical discussion of the results}

\section{A pattern of specific relationships between work characteristics and psychological outcome variables}

First of all, we may conclude that the theoretical model that was developed in chapter 2 (i.e., the proposed pattern of relationships between work characteristics and psychological outcome variables) holds in different samples. These results suggest that more accurate predictions regarding the relationships between a relevant range of work characteristics and psychological outcome variables are possible, and that more specific guidelines for interventions at the workplace may be formulated. The pattern of relationships that was developed and validated in this thesis may serve as the theoretical model that was missing in the area of work and organizational psychology (see chapter 2). Furthermore, these study results are in line with the results of Janssen, De Jonge and Bakker (1999) and with many empirical studies that focused on one of the three outcome variables intrinsic work motivation, emotional exhaustion, and turnover intention (e.g., Van Breukelen, 1989; Fried \& Ferris, 1987; Lee \& Ashforth, 1996; Tiegs et al., 1992; Schaufeli \& Enzmann, 1998). In addition, the panel study showed that the proposed pattern of relationships was stable over time points. In this regard, the longitudinal results strengthen the cross-sectional results of this study: the proposed pattern of relationships was found at both the first and the second measurement. Moreover, in the panel study we found support for causal 
predominance of the work characteristics over the outcome variables in both samples. That is, generally, time 1 work characteristics influence time 2 outcome variables, although in sample 2 a reverse causation pattern was found also. We did, however, not find all cross-lagged relationships between work characteristics and outcome variables to be significant.

In sum, this study provides a further validation of the proposed pattern of specific relationships between work characteristics and outcome variables depicted in Figure 2.6. These results are in line with the results of Janssen, De Jonge and Bakker (1999), as well as with existing theories in the area of Work and Organizational Psychology.

\section{Causality of the pattern of relationships: regular or reverse?}

With regard to the causal direction of relationships between work characteristics and outcome variables, we found in both samples evidence for a regular causation pattern: work characteristics seem to be the cause of psychological effects in employees. These results are, generally, in line with the relatively small number of methodologically adequate longitudinal studies in this area. For instance, Vogelaar and Van der Vlist (1995) provide a short overview of longitudinal studies regarding the relationships between task characteristics and psychological outcomes. They conclude that task characteristics rather influence psychological outcomes, than the other way around. Schaufeli and Enzmann (1998) provide an overview of longitudinal studies regarding burnout and conclude that only eight studies met their methodological criteria regarding adequate longitudinal research. These studies report regular as well as reverse causation, although regular causation is reported more frequently. With regard to turnover intention, longitudinal studies are scarce also (cf. Van Breukelen, 1989; Arnold \& Mackenzie Davey, 1999). In the longitudinal study of Arnold and Mackenzie Davey (1999) evidence was found for regular causation of career factors on turnover intention.

However, in sample 2 we also found evidence for reverse causation: time 1 outcome variables appeared to have an effect on time 2 work characteristics (i.e., in this sample reciprocal causation was found). Reciprocal causation has been reported before. For instance, Taris, Bok and Caljé (1998) and Tharenou (1993) report reciprocal causation between job characteristics on the one hand, and depression and absenteeism, respectively, on the other hand. James and Jones (1980) report reciprocal causation between job characteristics and job satisfaction. De Jonge et al. (2001), finally, also report reciprocal causation between several work characteristics and outcome variables, but conclude that regular causation is predominant.

In chapter 3, we provided two possible explanations for reverse causation: the drift hypothesis and the true strain-stressor hypothesis. We do not believe the drift hypothesis to be a plausible explanation for the findings in the present study, because the participants in this study did not drift to other jobs between measurements. Hence, the true strain-stressor hypothesis seems to be more plausible here. In some cases outcome variables might indeed have an influence on outcome variables. In the forthcoming subsection, we will address this issue somewhat more extensively. 
Generally, we may conclude that existing longitudinal studies in the field of Work and Organizational Psychology report regular as well as reciprocal causation between work characteristics and outcome variables, although overall the regular causation pattern receives more support (e.g., De Jonge et al., 2001; Schaufeli \& Enzmann, 1998). This is in line with the findings of this study: we found evidence for regular causation in both samples, although in one sample we also found evidence for reverse causation.

\section{Cross-lagged relationships between work characteristics and outcome variables} In sample 1 (bank employees) we found two significant cross-lagged relationships. First, there is the relationship between time 1 workload and time 2 emotional exhaustion. In the long term, high workload leads to high levels of emotional exhaustion. The direct effect of time 1 workload on time 2 emotional exhaustion was negative, however (which is opposite to our expectations, and does not line up with the sign of the synchronous paths). This phenomenon has also been reported by Lee and Ashforth (1993) and by Burke and Greenglass (1995). Lee and Ashforth provide an explanation in terms of high stability of the study variables, and Burke and Greenglass provide no explanation at all. We argued that this turn around of the sign of the relationship was caused by negative suppression (Maassen \& Bakker, 2000), and we interpreted the results by means of computing the total effects of the work characteristics on the study variables (in line with recommendations of Saris \& Stronkhorst, 1984). Another possible explanation for this negative direct effect might be that this effect is caused by an adjustment process (Frese \& Zapf, 1988) or an habituation process (Gaillard, 1996). These processes imply that even although the stressor (e.g., workload) is still present, the dysfunctioning (e.g., emotional exhaustion) decreases. People get used to the presence of the stressor and learn to cope with it more effectively over time. We believe, however, that the first statistical explanation (suppression) is more likely, because of the positive bivariate relationships between time 1 workload and time 2 emotional exhaustion.

The second significant cross-lagged relationship we found in sample 1 was the relationship between the additive MPS index and intrinsic work motivation (MPS at time 1 has a positive effect on intrinsic work motivation at time 2). Challenging work leads to intrinsic motivation, in the short term but also in the long term (cf. Hackman \& Oldham, 1980). This finding is in line with one of the final conclusions of Vogelaar and Van der Vlist (1995) regarding the direction of the relationships in the Job Characteristics Model: task characteristics rather influence the outcome variable intrinsic work motivation than the other way around.

In sample 2 (teachers), we found a cross-lagged relationship between time 1 workload and time 2 emotional exhaustion, just like in sample 1 . Also for teachers, workload has an increasing effect on emotional exhaustion one year later.

In addition, we found the reverse relationship between time 1 turnover intention and time 2 unmet career expectations to be significant. As was already mentioned above, the most likely explanation for this finding is probably the true strain-stressor 
hypothesis (cf. James \& Jones, 1980; De Jonge et al., 2001; see also chapter 3). In the short term, people may have unmet career expectations and therefore think about leaving the organization (i.e., the synchronous path between time 1 unmet career expectations and time 1 turnover was also significant). Once they have reached this stage, these employees as well as their supervisors, might put even less effort into career development. As a consequence, the level of unmet career expectations, or the perception of the level of unmet career expectations rises even further (i.e., a vicious circle). In other words, a redefinition of career expectations in accordance with the attitude regarding turnover may take place. This phenomenon might especially hold for teachers in The Netherlands, whose job alternatives are scarce (see also chapter 3 ). Therefore, it is rather difficult for them to actually leave the organization (bank employees probably have more job alternatives). Turnover intention cannot easily be transferred into turnover. This perception of the lack of alternatives at the labor market might be frustrating, and the frustration about the career possibilities within the organization might increase in turn.

A methodological explanation for the finding that the number of significant crosslagged relationships between work characteristics and outcome variables was rather small in comparison with the number of significant cross-sectional relationships, might be found in the statistical technique that was used. The true direct cross-lagged effects in a cross-lagged panel model might be underestimated as a result of the correction for stability effects (cf. Dormann \& Zapf, 1999). A second explanation can be found in the different time lags of the relationships included in the pattern of relationships that was tested in this study (see also section 6.3).

\section{Additional relationships ${ }^{4}$}

In section 6.2.2, we have arranged the additional relationships we found in this study (see Table 6.1). It appeared that particularly the negative relationship between social support and turnover intention was rather consistent throughout this study. It might indeed be conceivable that workers wish to leave an organization when they have conflicts with their supervisors and/or their colleagues. This relationship has been reported before (cf. McFadden \& Demetriou, 1993; Schaufeli \& Enzmann, 1998; Stremmel, 1991), but empirical results are mixed, however. Janssen, De Jonge and Bakker (1999), for instance, did not report this relationship. The non-finding of Janssen, De Jonge and Bakker (1999) might be explained by the fact that they only measured co-worker support, while in the present study a combined scale was used to measure social support (i.e., including co-worker support and supervisor support). It might be that conflicts and problems with supervisors are more salient to individual employees and their careers than conflicts with colleagues, and may as such have

NOTE

${ }^{4}$ These additional relationships were not explicitly tested anymore in the cross-lagged panel models. Additional analyses revealed, however, that these cross-lagged relationships were neither significant in sample 1 , nor in sample 2. 
more impact. Also in this regard empirical evidence is mixed, however. Several studies do not show differences in the effects of social support from co-workers or from supervisors (e.g., Buunk, 1990; Cohen \& Wills, 1985), while other studies do (e.g., Marcelissen, 1987). These differential effects of social support from supervisors and co-workers may be a topic for future research (see also section 6.5).

The precise meaning of the other additional relationships mentioned in Table 6.1 is not quite clear: they are not stable across different samples or time points. It is possible that these relationships are only temporarily, which means that they were measurement-specific. But still, in sample 2 (teachers), the negative relationship between the additive MPS index and emotional exhaustion was found twice. Apparently, among teachers, a decreasing level of the MPS index (e.g., less autonomy, less task variety, less task significance), not only leads to decreasing feelings of intrinsic work motivation, but also to increasing feelings of emotional exhaustion. This phenomenon was not signaled among bank employees. Traditionally, the education sector in The Netherlands is characterized by a feeling of "total malaise" (cf. Horn et al., 1997). This phenomenon might lead to a negative perception of the work content, and hence to emotional exhaustion.

Finally, it ought to be mentioned that we did not find an additional relationship between unmet career expectations and intrinsic work motivation. This non-finding confirms that salary and other conditions of employment that are external to the work content, are no significant predictors of intrinsic work motivation. This is in line with the expectations of Deci and Ryan (1985) and Wiersma (1992) discussed in section 2.3.

\section{The influence of personal characteristics}

We will discuss the results regarding the personal characteristics for each personal characteristic separately.

\section{Growth need strength}

The cross-sectional results revealed that growth need strength had a positive relationship with intrinsic work motivation, over and above the relationship between task characteristics and intrinsic work motivation. This relationship was also significant at time 2: it was stable over time. High growth need strength people are eager to grow in their work, and will consequently be highly motivated to perform well (Hackman \& Oldham, 1980). The cross-lagged (causal) relationship between growth need strength and intrinsic work motivation was not significant, however. These findings might imply that in the short term, people with high growth need strength are more intrinsically motivated than people with low growth need strength, regardless of the actual tasks they perform. It must be noted that the relationship between growth need strength and intrinsic work motivation was not as clear among bank employees as it was among teachers. It seems plausible that teachers are motivated by both an inner source (i.e., growth need strength) and the work content, while bank employees are particularly motivated by the specific content of the work they do. In this regard, Barnabé and Burns (1994) also argue that teachers might be motivated quite differently than business workers. The correlations they found between work characteristics and 
intrinsic work motivation (among teachers) were lower than those found in the business samples tested by Hackman and Oldham (1980).

Furthermore, in the cross-sectional analyses, we found an additional relationship between growth need strength and turnover intention in sample 2 (teachers). This relationship was not found in sample 1 (bank employees). This finding might be caused by the fact that for teachers career possibilities within the organization are rather limited, in comparison with the career possibilities for bank employees (see also chapter 3). Hence, teachers with a high level of growth need strength, who wish to develop themselves and find that this is not possible within their current job, might want to search for alternative jobs in alternative organizations.

In line with Oldham, Hackman and Pearce (1976), Fried and Ferris (1987) and Tiegs et al. (1992), we could not demonstrate a moderating effect of growth need strength. That is, the level of growth need strength has no influence on the relationship between task characteristics and intrinsic work motivation. We did find a significant relationship between task characteristics and intrinsic work motivation (both cross-sectionally and cross-lagged), however. In line with Vogelaar and Van der Vlist (1995), we may therefore conclude that a stimulating work content may be motivating for all employees, and not merely for employees scoring high on growth need strength.

\section{Negative affectivity}

The cross-sectional results revealed a positive relationship between negative affectivity and emotional exhaustion, over and above the relationships between workload and social support on the one hand, and emotional exhaustion on the other. This finding could be replicated in the panel study. That is, the relationship was significant at both time 1 and time 2. Additionally, in the panel study we found a direct effect of negative affectivity on emotional exhaustion, as well as a moderating effect of negative affectivity on the relationship between workload and emotional exhaustion. These findings imply that people who have a negative perspective on the world in general (people with a high level of negative affectivity), are more likely to become emotionally exhausted than people who do not have such a negative perspective. This effect appeared to be additive to the effect of a high workload and a low level of social support on emotional exhaustion. The latter effects are found for all employees, and not merely for high negative affectivity people. Moreover, people with a high level of negative affectivity seem to be more vulnerable to a high workload: the relationship between a high workload and emotional exhaustion is stronger for them than for low negative affectivity people. Thus, high negative affectivity teachers, for instance, are not only more inclined to get emotionally drained, but are also more vulnerable when workload increases, than there low negative affectivity colleagues.

In the cross-sectional study, nor in the panel study, negative affectivity moderated the relationship between social support and emotional exhaustion. These findings are in line with the results of Parkes (1990), who also demonstrated a moderating effect of negative affectivity on the relationship between workload and a health-related outcome variable, but not on the relationship between support and this outcome. In 
addition, our finding of a direct effect of negative affectivity on emotional exhaustion is also in line with contentions of Moyle (1995), who states that negative affectivity may also have a direct relationship with health outcomes: people with high negative affectivity experience a poorer health.

The finding of multiple effects of negative affectivity (i.e., direct, additive and moderating effects were found), is in line with findings of Moyle (1995) and of Spector et al. (2000). Spector and his colleagues describe several mechanisms, which can explain the ways in which negative affectivity relates to stressors and strains. The interactive effect may be explained by the hyper-responsivity mechanism, which states that high negative affectivity people have an exaggerated strain response (e.g., emotional exhaustion) to stressors (e.g., workload). Under the same environmental conditions, high negative affectivity people may feel job strains more readily. It is not necessary that they perceive the stressors differently, it is particularly their response to the stressors that differs. This mechanism has in an earlier stage been suggested by McCrae and Costa (1991) who state that certain personality traits represent individual differences in sensitivity or response magnitude to positive or negative stimuli. Examining the means of workload and emotional exhaustion among high and low negative affectivity people in our combined sample, reveals that high negative affectivity people have somewhat higher scores on workload (mean difference is .7 * $S D$ ), but considerably higher scores on emotional exhaustion than low negative affectivity people (mean difference is $2.5^{*} S D$ ). These figures support the hyperresponsivity mechanism.

In terms of Parkes (1994), our findings regarding the moderating effect of negative affectivity (i.e., the relationship between workload and emotional exhaustion was positive for both high and low negative affectivity people), support the perspective on personal characteristics as vulnerability factors: the combination of high levels of adverse work characteristics (e.g., workload) with high levels of adverse personal characteristics (e.g., negative affectivity), leads to the worst outcomes. Another possible explanation for an interaction effect would be a misfit between person and environment. In case of a suchlike misfit the sign of the relationship between the work characteristic and the outcome for high levels of a personal characteristic would be opposite to the sign of this relationship for low levels of the personal characteristic. Positive outcomes occur only when there is a match between person and environment (Parkes, 1994). When there is a mismatch, adverse outcomes occur. The results of this study do not support this perspective, however.

As mentioned above, our results regarding multiple effects of negative affectivity are in line with Moyle's (1995). However, Moyle performed only cross-sectional analyses, while we found cross-sectional as well as longitudinal evidence for the multiple effects of negative affectivity: Furthermore, we found that time 1 negative affectivity moderates the relationship between time 1 workload and time 2 emotional exhaustion. These results indicate that negative affectivity is predictive of cross-situational stress (see also Costa \& McCrae, 1980). The negative effects of negative affectivity appear to be long-lasting. 
Finally, in line with Moyle (1995), we may conclude that the role of negative affectivity in the stress process is a very complex one, which cannot be explained by one mechanism or process. But anyhow, negative affectivity remains an important variable in stress research and a variable that can be a promising starting point for interventions aimed at the individual employee.

\section{Upward striving}

The cross-sectional results revealed that upward striving had a positive relationship with turnover intention (in addition to the relationship between unmet career expectations and turnover intention). Furthermore, we found that upward striving moderated the relationship between unmet career expectations and turnover intention. We also found a relationship between upward striving and turnover intention at time 2 in the panel study, but we could not demonstrate a significant cross-lagged relationship between this personal characteristic and turnover intention. The crosssectional findings are in line with the expectations of De Gilder et al. (1998) and the findings of Mathieu and Zajac (1990). People scoring high on upward striving, are more prone to leave the organization voluntarily, than people scoring low on this personal characteristic, especially when career opportunities are low. Thus, in order to preserve people with high upward striving for an organization, it is important to pay attention to career opportunities. It should be mentioned here that the interaction effect was not strong. For high as well as for low upward striving people, a positive relationship was found between unmet career expectations and turnover intention (i.e., personal characteristics as vulnerability factors; cf. Parkes, 1994), which means that improvement of the career opportunities for all employees might have a positive effect for the organization. In addition, the interaction effect was more prone among teachers than among bank employees. This might be explained by the fact that career opportunities within schools for teachers in The Netherlands seem to be rather limited (cf. Van Horn et al., 1997). Thus, when a teacher has a high level of upward striving, and also scores high on unmet career expectations, a high level of turnover intention may originate because opportunities to develop oneself within the school are generally not very large. In other words, even although alternatives at the Dutch labor market are scarce, for teachers with high levels of upward striving, unmet career expectations may lead to high turnover intention. For bank employees, on the contrary, opportunities to develop themselves within their jobs and organizations seem larger and thus, for them it may be less urgent to leave the organization in order to fulfill their needs.

In sum, with regard to growth need strength and upward striving, the only significant relationships we found, were cross-sectional relationships. With regard to negative affectivity we also found significant cross-lagged results. This finding might be due to a difference in true time lags. More specifically, it is possible that the true time lag of the two above-mentioned relationships is shorter than the true time lag of the relationship between negative affectivity and emotional exhaustion (see section 6.3).

The methodological explanation for the relatively low number of significant cross- 
lagged relationships provided for the work characteristics (i.e., correction for stability effects), of course also counts for the personal characteristics (cf. Dormann \& Zapf, 1999).

\section{Moderating effects of the personal characteristics}

in both the cross-sectional and the panel study, we only found one significant interaction effect. The following explanations may be provided for this finding.

In the cross-sectional study, we used interaction terms to analyze the moderating effects. The statistical output that is provided by LISREL (fit indices, standard errors, et cetera) is based on linearity and normality assumptions (interaction terms are not normally distributed), and we may not have results that are robust enough to recognize the presence of an interaction effect unless it is substantial (cf. Schumacker \& Lomax, 1996). As we found considerable linear effects of work characteristics and personal characteristics, the interaction effect should be rather strong in order to be detected, because in the procedure we used it was tested whether there is an interaction effect above and beyond the direct effects of work characteristics and personal characteristics (Schumacker \& Lomax, 1996). In other words, the statistical power of the available techniques to analyze interaction effects is rather low (see also Aguinis, 2001). Unfortunately, this is a common problem in the area of Work and Organizational Psychology, which might lead to the erroneous conclusion that there is no interaction effect when there is in fact a moderator in the population. In order to solve this problem, much larger sample sizes are needed. However, at the same time large sample sizes might be problematic for several LISREL analyses (cf. Schumacker \& Lomax, 1996). Hence, the problem is difficult to solve.

Also in the panel study, only one out of four interaction effects proved to be significant. This finding is in accordance with contentions of Dormann and Zapf (1999), who state that it is rather difficult to demonstrate moderating effects in longitudinal research in which prior states of outcome variables are controlled for. According to them this might be due to inappropriate time lags, non-specific measures, insufficient variance in the model variables, and so forth.

\section{Final conclusion with regard to the influence of personal characteristics}

In sum, it may be concluded that the results of this study provide more information with regard to the specific influence of personal characteristics on outcome variables. The personal characteristics growth need strength, negative affectivity and upward striving appear to be primarily and particularly related to the outcome variables intrinsic work motivation, emotional exhaustion and turnover intention, respectively. These results imply that a further refinement of the pattern of relationships between work characteristics and outcome variables seems possible, and that the prediction of outcome variables can be improved by taking into account the influence of specific personal characteristics.

With regard to negative affectivity, the finding that this personal characteristic had longitudinal direct and additive effects on emotional exhaustion, as well as a 
moderating effect on the relationship between workload and emotional exhaustion (longitudinal), can be considered a salient result of this study. Negative affectivity appears to have a substantial effect on health-related outcome variables, rather than, for instance, an indirect (or mediation) effect (e.g., via workload; cf. Iverson et al., 1998) or a confounding effect (see also Moyle, 1995; Spector et al., 2000).

\section{Cross-sectional versus longitudinal results}

In the results regarding the effects of work characteristics, as well as in the results regarding the effects of personal characteristics, we have seen that the number of significant cross-sectional relationships is clearly larger than the number of significant cross-lagged relationships. Partly, this is due to features of thee available statistical techniques to analyze longitudinal data (e.g., the statistical power of these techniques seems to be rather low). The second explanation we provided was the true time lag problem. This true time lag is very likely to differ among the variables and relationships included in this study. We have seen that it is plausible that there exist relationships that can only be examined using very short time lags, or even cross-sectional analysis (see also section 6.3). Such effects could also be investigated by means of experiments, although the external validity of the results of such experiments might be questioned (cf. Baarda \& De Goede, 1995). In addition, a cross-sectional correlation might not only be the reflection of a short term effect of a work characteristics on a outcome variable, but may also be the reflection of the endpoint of a process of a work characteristic influencing an employee. For instance, a group of employees perceive their working situation as negative for a certain period. After a prolonged period of time this may lead to a diminished sense of intrinsic work motivation. When at moment $X$, both the work content and the intrinsic work motivation are measured, a significant positive correlation between work content and intrinsic work motivation is likely to be found, which is not the reflection of a short term relationship, but of a long term causal process.

Considering the issues regarding the analysis of longitudinal data discussed above, we believe that, for the time being, a combination of both cross-sectional and longitudinal analyses provides the best insight in reality. Cross-sectional data provide more insight into the detailed associations between variables, and probably also in relationships with short time lags (cf. Zapf et al., 1996). Longitudinal analyses may provide more insight into the causal order of variables and relationships with longer true time lags. At the same time, however, structural cross-lagged panel models generally fail to demonstrate significant relationships between time 1 and time 2 variables.

Paradoxically, over the course of time, cross-sectional study results have been strongly devalued. Considering the insights cross-sectional results may provide, and the problems that are associated with longitudinal research, we question the justifiability of this devaluation. 


\subsubsection{Practical implications of the study results}

\section{General implications}

What are the implications of the study results for the people at the workplace, and are there clues for interventions at the workplace?

Generally, our study results suggest that more accurate predictions regarding the associations between work characteristics and outcome variables are possible. Previous research, as well as several existing models (e.g., the Michigan Model and the Model of Work, Stress and Health) mainly indicate that "problems at the workplace" lead to "problems with employees' health". The results of our study, however, indicate what specific work characteristics and personal characteristics are in particular salient or relevant with regard to certain problems at the workplace. For instance, when employees report a lack of intrinsic work motivation, the most effect can probably be gained by redesigning tasks in such a way that the work includes more autonomy, task variety, feedback possibilities, task identity and task importance. In other words, more specific guidelines for interventions aimed at improving the workers' health and well-being at the workplace can be formulated. The efficiency of interventions at the workplace could be enhanced, accordingly. These results can, for instance, provide clues for the Dutch occupational health services, and would fit very well in a so-called "integral approach to the improvement of working conditions" (see Janssen, Nijhuis, Lourijsen \& Schaufeli, 1996). Such an integral approach consists of, among other things, a recurrent Inventory of Risks, the improvement and maintenance of the quality of the work content, working conditions, labor relations, and conditions of employment, and the improvement of the capabilities and knowledge of employees. In order to introduce such an integral approach, an organization should operate very systematically, and step by step (Janssen, Nijhuis, Lourijssen \& Schaufeli, 1996). An important first step in this regard is the determination of topics and aspects of the working situation to take into account when performing an Inventory of Risks, and the determination of measures that will be used. The model developed and validated in this thesis can particularly be helpful in this regard, as it covers a relatively broad range of work characteristics and outcome variables. Hence, the development of a diagnostic measurement instrument to be used in a certain organization could be based on (the variables included in) this model.

Furthermore, a regular Inventory of Risks, as it is applied by most Dutch occupational health services, particularly draws attention to bottlenecks and problems in the working situation and perhaps the health of the employees, but it does not provide information about relationships between these bottlenecks regarding work characteristics and outcome variables, such as health. For instance, an Inventory of Risks may show that many employees are burned out, and that many employees report high levels of workload, but it will not explicitly show that this high workload is the direct cause of the burnout problem. The model that was developed and tested in this study, however, is aimed at determining specific causes of problems in the working situation, and may as such be a sound basis for the selection of interventions. In addition, these interventions can be fine-tuned to the individual by means of taking 
into account specific personal characteristics of employees (e.g., negative affectivity appeared to contribute to the prediction of emotional exhaustion).

\section{Specific implications}

More specifically, the following suggestions may be formulated. First, we found a significant and positive relationship between task characteristics and intrinsic work motivation. This means that job redesign might be a useful intervention for employers to improve intrinsic work motivation, when necessary. The results show that task redesign may influence the intrinsic work motivation of employees in the short term as well as in the long term. This might imply that the positive effects of job redesign will not fade away in a short period of time, contrary to the positive effects of, for instance, a salary raise (Thierry, 1998). A well-known example of a job redesign method is job enrichment (changing a job horizontally -by means of adding tasks-, and/or vertically -by means of adding responsibility and authority-). Job enrichment is a rather longstanding concept, but may still have positive effects for employees and organizations. By means of job enrichment employees may obtain more autonomy, more task variety, a higher task identity, and they may experience their tasks as more important to their department or organization. An example of job enrichment for teachers might be the assignment of extra tasks, besides teaching, such as mentoring individual students during their work placement. Job enrichment might be useful for all employees (i.e., the positive relationship between task characteristics and intrinsic work motivation was found for all employees, and not merely for employees scoring high on growth need strength). Moreover, job enrichment is less fundamental than a complete reorganization of the division of labor, as is suggested in, for instance, the sociotechnical approach (cf. Janssen, Nijhuis, Lourijsen \& Schaufeli, 1996), and may as such be more feasible to organizations.

In addition, we found a positive relationship between growth need strength and intrinsic work motivation, particularly among teachers. Hence, this specific personal characteristic may also be a starting point for interventions aimed at improving work motivation. However, the question remains whether growth need strength can and should be influenced (cf. Vogelaar \& Van der Vlist, 1995). Moreover, in our study samples at least, mean scores on growth need strength were already high. One might question the usefulness of trying to enhance levels of growth need strength from high to very high. Thus, with regard to intrinsic work motivation, changing the environment seems more useful than changing the employee (see also Vogelaar \& Van der Vlist, 1995).

Organizations that are interested in the prevention of burnout, should pay attention to work characteristics (workload and social support) as well as to characteristics of the individual employee (negative affectivity). We have seen in chapter $\uparrow$ that the level of workload in many occupations is high and still increasing. In addition, workload is one of the strongest predictors of burnout and other health problems. Hence, interventions aimed at decreasing or controlling the workload might be very effective. Examples of interventions in this regard might be the introduction of shorter working hours, flexible 
working times, and more opportunity to influence one's own working pace and method. For instance, a teachers who is assigned several additional tasks besides teaching, should have less teaching hours.

Furthermore, social support appeared to be important in the origination of burnout. Social contacts with colleagues and a good relationship with supervisors are important for employees. Interviews with teachers in our study, for instance, have shown that bad relationships with supervisors were an important source of stress for many teachers in this education center. Workshops for supervisors aimed at improving their social and communicative capabilities might be useful in this regard.

Additionally, our study indicated that a high level of negative affectivity in employees was an important predictor of burnout. A high level of negative affectivity might, for instance, be diminished by means of personal training programs in which people are stimulated to look at the world around them from another, more positive perspective (cf. Zellars et al., 1999). Furthermore, Zellars et al. (1999) suggest that high negative affectivity individuals may respond very well to improving working conditions (e.g., a lower workload), even more so than low negative affectivity people. They base this suggestion on contentions of Fiske and Taylor (1991). The latter authors explain that stimuli that are not expected by individuals, are more salient to them than the expected stimuli. As high negative affectivity people generally expect negative stimuli, positive stimuli from their work environment may be more salient to them then to low negative affectivity people. This would imply that high negative affectivity individuals response more intense than low negative affectivity individuals on positive and on negative stimuli in the work environment. Hence, interventions aimed at lowering the workload (a positive stimulus) may have positive effects for both high negative affectivity and low negative affectivity people, although high negative affectivity employees may benefit more. At the same time, high negative affectivity people respond more intense to an increase in workload.

Finally, by means of paying attention to career expectations of employees (e.g., career development programs, education programs), retention of valuable employees might be accomplished. The issue of career development, however, is rather difficult for many organizations (cf. Arnold \& Mackensie Davey, 1999). Especially when organizations are preoccupied with surviving in a competitive environment, with mergers, and with flexibility of the workforce (see also chapter 1), there might be less attention for career management. However, engaging in career management might have a substantial payoff for organizations (see also Arnold \& Mackensie Davey, 1999). A suggestion for "modern" career management might be to introduce a more facilitating way of career management. That is, indicating and outlining to employees what career possibilities (educational, promotional, financial) exist within the organization, as well as what an employee should perform in order to have a claim on these possibilities. In this way, both the employee and the organization have a responsibility with regard to career management. In addition, the competencies of the employees are optimally developed, which is beneficial to both the employee and the 
organization. Of course, the development of a suchlike career management program is easier in large hierarchical organizations than in small companies.

In sum, the results of this study have indicated that organizations should pay attention to work-related variables as well as characteristics of the individual employee, when they are developing interventions aimed at improving work-related outcomes, such as intrinsic work motivation, health and turnover. This recommendation is in line with the most recent suggestions of Maslach et al. (2001) who suggest that, although there are pragmatic and philosophical reasons to focus on the individual (i.e., it is cheaper, and individuals have their own responsibility), it is most effective to change both the organization and the individual. Moreover, individuals have much less control over the stressors in their working situation than in other domains of their lives. Thus, it does not seem fair to leave everything to the individual employee.

In addition, these contentions are in line with recommendations of Gaillard (1996), who states that changing the workplace (and enhancing the quality of labor) may be helpful in preventing work-related problems, which might be considerably cheaper than paying for the sickness absence and disability benefits of employees who have fallen ill. Until recently, employers did not pay much attention to the improvement of the quality of the working situation, due to several factors (Gaillard, 1996). Stress was connected to personal problems and personality rather than to work characteristics. In case of high sickness absence levels, employers aimed at changing employees and not the organization. Second, in occupational health care the focus was traditionally on physical working conditions (e.g., toxic agents, physical workload, climate). Nowadays there is much attention for the relationships between employees and computers. Stress and psychological well-being at work, however, have received less attention. As we have concluded previously (chapter 1), the balance of work has shifted from hand to head, and hence, this focus on physical aspects of the working situation seems odd. Third, employers considered improving the working situation not cost-effective. However, as interventions in this regard are likely to stimulate health, well-being and motivation, in the longer term many profits may be gained: less sickness absence, higher motivation (and hence a higher productivity), and less turnover costs (cf. Maslach et al., 2001).

Finally, we should mention that the formulation of concrete interventions is difficult, and is very much related to the specific kind of work that is done in the organization. Moreover, it is hardly feasible to change all aspects of the working situation (cf. Gaillard, 1996). But, especially with regard to the latter problem, the research model proposed in this chapter might be very helpful in determining what work characteristics to change first, in order to achieve an optimal effect.

\subsection{Recommendations for future research}

The results of this study reveal several clues for future research. Below we will provide several theoretical and methodological recommendations in this regard. 


\section{Theoretical recommendations for future research}

First, the basic pattern of relationships (see Figure 2.6) appeared to hold in several samples. We found, however, one consistent additional relationship: the relationship between social support and turnover intention. Future research might clarify whether this relationship is stable in the context of the model developed in this thesis, and whether there are differential effects of social support from supervisors and colleagues.

A second topic for future research might be to replicate the validation of the model in multiple and different occupational groups. As we have concluded previously, hitherto the model has been validated in non-industrial samples. The replication of the model in industrial samples and blue collar workers would be a further validation of the model. However, it might be that in this case the specific operationalizations of the four categories of work characteristics (i.e., task characteristics, workload, social support and unmet career expectations) must be replaced by other operationalizations. For instance, it is plausible that in certain industrial sectors, the category of working conditions is better represented by physical working conditions than by mental workload. Physical working conditions are more salient in this sector. In other words, the model may in this regard be considered a framework in which the variables are operationalized such that they match the occupational group the model is applied to. In this line, it is also possible to replace the outcome variable burnout by psychological or psychosomatic health complaints. In sum, it might be advisable to examine the proper operationalization of all model variables when applying the model to occupations that considerably differ from the occupations that were tested in the present study.

Third, in the present study, we have only included psychological outcome variables. We found that work characteristics are adequate predictors of these outcome variables. An interesting step forward might be to extend the model with behavioral outcomes, and test whether it still holds. For instance, intrinsic work motivation might be an adequate predictor of performance at the work place. Mental health variables can be adequate predictors of sickness absence and disablement for work, and turnover intention is likely to be a good predictor of turnover. This might be a first step in the development of a process model: work characteristics lead to psychological outcomes, which in turn lead to several behavioral outcomes.

A fourth subject for future research might be to investigate the pattern of interrelationships between the outcome variables. In the present study, we focused on the pattern of relationships between work characteristics and outcomes. However, some research suggests, for instance, a positive relationship between emotional exhaustion and turnover intention (Geurts, Schaufeli \& De Jonge, 1998; Weisberg \& Sagie, 1999; Wright \& Cropanzano, 1998). A further elaboration on this subject seems to be an interesting research topic, and might also lead to the development of process models.

Finally, in the present study we aimed to "match" work characteristics and personal characteristics to outcome variables: what work characteristics and personal characteristics are in particular useful to predict certain outcome variables. Another 
approach might be to "match" work characteristics with other work characteristics, for instance, job demands (e.g., a high workload, emotional demands) and job resources (e.g., autonomy). An interesting question in this regard might be the following. When a work situation is characterized by a high level of emotional demands, it might be possible to identify matching work characteristics (e.g., a resource such as emotional support from colleagues) that compensate for the demanding work characteristics. When there exists a well-balanced mixture between demands and resources, the origination of health problems may be prevented, and psychological growth and motivation may ensue (cf. Hobfoll \& Freedy, 1993; De Jonge, Bosma, Peter \& Siegrist, 2000).

\section{Methodological recommendations for future research}

Methodological challenges for future research may be found in refining the statistical techniques to analyze longitudinal data. There is still some unclearity about the best way to analyze longitudinal data. In the present study, we have seen that the interpretation of structural panel models is at times unclear, and that problems like negative suppression may occur in these models.

Second, in the present study we performed a panel study with two waves. Probably multi-wave studies that incorporate natural changes in the working situation (e.g., job redesign, interventions aimed at lowering the workload) are more appropriate to demonstrate causal effects of work characteristics on the outcome variables. In a study with multiple waves, there is more opportunity to test different time lags for different relationships (cf. Frese \& Zapf, 1988; Zapf et al., 1996). However, for practical reasons (time, resources) it is often not possible to perform multi-wave studies. Hence, more attention for combining cross-sectional and two-wave longitudinal results might be helpful in this regard.

All in all, we believe our study method and results to be interesting, because we tested both synchronous and cross-lagged effects of several personal characteristics and work characteristics, using a cross-lagged structural panel model, that enables the test of causal predominance. Longitudinal studies in this specific area appear to be rather scarce (cf. Dormann \& Zapf, 1999; Zapf et al., 1996). This study has provided valuable insights into the specific effects work may have on various aspects of employees, as well as on the influence personal characteristics may have in this regard. But still, there are some unsolved issues that deserve attention in future research. 
Samenvatting

(Summary in Dutch) 
In dit proefschrift worden de werk- en persoonsgerelateerde specifieke determinanten van motivatie, gezondheid en verloop in kaart gebracht en onderzocht.

In hoofdstuk 1 wordt een algemene inleiding gegeven op het onderwerp dat in deze studie centraal staat, en wordt de achtergrond van het onderzoek geschetst. Het blijkt dat de hoeveelheid werkstress in de Westerse wereld over het algemeen hoog is en nog steeds toeneemt. Dit gaat gepaard met allerlei gezondheidsklachten, motivatieproblemen, een hoog ziekteverzuim, een hoge toetreding tot de WAO, en dus ook met hoge kosten. Om deze problemen het hoofd te bieden is er behoefte aan een model dat een integraal overzicht biedt van de werksituatie, dat de specifieke relaties tussen werkkenmerken, persoonskenmerken en effectvariabelen weergeeft en dat aldus de basis kan vormen voor gerichte interventies op de werkplaats. De bekende stressmodellen zoals het Michigan Model blijken in dit opzicht nogal vaag te zijn en vooral een heuristisch overzicht te bieden van relaties tussen (categorieën van) variabelen. Er worden echter geen specifieke relaties beschreven in deze bestaande modellen. Voor dit onderzoek werden dan ook twee onderzoeksvragen geformuleerd:

1. Wat zijn de specifieke relaties tussen werkkenmerken en werkgerelateerde effectvariabelen?

2. Wat is de specifieke invloed van persoonskenmerken op de werkgerelateerde effectvariabelen, en op de relaties tussen werkkenmerken en deze effectvariabelen?

Deze onderzoeksvragen zullen worden onderzocht in een studie bestaande uit een cross-sectioneel en een longitudinaal deel, en in twee steekproeven: medewerkers van een grote Nederlandse bank en docenten uit het middelbaar beroepsonderwijs.

Hoofdstuk 2 is een theoretisch hoofdstuk. In het eerste deel van dit hoofdstuk wordt aandacht geschonken aan enkele meta-theoretische vraagstukken met betrekking tot modelontwikkeling, met als doel een kader te schetsen voor het bespreken van bestaande stressmodellen en aanknopingspunten te bieden voor het ontwikkelen van een model dat het antwoord moet vormen op de onderzoeksvragen.

Er kunnen vier niveaus van model- of theorieontwikkeling onderscheiden worden: metatheorieën (deze richten zich op filosofische en methodologische vraagstukken met betrekking tot modelontwikkeling), conceptuele modellen (deze bieden een raamwerk voor onderzoek, maar zijn weinig specifiek, en dus nauwelijks toetsbaar), theoretische modellen (deze zijn voorspellend van aard, toetsbaar, en bieden toch een goed overzicht van relevante variabelen uit een bepaald vakgebied), en tot slot de (praktijk)theorieën (deze zijn heel specifiek, en richten zich dan ook op een kleiner deel van de werkelijkheid dan de theoretische modellen). Er wordt geconcludeerd dat er ten behoeve van het beantwoorden van de onderzoeksvragen behoefte is aan een theoretisch model. Immers, een theoretische model beschrijft specifieke relaties, en biedt tegelijkertijd een overzicht van een vakgebied. Een dergelijk model blijkt op het eerste gezicht niet voorhanden binnen de Arbeids- en Organisatie psychologie. Een dergelijk theoretisch model zou zowel de globale inzichten met betrekking tot de invloed van werk op de gezondheid en het welzijn van werknemers, als de meer 
specifieke inzichten met betrekking tot de effecten van bepaalde werkkenmerken op bepaalde effectvariabelen moeten omvatten. Bovendien zou een dergelijk model moeten voldoen aan bepaalde criteria zoals zinvolheid, toetsbaarheid, generaliseerbaarheid en spaarzaamheid. De globale inzichten waarnaar hierboven verwezen wordt, zouden afgeleid kunnen worden uit bestaande conceptuele stressmodellen. Er worden vervolgens dan ook drie bekende stressmodellen besproken: het Michigan Model, het Demand-Control-Support Model, en het Model voor Arbeid, Stress en Gezondheid. Deze modellen hebben een aanzienlijke hoeveelheid empirische onderzoeken gegenereerd en veel kennis opgeleverd. Het Model voor Arbeid, Stress en Gezondheid biedt bovendien een zeer bruikbare indeling van werkkenmerken in vier categorieën (werkinhoud, arbeidsomstandigheden, arbeidsverhoudingen en arbeidsvoorwaarden). Echter, deze modellen bieden geen inzicht in specifieke relaties tussen werkkenmerken, persoonskenmerken en effectvariabelen.

In het tweede deel van dit hoofdstuk wordt dan ook in een aantal stappen een model geformuleerd dat de specifieke relaties tussen werkkenmerken en effectvariabelen weergeeft. Hierbij wordt een reeds bestaand model dat hetzelfde beoogde, maar minder uitgebreid onderbouwd en gevalideerd is, als uitgangspunt genomen.

In de eerste plaats worden drie psychologische effectvariabelen geselecteerd: intrinsieke werkmotivatie, emotionele uitputting (de kerndimensie van burnout) en verloopintentie. De werkkenmerken worden ingedeeld volgens de vier categorieën uit het model voor Arbeid, Stress en Gezondheid. Vervolgens worden op basis van een uitgebreide literatuurstudie de specifieke relaties tussen de geselecteerde werkkenmerken en effectvariabelen in kaart gebracht. Er wordt geconcludeerd dat (1) intrinsieke werkmotivatie primair gerelateerd is aan taakkenmerken (zoals autonomie, afwisseling en taakidentiteit; arbeidsinhoud); (2) emotionele uitputting primair gerelateerd is aan werkdruk (arbeidsomstandigheden) en sociale steun (arbeidsverhoudingen); en (3) dat verloopintentie primair gerelateerd is aan onvervulde loopbaanwensen (arbeidsvoorwaarden).

Uit de literatuur kan tevens worden geconcludeerd dat niet iedereen hetzelfde reageert op een bepaalde (werk)situatie. Daarom wordt in het derde deel van dit hoofdstuk ingegaan op de invloed van persoonskenmerken. $\mathrm{Er}$ worden drie persoonskenmerken geselecteerd die in het bijzonder lijken bij te dragen aan de voorspelling van de drie geselecteerde effectvariabelen. Met betrekking tot de drie effectvariabelen intrinsieke werkmotivatie, emotionele uitputting en verloopintentie worden respectievelijk de persoonskenmerken "growth need strength" (groeibehoefte), "negative affectivity" (negatieve affectiviteit), en "upward striving" (behoefte aan het maken van opwaartse carrière) geselecteerd. Er wordt verondersteld dat deze persoonskenmerken zowel additieve als modererende effecten kunnen hebben op respectievelijk de effectvariabelen en de relaties tussen werkkenmerken en effectvariabelen.

In hoofdstuk 3 komen de onderzoeksmethode, de procedure, de steekproeven, de meetinstrumenten en de analysemethoden aan de orde. Om een zo compleet 
mogelijk beeld te krijgen van de werkelijkheid bestaat het onderzoek uit twee delen: een cross-sectioneel deel en een longitudinaal deel (een zogenaamde panel studie met twee meetmomenten en een tijdsinterval van één jaar). Voor beide onderzoeksdelen werden aparte theoretische hypotheses geformuleerd met betrekking tot de specifieke relaties tussen werkkenmerken, persoonskenmerken en effectvariabelen. In de hypotheses met betrekking tot het cross-sectionele deel ligt de nadruk op specifieke associaties, en in de hypotheses met betrekking tot het longitudinale deel ligt de nadruk op de causaliteit van de relaties. Met betrekking tot dit laatste wordt verondersteld dat werkkenmerken op tijdstip 1 van invloed zijn op effectvariabelen op tijdstip 2 (een regulier causatiepatroon).

Er worden twee steekproeven gebruikt in dit onderzoek, één uit een profit sector, en één uit een non-profit sector. De eerste steekproef bestaat uit werknemers van een grote Nederlandse bank. Er wordt een willekeurige steekproef van 500 medewerkers getrokken uit het totale werknemersbestand van deze bank. De tweede steekproef bestaat uit onderwijzers uit het middelbaar beroepsonderwijs. Alle onderwijzers werkzaam bij een Regionaal Opleidingscentrum in Limburg worden geïncludeerd ( $N=$ 644). Met betrekking tot het gebruik van twee steekproeven worden nog twee extra methodologische hypothesen geformuleerd. Deze hebben betrekking op de stabiliteit van de relaties over beide steekproeven.

Op tijdstip 1 was de respons in beide steekproeven ongeveer $50 \%$. Al deze werknemers worden opgenomen in het cross-sectionele deel van de studie. Op tijdstip 2 was de respons ook ongeveer $50 \%$. De uiteindelijke panelgroep (medewerkers die zowel op tijdstip 1 als op tijdstip 2 respondeerden) bestaat in beide steekproeven uit ongeveer $30 \%$ van de initiële steekproef. Deze panelgroep wordt opgenomen in het longitudinale deel van de studie. Een vergelijking van de panelgroep met de uitvallers (medewerkers die alleen op tijdstip 1 respondeerden) toont aan dat er geen grote verschillen bestaan tussen beide groepen met betrekking tot de demografische factoren leeftijd en geslacht. Om alle onderzoeksvariabelen te meten wordt gebruik gemaakt van een schriftelijke vragenlijst die is samengesteld uit gevalideerde, bestaande schalen. Om de data te analyseren wordt gebruik gemaakt van Structural Equation Modeling (SEM), Multi-Sample Analyse (met behulp van SEM), cross-lagged panel modellen, en voor het toetsen van interactie-effecten tenslotte, wordt gebruik gemaakt van SEM en multi-groep analyse. Deze technieken worden aan het einde van hoofdstuk 3 toegelicht.

In hoofdstuk 4 worden de resultaten van het cross-sectionele deel van de studie besproken. Ten eerste wordt in dit hoofdstuk het patroon van specifieke relaties tussen de werkkenmerken en effectvariabelen integraal en in beide steekproeven tegelijkertijd getoetst door middel van Multi-Sample Analyse. Uit deze analyse blijkt dat het patroon van relaties significant en invariant is over beide steekproeven. Dit betekent dat zowel de richting als de sterkte van de relaties in beide steekproeven gelijk zijn. Deze bevinding kan worden beschouwd als een sterke validering van het patroon van relaties. Er wordt geconcludeerd dat de cross-sectionele hypotheses met betrekking tot de relaties tussen werkkenmerken en effectvariabelen bevestigd zijn in 
beide steekproeven. Uitdagend werk dat hoog scoort op taakkenmerken zoals autonomie en afwisseling, is gerelateerd aan intrinsieke werkmotivatie; werkdruk en sociale steun zijn gerelateerd aan emotionele uitputting; en onvervulde loopbaanwensen zijn gerelateerd aan verloopintentie. Behalve het bovenstaande relatiepatroon worden ook enkele additionele relaties gevonden. In de eerste steekproef (bank medewerkers) wordt een relatie gevonden tussen werkdruk en intrinsieke werkmotivatie. In de tweede steekproef (onderwijzers) wordt een relatie aangetoond tussen taakkenmerken en emotionele uitputting. Bovendien wordt in beide steekproeven een relatie gevonden tussen sociale steun en verloopintentie. Deze laatste relatie blijkt dus wat meer consistent te zijn, terwijl de overige twee additionele relaties als steekproef-specifiek worden beschouwd.

in het tweede deel van hoofdstuk 4 wordt de invloed van persoonskenmerken getoetst. Enkele voorbereidende analyses (waarin alleen persoonskenmerken en effectvariabelen werden opgenomen) tonen aan dat, in overeenstemming met de verwachtingen, growth need strength met name gerelateerd is aan intrinsieke werkmotivatie, dat negative affectivity met name gerelateerd is aan emotionele uitputting, en dat upward striving met name gerelateerd is aan verloopintentie. Deze resultaten worden in beide steekproeven gevonden. Verder wordt er in beide steekproeven een additionele relatie gevonden tussen negative affectivity en verloopintentie. Deze relatie is in vergelijking met de bovenstaande relaties echter tamelijk zwak. Na deze veelbelovende voorbereidende analyses worden vervolgens de additieve en modererende effecten van de persoonskenmerken getoetst. Hiertoe worden, voor ieder persoonskenmerk afzonderlijk, het persoonskenmerk en de bijbehorende interactie term (persoonskenmerk * werkkenmerk) aan het structureel model toegevoegd. Wederom wordt gebruik gemaakt van multi-sample analyse. De resultaten van deze analyses laten het volgende zien: growth need strength heeft een positief additief effect op intrinsieke werkmotivatie, boven op het effect van taakkenmerken. Dit effect is bij de onderwijzers duidelijker zichtbaar dan bij de bankmedewerkers. Negative affectivity heeft een positief additief effect op emotionele uitputting, boven op de effecten van werkdruk en sociale steun. Deze twee effecten zijn wel in beide steekproeven significant, maar zijn niet invariant over beide steekproeven (de relaties hadden niet dezelfde sterkte in beide steekproeven). Upward striving blijkt in beide steekproeven een positief additief effect te hebben op verloopintentie, en heeft bovendien een modererend effect op de relatie tussen onvervulde loopbaanwensen en verloopintentie. Hoe hoger de score op upward striving, hoe sterker de relatie tussen onvervulde loopbaanwensen en verloopintentie. Deze effecten zijn invariant over beide steekproeven.

Resumerend kan gesteld worden dat voor alledrie de persoonskenmerken specifieke additieve effecten worden aangetoond in de cross-sectionele studie, maar dat alleen voor upward striving een modererend effect wordt gevonden.

Strikt genomen is er in hoofdstuk 4 alleen evidentie gevonden voor associaties tussen variabelen. Er kunnen nog geen uitspraken gedaan worden over de causaliteit van de relaties. Dit punt zal dan ook in hoofdstuk 5 aan de orde komen. 
In hoofdstuk 5 worden de resultaten van de panelstudie besproken. In het eerste deel van dit hoofdstuk wordt het veronderstelde patroon van relaties tussen werkkenmerken en effectvariabelen longitudinaal getoetst in beide steekproeven afzonderlijk, door middel van een cross-lagged panel model. Eerst worden echter enkele voorbereidende analyses uitgevoerd. Hieruit blijkt dat het veronderstelde patroon van relaties tussen werkkenmerken en effectvariabelen stabiel (invariant) is over de steekproeven en consistent in de tijd. Behalve de relatie tussen sociale steun en verloopintentie, blijken de additionele relaties minder stabiel te zijn. Vervolgens wordt de causaliteit van het patroon van relaties onderzocht. In steekproef 1 (bankmedewerkers) lijkt een regulier causatiepatroon dominant te zijn (in overeenstemming met de verwachtingen): werkkenmerken op tijdstip 1 beïnvloeden de effectvariabelen op tijdstip 2. In steekproef 2 (onderwijzers) wordt ondersteuning gevonden voor een reciprook causatiepatroon. Werkkenmerken op tijdstip 1 beïnvloeden de effectvariabelen op tijdstip 2, maar het is ook mogelijk dat de effectvariabelen op tijdstip 1 van invloed zijn op de werkkenmerken op tijdstip 2. In beide steekproeven worden enkele significante longitudinale paden gevonden (ondanks het feit dat er gecorrigeerd werd voor stabiliteiten). In steekproef 1 worden relaties aangetoond tussen taakkenmerken op tijdstip 1 en intrinsieke werkmotivatie op tijdstip 2, en tussen werkdruk op tijdstip 1 en emotionele uitputting op tijdstip 2 . In steekproef 2 wordt een relatie aangetoond tussen werkdruk op tijdstip 1 en emotionele uitputting op tijdstip 2 , en een relatie tussen verloopintentie op tijdstip 1 en onvervulde loopbaanwensen op tijdstip 2. Resumerend wordt in beide steekproeven ondersteuning gevonden voor een regulier causatiepatroon, hoewel in steekproef 2 alternatieve causatiepatronen niet geheel kunnen worden uitgesloten.

In het tweede deel van dit hoofdstuk worden de effecten van de persoonskenmerken longitudinaal getoetst. Om methodologische redenen werden beide steekproeven voor deze analyses samengevoegd tot één grotere steekproef bestaande uit bankmedewerkers en onderwijzers. Voor de analyse van de gegevens wordt wederom gebruik gemaakt van een cross-lagged panel model. Uit enkele voorbereidende analyses (waarin alleen persoonskenmerken en effectvariabelen worden opgenomen) blijkt dat alle synchrone paden tussen de persoonskenmerken en effectvariabelen significant zijn: growth need strength is met name gerelateerd aan intrinsieke werkmotivatie (zowel op tijdstip 1 als op tijdstip 2), negative affectivity is met name gerelateerd aan emotionele uitputting (zowel op tijdstip 1 als op tijdstip 2), en upward striving is met name gerelateerd aan verloopintentie (zowel op tijdstip 1 als op tijdstip 2). Bovendien blijkt er ondersteuning te bestaan voor een regulier causatiepatroon: de persoonskenmerken op tijdstip 1 zijn van invloed op de effectvariabelen op tijdstip 2 . Er blijkt echter maar één significant longitudinaal pad te bestaan, namelijk het pad tussen negative affectivity op tijdstip 1 en emotionele uitputting op tijdstip 2. Verder blijkt dat negative affectivity een positief additief en longitudinaal effect heeft op emotionele uitputting, boven op de effecten van de werkkenmerken werkdruk en sociale steun. Uit een toets van de moderatoreffecten van de persoonskenmerken (door middel van multi-groep analyses) blijkt dat alleen negative affectivity een modererend effect heeft, namelijk op de relatie tussen werkdruk op tijdstip 1 en 
emotionele uitputting op tijdstip 2. Hoe hoger de score op negative affectivity, hoe sterker de relatie tussen werkdruk en emotionele uitputting.

Resumerend kan gesteld worden dat alleen voor negative affectivity longitudinale effecten aangetoond worden. Growth need strength en upward striving blijken geen significante longitudinale effecten te hebben.

In hoofdstuk 6 tenslotte worden ten eerste de belangrijkste bevindingen van deze studie geordend en worden enkele conclusies getrokken. Vervolgens worden enkele methodologische kanttekeningen geplaatst bij achtereenvolgens het onderzoeksdesign, de steekproeven, de meetinstrumenten en de statistische analysemethoden. Het blijkt onder andere dat ook aan longitudinaal onderzoek enkele problemen kleven. Ten eerste is er het "time lag" probleem. In ieder longitudinaal onderzoek moet een keuze gemaakt worden voor een bepaald tijdsinterval tussen de meetmomenten. Het is echter zeer wel mogelijk dat het echte tijdsinterval tussen de onderzochte onafhankelijke en afhankelijke variabelen hiervan afwijkt. Verder is in longitudinaal onderzoek non-respons een groot probleem. Bij ieder meetmoment wordt de nonrespons groter. Ten derde kleven er aan de beschikbare analyse methoden (SEM) nog enkele haken en ogen. Een voorbeeld hiervan is het vóórkomen van negatieve suppressie (een onverwachte omdraaiing van het teken van de longitudinale paden) in cross-lagged panel modellen. Het is vooralsnog niet duidelijk hoe dit precies geïnterpreteerd moet worden. We concluderen dan ook dat het beste beeld van de werkelijkheid verkregen wordt door zowel de cross-sectionele resultaten als de longitudinale resultaten in ogenschouw te nemen. Op deze manier kunnen zowel korte termijn als lange termijn effecten worden onderzocht en kan een beeld worden verkregen van de stabiliteit van relatiepatronen.

Vervolgens worden de theoretische en praktische implicaties van de resultaten van deze studie besproken. Ten eerste kan geconcludeerd worden dat het veronderstelde patroon van specifieke relaties tussen werkkenmerken en effectvariabelen invariant is over steekproeven, stabiel is in de tijd, en ook in longitudinale analyses (deels) stand houdt. Het patroon lijkt op overtuigende wijze gevalideerd te zijn. Deze bevindingen zijn in overeenstemming met veel literatuur op dit gebied en een eerder uitgevoerde studie naar dit model. Hiernaast worden enkele additionele relaties gevonden. De relatie tussen sociale steun en verloopintentie blijkt het meest consistent te zijn. Het blijkt inderdaad dat deze relatie ook in enkele bestaande empirische studies aangetoond wordt, echter niet frequent. Verder onderzoek zal moeten uitwijzen of deze relatie consistent is.

De aanwezigheid van enkele significante longitudinale paden toont aan dat werkkenmerken (werkdruk bijvoorbeeld) zowel op de korte als de lange termijn van invloed zijn op effectvariabelen (emotionele uitputting bijvoorbeeld). De "omgekeerde" longitudinale relatie tussen verloopintentie op tijdstip 1 en onvervulde loopbaanwensen op tijdstip 2 bij onderwijzers zou verklaard kunnen worden door de het gebrek aan alternatieven voor onderwijzers. Onderwijzers met een hoge verloopintentie hebben weinig andere mogelijkheden dan onderwijzer te blijven. Bovendien is de problematiek op veel Nederlandse scholen gelijksoortig. Met andere 
woorden, verloopintentie kan niet gemakkelijk worden getransformeerd in daadwerkelijk verloop, met als gevolg dat de frustratie over de loopbaanmogelijkheden binnen de eigen instelling verder toeneemt. Met betrekking tot de persoonskenmerken kan worden opgemerkt dat deze wel direct van invloed zijn op de effectvariabelen, maar dat de relaties tussen werkkenmerken en effectvariabelen niet sterk gemodereerd worden door persoonskenmerken. Dit betekent bijvoorbeeld dat voor zowel mensen die hoog scoren op negative affectivity als voor mensen die laag scoren op dit persoonskenmerk, de relatie tussen werkdruk en emotionele uitputting positief is, en dat voor beide categorieën werknemers het verlagen van de werkdruk zinvol lijkt. Aan het einde van dit hoofdstuk worden enkele praktische aanbevelingen gedaan op basis van de studieresultaten. Er wordt onder andere geconstateerd dat het in dit onderzoek ontwikkelde en gevalideerd theoretisch model aanknopingspunten kan bieden voor specifieke interventies en richtinggevend kan zijn voor het verbeteren van de kwaliteit van de arbeid. Indien op de werkvloer een bepaald probleem wordt geconstateerd met betrekking tot bijvoorbeeld motivatie, laat dit model zien dat aanpassing van de arbeidsinhoud in dit geval de meest zinvolle interventie zou zijn. Het hoofdstuk wordt afgesloten met enkele aanbevelingen voor toekomstig onderzoek. 


\section{References}


Aguinis, H. (2001). Pitfalls in estimating moderating effects: Implications for W\&O psychology research and practice. Paper presented at the Tenth European Congress on Work and Organizational Psychology, Prague, Czech Republic.

Aiken, L.S., \& West, S.G. (1991). Multiple regression: Testing and interpreting interactions. Newbury Park, CA: Sage.

Ajzen, I. (1987). Attitudes, traits and actions: Dispositional prediction of behavior in personality and social psychology. In L. Berkowitz (Ed.), Advances in experimental social psychology (Vol. 20, pp. 1-63). San Diego: Academic Press.

Ajzen, I., \& Fishbein, M. (1980). Understanding attitudes and predicting social behavior. Englewood Cliffs: Prentice Hall.

Algera, J.A. (1981). Kenmerken van werk [Work characteristics]. Lisse, The Netherlands: Swets \& Zeitlinger.

Algera, J.A. (1990). The job characteristics model of work motivation revisited. In U. Kleinbeck, H.H. Quast, H. Thierry, \& H. Häcker (Eds.), Work motivation (pp. 85-103). Hillsdale, NJ: Lawrence Erlbaum.

Algera, J.A. (1992) Taakkenmerken [Task characteristics]. In P.J.D. Drenth, H. Thierry, \& C.J. de Wolff (Eds.), Nieuw handboek arbeids- en organisatiepsychologie. Houten, The Netherlands: Bohn Stafleu Van Loghum.

Anderson, J.C., \& Gerbing, D.W. (1988). Structural equation modelling in practice: A review and recommended two-step approach. Psychological Bulletin, 103, 411-423.

Arnold, J., \& Mackenzie Davey, K. (1999). Graduates' work experiences as predictors of organisational commitment, intention to leave, and turnover: Which experiences really matter? Applied Psychology: An International Review, 48, 211-238.

Baarda, D.B., \& Goede, M.P.M. de (1995). Methoden en technieken. Basisboek: Praktische handleiding voor het opzetten en uitvoeren van onderzoek [Research methods and techniques. Manual for the design and implementation of scientific research] (2nd ed.). Houten: The Netherlands: Stenfert Kroese.

Barnabé, C., \& Burns, M. (1994). Teachers' job characteristics and motivation. Educational Research, $36,171-185$.

Bentler, P.M. (1990). Comparative fit indices in structural models. Psychological Bulletin, 107, 238-246.

Bentler, P.M., \& Bonett, D.G. (1980). Significance tests and goodness of fit in the analysis of covariance structures. Psychological Bulletin, 88, 588-606.

Bergers, G.P.A., Marcelissen, F.H.G., \& Wolff, C.J. de (1986). VOS-D. Vragenlijst Organisatie-stress-D: Handleiding [VOS-D. Work Stress Questionnaire Doetinchem: Manual]. Nijmegen, The Netherlands: University of Nijmegen.

Berkhout, A.J.M.B. (2000). Resident-oriented care in nursing homes. An evaluation study of the model of resident-oriented care, the implementation and the effects. PhD thesis, Maastricht University, Maastricht, The Netherlands.

Blanc, P.M. le, Jonge, J. de, \& Schaufeli, W.B. (2000). Job stress and health. In N. Chmiel (Ed.), Introduction to work and organizational psychology: A European perspective (pp. 148-177). Malden, MA: Blackwell Publishers.

Blau, G. (1989). Testing the generalizability of a career commitment measure and its impact on employee turnover. Journal of Vocational Behavior, 35, 88-103.

Bluedorn, A.C. (1978). A taxonomy of turnover. Academy of Management Review, 3, 647-651.

Bluedorn, A.C. (1982). A unified model of turnover from organizations. Human Relations, 35, 135-153.

Bollen, K.A. (1989). Structural equations with latent variables. New York: Wiley.

Bosman, H.W.J. (1983). Het Nederlandse bankwezen [The Dutch banking sector] (3d ed.). Amsterdam/Deventer, The Netherlands: Nederlands Instituut voor het Bank- en Effectenbedrijf/Kluwer.

Boumans, N.P.G., \& Landeweerd, J.A. (1993). Some problems concerning the measurement of job characteristics in nursing work. The European Work and Organizational Psychologist, 2, 303-317. 
Bouter, L.M., \& Dongen, M.C.J.M. van (2000). Epidemiologisch onderzoek. Opzet en interpretatie [Epidemiological research. Design and interpretation] (4th ed.). Houten, The Netherlands: Bohn Stafleu Van Loghum.

Breukelen, G. van (1999). Personal communication. April 1999.

Breukelen, J.W.M. van (1989). Personeelsverloop in organisaties. Een literatuuroverzicht en een model [Turnover in organizations. A literature review and a model]. Gedrag \& Organisatie, 6, 37-65.

Brief, A.P., Burke, M.J., George, J.M., Robinson, B.S., \& Webster, J. (1988). Should negative affectivity remain an unmeasured variable in the study of job stress? Journal of Applied Psychology, 73, 193-198.

Browne, M.W., \& Cudeck, R. (1989). Single sample cross-validation indices for covariance structures. Multivariate Behavioral Research, 24, 445-455.

Burke, R.J., \& Greenglass, E.R. (1989). Psychological burnout among men and women in teaching: A critical examination of the Cherniss model. Human Relations, 42, 261-273.

Burke, R.J., \& Greenglass, E.R. (1995). A longitudinal examination of the Cherniss model of psychological burnout. Social Science and Medicine, 40, 1357-1363.

Burke, R.J., Shearer, J., \& Deszca, G. (1984). Burnout among men and women in police work: An examination of the Cherniss model. Journal of Health and Human Resources Administration, 7 , 162-188.

Buunk, B.P. (1990). Affiliation and helping interactions within organizations: A critical analysis of the role of social support with regard to occupational stress. European review of social psychology (Vol. 1, pp. 293-322). New York: Wiley.

Buunk, B.P. (1993). Persoonlijkheidskenmerken, sociale ondersteuning en stress op het werk [Personal characteristics, social support and stress at work]. In B.P. Buunk, \& J. Gerrichhauzen (Eds.), Stress en werk (pp. 63-78). Groningen, The Netherlands: Wolters Noordhoff.

Buunk, B.P., \& Janssen, P.P.M. (1992). Relative deprivation, career issues and mental health among men in midlife. Journal of Vocational Behavior, 40, 338-350.

Buunk, B.P., Jonge, J. de, Ybema, J.F., \& Wolff, C.J. de (1998). Psychosocial aspects of occupational stress. In P.J.D. Drenth, H. Thierry, \& C.J. de Wolff (Eds.), Handbook of work and organizational psychology (Vol. 2, 2nd ed., pp. 145-182). Hove, UK: Psychology Press/Eribaum.

Buunk, B.P., \& Verhoeven, K. (1991). Companionship and support at work: A micro-analysis of the stress-reducing features of social interaction. Basic and Applied Social Psychology, 12, 243-258.

Byrne, B.M. (1991). The Maslach Burnout Inventory: Validating factorial structure and invariance across intermediate, secondary, and university educators. Multivariate Behavioral Research, 26, 583605.

Byrne, B.M. (1994). Burnout: testing for the validity, replication, and invariance of causal structure across elementary, intermediate, and secondary teachers. American Education Research Journal, 31, 645-673.

Byrne, B.M. (1998). Structural equation modeling with LISREL, PRELIS, and SIMPLIS. Mahwah: Lawrence Erlbaum.

Caplan, R.D. (1971). Organizational stress and individual strain: A social psychological study of risk factors in coronary heart disease among administrators, engineers and scientists. Ann Arbor: Institute for Social Research, University of Michigan.

Caplan, R.D., Cobb, S., French, J.R.P. Jr., Harrison, R. van, \& Pinneau, S.R. Jr. (1975). Job demands and worker health: Main effects and occupational differences. Washington, DC: US Government Printing Office.

Cascio, W.F. (1995). Whither industrial and organizational psychology in a changing world of work? American Psychologist, 50, 928-939.

Cassar, V., \& Tattersall, A. (1998). Occupational stress and negative affectivity in Maltese nurses: Testing moderating influences. Work \& Stress, 12, 85-94.

Caudill, H.L. (1996/1997). An empirical investigation of personality and situational predictors of job burnout. Dissertation Abstracts International, 57 (11), 4816A.

CBS (Centraal Bureau voor de Statistiek) (2000a). Enquête beroepsbevolking 1999 [Labour force survey 1999]. Voorburg/Heerlen, The Netherlands: Author. 
CBS (Centraal Bureau voor de Statistiek) (2000b). Statline [Online]. Available: http://statline.cbs.nl/statweb/cgi-bin/ [April 5, 2001].

Cherniss, C. (1980). Professional burnout in the human service organizations. New York: Praeger.

Cohen, J., \& Cohen, P. (1983). Applied multiple regression/correlation analysis for the behavioral sciences (2nd ed.). Hillsdale, $\mathrm{NJ}$ : Lawrence Erlbaum.

Cohen, S., \& Wills, T.A. (1985). Stress, social support, and the buffering hypothesis. Psychological Bulletin, 98, 310-357.

Cook, T.D., \& Campbell, D.T. (1979). Quasi-experimentation. Design and analysis for field settings. Boston: Houghton Mifflin.

Cook, J.D., Hepworth, S.J., Wall, T.D., \& Warr, P.B. (1981). The experience of work: A compendium and review of 249 measures and their use. London: Academic Press.

Cooper, C.L. (1998). Introduction. In C.L. Cooper (Ed.), Theories of organizational stress (pp. 1-5). Oxford: Oxford University Press.

Cooper, C.L., Liukkonen, P., \& Cartwright, S. (1996). Stress prevention in the workplace: Assessing the costs and benefits to organisations. Dublin: European Foundation for the Improvement of Living and Working Conditions.

Cooper, C.L., \& Payne, R. (1988). Causes, coping and consequences of stress at work. Chichester: Wiley.

Cordes, C.L., \& Dougherty, T.W. (1993). A review and integration of research on job burnout. Academy of Management Review, 18, 621-656.

Cornelisse, F.H. (1985). Inleiding tot de wetenschapsfilosofie [Introduction to the philosophy of science]. Amsterdam, The Netherlands: Van Loghum Slaterus.

Costa, P.T., \& McCrae, R.R. (1980). Influence of extroversion and neuroticism on subjective well-being: Happy and unhappy people. Journal of Personality and Social Psychology, 38, 36-51.

Cox, T., Kuk, G., \& Leiter, M.P. (1993). Burnout, health, work stress, and organizational healthiness. In W.B. Schaufeli, C. Maslach, \& T. Marek (Eds.), Professional burnout. Recent developments in theory and research (pp. 177-193). Washington, DC: Taylor \& Francis.

Cummings, T.G., \& Worley, C.G. (1997). Organizational development and change (6th ed.). Minneapolis: West Publishing Company.

Daniels, K., \& Jonge, J. de (2001). Longitudinal designs in work stress research and the question of validity. Paper presented at the Tenth European Congress on Work and Organizational Psychology, Prague, Czech Republic.

De Cenzo, D.A., \& Robbins, S.P. (1996). Human resource management (5th ed.). New York: Wiley.

Deci, E.L., \& Ryan, R.M. (1985). Intrinsic motivation and self determination in human behavior. New York: Plenum Press.

Diamantopoulos, A. (1994). Modelling with LISREL, a guide for the uninitiated. Journal of Marketing Management, 10, 105-136.

Diener, E., Suh, E.M., Lucas, R.E., \& Smith, H.I. (1999). Subjective well-being: Three decades of progress. Psychological Bulletin, 125, 267-302.

Dierendonck, D. van (1997). Balancing give and take. An equity approach to burnout. PhD thesis, Utrecht University, Utrecht, The Netherlands.

Ding, L., Velicer, W.F., \& Harlow, L.L. (1995). Effects of estimation methods, number of indicators per factor, and improper solutions on structural equation modeling fit indices. Structural Equation Modeling, 2, 119-143.

Dormann, C., \& Zapf, D. (1999). Social support, social stressors at work, and depressive symptoms: Testing for main and moderating effects with structural equations in a three-wave longitudinal study. Journal of Applied Psychology, 84, 874-884.

Dougherty, T.W., Bluedorn, A.C., \& Keon, T.L. (1985). Precursors of employee turnover: A multi-sample causal analysis. Journal of Occupational Behavior, 6, 259-271.

Dul, J., \& Houtman, I.L.D. (1995). Biomedische metingen van fysieke en psychische arbeidsbelasting [Biomedical measures of physical and psychological workload]. In P.G.W. Smulders, \& J.M.J. op de Weegh (Eds.), Arbeid en gezondheid. Risicofactoren (pp. 335-345). Utrecht, The Netherlands: Lemma. 
Dul, J., \& Vink, P. (1995). Houding en beweging: statische en dynamische belasting [Position and motion: static and dynamic demands]. In P.G.W. Smulders, \& J.M.J. op de Weegh (Eds.), Arbeid en gezondheid. Risicofactoren (pp. 137-146). Utrecht, The Netherlands: Lemma.

Dunnette, M.D. (1998). Emerging trends and vexing issues in industrial and organizational psychology. Applied Psychology: An International Review, 47, 129-153.

Duquette, A., Kérouac, S., Sandhu, B.K., \& Beaudet, L. (1994). Factors related to nursing burnout: A review of empirical knowledge. Issues in Mental Nursing, 15, 337-358.

Dwyer, D.J., Schwartz, R.H., \& Fox, M.L. (1992). Decision-making autonomy in nursing. Journal of Nursing Administration, 22, 17-23.

Dijk, J.K. van (1990). Personeelsmanagement in de jaren '90 [Management of personnel in the nineties]. Utrecht, The Netherlands: Nationale Ziekenhuisraad.

Dijk, J.K. van (1992). Personeelsmanagement: Een plaatsbepaling [Management of personnel: An orientation]. In J.K. van Dijk, J.E. Grunveld, \& J. Pool (Eds.), Personeelsmanagement in de gezondheidszorg. Theorie en praktijk (pp. 25-40). Houten, The Netherlands: Bohn Stafleu Van Loghum.

Dijkhuizen, N. van (1980). From stressors to strains: Research into their relationships. Lisse, The Netherlands: Swets \& Zeitlinger.

Earp, J.A., \& Ennett, S.T. (1991). Conceptual models for health education research and practice. Health Education Research, 6, 163-171.

European Commission (1997). Report on work-related stress. Luxembourg: The Advisory Committee for Safety, Hygiene and Health Protection at Work.

Evans, M.G. (1991). The problem of analysing multiplicative composites. Interactions revisited. American Psychologist, 46, 6-15.

Farh, J.L., \& Scott, W.E. (1983). The experimental effect of "autonomy" on performance and self-reports of satisfaction. Organizational Behavior and Human Performance, 31, 203-222.

Finkel, S.E. (1995). Causal analysis with panel data. Thousand Oaks, CA: Sage.

Fishbein, M., \& Ajzen, I. (1975). Belief, attitude, intention and behavior. Reading, MA: Addison-Wesley.

Fiske, S.T., \& Taylor, S.E. (1991). Social cognition (2nd ed.). New York: McGraw-Hill.

Francis-Felsen, L.C., Coward, R.T., Hogan, T.L., Duncan, R.P., Hilker, M.A., \& Horne, C. (1996). Factors influencing intentions of nursing personnel to leave employment in long-term care settings. The Journal of Applied Gerontology, 15, 450-470.

Frese, M. (1985). Stress at work and psychosomatic complaints: A causal interpretation. Journal of Applied Psychology, 70, 314-328.

Frese, M. (2000). The changing nature of work. In N. Chmiel (Ed.), Introduction to work and organizational psychology (pp. 424-439). Oxford: Blackwell Publishers.

Frese, M., \& Zapf, D. (1988). Methodological issues in the study of work stress: objective versus subjective measurement of work stress and the question of longitudinal studies. In C.L. Cooper, \& R. Payne (Eds.), Causes, coping, and consequences of stress at work (pp. 375-411). Chichester: Wiley.

Fried, Y., \& Ferris, G.R. (1987). The validity of the job characteristics model: A review and a metaanalysis. Personnel Psychology, 40, 287-322.

Furda, J. (1995). Werk, persoon en welzijn. Een toetsing van het Job Demand-Control model [Work, person and well-being. A test of the Job Demand-Control Model]. PhD thesis, Enschede, The Netherlands: Copyprint 2000).

Furnham, A. (1992). Personality at work. The role of individual differences in the workplace. London: Routledge.

Gagné, M., Senécal, C.B., \& Koestner, R. (1997). Proximal job characteristics, feelings of empowerment, and intrinsic work motivation: A multidimensional model. Journal of Applied Social Psychology, 27, 1222-1240.

Gaillard, A.W.K. (1996). Stress. Produktiviteit en gezondheid [Stress. Productivity and health]. Amsterdam, The Netherlands: Nieuwezijds. 
Ganster, D.C., \& Fusilier, M.R. (1989). Control in the workplace. In C.L. Cooper, \& I.T. Robertson (Eds.), International review of industrial and organizational psychology (pp. 235-280). Chichester: Wiley.

Ganster, D.C., \& Schaubroeck, J. (1995). The moderating effects of self-esteem on the work stress employee health relationship. In R. Crandell, \& P.L. Perrewé (Eds.), Occupational stress: A handbook (pp. 167-177). Philadelphia: Taylor \& Francis.

Gaziel, H. (1989). Determinants of perceived deficiency of autonomy among elementary school administrators. Social Behavior and Personality, 17, 57-65.

Gehlers, C.G., \& Lemmens, R.H.M.M. (1993). Handboek verzuimmanagement. Strategieën en modellen voor de praktijk [Handbook of absence management. Strategies and models for practice]. Utrecht, The Netherlands: De Tijdstroom.

Geurts, S., Schaufeli, W.B., \& Jonge, J. de (1998). Burnout and intention to leave among mental healthcare professionals: A social psychological approach. Journal of Social and Clinical Psychology, $17,341-362$.

Gilder, D. de, Ellemers, N., Heuvel, H. van den, \& Blijleven, G. (1998). Arbeidssatisfactie, commitment en uitstroom. Overeenkomsten en verschillen tussen mannen en vrouwen [Work satisfaction, commitment and turnover. Similarities and differences between men and women]. Gedrag \& Organisatie, 11, 25-35.

Golembiewski, R.T., Boudreau, R.A., Munzenrider, R.F., \& Luo, H. (1996). Global burnout: A worldwide pandemic explored by the Phase Model. Greenwich, CT: JAI Press.

Golembiewski, R.T., \& Munzenrider, R.F. (1988). Phases of burnout: Developments in concepts and applications. New York: Praeger.

Golembiewski, R.T., Munzenrider, R.F., \& Stevenson, J.G. (1986). Stress in organizations: Toward a phase model of burnout. New York: Praeger.

Gray-Toft, P., \& Anderson, J.G. (1981). Stress among hospital nursing staff: Its causes and effects. Social Science and Medicine, 15A, 639-647.

Griffeth, R.W., \& Hom, P.W. (1988). A comparison of different conceptualizations of perceived alternatives in turnover research. Journal of Organizational Behavior, 9, 103-111.

Groot, A.D. de (1981). Methodologie: Grondslagen van onderzoek en denken in de gedragswetenschappen [Methodology: Foundations of research in behavioral sciences]. 's Gravenhage, The Netherlands: Mouton.

Grunveld, J.E. (1992). Werklast en dienstroosters [Workload and duty rosters]. In J.K. van Dijk, J.E. Grunveld, \& J. Pool (Eds.), Personeelsmanagement in de gezondheidszorg. Theorie en praktijk (pp. 128-149). Houten, The Netherlands: Bohn Stafleu Van Loghum.

Hackman, J.R., \& Lawler, E.E. III (1971). Employee reactions to job characteristics. Journal of Applied Psychology Monograph, 55, 259-286.

Hackman, J.R., \& Oldham, G.R. (1976). Motivation through the design of work: Test of a theory. Organizational Behavior and Human Performance, 16, 250-279.

Hackman, J.R., \& Oldham, G.R. (1980). Work redesign. Reading, MA: Addison-Wesley.

Hagenaars, J.A. (1990). Categorical longitudinal data: Log-linear panel, trend and cohort analysis. Newbury Park, CA: Sage.

Hall, D.T. (1976). Careers in organizations. Santa Monica: Goodyear.

Hayduk, L.A. (1987). Structural equation modeling with LISREL: Essentials and advances. Baltimore: John Hopkins University Press.

Heinisch, D.A., \& Jex, S.M. (1997). Negative affectivity and gender as moderators of the relationship between work-related stressors and depressed mood at work. Work \& Stress, 11, 46-57.

Herzberg, F., Mausner, B., \& Snyderman, B.B. (1959). The motivation to work. New York: Wiley.

Heuvel, H. van den, Ellemers, N., \& Seghers, B. (1995). Het belang van carrière commitment en collegiale commitment bij mannelijke en vrouwelijke werknemers: Een studie onder promovendi [The importance of career commitment en fraternal commitment among male and female employees: A study among PhD students]. Sociale Psychologie en Haar Toepassingen, 9, 168186. 
Heijden, T.J. van der (1997). Management van uitstroom [Management of turnover]. In F. Kluytmans (Ed.), Leerboek personeelsmanagement (3d ed., pp. 173-201). Deventer, The Netherlands: Kluwer Bedrijfswetenschappen.

Hobfoll, S.E., \& Freedy, J. (1993). Conservation of resources: A general stress theory applied to burnout. In W.B. Schaufeli, C. Maslach, \& T. Marek (Eds.), Professional burnout. Recent developments in theory and research (pp. 115-131). Washington, DC: Taylor \& Francis.

Hobfoll, S.E., \& Shirom, A. (1993). Stress and burnout in the workplace: Conservation of resources. In R.T. Golembiewski (Ed.), Handbook of organizational behavior (pp. 41-60). New York: Dekker.

Hofstee, W.K.B., Raad, B. de, \& Goldberg, L.R. (1992). Integration of the Big Five and circumplex approaches to trait structure. Journal of Personality and Social Psychology, 63, 146-163.

Hom, P.W., \& Griffith, R.W. (1991). Structural equations modeling test of a turnover theory: Crosssectional and longitudinal analysis. Journal of Applied Psychology, 76, 350-366.

Hoogstad, J., \& Weststeijn, H. (1997). Beloningen en beloningssystemen [Rewards and reward systems]. In F. Kluytmans (Ed.), Leerboek personee/smanagement (3d ed., pp. 265-282). Deventer, The Netherlands: Kluwer Bedrijfsinformatie.

Horn, J.E. van, Caljè, D.G., Schreurs, P.J.G., \& Schaufeli, W.B. (1997). Stress en burnout bij docenten. Een literatuuroverzicht [Stress and burnout among teachers. A literature review]. Gedrag \& Organisatie, 10, 247-256.

Houkes, I., \& Janssen, P.P.M. (1999). A test of Leiter's process model of burnout. Journal of Health and Human Services Administration, 21, 533-560.

Houkes, I., Janssen, P.P.M., Jonge, J., de \& Nijhuis, F.J.N. (1997). Verbanden tussen werkkenmerken en reacties: Een literatuurstudie naar specifieke determinanten van motivatie, gezondheid en verloop [Relationships between work characteristics and outcome variables: A literature study regarding specific determinants of motivation, health and turnover]. Studies bedriffsgezondheidszorg nummer 12. Maastricht, The Netherlands: Maastricht University.

Houkes, I., Janssen, P.P.M., Jonge, J. de, Nijhuis, F.J.N. (2001). Specific relationships between work characteristics and intrinsic work motivation, burnout and turnover intention: A multi-sample analysis. European Journal of Work and Organizational Psychology, 10, 1-23.

Houkes, I., Janssen, P.P.M., Jonge, J. de, \& Nijhuis, F.J.N. (in press). Work and individual determinants of intrinsic work motivation, emotional exhaustion and turnover intention: A multi-sample analysis. International Journal of Stress Management.

Houkes, I., Janssen, P.P.M., Jonge, J. de, \& Bakker, A.B. (2001a). Personality, work characteristics, and employee well-being. A longitudinal analysis of additive and moderating effects. Manuscript submitted for publication.

Houkes, I., Janssen, P.P.M., Jonge, J. de, \& Bakker, A.B. (2001b). Specific determinants of intrinsic work motivation, emotional exhaustion and turnover intention: A multi-sample longitudinal study. Manuscript submitted for publication.

Houtman, I.L.D., Kompier, M.A.J., Smulders, P.G.W., \& Bongers, P.M. (1994). Werkstress-risico's en gezondheid [Work stress risks and health]. Tijdschrift voor Sociale Gezondheidszorg, 72, 198203.

Houtman, I.L.D., Smulders, P.G.W., Bloemhoff, A., \& Kompier, M.A.J. (1994). Bedrijfs- en beroepsgebonden werkstress-risico's en ontwikkelingen hiervan in de tijd [Organizational and occupational stress risks at work and their development over time]. Tijdschrift voor Sociale Gezondheidszorg, 72, 128-137.

Howard, A. (1995). A framework for work change. In A. Howard (Ed.), The changing nature of work (pp. 3-44). San Francisco: Jossey-Bass.

Hu, L., \& Bentler, P.M. (1998). Fit indices in covariance structure modeling: Sensitivity to underparameterized model misspecification. Psychological Methods, 3, 424-453.

Hulin, C.L., \& Blood, M.R. (1968). Job enlargement, individual differences, and worker responses. Psychological Bulletin, 69, 41-55.

Huselid, M.A., \& Day, N.E. (1991). Organizational commitment, job involvement, and turnover: A substantive and methodological analysis. Journal of Applied Psychology, 76, 380-391.

International Labour Office (1993). World Labour Report 1993. Geneva, Switzerland: Author. 
Iverson, R.D., Olekalns, M., \& Erwin, P.J. (1998). Affectivity, organizational stressors, and absenteeism: A causal model of burnout and its consequences. Journal of Vocational Behavior, 52, 1-3.

Iverson, R.D., \& Roy, P. (1994). A causal model of behavioral commitment: Evidence from a study of Australian blue-collar employees. Journal of Management, 20, 15-41.

Jaccard, J., \& Wan, C.K. (1996). LISREL approaches to interaction effects in multiple regression. Newbury Park, CA: Sage.

Jackson, S.E., \& Schuler, R.S. (1985). A meta-analysis and conceptual critique of research on role ambiguity and role conflict in work settings. Organizational Behavior and Human Decision Processes, 36, 16-78.

James, L.R., \& Jones, A.P. (1980). Perceived job characteristics and job satisfaction: An examination of reciprocal causation. Personnel Psychology, 33, 97-135.

James, L.R., \& Tetrick, L.E. (1986). Confirmatory analytic tests of three causal models relating job perceptions to job satisfaction. Journal of Applied Psychology, 71, 77-82.

Janssen, P.P.M. (1992). Relatieve deprivatie in de middenloopbaanfase bij hoger opgeleide mannen. Een vergelijking tussen drie leeftijdsgroepen [Relative deprivation in midcareer among highly educated men. A comparison between three age groups]. PhD thesis, University of Nijmegen, Nijmegen, The Netherlands.

Janssen, P.P.M., \& Buunk, B.P. (1990). De invloed van relatieve deprivatie op interne en externe verloopintentie [The effect of relative deprivation upon turnover in various career stages]. Gedrag \& Organisatie, 3, 126-137.

Janssen, P.P.M., \& Houkes, I. (2000a). Determinanten en gevolgen van werkstress [Determinants and outcomes of work stress]. In M. Schabracq, H. Maassen van den Brink, W. Groot, P.P.M. Janssen, \& I. Houkes, De prijs van stress (pp. 55-62). 's Gravenhage, The Netherlands: Elsevier Bedrijfsinformatie.

Janssen, P.P.M., \& Houkes, I. (2000b). Drie belangrijke stressgevolgen en de relatie met kosten: motivatie, gezondheid en verloop [Three important stress outcomes and their relationships with costs: motivation, health and turnover]. In M. Schabracq, H. Maassen van den Brink, W. Groot, P.P.M. Janssen, \& 1. Houkes, De prijs van stress (pp. 75-84). 's Gravenhage, The Netherlands: Elsevier Bedrijfsinformatie.

Janssen, P.P.M., \& Houkes, I. (2000c). Specifieke verbanden tussen werkkenmerken en stressgevolgen: theorie en empirie [Specific relationships between work characteristics and stress outcomes: theory and empirical studies]. In M. Schabracq, H. Maassen van den Brink, W. Groot, P.P.M. Janssen, \& I. Houkes, De prijs van stress (pp. 63-74). 's Gravenhage, The Netherlands: Elsevier Bedrijfsinformatie.

Janssen, P.P.M., Jonge, J. de, \& Bakker, A.B. (1999). Specific determinants of intrinsic work motivation, burnout and turnover intentions: A study among nurses. Journal of Advanced Nursing, 29, 1360 1369.

Janssen, P.P.M., Nijhuis, F.J.N., Lourijsen, E.C.M.P., \& Schaufeli, W.B. (1996). Gezonder werken: minder verzuim! Handleiding voor integrale gezondheidsbevordering op het werk [Healthier work: lower levels of sickness absence! Manual for integral health promotion at the work place]. Amsterdam, The Netherlands: Nederlands Instituut voor Arbeidsomstandigheden.

Janssen, P.P.M., Nijhuis, F.J.N., Peeters, M.C.W., \& Jonge, J. de (1996). Intrinsieke werkmotivatie: Een heroriëntatie op het begrip en een verklaring vanuit de motivatie- en taakkenmerkenbenadering [Intrinsic work motivation: A reorientation and an explanation from the motivational and task characteristics approach]. Gedrag \& Organisatie, 9, 290-304.

Janssen, P.P.M., Schaufeli, W.B., \& Houkes, I. (1999). Work-related and individual determinants of the three burnout-dimensions. Work \& Stress, 13, 74-86.

Jessor, R., \& Jessor, S.L. (1973). The perceived environment in behavioral science: Some conceptual issues and some illustrative data. American Behavioral Scientist, 16, 801-828.

Jex, S.M., \& Spector, P.E. (1996). The impact of negative affectivity on stressor-strain relations: A replication and extension. Work \& Stress, 10, 36-45. 
Johnson, J.V., \& Hall, E.M. (1988). Job strain, work place support and cardiovascular disease: A crosssectional study of a random sample of the Swedish working population. American Journal of Public Health, 78, 1336-1342.

Johnston, M.W., Griffeth, R.W., Burton, S., \& Carson, P.P. (1993). An exploratory investigation into the relationships between promotion and turnover: A quasi-experimental longitudinal study. Journal of Management, 19, 33-49.

Jones, F., \& Fletcher, B.C. (1996). Job control and health. In M.J. Schabracq, J.A.M. Winnubst, \& C.L. Cooper (Eds.), Handbook of work and health psychology. New York: Wiley.

Jonge, J. de (1992). Autonomie in het werk. Een literatuuroverzicht [Job autonomy. A review of the literature]. Studies bedrijfsgezondheidszorg nummer 8. Maastricht, The Netherlands: University of Limburg.

Jonge, J. de (1995). Job autonomy, well-being, and health. PhD thesis, Maastricht, The Netherlands: Datawyse.

Jonge, J. de, Bosma, H., Peter, R., \& Siegrist, J. (2000). Twee werkstress-modellen en psychische gezondheid: Het Job Demand-Control Model en het Effort-Reward Imbalance Model [Two work stress models and psychological health: The Job Demand-Control Model and the Effort-Reward Imbalance Model]. Gedrag \& Gezondheid, 28, 106-122.

Jonge, J. de, Braakhuis, R., \& Hell, J. (1996). Evaluatieonderzoek Dienst Afvalstoffen en Reiniging Nijmegen [Evaluation study Sanitation Service Nijmegen] (Internal report). Nijmegen, The Netherlands: University of Nijmegen.

Jonge, J. de, Dollard, M.F., Dormann, C., Blanc, P.M. le, \& Houtman, I.L.D. (2000). The DemandControl Model: Specific demands, specific control, and well-defined groups. International Journal of Stress Management, 7, 269-287.

Jonge, J. de, Dormann, C., Janssen, P.P.M., Dollard, M.F., Landeweerd, J.A., \& Nijhuis, F.J.N. (2001). Testing reciprocal relationships between job characteristics and psychological well-being: $A$ cross-lagged structural equation model. Journal of Occupational and Organizational Psychology, $74,29-46$.

Jonge, J. de, \& Geurts, S. (1997). Gevolgen van flexibilisering van de arbeid: Een tussentijdse balans [Consequences of flexibility of the workforce. An interim balance]. Gedrag \& Organisatie, 10, 195211.

Jonge, J. de, \& Kompier, M.A.J. (1997). A critical examination of the Demand-Control-Support Model from a work psychological perspective. International Journal of Stress Management, 4, 235-258.

Jonge, J. de, \& Landeweerd, J.A. (1993). Toetsing van de Job Demand-Control benadering bij werknemers in de gezondheidszorg: Een secundaire data-analyse [Testing of the Job DemandControl approach among health care workers: A secondary analysis]. Gedrag \& Organisatie, 6, 79-92.

Jonge, J. de, Landeweerd, J.A., \& Nijhuis, F.J.N. (1993). Constructie en validering van de vragenlijst ten behoeve van het project "autonomie in het werk" [Construction and validation of the questionnaire for the "job autonomy project"]. Studies bedrijfsgezondheidszorg nummer 9. Maastricht, The Netherlands: University of Limburg.

Jonge, J. de, \& Schaufeli, W.B. (1998). Job characteristics and employee well-being: A test of Warr's Vitamin model in health care workers using structural equation modelling. Journal of Organizational Behavior, 19, 387-407.

Jordan, P.C. (1986). Effects of an extrinsic reward on intrinsic motivation: A field experiment. Academy of Management Journal, 29, 405-412.

Jöreskog, K.G. (1993). Testing structural equation models. In K.A. Bollen, \& J. Scott Long (Eds.), Testing structural equation models (pp. 294-316). Newbury Park, CA: Sage.

Jöreskog, K.G., \& Sörbom, D. (1993a). LISREL 8: Structural equation modeling with the SIMPLIS command language. Chicago: Scientific Software International.

Jöreskog, K.G., \& Sörbom, D. (1993b). LISREL 8: User's reference guide. Chicago: Scientific Software International. 
Judge, T.A., Erez, A., \& Thoresen, C.J. (2000). Why negative affectivity (and self-deception) should be included in job stress research: bathing the baby with the bath water. Journal of Organizational Behavior, 21, 101-111.

Kahn, R.L. (1981). Work and health. New York: Wiley.

Kahn, R.L., \& Byosiere, P. (1992). Stress in organizations. In M.D. Dunnette, \& L.M. Hough (Eds.), Handbook of industrial and organizational psychology (Vol. 3, 2nd ed., pp. 571-650). Palo Alto, CA: Consulting Psychologists Press.

Kahn, R.L., Wolfe, D.M., Quinn, R.P., Snoek, J.D., \& Rosenthal, R.A. (1964). Organizational stress: Studies in role conflict and ambiguity. New York: Wiley.

Karasek, R.A. (1979). Job demands, job decision latitude, and mental strain: Implications for job redesign. Administrative Science Quarterly, 24, 285-308.

Karasek, R.A. (1989). Control in the workplace and its health-related aspects. In S.L. Sauter, J.J Hurrell, \& C.L. Cooper (Eds.), Job control and worker health (pp. 129-159). Chichester: Wiley.

Karasek, R.A., \& Theorell, T. (1990). Healthy work: Stress, productivity and the reconstruction of working life. New York: Basic Books.

Kasl, S.V. (1996). The influence of the work environment on cardiovascular health: A historical, conceptual and methodological perspective. Journal of Occupational Health Psychology, 1, 4256.

Kasl, S.V., \& Rapp, S.R. (1991). Stress, health and well-being: the role of individual differences. In C.L. Cooper, \& R. Payne (Eds.), Personality and stress: Individual differences in the stress process (pp. 269-284). Chichester: Wiley.

Kenny, D.A., \& Judd, C.M. (1984). Estimating the nonlinear and interactive effects of latent variables. Psychological Bulletin, 96, 201-210.

Kessler, R.C., \& Greenberg, D.F. (1981). Linear panel analysis. Models of quantitative change. New York: Academic Press.

Kleber, R.J. (1982). Stressbenaderingen in de psychologie [Stress approaches in psychology] Deventer, The Netherlands: Van Loghum Slaterus.

Kleinbaum, D.G., Kupper, L.L., \& Mulier, K.E. (1988). Applied regression analysis and other multivariable methods (2nd ed.). Boston: PWS-Kent.

Kluytmans, F. (Ed.). (1997). Leerboek personeelsmanagement [Handbook of personnel management] (3d ed.). Deventer, The Netherlands: Kluwer Bedrijfswetenschappen.

Kluytmans, F., \& Laanen, C. van (1993). Management van arbeidsverhoudingen: Vraagstukken van overleg, medezeggenschap en participatie [Management of labor relations: Issues of consideration and employee participation]. In F. Kluytmans, C. Hancké (Eds.), Leerboek personeelsmanagement (2nd ed., pp.383-402 ). Deventer, The Netherlands: Kluwer Bedrijfswetenschappen.

Kiyak, H.A., Namazi, K.H., \& Kahana, E.F. (1997). Job commitment and turnover among women working in facilities serving older persons. Research on Aging, 19, 223-246.

Kompier, M.A.J. (1995). Geestelijke werkbelasting [Mental workload]. In P.G.W. Smulders \& J.M.J. op de Weegh (Eds.), Arbeid en gezondheid. Risicofactoren (pp. 83-95). Utrecht, The Netherlands: Lemma.

Kompier, M.A.J. (1996). "The best of both worlds". Arbeids- en organisatiepsychologie tussen theorie en praktijk [Work and organizational psychology between theory and practice]. Inaugural lecture, University of Nijmegen, Nijmegen, The Netherlands.

Kompier, M.A.J., \& Di Martino, V. (1995). Review of bussdrivers's occupational stress and stress prevention. Stress Medicine, 11, 253-262.

Kompier, M.A.J., Dijk, F.J.H. van, Dormolen, M. van, \& Meijman, T.F. (1990). Stressonderzoek en belastingsonderzoek in wederzijds perspectief [Stress research and research on workload in mutual perspective]. Tijdschrift voor Sociale Gezondheidszorg, 68, 11-18.

Kompier, M.A.J., \& Houtman, I.L.D. (1995). Stressreacties. In P.G.W. Smulders, \& J.M.J. op de Weegh (Eds.), Arbeid \& gezondheid. Risicofactoren [Work and health. Risk factors]. Utrecht, The Netherlands: Lemma. 
Kompier, M.A.J., \& Marcelissen, F.H.G. (1990). Handboek werkstress [Handbook work stress]. Amsterdam, The Netherlands: Nederlands Instituut voor Arbeidsomstandigheden.

Kompier, M.A.J., \& Vink, P. (1994). Arbo. Een praktische aanpak [Working conditions. A practical approach]. Utrecht, The Netherlands: Stichting Educatieve Omroep Teleac.

Krisiensen, T.S. (1995). The Demand-Control-Support Model: Methodological challenges for future research. Stress Medicine, 11, 17-26.

Kristensen, T.S. (1996). Job stress and cardiovascular disease: A theoretical critical review. Journal of Gccupational Health Psychology, 1, 246-260.

Kruse, M.I.M., \& Grunveld, J.E. (1992). Arbeidsomstandigheden [Working conditions]. In J.K. van Dijk, J.E. Grunveld, \& J. Pool (Eds.), Personeelsmanagement in de gezondheidszorg. Theorie en praktijk (pp. 117-150). Houten, The Netherlands: Bohn Stafleu Van Loghum.

Landeweerd, J.A., \& Boumans, N.P.G. (1994). The effect of work dimensions and need for autonomy on nurses' work satisfaction and health. Journal of Occupational and Organizational Psychology, $67,207-217$

Landeweerd, J.A., Jonge, J. de, \& Stikvoort, R.C.P.D. (1995). Work situation characteristics and worker reactions in nursing homes. In M. Hagberg, F. Hofmann, U. Stössel, \& G. Westlander (Eds.), Occupational health for health care workers. (Vol. 2, pp. 113-117). Landsberg, The Netherlands: Ecomed

Langdon, M.C. (1997). Organizational variables that contribute to a high voluntary turnover rate among salespeople. Dissertation Abstracts International, 57 (12), $7713 \mathrm{~B}$.

Laterveer, R. (1996). Gezondheidsbevordering op de werkplek: Visie van SZW [Health promotion at the workplace: Vision of the Ministry of Social Affairs and Employment]. In P. Baart, G. Roerink, \& M. Selie (Eds.), Gezondheidsbevordering op de werkplek. Toekomstig element van bedrifsvoering. Amsterdam, The Netherlands: Nederlands Instituut voor Arbeidsomstandigheden.

Lave, C.A., \& March, J.G. (1980). Modellen in de sociale wetenschappen. Een inleiding [Models in social science. An introduction]. Alphen aan den Rijn, The Netherlands: Samsom.

Lease, S.H. (1998). Annual review, 1993-1997: Work attitudes and outcomes. Journal of Vocational Behavior, 53, 154-183.

Lee, R.T., \& Ashforth, B.E. (1993). A longitudinal study of burnout among supervisors and managers: Comparison between the Leiter and Maslach (1988) and Golembiewski et al. (1986) models. Organizational Behavior and Human Decision Processes, 54, 369-398.

Lee, R.T., \& Ashforth, B.E. (1996). A meta-analytic examination of the correlates of the three dimensions of job burnout. Journal of Applied Psychology, 81, 123-133.

Lee, T.W., \& Mowday, R.T. (1987). Voluntary leaving an organization: An empirical investigation of Steers and Mowday's model of turnover. Academy of Management Journal, 30, 721-753.

Leiter, M.P. (1993). Burnout as a developmental process: Consideration of models. In W.B. Schaufeli, C. Maslach, \& T. Marek (Eds.), Professional burnout. Recent developments in theory and research (pp. 237-250). Washington, DC: Taylor \& Francis.

Leiter, M.P., \& Harvie, P.L. (1996). Burnout among mental health workers: A review and a research agenda. International Journal of Social Psychiatry, 42, 90-101.

Leiter, M.P., Harvie, P.L., \& Frizzel, C. (1998). The correspondence of patient satisfaction and nurse burnout. Social Science and Medicine, 47, 1611-1617.

Lenderink, A. (1998). Arbo index 1999 [Index of working conditions 1999]. 's Gravenhage, The Netherlands: SDU.

Lensink, A. (2000). "Enige zekerheid: Banken moeten iets ondernemen" ["The only certainty of banks: they have to undertake something"]. Banking Review, 11, (7), 10-12.

Levi, L. (1998). Preface: Stress in organizations - Theoretical and empirical approaches. In C.L. Cooper (Ed.), Theories of organizational stress (pp. V-XII). Oxford: Oxford University Press.

Lewis, J., \& Thomas, K. (1987). Occupational change and career development amongst graduate engineers and scientists. British Journal of Guidance and Counseling, 15, 182-196.

LISV (Landelijk Instituut Sociale Verzekeringen) (2000). Ontwikkeling arbeidsongeschiktheid. Jaaroverzicht WAONAZWajong 1999 [Developments in disablement for work. Yearly report of WAOMAZMajong 1999]. Amsterdam, The Netherlands: Author. 
Locke, E.A. (1991). The motivation sequence, the motivation hub, and the motivation core. Organizational Behavior and Human Decision Processes, 50, 288-299.

Maassen, G.H., \& Bakker, A.B. (2000). Suppressor variabelen in padmodellen: Definities en interpretaties [Suppressor variables in path models: Definitions and interpretations]. Kwantitatieve Methoden, 21, 43-69.

MacCallum, R.C., Wegener, D.T., Uchino, B.N., \& Fabrigar, L.R. (1993). The problem of equivalent models in applications of covariance structure analysis. Psychological Bulletin, 114, 185-169.

Manlove, E.E., \& Guzell, J.R. (1997). Intention to leave, anticipated reasons for leaving, and 12-month turnover of child care center staff. Early Childhood Research Quarterly, 12, 145-167.

Marcelissen, F.H.G. (1987). Gangmakers van stressproces. De rol van type-A gedrag en sociale ondersteuning bij het stressproces in de werksituatie [Initiators of the stress process. The role of type $A$ behavior and social support in the stress process in the working situation]. PhD thesis, University of Nijmegen, Nijmegen, The Netherlands.

Marcoulides, G.A., \& Schumacker, R.E. (Eds.). (1996). Advanced structural equation modeling: Issues and techniques. Hillsdale. $\mathrm{NJ}$ : Lawrence Erlbaum.

Maslach, C. (1993). Burnout: A multi-dimensional perspective. In W.B. Schaufeli, C. Maslach, \& T. Marek (Eds.), Professional burnout. Recent developments in theory and research (pp. 19-32). Washington, DC: Taylor \& Francis.

Maslach, C. (1998). A multidimensional theory of burnout. In C.L. Cooper (Ed.), Theories of organizational stress (pp. 68-85). Oxford: Oxford University Press.

Maslach, C., \& Goldberg, J. (1998). Prevention of burnout: new perspectives. Applied and Preventive Psychology, 7, 63-74.

Maslach, C., \& Jackson, S.E. (1986). Maslach Burnout Inventory. Manual (2nd ed.). Palo Alto, CA: Consulting Psychologists Press.

Maslach, C., Jackson, S.E., \& Leiter, M.P. (1996). Maslach Burnout Inventory. Manual (3d ed.). Palo Alto, CA: Consulting Psychologists Press.

Maslach, C., \& Leiter, M.P. (1997). The truth about burnout. San Francisco; Jossey-Bass.

Maslach, C., Schaufeli, W.B., \& Leiter, M.P. (2001). Job burnout. Annual Review of Psychology, 52, 397-422.

Mathieu, J.E., \& Zajac, D.M. (1990). A review and meta-analysis of the antecedents, correlates and consequences of organizational commitment. Psychological Bulletin, 108, 171-194.

McCrae, R.R., \& Costa, P.T. (1991). Adding liebe und arbeit: The full five-factor model and well-being. Bulletin of Personality and Social Psychology, 17, 227-232.

McFadden, M., \& Demetriou, E. (1993). The role of immediate work environment factors in the turnover process: A systemic intervention. Applied Psychology: An International Review, 42, 97-115.

Merllié, D., \& Paoli, P. (2001). Ten years of working conditions in the European Union. Summary. Dublin: European Foundation for the Improvement of Living and Working Conditions.

Mobley, W.H. (1977). Intermediate linkages in the relationship between job satisfaction and employee turnover. Journal of Applied Psychology, 62, 237-240.

Moorhead, G., \& Griffin, R.W. (1995). Organizational behavior. Managing people and organizations. Boston: Houghton Mifflin.

Moyle, P. (1995). The role of negative affectivity in the stress process: Tests of alternative models. Journal of Organizational Behavior, 16, 647-668.

Muchinsky, P.M., \& Morrow, P.C. (1980). A multi-disciplinary of voluntary turnover. Journal of Vocational Behavior, 17, 43-77.

Muntaner, C., \& O'Campo, P.J. (1993). A critical appraisal of the Demand/Control Model of the psychosocial work environment: Epistemological, social, behavioral and class considerations. Social Science and Medicine, 36, 1509-1517.

NIBE-SW (Nederlands Instituut voor het Bank- en Effectenbedrijf) (1999). Algemene opleiding bankbedrijf. Nederlands Instituut voor het Bank-, Verzekerings- en Effectenbedrijf [General training banking sector]. Amsterdam, The Netherlands: Author.

Nunnally, J.C. (1978). Psychometric theory (2nd ed.). New York: McGraw-Hiil. 
Oldham, G.R., Hackman, J.R., \& Pearce, J.L. (1976). Conditions under which employees respond positively to enriched work. Journal of Applied Psychology, 61, 395-403.

O'Leary, L. (1993). Mental health at work. Occupational Health Review, 45, 23-26.

Paoli, P. (1992). First European survey on the work environment 1991-1992. Dublin: European Foundation for the Improvement of Living and Working Conditions

Paoli, P. (1997). Working conditions in Europe. The second European survey on working conditions. Dublin: European Foundation for the Improvement of Living and Working Conditions.

Parker, S., \& Wall, T. (1998). Job and work design: Organizing work to promote well-being and effectiveness. Thousand Oaks, CA: Sage.

Parkes, K.R. (1990). Coping, negative affectivity, and the work environment: Additive and interactive predictors of mental health. Journal of Applied Psychology, 75, 399-409.

Parkes, K.R. (1991). Locus of control as moderator: An explanation for additive versus interactive findings in the demand-discretion model of work stress? British Journal of Psychology, 82, 291312.

Parkes, K.R. (1994). Personality and coping as moderators of work stress processes: Models, methods and measures. Work \& Stress, 8, 110-129.

Pines, A.M. (1993). Burnout: An existential perspective. In W.B. Schaufeli, C. Maslach, \& T. Marek (Eds.), Professional burnout. Recent developments in theory and research (pp. 33-52). Washington, DC: Taylor \& Francis.

Pool, J., Elburg, B.A.M. van, \& Nusselder, M. (1992). Loopbaanbeleid in instellingen [Career management in organizations]. In J.K. van Dijk, J.E. Grunveld, \& J. Pool (Eds.), Personeelsmanagement in de gezondheidszorg. Theorie en praktijk (pp. 153-172). Houten, The Netherlands: Bohn Stafleu Van Loghum.

Pool, J., Meeuwsen, E.A.M., \& Michels, K.J.A.M. (1992). Verloop en verloopbeheersing [Turnover and management of turnover]. In J.K. van Dijk, J.E. Grunveld, \& J. Pool (Eds.), Personeelsmanagement in de gezondheidszorg. Theorie en praktijk (pp. 77-94). Houten, The Netherlands: Bohn, Stafleu, Van Loghum.

Price, J.L. (1977). The study of turnover. Ames, lowa: lowa State University Press.

Renn, R.W., \& Vandenberg, R.J. (1995). The critical psychological states: An underrepresented component in Job Characteristics Model research. Journal of Management, 21, 279-303.

Rogosa, D. (1980). A critique of cross-lagged correlation. Psychological Bulletin, 88, 245-258.

Rogosa, D. (1987). Causal models do not support scientific conclusions: A comment in support of Freedman. Journal of Educational Statistics, 12, 185-195.

Rosse, J.G., \& Miller, H.E. (1984). Relationship between absenteeism and other employee behaviors. In P.S. Goodman, \& R.S. Atkin (Eds.), Absenteeism (pp. 194-227). San Francisco: Jossey-Bass.

Sager, J.K., Futrell, C.M., \& Varadarajan, R. (1989). Exploring salesperson turnover: A causal model. Journal of Business Research, 18, 303-326.

Saris, W.E., \& Stronkhorst, L.H. (1984). Causal modelling in nonexperimental research. Amsterdam, The Netherlands: Sociometric Research Foundation.

SBO (Sectorbestuur Onderwijsmarkt) (2000). SBO Jaarboek 2000. De onderwijsarbeidsmarkt in beeld [SBO Annual 2000. The labor market for the education sector]. 's Gravenhage, The Netherlands: Author.

Schaefer, J.A., \& Moos, R.M. (1993). Work stressors in health care: Contexts and outcomes. Journal of Community and Applied Social Psychology, 3, 235-242.

Schaufeli, W.B. (1990). Opgebrand. Achtergronden van werkstress bij contactuele beroepen: Het burnoutsyndroom [Burnout. Backgrounds of work stress in contactual occupations: The burnout syndrom]. Rotterdam, The Netherlands: Donker.

Schaufeli, W.B., \& Dierendonck, D. van (1995). A cautionary note about the cross-national clinical validity of cut-off points for the Maslach Burnout Inventory. Psychological Reports, 76, 10831090

Schaufeli, W.B., \& Dierendonck, D. van (2000). Utrechtse Burnout Schaal- UBOS: Handleiding [Utrecht Burnout Scale - UBOS: Manual]. Lisse, The Netherlands: Swets \& Zeitlinger. 
Schaufeli, W.B., \& Enzmann, D. (1998). The bumout companion to study and practice. A critical analysis. London: Taylor \& Francis.

Schaufeli, W.B., Leiter, M.P., Maslach, C., \& Jackson, S.E. (1996). The MBI-General Survey. in C. Maslach, S.E. Jackson, \& M.P. Leiter (Eds.), Maslach Burnout Inventory (3d ed., pp. 19-26). Palo Alto, CA: Consulting Psychologists Press.

Schaufeli, W.B., Maslach, C. \& Marek, T. (Eds.). (1993). Professional burnout. Recent developments in theory and research. Washington, DC: Taylor \& Francis.

Schein, E. (1978). Career dynamics: Matching individual and organizational needs. Reading, MA: Addison-Wesley.

Schumacker, R.E., \& Lomax, R.G. (1996). A beginner's guide to structural equation modeling. Mahwah: Lawrence Erlbaum.

Scott Long, J. (1983). Covariance structure models: An introduction to LISREL. Newbury Park, CA: Sage.

Shore, L.M., \& Martin, H.J. (1989). Job satisfaction and organizational commitment in relation to work performance and turnover intentions. Human Relations, 42, 625-638.

Smulders, P.G.W. (1995). Arbeid en gezondheid: Inleiding [Work and health: Introduction]. In P.G.W. Smulders, \& J.M.J. op de Weegh (Eds.), Arbeid en gezondheid. Risicofactoren (pp. 19-44). Utrecht, The Netherlands: Lemma.

Spector, P.E. (1992). A consideration of the validity and meaning of self-report measures of job conditions. In C.L. Cooper, \& I.T. Robertson (Eds.), International review of industrial and organizational psychology (Vol. 7, pp. 123-151). New York: Wiley.

Spector, P.E. (1999). Objective versus subjective approaches to the study of job stress. Journal of Organizational Behavior, 20, 737-738.

Spector, P.E., \& O'Connell, B.J. (1994). The contribution of personality traits, negative affectivity, locus of control and type $A$ to the subsequent reports of job stressors and job strains. Journal of Occupational and Organizational Psychology, 67, 1-11.

Spector, P.E., Zapf, D., Chen, P.Y., \& Frese, M. (2000). Why negative affectivity should not be controlled in job stress research: Don't throw out the baby with the bath water. Journal of Organizational Behavior, 21, 79-95.

Stedham, Y., \& Mitchell. M.C. (1996). Voluntary turnover among non-supervisory casino employees. Journal of Gambling Studies, 12, 269-291.

Stremmel, A.J. (1991). Predictors of intention to leave child care work. Early Childhood Research Quarterly, 6, 285-298.

Taber, T.D., \& Taylor, E. (1990). A review and evaluation of the psychometric properties of the Job Diagnostic Survey. Personnel Psychology, 43, 467-500.

Taris, T.W., Bok, I.A., \& Caljé, D.G. (1998). On the relation between job characteristics and depression: A longitudinal study. International Journal of Stress Management, 5, 157-167.

Tharenou, P. (1993). A test of reciprocal causality for absenteeism. Journal of Organizational Behavior, 14, 269-290.

Theorell, T., \& Karasek, R.A. (1996). Current issues relating to psychological job strain and cardiovascular disease research. Journal of Occupational Health Psychology, 1, 9-26.

Thierry, H. (1998). Motivation and satisfaction. In P.J.D. Drenth, H. Thierry, \& C.J. de Wolff (Eds.), Handbook of work and organizational psychology (Vol. 4, 2nd ed., pp. 253-289). Hove, UK: Psychology Press/Erlbaum.

Tiegs, R.B., Tetrick, L.E., \& Fried, Y. (1992). Growth need strength and context satisfaction as moderators of the Job Characteristics Model. Journal of Management, 18, 575-593.

Tremblay, M., Roger, A., \& Toulouse, J.M. (1995). Career plateau and work attitudes: An empirical study of managers. Human Relations, 48, 221-237.

Turner, A.N., \& Lawrence, P.R. (1965). Industrial jobs and the worker: An investigation of response to task attributes. Boston: Harvard Graduate School of Business Administration.

Tzelgov, J., \& Henik, A. (1991). Suppression situations in psychological research: Definitions, implications, and applications. Psychological Bulletin, 109, 524-536. 
Veldhoven, M.J.P.M. van (1996). Psychosociale arbeidsbelasting en werkstress [Psychosocial workload and work stress]. PhD thesis, Lisse, The Netherlands: Swets \& Zeitlinger.

Veldhoven, M. van, Broersen, J.P.J., Fortuin, R.J. (1999). Werkstress in beeld. Psychosociale arbeidsbelasting en werkstress in Nederland [Work stress in the picture. Psychosocial workload and work stress in The Netherlands]. Amsterdam, The Netherlands: Stichting Kwaliteitsbevordering Bedrijfsgezondheidszorg.

Veldhoven, M. van, \& Meijman, T. (1994). Het meten van psychosociale arbeidsbelasting met een vragenlijst. De Vragenlijst Beleving en Beoordeling van de Arbeid (VBBA) [Measuring psychosocial workload by means of a questionnaire. Questionnaire on the Experience and Evaluation of Work]. Amsterdam, The Netherlands: Nederlands Instituut voor Arbeidsomstandigheden.

Verbeek, M.J.C.M. (1991). The design of panel surveys and the treatment of missing observations. PhD thesis, NWO, Nijmegen, The Netherlands.

Vermaat, K. (1994). Flexibele werklast beheersing in de verpleging [Flexible workload control in nursing]. Master's thesis, Maastricht University, Maastricht, The Netherlands.

Verschuren, P.J.M. (1991). Structurele modellen tussen theorie en praktijk [Structural models between theory and practice]. Utrecht, The Netherlands: Spectrum.

Vogelaar, A.L.W., \& Vlist, R. van der (1995). Het Job Characteristics Model en taakherontwerp [The Job Characteristics Model and job redesign]. Gedrag \& Organisatie, 8, 65-87.

Vries, N.K. de (1988). Het meten van attitudes en het voorspellen van gedrag [The measurement of attitudes and the prediction of behavior]. In R.W. Meertens \& J. von Grumbkow (Eds.), Sociale Psychologie (pp. 161-176). Groningen, The Netherlands: Wolters-Noordhoff.

Vuuren, C.V. van (1991). Angst voor ontslag en de motivatie om te werken [Fear of being fired and the motivation to work]. Gedrag \& Organisatie, 4, 369-384.

Walker, L.O., \& Avant, K.C. (1995). Strategies for theory construction in nursing (3d ed.). Norwalk, CT: Appleton \& Lange.

Warr, P.B. (1987). Work unemployment and mental health. Oxford: Clarendon Press.

Warr, P.B. (1994). A conceptual framework for the sfudy of work and mental health. Work \& Stress, 8 , 84-97.

Warr, P.B. (1996). Employee well-being. In P.B. Warr (Ed.), Psychology at work. Harmondsworth: Penguin.

Warr, P.B. (1999). Well-being at the workplace. In D. Kahneman, \& E. Diener (Eds.), Well-being: The foundations of hedonic psychology (pp. 392-412). New York: Russell Sage Foundation.

Warr, P.B., Cook, J.C., \& Wall, P.B. (1979). Scales for the measurement of some attitudes and aspects of psychological well-being. Joumal of Occupational Psychology, 52, 129-148.

Watson, D., \& Clark, L.A. (1984). Negative affectivity: The disposition to experience aversive emotional states. Psychological Bulletin, 96, 465-490.

Watson, D., Clark, L.A., \& Tellegen, A. (1988). Development and validation of brief measures of positive and negative affect: the PANAS scales. Journal of Personality and Social Psychology, 54, 10631070.

Watson, D., \& Tellegen, A. (1985). Toward a consensual structure of mood. Psychological Bulletin, 98, 219-235.

Weisberg, J. \& Sagie, A. (1999). Teachers' physical, mental, and emotional burnout: Impact on intention to quit. Journal of Psychology, 133, 333-339.

WGVB (Werkgeversvereniging voor het Bankbedrijf (2000). Algemene bank-CAO. Collectieve arbeidsovereenkomst voor de periode 1 juni 2000 tot 1 juli 2001 [Collective Labor Agreement for the banking sector for the period from June 1, 2000 to July 1, 2001]. Amsterdam, The Netherlands: Author.

WGVB (Werkgeversvereniging voor het Bankbedrijf) (2001a). Decentrale ontwikkelingen [Decentralized developments] [Online]. Available: http://www.wgvb.nl/mapica/fricao1.htm [March 26, 2001].

WGVB (Werkgeversvereniging voor het Bankbedrijf) (2001b). Personal communication. March 2001.

Wiersma, U.J. (1992). The effects of extrinsic rewards in intrinsic motivation: A meta-analysis. Journal of Occupational and Organizational Psychology, 65, 101-114. 
Williams, L.J., \& Brown, B.K. (1994). Method variance in organizational behavior and human resources research: Effects on correlations, path coefficients, and hypothesis testing. Organizational Behavior and Human Decision Processes, 57, 185-209.

Wollack, S., Goodale, J.G., Wijting, J.P., \& Smith, P.C. (1971). Development of the survey of work values. Journal of Applied Psychology, 55, 331-338.

Woodman, R.W. (1989). Organizational change and development: New arenas for inquiry and action. Journal of Management, 15, 205-228.

Wright, T.A., \& Cropanzano, R. (1998). Emotional exhaustion as a predictor of job performance and voluntary turnover. Journal of Applied Psychology, 83, 486-493.

Zapf, D. (1989). Selbst- und Fremdbeobachtung in der psychologischen Arbeitsanalyse. Methodische probleme bei der Erfassung von Stress am Arbeitsplatz [Self and expert observation in psychological job analysis. Methodological problems in the measurement of stressors at work]. Göttingen, Germany: Hogrefe.

Zapf, D., Dormann, C., \& Frese, M. (1996). Longitudinal studies in organisational stress research: A review of the literature with reference to methodological issues. Journal of Occupational Health Psychology, 1, 145-169.

Zellars, K.L., Perrewé, P.L., \& Hochwarter, W.A. (1999). Mitigating burnout among high-NA employees in health care: What can organizations do? Journal of Applied Social Psychology, 29, 2250-2271.

Zijlstra, F.R.H., \& Mulder, G. (1989). Mentale belasting: Theoretische gezichtspunten en een overzicht van meetmethoden [Mental workload: Theoretical perspectives and an overview of measurement methods]. In T.F. Meijman (Ed.), Mentale belasting en werkstress: Een arbeidspsychologische benadering (pp. 21-41). Assen, The Netherlands: Van Gorcum. 


\section{Appendix}

\section{Measurement instruments}




\section{Personal characteristics}

Growth need strength

I would like to have:

1. stimulating and challenging work.

2. chances to exercise independent thought and action in my job.

3. opportunities to learn new things from my work.

4. opportunities to be creative and imaginative in my work.

5. opportunities for personal growth and development in my job.

6. a sense of worthwhile accomplishment in my work.

\section{Negative affectivity}

Indicate to what extent you, generally, experience the following mood states:

1. Distressed.

2. Upset.

3. Guilty.

4. Scared.

5. Hostile.

6. Irritable.

7. Ashamed.

8. Nervous.

9. Jittery.

10. Afraid.

\section{Upward striving}

1. Even if a person has a good job, the person should always be looking for a better job.

2. In choosing a job, a person ought to consider chances for advancement as well as other factors. (this item was left out)

3. One should always be thinking about pulling oneself up in the world and should work hard with the hope of being promoted to a higher-level job.

4. If a person likes his job, the person should be satisfied with it and should not push for a promotion to another job. ${ }^{\mathrm{R}}$

5. The trouble with too many people is that when they find a job in which they are interested, they don't try to get a better job.

6. A worker who turns down a promotion is probably making a mistake.

7. A promotion to a higher-level job usually means more worries and should be avoided for that reason. ${ }^{R}$

8. A well-paying job that offers little opportunity for advancement is not a good job for me.

9. One is better off if one is satisfied with one's own job and is not concerned about being promoted to another job. ${ }^{R}$

\footnotetext{
${ }^{R}$ These items were recoded.
} 


\section{Work characteristics}

\section{Task characteristics}

1. My job involves a whole and identifiable piece of work. (task identity)

2. Just doing the work required by the job provides many chances for me to figure out how well I am doing. (feedback)

3. My job permits me to decide on my own how to go about doing the work. (autonomy)

4. My job is varied. (task variety)

5. My job requires me to do many different things at work, using a variety of skills and talents. (task variety)

6. The results of my work are likely to significantly affect the lives or well-being of other people. (task significance).

7. The job requires me to use a number of complex or high level skills. (task variety)

8. The job is arranged so that I do not have the chance to do an entire piece of work from beginning to end. ${ }^{\mathrm{R}}$ (task identity)

9. My work is quite simple. ${ }^{R}$ (task variety)

10. My work is quite repetitive. ${ }^{R}$ (task variety)

11. The job gives me considerable opportunity for independence and freedom in how / do the work. (autonomy)

12. The job itself is not very significant or important in the broader scheme of things. ${ }^{\mathrm{R}}$ (task significance)

13. This job is one where a lot of people can be affected by how well the work gets done. (task significance)

14. The job denies me any chance to use my personal initiative or judgment in carrying out the work. ${ }^{\mathrm{R}}$ (autonomy)

15. The job provides me the chance to completely finish the pieces of work I begin. (task identity)

16. The job itself provides very few clues about whether or not 1 am performing well. $^{R}$ (feedback)

\section{Workload}

Where I work:

1. work is carried out under pressure of time.

2. there are peaks in the work.

3. staff have to work too hard.

4. too much work has to be done.

5. there is too little time to finish the work.

6. the pace of work is too high.

7. the work is mentally exacting.

8. the work is too complicated.

\footnotetext{
${ }^{\mathrm{R}}$ These items were recoded.
} 


\section{Social support}

1. How is your relationship with your supervisor?

2. How is your relationship with your colleagues?

3. How often do you have conflicts with your supervisor? ${ }^{R}$

4. How often do you have conflicts with your colleagues? ${ }^{R}$

5. If there are problems at work, can you talk about them with your supervisor?

6. If there are problems at work, can you talk about them with your colleagues?

7. To what extent can you count on your supervisor, when you have difficulties in your work?

8. To what extent can you count on your colleagues, when you have difficulties in your work?

9. Do you feel appreciated in your job by your supervisor?

10. Do you feel appreciated in your job by your colleagues?

\section{Unmet career expectations}

1. I want to have a higher hierarchic position than I have now.

2. I want to have more responsibility than I have now.

3. I want to have a higher salary than I have now.

4. I want to have more opportunities to develop knowledge and skills than I have now.

5. I want to have more job security than I have now.

\section{Outcome variables}

Intrinsic work motivation

1. I feel a sense of personal satisfaction when I do this job well.

2. My opinion of myself goes down when I do this job badly.

3. I take pride in doing the work as well as I can.

4. I feel unhappy when my work is not up to my usual standard.

5. I like to look back on the day's work with a sense of a job well done.

6. I try to think of ways of doing my job effectively.

${ }^{\mathrm{R}}$ These items were recoded. 


\section{Emotional exhaustion}

1. I feel emotionally drained by my work.

2. Working all day is really a strain for me.

3. I feel burned out by my work.

4. I feel used up at the end of the workday.

5. I feel tired when I get up in the morning and have to face another day on the job.

\section{Turnover intention}

1. Sometimes I think about getting another job.

2. Sometimes / think about leaving this organization.

3. I intend to get another job this year.

4. I intend to leave this organization this year. 


\section{Dankwoord (Acknowledgement in Dutch)}

Zoals velen voor mij al geconstateerd hebben, is het uitvoeren van een promotieonderzoek en het schrijven van een proefschrift een zware taak, die met name tijdens de eindfase zweet en tranen kost. Het volbrengen van dit karwei zou mij zeker niet gelukt zijn zonder de steun van velen.

In de eerste plaats wil ik Peter Janssen bedanken die als copromotor het leeuwendeel van de begeleiding op zich heeft genomen. Peter, bedankt voor je gedetailleerde commentaar op mijn rapporten, conceptartikelen, proefschrift-hoofdstukken, en je kritische vragen over de analyses en resultatenbeschrijving. Ook bedankt voor de kansen die je me hebt gegeven om te laten zien wat ik kan binnen de capaciteitsgroep BEOZ.

In de tweede plaats gaat mijn dank uit naar mijn tweede copromotor Jan de Jonge (Universiteit Utrecht). Jan, met name bij de vele, soms complexe LISREL-analyses waren jouw deskundigheid en nuchterheid een grote hulp. Ook bedankt voor je commentaren op al mijn schrijfsels en je prompte reacties op mijn vele e-mails met analyse- en andere vragen.

Ten derde ben ik dank verschuldigd aan mijn promotor Frans Nijhuis (Hoensbroeck Centrum voor Arbeidsperspectief/Universiteit Maastricht). Frans, bedankt voor je bijdrage aan de totstandkoming van dit proefschrift en voor het feit dat je ondanks je vertrek naar Hoensbroek halverwege de rit, toch betrokken bent gebleven.

Ook wil ik Arnold Bakker (Universiteit Utrecht) bedanken, die als coauteur heeft meegedacht over en meegeschreven aan de twee "longi-artikelen" uit dit proefschrift. Arnold, bedankt voor je commentaar op de concept-artikelen en voor het meedenken over de meest geschikte analysemethoden voor de nogal complexe vraagstellingen uit deze artikelen.

De leden van de beoordelingscommissie, prof. dr. Martijn Berger, dr. Ab Landweerd, dr. René Schalk, prof. dr. Wilmar Schaufeli en prof. dr. Hein de Vries dank ik voor de beoordeling van dit proefschrift.

Een onderzoek zoals beschreven in dit proefschrift zou niet uitgevoerd kunnen worden zonder de antwoorden die de respondenten (bankmedewerkers en onderwijzers) hebben gegeven op de vele items uit mijn vragenlijsten. Bedankt voor het invullen van de lijsten. Ook de twee organisaties die mij de gelegenheid hebben geboden om hun medewerkers lastig te vallen met vragenlijsten wil ik op deze plek bedanken. Erik Jan en Hans: bedankt.

Math Reintjens wil ik bedanken voor het invoeren van alle antwoorden van de respondenten en het aanleveren van perfecte databestanden. Gerard van Breukelen en Math Candel, bedankt voor de tips met betrekking tot de statistische analyses. Jan van Emmerik, bedankt voor je hulp bij het "pdf-en". 
In mijn vijf jaar bij BEOZ heb ik drie kamergenootjes "versleten", en alledrie hebben ze mij met raad en daad gesteund. Ten eerste Marike. Marike, ik heb nog steeds heel goede herinneringen aan onze tijd op de UNS 50 . We hebben vele gesprekken gevoerd over onderzoek, onderwijs en andere zaken, en een hele leuke tijd gehad. Ik weet nog hoe erg ik het vond dat je wegging. Bedankt voor je steun en betrokkenheid. Leuk dat je mijn paranimf wilt zijn.

Toen Marike wegging nam Liezeth haar plaats in, en zij bleek een waardige plaatsvervangster te zijn. Liezeth, ook jij bedankt voor je interesse in mijn onderzoek en mijn overige activiteiten.

En tot slot Maria, met haar deelde ik na de verhuizing van BEOZ naar de UNS 40 een kamer. Maria, bedankt voor je steun, de gezelligheid en de discussies over werkgerelateerde en niet werkgerelateerde zaken. Ik wens je heel veel succes met de afronding van je eigen promotie-onderzoek.

Naast kamergenootjes waren er natuurlijk ook andere collega's bij BEOZ van wie ik veel steun heb gehad en die mijn tijd bij BEOZ naast nuttig en leerzaam, ook heel gezellig hebben gemaakt: Gladys, Nathalie, Silvia E., Sylvia V., Catelijne, Astrid, Isel, Peggy, Sandy, Brigitte vdZ., Brigitte vL., Adje, Ab, Femke vdL., Femke K. en alle anderen: bedankt hiervoor! Gladys, bedankt voor je interesse en alle gezellige kletspauzes.

Ook mijn nieuwe SW-collega's van de Open Universiteit Nederland wil ik bedanken voor hun interesse in mijn promotie-onderzoek.

Niet alleen op het werk, maar ook van familie en vrienden heb ik veel sociale steun ontvangen. Ze bleven altijd zeer geïnteresseerd vragen wanneer ik nou eens ging "afstuderen". Pap, mam, Tanja en Maarten, Anneke, Pascal en Fleur, Yoka en Mathijs, Nelly en Louis, mede dankzij jullie ben ik niet emotioneel uitgeput geraakt. Tanja, ik vind het heel leuk dat ook jij mijn paranimf wilt zijn.

Last, but not least wil ik Olaf bedanken. Olaf, bedankt voor je onvoorwaardelijke steun en betrokkenheid tijdens mijn hele AlO-periode, en met name tijdens de laatste fase, het schrijven van het boekje. En natuurlijk bedankt voor je hulp bij het lay-outen en het ontwerpen van het omslag. In de afgelopen jaren zijn de vakanties er helaas bij ingeschoten, maar hopelijk kunnen we nu het een en ander gaan inhalen.

Inge Houkes

Sittard, 2001 


\section{Curriculum Vitae}

Inge Houkes was born on April 27th, 1973 in Heerlen, The Netherlands. In 1991, she graduated from the Rombouts College in Brunssum. From September 1991 until December 1995, she studied Health Sciences at Maastricht University. This resulted in a "cum laude" graduation at this university. From January 1996 until July 1996, she worked as a research assistant at the department of Rheumatology at the Leiden University Medical Center.

In September 1996, she started working as a PhD student/lecturer at the department of Health Organisation, Policy and Economics (HOPE) from the Faculty of Health Sciences, Maastricht University, under the flag of the Maastricht Health Research Institute for Prevention and Care. During this period, the research that is described in this thesis was carried out. Furthermore, she educated Work \& Health students at Maastricht University, and functioned as a board member of both the PhD association of Maastricht University and the Maastricht Health Research Institute for Prevention and Care. From June 2001 until October 2001, she worked as a researcher at the department of Health Organisation, Policy and Economics (HOPE) of Maastricht University. In November 2001, she became assistant professor at Open University in Heerlen. 